Final Report

FHWA/IN/JTRP-2005/23

\title{
SIMPLIFICATION OF RESILIENT MODULUS TESTING FOR SUBGRADES
}

\author{
by \\ Daehyeon Kim, Ph.D, P.E. \\ INDOT Division of Research \\ and \\ Nayyar Zia Siddiki, M.S, P.E. \\ INDOT Division of Materials and Tests \\ Joint Transportation Research Program \\ Project No. C-36-52S \\ File No. 6-20-18 \\ SPR- 2633

\begin{abstract}
Conducted in Cooperation with the Indiana Department of Transportation

Federal Highway Administration
\end{abstract} \\ and the U.S. Department of Transportation
}

The content of this report reflect the views of the authors who are responsible for the facts and the accuracy of the data presented herein. The contents do not necessarily reflect the official views or policies of the Indiana Department of Transportation or the Federal Highway Administration at the time of publication. This report does not constitute astandard, speculation or regulation.

\author{
School of Civil Engineering \\ Purdue University \\ February 2006
}




\section{TECHNICAL Summary}

INDOT Research

Technology Transfer and Project Implementation Information

TRB Subject Code: 62-7 Subgrades and Bases

Publication No.: FHWA/IN/JTRP-2005/23, SPR-2633

February 2006

Final Report

\section{Simplification of Resilient Modulus Testing for Subgrades}

\section{Introduction}

Since "the AASHTO 1986 Guide for Design of Pavement Structures" recommended highway agencies to use a resilient modulus (Mr) obtained from a repeated triaxial test for the design of subgrades, many researchers have made a large number of efforts to obtain more accurate, straightforward, and reasonable $\mathrm{Mr}$ values which are representative of the field conditions. Resilient modulus has been used for characterizing the non-linear stress-strain behavior of subgrade soils subjected to traffic loadings in the design of pavements.

Over the past ten years, the Indiana Department of Transportation (INDOT) has advanced the characterization of subgrade materials by incorporating the resilient modulus testing, which is known as the most ideal triaxial test for the assessment of behavior of subgrade soils subjected to repeated traffic loadings.

The National Cooperative Highway Research Program (NCHRP) has recently released the New Mechanistic-Empirical Design Guide (Guide for Mechanistic-Empirical Design of New and Rehabilitated Pavement Structures, NCHRP 1-37A, Final Report, July 2004) for pavement structures. The new M-E Design Guide requires that the resilient modulus of unbound materials be inputted in characterizing layers for their structural design. It recommends that the resilient modulus for design inputs be obtained from either a resilient modulus test for Level 1 input (the highest input level) or available correlations for Level 2 input.

Due to the complexity and high cost associated with the $\mathrm{Mr}$ testing in the past, extensive use of the resilient modulus test in the state DOTs was hindered. With a fast growing technology, it becomes much easier to run a resilient modulus test. Therefore, it would be necessary for the department of transportation to appropriately implement the resilient modulus test for an improved design of subgrades.

In the present study, physical property tests, unconfined compressive tests, resilient modulus (Mr) tests and several Dynamic Cone Penetrometer (DCP) tests were conducted to assess the resilient and permanent strain behavior of 14 cohesive subgrade soils and five cohesionless soils encountered in Indiana. An attempt was made to simplify the existing resilient modulus test, AASHTO T 307. This attempt was made by reducing the number of steps and cycles of the resilient modulus test. The M-E Design guide requires the material coefficients $k_{1}, k_{2}$, and $k_{3}$. Three models for estimating the resilient modulus are proposed based on the unconfined compressive tests. A predictive model to estimate material coefficients $k_{1}, k_{2}$, and $k_{3}$ using 12 soil variables obtained from the soil property tests and the standard Proctor tests is developed. A simple mathematical approach is introduced to calculate the resilient modulus. Although the permanent strain occurs during the resilient modulus test, the permanent strain behavior of subgrade soils is generally neglected. In order to capture both the permanent and the resilient behavior of subgrade soils, a constitutive model based on the Finite Element Method (FEM) is proposed. A comparison of the measured permanent strains with those obtained from the Finite Element (FE) analysis shows a reasonable agreement. An extensive review of the M-E design is done. Based on the test results and review of the M-E Design, implementation initiatives are proposed. 


\section{Findings}

The objectives of this study are to simplify the resilient modulus testing procedure specified in AASHTO T307 based on the prevalent conditions in Indiana, to generate database of $\mathrm{Mr}$ values following the existing resilient modulus test method (AASHTO T307) for Indiana subgrades, to develop useful predictive models for use in Level 1 and Level 2 input of subgrade $\mathrm{Mr}$ values following the New M-E Design Guide, to develop a simple mathematical calculation method and to develop a constitutive model based on the Finite Element Method (FEM) to account for both the resilient and permanent behavior of subgrade soils.

Results show that it may be possible to simplify the complex procedures required in the existing $\mathrm{Mr}$ testing to a single step with a confining stress of 2 psi and deviator stresses of 2, 4, 6, 8, 10 and 15 psi. Three models for estimating the resilient modulus are proposed based on the unconfined compressive tests. A predictive model to estimate material coefficients $\mathrm{k}_{1}, \mathrm{k}_{2}$, and $\mathrm{k}_{3}$ using 12 soil variables obtained from the soil property tests and the standard Proctor tests is developed. The predicted resilient moduli using all the predictive models compare satisfactorily with measured ones. A simple mathematical approach is introduced to calculate the resilient modulus. Although the permanent strain occurs during the resilient modulus test, the permanent behavior of subgrade soils is currently not taken into consideration. In order to capture both the permanent and the resilient behavior of subgrade soils, a constitutive model based on the Finite Element Method (FEM) is proposed. A comparison of the measured permanent strains with those obtained from the Finite Element (FE) analysis shows a reasonable agreement. An extensive review of the M-E design is done. Based on the test results and review of the $\mathrm{M}$-E Design, implementation initiatives are proposed.

\section{Implementation}

With the advent of the new M-E Design Guide, highway agencies are encouraged to implement an advanced design following its philosophies. Not only were the resilient and permanent behavior of subgrade soils investigated in this study, but also an extensive review was made on the features embedded in the New M-E Design Guide for subgrades as part of implementation of the M-E Design Guide. The following can be implemented from this study:

1) Simplified procedure can be used in $\mathrm{Mr}$ testing with reasonable accuracy;

2) Designers can use the predictive models developed to estimate the design resilient modulus for Indiana subgrades;
3) The M-E Design Guide assumes that the subgrade is compacted at optimum moisture content, leading to unconservative design. In order to ensure a conservative design for subgrades, the use of the average values is recommended;

4) When laboratory testing for evaluating thawed $\mathrm{Mr}$ is not available, the use of $\mathrm{Mr}$ for wet of optimum would be reasonable;

5) Caution needs to be taken to use the unconservative frozen $\mathrm{Mr}$ value suggested in $\mathrm{M}$ E Design Guide. 


\section{Contacts}

For more information:

Dr. Daehyeon Kim

Principal Investigator

Indiana Department of Transportation

Office of Research and Develop,emt

1205 Montgomery Street

P.O. Box 2279

West Lafayette, IN 47906

Phone: (765) 463-1521

Fax: (765) 497-1665

E-mail: dkim@indot.in.gov
Indiana Department of Transportation

Division of Research

1205 Montgomery Street

P.O. Box 2279

West Lafayette, IN 47906

Phone: (765) 463-1521

Fax: (765) 497-1665

Purdue University

Joint Transportation Research Program

School of Civil Engineering

West Lafayette, IN 47907-1284

Phone: (765) 494-9310

Fax: (765) 496-7996

E:mail: jtrp@ecn.purdue.edu

http://www.purdue.edu/jtrp 


\section{ACKNOWLEDGEMENTS}

The authors deeply appreciate the opportunity to conduct this research under the auspices of the Joint Transportation Research Program (JTRP) with support from the Indiana Department of Transportation and the Federal Highway Administration. They wish to recognize the active input from the Study Advisory Committee members: Dr. Samy Noureldin, and Mr. Kumar Dave of INDOT, Dr. Vincent Drnevich of Purdue University, Val Straumins and Tony Perkinson of the FHWA Indiana Division. The authors also express special thanks to Mr. Michael Klobucar for performing some of the tests and analyses. 


\section{TABLE OF CONTENTS}

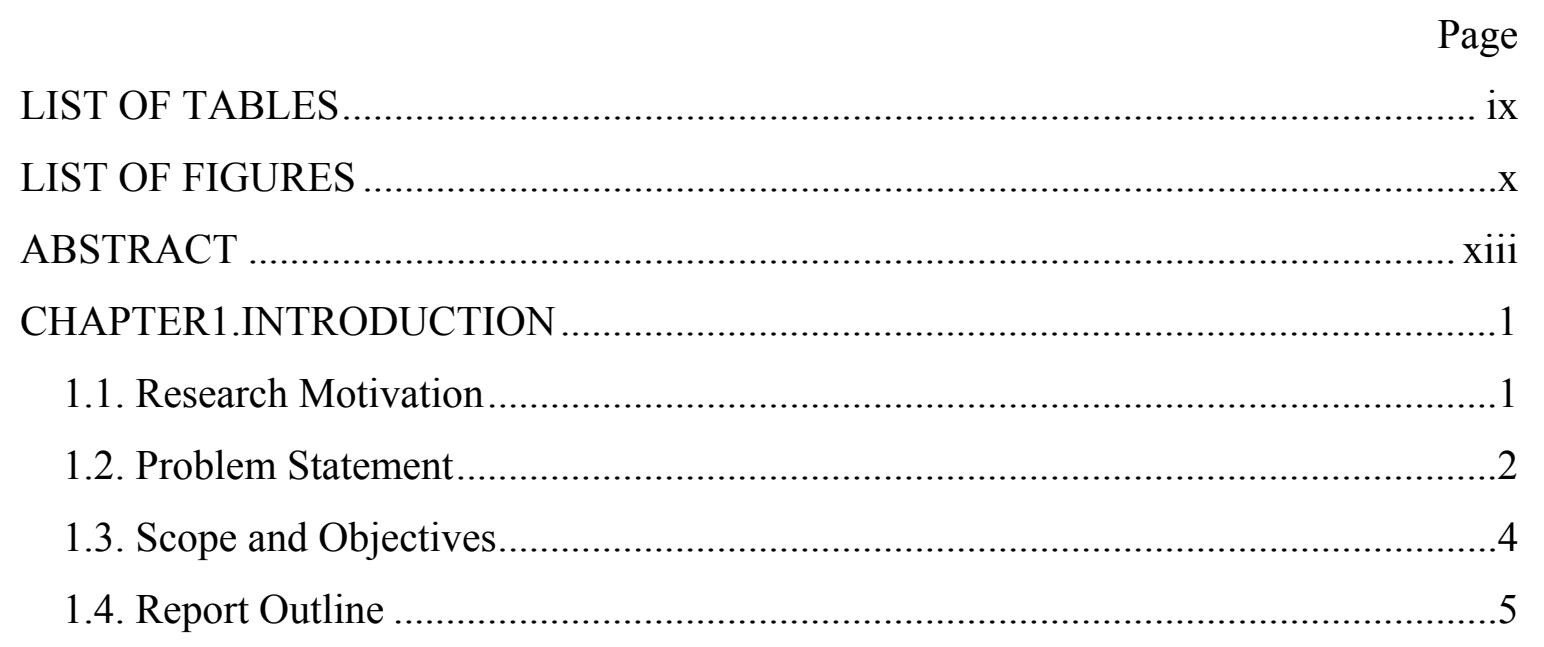

CHAPTER 2. LITERATURE REVIEW ON BEHAIVOR OF SUBGRADE SOILS.......7

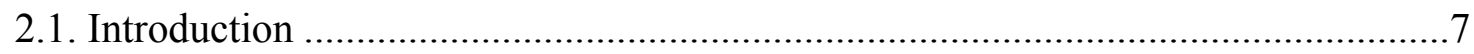

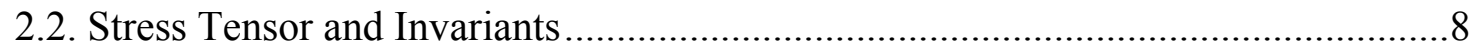

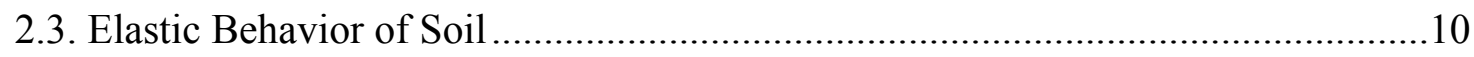

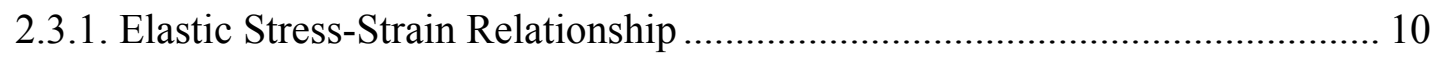

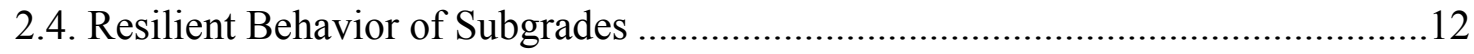

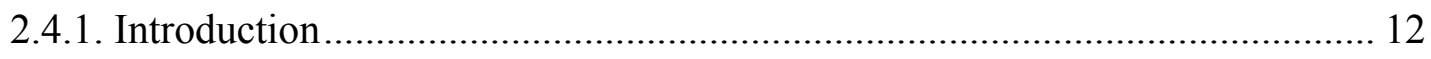

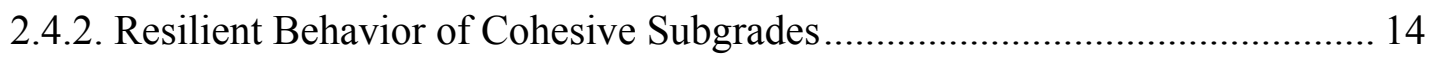

2.4.3. Resilient Behavior of Cohesionless Subgrades......................................... 22

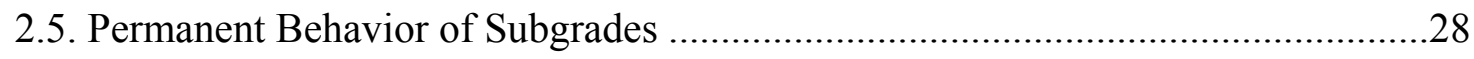

2.5.1. Permanent Deformations of Cohesive Subgrades....................................... 28

2.5.2. Permanent Deformations of Cohesionless Subgrades ................................ 41

CHAPTER 3. REVIEW OF THE NEW M-E DESIGN GUIDE ...................................51

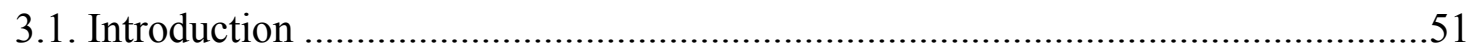


3.1.1. Major Differences between the AASHTO Design Guide and M-E Design Guide. 51

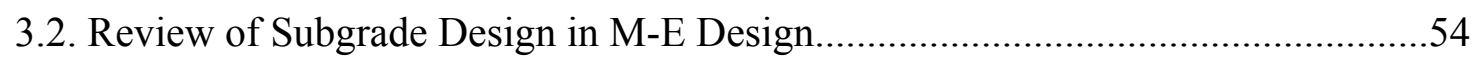

3.2.1. Hierarchical Design Inputs - Level 1, Level 2, Level 3 ................................ 54

3.2.2. Input Parameters for Unbound Materials and Sugrades ................................ 54

3.2.3. Assumptions Related to Subgrade Compactions in the M-E Design ............. 59

3.2.4. Climatic and Environmental Effects in the M-E Design ................................. 62

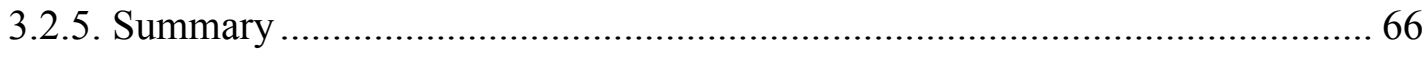

CHAPTER 4. LABORATORY TESTING PROGRAM ………………………….......68

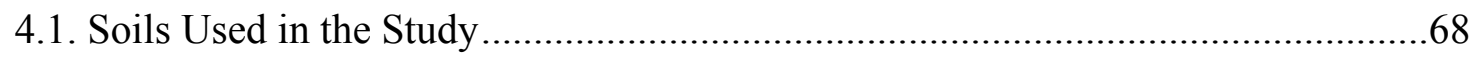

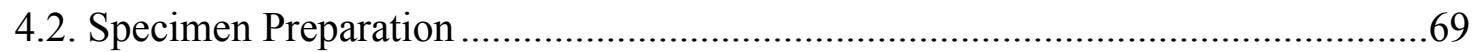

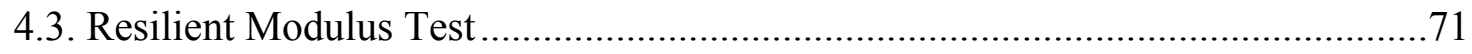

4.4. Dynamic Cone Penetration (DCP) Tests ..................................................................74

CHAPTER 5. DISCUSSION OF THE TEST RESULTS...............................................

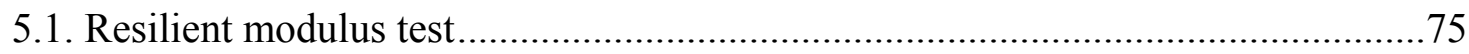

5.1.1. Results of Resilient Modulus Test on Cohesive Subgrade Soils .................... 75

5.1.2. Results of Resilient Modulus Test on Cohesionless Subgrade Soils .............. 99

5.2. Preliminary Dynamic Cone Penetrometer (DCP) Test..........................................102

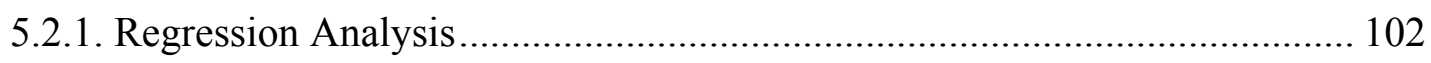

CHAPTER 6. RESILIENT BEHVAIOR OF LIME AND LKD TREATED

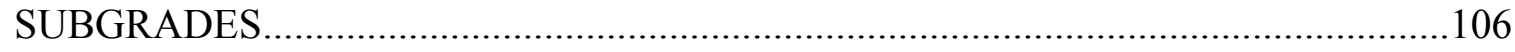

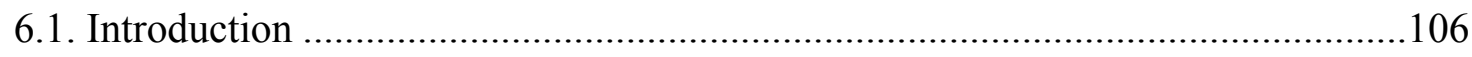

6.2. Engineering Properties of Soils Treated with LKD and LIME ...........................108

6.2. Experimental Program ..........................................................................................109

6.2.1. LKD and Hydrated Lime used in the study ............................................. 109

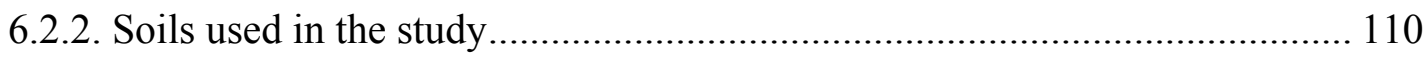

6.3. Discussion of the Test Results......................................................................113

6.3.1. Unconfined Compression Strength ............................................................. 113

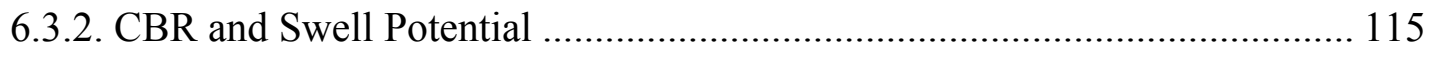

6.3.3. Resilient Behavior of Soil-LKD and Soil-Lime Mixtures............................ 117 
CHAPTER 7. THEORETICAL INVESTIGATION OF BEHAVIOR OF SUBGRADES .

7.1. Mathematical Expression of the Loading Cycles in AASHTO T307 129

7.2. Development of a Constitutive Model for a soil having Permanent Strain Subjected to the Resilient Modulus Test ...............................................................133

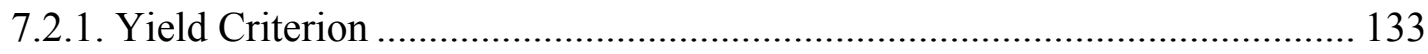

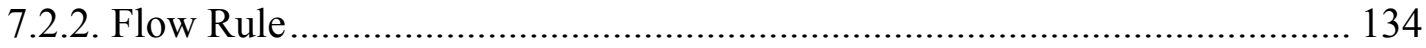

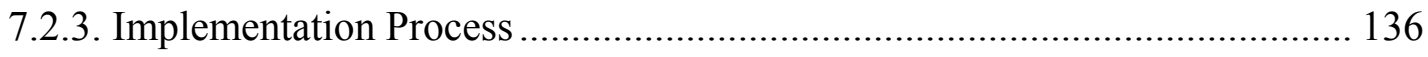

CHAPTER 8. CONCULUSIONS AND RECOMMENDATION ...............................140

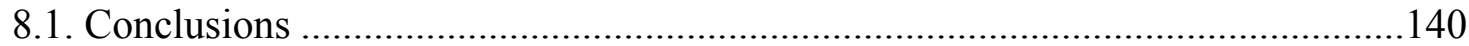

8.2. Implementation of Unbound Material Design Inputs ......................................143

8.2.1. Subgrade Design Input Level 3 ......................................................... 143

8.2.2. Subgrade Design Input Level 2 ............................................................. 143

8.2.3. Subgrade Design Input Level 1.................................................................. 145

8.2.4. Design Example - Level 1, Level 2 ...................................................... 146

8.2.5. Summary of Implementation Initiatives ................................................ 154

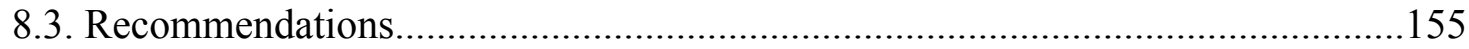

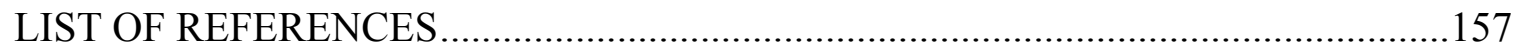

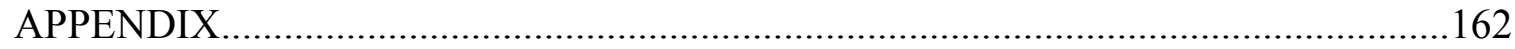




\section{LIST OF TABLES}

Table

Page

Table 1. Major differences in subgrade design between the AASHTO Guide design guide and M-E design guide 53

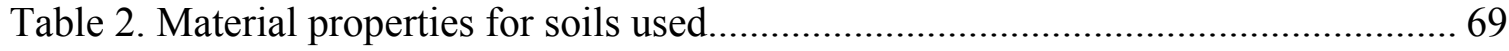

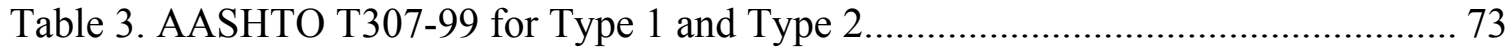

Table 4. Measured Mr values for Dry, OMC and Wet samples $\left(\sigma_{\mathrm{c}}=2 \mathrm{psi}, \sigma_{\mathrm{d}}=6 \mathrm{psi}\right) . .81$

Table 5. Index properties 112

Table 6. CBR and swell potential for untreated and $5 \%$ LKD and $5 \%$ lime treated soils compacted at $\mathrm{OMC}$

Table 7. Regression coefficient for the untreated, $5 \%$ LKD treated, $5 \%$ lime treated soils

Table 8. Material properties for a design example

Table 9. Parameters for use in equation (8.2) 


\section{LIST OF FIGURES}

Figure

Page

Figure 1. Effect of deviator stress on a A-7-6 subgrade soil (Wilson et al. 1990) ........... 16 Figure 2. Effect of compaction water content and moisture density on a cohesive subgrade (Lee et al. 1997).

Figure 3. Effect of post-compaction saturation on resilient modulus of an A-7-5 subgrade

soil (Drumm et al. 1997).

Figure 4. Effect of deviator stress on the resilient modulus of an A-1 subgrade soil

(Wilson et al. 1990). 23

Figure 5. Influence of dry density on the resilient modulus of granular subgrades (Hicks and Monismith 1971). 24

Figure 6. Effect of method compaction (Lee et al. 1997) ........................................... 25

Figure 7. Results from tests on compacted at dry of optimum A-6 subgrade soil (Muhanna et al. 1998).

Figure 8. Results from tests on compacted at optimum A-6 subgrade soil (Muhanna et al. 1998) 29

Figure 9. Results from tests on compacted at wet of optimum A-6 subgrade soil (Muhanna et al. 1998) 30

Figure 10. Results from tests on silty clay; left: $\sigma_{3}=0 \mathrm{psi}, \gamma_{\mathrm{d}}=129.5 \mathrm{lb} / \mathrm{ft}^{3}, \mathrm{~m}=7 \% \mathrm{right}$ : $\sigma_{3}=14.5 \mathrm{psi}, \gamma_{\mathrm{d}}=129.5 \mathrm{lb} / \mathrm{ft}^{3}, \mathrm{~m}=7 \%($ Raad and Zeid 1990) 31

Figure 11. Results from tests on silty clay; left: $\sigma_{3}=0 \mathrm{psi}, \gamma_{\mathrm{d}}=129.5 \mathrm{lb} / \mathrm{ft}^{3}, \mathrm{~m}=10 \%$ right: $\sigma_{3}=14.5 \mathrm{psi}, \gamma_{\mathrm{d}}=129.5 \mathrm{lb} / \mathrm{ft}^{3}, \mathrm{~m}=10 \%($ Raad and Zeid 1990) ....................................... 32 Figure 12. Influence of stress history on permanent strains (Monismith et al. 1975) ...... 33 Figure 13. Effect of period of rest on deformation under repeated loading of silty clay with high degree of saturation (Seed and Chan 1958) ................................................ 35 Figure 14. Effect of period of rest on deformation under repeated loading of silty clay

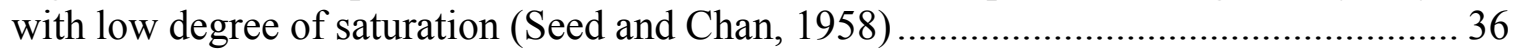
Figure 15. Effect of frequency of stress application on deformation of silty clay with high

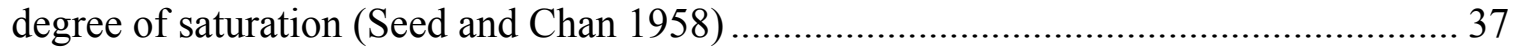
Figure 16. Effect of frequency of stress application on deformation of silty clay with low degree of saturation (Seed and Chan 1958) ........................................................... 38

Figure 17. Permanent axial strains for Sydenham sand (Gaskin et al. 1979) ................... 43

Figure 18. Plastic axial strains for Coteau Balast (Diyaljee and Raymond 1983)........... 44 Figure 19. Effect of confining stress on permanent strain at $\mathrm{N}=10,000$ for the Florida

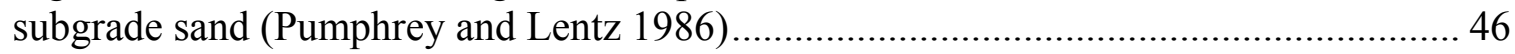
Figure 20. Effect of dry unit weight and moisture content on permanent strainat $\mathrm{N}=10,000$ (Pumphrey and Lentz 1986) 48 
Figure 21. Design inputs for unbound layers-response model ................................... 55

Figure 22. Design inputs for unbound layers-ECIM inputs......................................... 56

Figure 23. Variation in moisture contents for the compacted subgrade ........................ 61

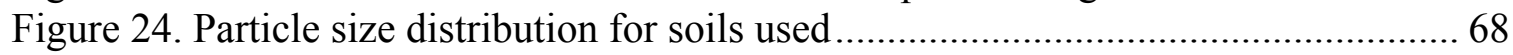

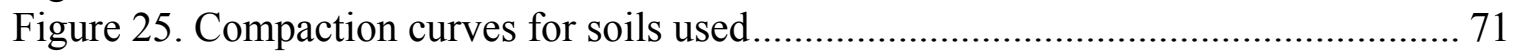

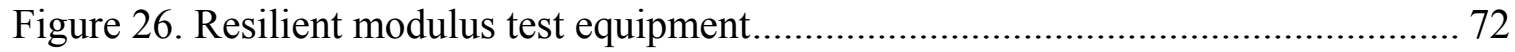

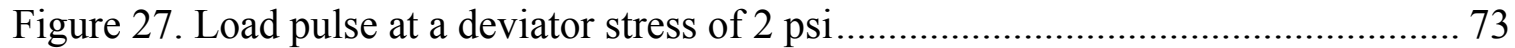

Figure 28. Evaluation points of multi-elastic analyses for typical Indiana subgrades...... 76

Figure 29. Deviator stresses induced in the subgrade for cross-section 3 ...................... 77

Figure 30. Comparison of Mr between the Simplified (500 repetitions for conditioning and 100 repetitions for main testing) and the AASHTO procedures............................ 79

Figure 31. Comparison of Mr between the Simplified (250 repetitions for conditioning and 50 repetitions for main testing) and the AASHTO procedures between the Simplified

Figure 32. Unconfined compressive test results for Dry, OMC, Wet samples for I65-146

Figure 33. Unconfined compressive test results for Dry, OMC, Wet samples for I65-158

Figure 34. Unconfined compressive test results for Dry, OMC, Wet samples for I65-172

Figure 35. Unconfined compressive test results for Dry, OMC, Wet samples for Dsoil . 84

Figure 36. Permanent strains for I65-146 wet sample in the conditioning stage............. 86

Figure 37. Permanent strains for I65-146 wet sample in the $5^{\text {th }}$ step............................ 87

Figure 38. Mr values for original length and deformed length ................................... 87

Figure 39. Correlations between $\mathrm{Mr}$ and properties obtained from unconfined

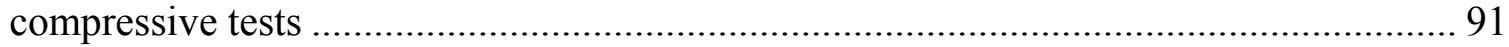

Figure 40. Comparison between predicted and measured resilient moduli using equation

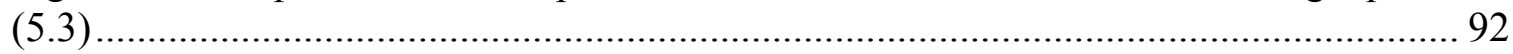

Figure 41.Comparison between predicted and measured resilient moduli using equation

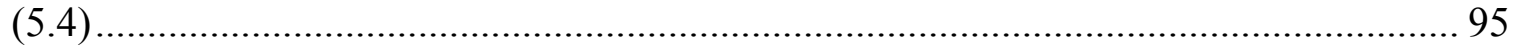

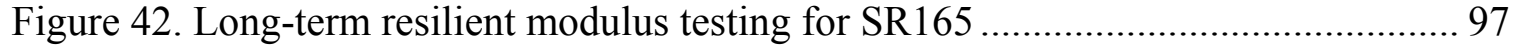

Figure 43. Long-term resilient modulus testing for Orchard clay ................................ 97

Figure 44. Permanent Strain of SR 165 Soil (long term Mr test) .................................. 98

Figure 45. Permanent strain of SR 165 Soil (standard test) ........................................ 99

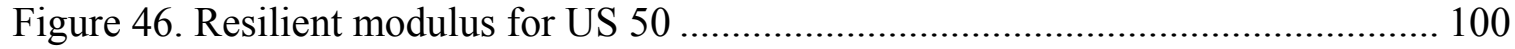

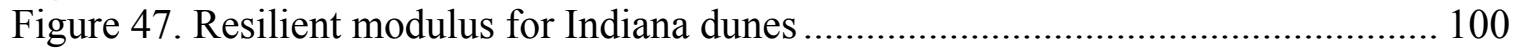

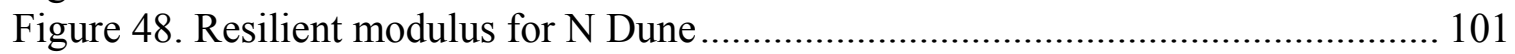

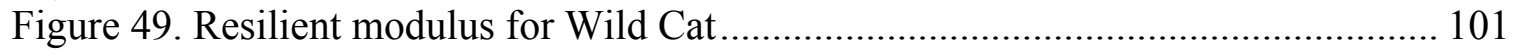

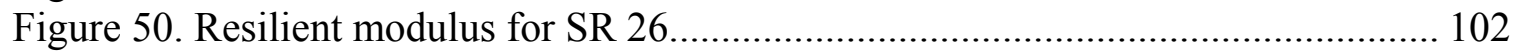

Figure 51. Penetration Index vs. resilient modulus..................................................... 103

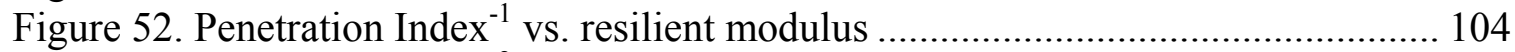

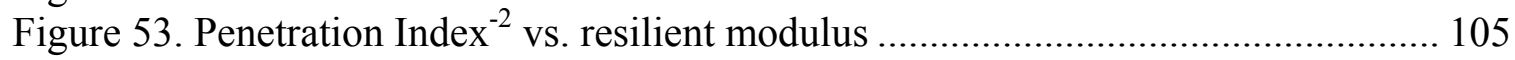

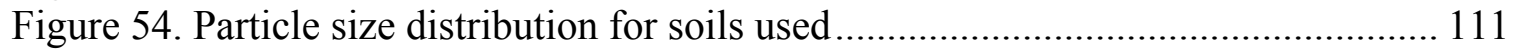

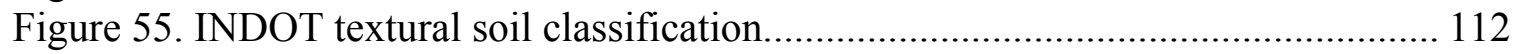

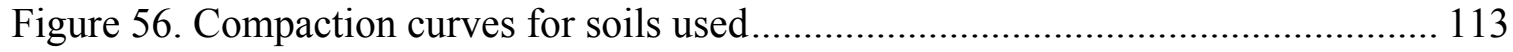


Figure 57. Unconfined strength vs. \% compaction for A-4 (US-41)........................... 114

Figure 58. Unconfined strength vs. \% compaction for A-6 (SR-37) ......................... 115

Figure 59. Resilient modulus vs. deviator stress for untreated soils for A-6 (SR-37) ... 119

Figure 60. Resilient modulus vs. deviator stress for $5 \%$ LKD treated soils for A-6 (SR-37)

Figure 61. Resilient modulus vs. deviator stress for $5 \%$ Lime treated soils for A-6 (SR-

37) 120

Figure 62. Resilient modulus vs. deviator stress for A-6 (SR-37) in terms of confining stress of 2 psi

Figure 63. Resilient modulus vs. deviator stress for A-7-6 (SR-46) in terms of confining stress of 2 psi.

Figure 64. Resilient modulus vs. deviator stress for A-4 (US-41) in terms of confining stress of 2 psi

Figure 65. Resilient modulus vs. deviator stress for A-6 (US-41) in terms of confining stress of 2 psi.

Figure 66. Measured vs. predicted Mr for untreated soils ....................................... 125

Figure 67. Measured vs. predicted Mr for $5 \%$ LKD treated soils................................ 125

Figure 68. Measured vs. predicted Mr for $5 \%$ Lime treated soils ............................... 125

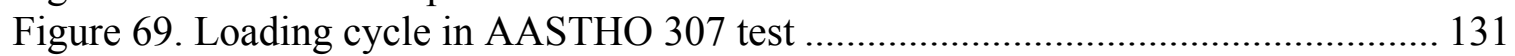

Figure 70. Plot of $\mathrm{F}(\mathrm{t})$ as a function of time at a deviator stress of 2 psi..................... 132

Figure 71. Change in displacement with respect to time ......................................... 132

Figure 72. Comparison between the measured and predicted stress-strain relationship 139

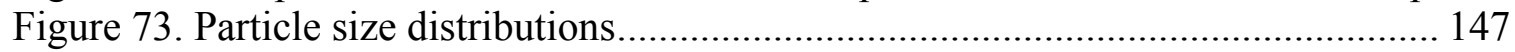

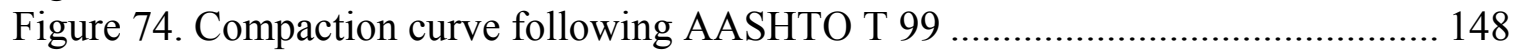

Figure 75. Unconfined compressive tests for Dry, OMC and Wet samples................. 148

Figure 76. Resilient modulus test for OMC sample following AASHTO T-307 .......... 149

Figure 77. Resilient modulus test for wet sample following AASHTO T-307 ............. 149

Figure 78. Modulus ratio due to change in moisture .............................................. 153

Figure 79. Comparison of permanent deformations (rutting) between optimum and

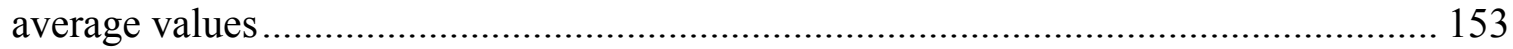

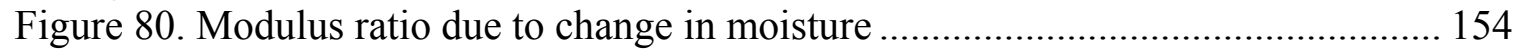

Figure 81. Modulus ratio due to change in moisture (expanded) ................................. 154 


\section{CHAPTER1.INTRODUCTION}

\subsection{Research Motivation}

Since "the AASHTO 1986 Guide for Design of Pavement Structures" recommended highway agencies to use a resilient modulus (Mr) obtained from a repeated triaxial test for the design of subgrades, many researchers have made significant effort to obtain more accurate, straightforward, and reasonable $\mathrm{Mr}$ values which are representative of the field conditions. Over the past ten years, the Indiana Department of Transportation (INDOT) has advanced the characterization of subgrade materials by incorporating the resilient modulus testing, which is considered as the most ideal triaxial test for the assessment of behavior of subgrade soils subjected to repeated traffic loadings.

The National Cooperative Highway Research Program (NCHRP) has recently released the New Mechanistic-Empirical Design Guide (Guide for Mechanistic-Empirical Design of New and Rehabilitated Pavement Structures, NCHRP 1-37A, Final Report, July 2004) for pavement structures. The new M-E Design Guide requires that the resilient modulus of pavement materials be inputted in characterizing pavement layers for their structural design. It recommends that the resilient modulus for design inputs be obtained from either a resilient modulus test for Level 1 input (the highest input level) or available correlations for Level 2 input.

Due to complexity and high cost associated with the Mr testing in the past, extensive use of the resilient modulus test in the state DOTs was hindered. With a fast growing technology, it becomes much easier to run a resilient modulus test. Therefore, it would be 
necessary for the department of transportation to appropriately implement the resilient modulus test for an improved design of subgrades.

\subsection{Problem Statement}

Over many past decades, the California Bearing Ratio (CBR) has been used for the characterization of subgrade soils. The CBR value is similar to the undrained shear strength of soil which is independent of confining stress conditions, and is different from the stiffness of soil. Due to its limitation to account for realistic behavior of the subgrade soils subjected to moving traffic loads, the modern design philosophies related to subgrade soils have evolved to take the resilient modulus into consideration for a design of subgrade.

In order to reflect the recommendation of "the AASHTO 1986 Guide for Design of Pavement Structures", two research projects (FHWA/INDOT/JHRP 92-32 and FHWA/INDOT/JTRP-98/2) on the resilient modulus (Mr) of subgrade soils were completed under the Joint Transportation Research Program (JTRP) in Indiana. However, the resilient modulus test is only being performed by specialized laboratories due to its complexity and difficulty.

Many researchers have proposed numerous correlations between $\mathrm{Mr}$ values from repeated triaxial tests and measurements obtained from nondestructive field testing methods, such as the Cone Penetration Test (CPT), the Dynamic Cone Penetration Test (DCPT), the Falling Weight Deflectometer (FWD), and the Plate Load Test (PLT). At small strain levels (i.e. less than $0.1 \%$ ), some laboratory tests, such as the unconfined compression test (Drum et al. 1990, Lee et al. 1997) and the static triaxial test (Kim et al. 2001) were suggested as alternatives to the repeated triaxial test, due to its complexity 
and difficulty. Therefore, there is a need to simplify the complex procedure of the existing resilient modulus test to allow the operator of the resilient modulus testing to readily perform the $\mathrm{Mr}$ test.

Note that the AASHTO Design guide recommends highway agencies to use representative confining and deviator stresses in subgrade layers under traffic loading conditions. When simplifying the Mr test procedure, it is necessary to investigate the range of confining and deviator stresses resulting from the traffic loadings in Indiana and to account for such reasonable stress levels in the Mr test. Over- or underestimation of the stress levels in the subgrades will lead to erroneous results of resilient modulus results (Houston et al. 1993). As one resilient modulus corresponding to the representative confining and deviator stress for a given subgrade is needed in designing a pavement, the complex testing procedure may be simplified for practical design purpose.

In the previous JTRP project, resilient modulus tests based on AASHTO T 274 were performed by Lee et al. (1993) on several predominant soils and correlations were made between the resilient modulus and the unconfined compressive strength. However, using their correlations for all of subgrade soils encountered in Indiana is not feasible as their correlations are not based on the soil properties. Moreover, the resilient modulus test method has been changed to AASHTO T307. In order to successfully design subgrades following the New M-E Design Guide, predictive models based on the soil properties, standard Proctor tests, and unconfined compressive tests are necessary for designers to use those models conveniently for wide range of subgrade soils encountered in Indiana.

The basic principle of the loading adopted in AASHTO T 307 is the simulation of a typical moving load in a sinusoidal form. The peak point of the loading is analogous to 
the loading condition where the traffic is immediately above the subgrade. A soil specimen subjected to resilient modulus testing can be simply modeled as a onedimensional forced vibration of a spring-mass system and the feasibility of the mathematical approach needs to be explored to suggest a simple calculation method to obtain the resilient modulus.

Generally, the permanent strain of subgrade soils is not taken into consideration in the resilient modulus test. This is due to the assumption that the subgrade would be in the elastic state. However, subgrade soils may exhibit the permanent strain even at a much smaller load than that causing shear failure. It is fairly necessary to develop a constitutive model that describes the realistic behavior of subgrade soils, such as resilient and permanent behavior.

\subsection{Scope and Objectives}

The objectives of this study are to simplify the resilient modulus testing procedure specified in AASHTO T307 based on the prevalent conditions in Indiana, to generate database of Mr values following the existing resilient modulus test method (AASHTO T307) for Indiana subgrades, to develop useful predictive models for use in Level 1 and Level 2 input of subgrade Mr values following the New M-E Design Guide, to develop a simple calculation method, and to develop a constitutive model based on the Finite Element Method (FEM) to account for both the resilient and permanent behavior of subgrade soils. The detailed goals of the research will be:

(1) Simplification of the standard resilient modulus testing; 
(2) Clarification of confining pressure effects on resilient modulus of cohesive subgrades;

(3) Construction of database of resilient modulus depending on soil types in Indiana;

(4) Development of predictive models to estimate the resilient moduli for subgrades encountered in Indiana;

(5) Development of a simple mathematical method to calculate the resilient modulus;

(6) Development of a constitutive model based on the Finite Element Method that can describe both resilient and permanent behavior of subgrade soils.

\subsection{Report Outline}

This report consists of eight chapters, including this introduction.

Chapter 2 presents the literature review on the resilient behavior and permanent behavior of cohesive and cohesionless soils, and fundamental theories related to behavior of subgrade soils.

Chapter 3 reviews the important features embedded in "the New MechanisticEmpirical Design Guide".

Chapter 4 describes the experimental program of the project. This chapter covers the soils used, resilient modulus tests, unconfined compressive tests, physical property tests and DCPT tests.

Chapter 5 discusses the results of resilient modulus tests on compacted subgrade soils. Predictive models to estimate resilient modulus based on soil properties are discussed.

Chapter 6 reports the results of resilient modulus tests on chemically modified soils which were previously conducted as part of implementation. 
Chapter 7 introduces a simple mathematical method to obtain resilient modulus and a constitutive model based on Finite Element Method that can describe permanent and resilient behavior.

Chapter 8 summarizes the conclusions and recommendations drawn from this study and proposes implementation initiatives. 


\section{CHAPTER 2. LITERATURE REVIEW ON BEHAIVOR OF SUBGRADE SOILS}

\subsection{Introduction}

In a road structure subjected to repeated traffic loadings, subgrade soils play a role in supporting the asphalt and base layers and traffic loadings. Due to this important role, the subgrade should have enough bearing capacity to perform its function appropriately. If the subgrade soils respond primarily in an elastic mode, the rutting problem typical in weak subgrades will not occur.

However, rutting problems are observed in many roads, resulting in expensive rehabilitation efforts. Therefore, the assumption that subgrade soils are purely elastic is not consistent with most observation mode in practice. It is more realistic to treat the subgrade soils as elasto-plastic materials. In reality, subgrade soils subjected to repeated traffic loadings exhibit nonlinear resilient and permanent behavior even at small strains, before reaching their yield strengths.

In this chapter, to facilitate the understanding of the resilient and permanent behavior of subgrade soils, the following topics will be discussed: stress tensors and invariants, elastic stress-strain relationship, resilient and permanent behavior of subgrade. 


\subsection{Stress Tensor and Invariants}

In order to look into the behavior of soils, stress-strain analysis is needed. In a Cartesian coordinate system, the stress tensor $\sigma_{\mathrm{ij}}$ of a soil element is composed of nine stress components:

$$
\sigma_{i j}=\left[\begin{array}{lll}
\sigma_{11} & \sigma_{12} & \sigma_{13} \\
\sigma_{21} & \sigma_{22} & \sigma_{23} \\
\sigma_{31} & \sigma_{32} & \sigma_{33}
\end{array}\right] \equiv\left[\begin{array}{ccc}
\sigma_{x x} & \sigma_{x y} & \sigma_{x z} \\
\sigma_{y x} & \sigma_{y y} & \sigma_{y z} \\
\sigma_{z x} & \sigma_{z y} & \sigma_{z z}
\end{array}\right] \equiv\left[\begin{array}{ccc}
\sigma_{x} & \tau_{x y} & \tau_{x z} \\
\tau_{y x} & \sigma_{y} & \tau_{y z} \\
\tau_{z x} & \tau_{z y} & \sigma_{z}
\end{array}\right]
$$

where $\sigma$ and $\tau$ represent normal and shear stress state components, respectively. Applying the moment equation of motion in the absence of body moments allows the stress tensor to be symmetric.

Thus, $\sigma_{i j}=\sigma_{j i}$ or $\sigma_{12}=\sigma_{21}, \sigma_{13}=\sigma_{31}, \sigma_{23}=\sigma_{32}, \sigma_{x y}=\sigma_{y x}, \sigma_{y z}=\sigma_{z y}$, etc.

According to the Cayley-Hamilton theorem (Desai and Siriwardane 1984), for the $3 \times 3$ square matrix given in (2.1), the characteristic equation is written as follows.

$$
\sigma^{3}-I_{1} \sigma^{2}+I_{2} \sigma-I_{3}=0
$$

The coefficients $I_{1}, I_{2}$ and $I_{3}$ of the characteristic equation, the invariants of the stress tensor, can now be obtained as follows.

$$
\begin{gathered}
I_{1}=\sigma_{11}+\sigma_{22}+\sigma_{33}=\text { sum of the diagonal terms of } \sigma_{\mathrm{ij}} \\
I_{2}=\left|\begin{array}{ll}
\sigma_{11} & \sigma_{12} \\
\sigma_{21} & \sigma_{22}
\end{array}\right|+\left|\begin{array}{ll}
\sigma_{22} & \sigma_{23} \\
\sigma_{23} & \sigma_{33}
\end{array}\right|+\left|\begin{array}{ll}
\sigma_{11} & \sigma_{13} \\
\sigma_{13} & \sigma_{33}
\end{array}\right| \\
=\text { sum of the cofactors of the diagonal terms of } \sigma_{\mathrm{ij}} \\
I_{3}=\left|\begin{array}{lll}
\sigma_{11} & \sigma_{12} & \sigma_{13} \\
\sigma_{21} & \sigma_{22} & \sigma_{23} \\
\sigma_{31} & \sigma_{32} & \sigma_{33}
\end{array}\right|=\text { determinant of } \sigma_{\mathrm{ij}}
\end{gathered}
$$


$I_{1}, I_{2}$ and $I_{3}$ are called invariants because they do not change when the coordinate axes are rotated. Although there is a change of coordinates, the principal stresses and principal axes remain the same. The first invariant $I_{1}$ is often referred to as bulk stress $\theta$.

In order to express the stress state for a soil in $3 \mathrm{D}$ space, principal stresses are generally used because the principal stresses are also invariants regardless of rotation of axes. Now expressing the stress tensor in terms of principal stresses, (2.1) becomes

$$
\sigma_{i j}=\left[\begin{array}{ccc}
\sigma_{1} & 0 & 0 \\
0 & \sigma_{2} & 0 \\
0 & 0 & \sigma_{3}
\end{array}\right]
$$

when $\sigma_{1}>\sigma_{2}>\sigma_{3}, \sigma_{1}, \sigma_{2}$, and $\sigma_{3}$ are major, intermediate and minor pricipal stresses, respectively.

A more accessible formulation results by decomposing a stress tensor into a deviatoric tensor and a hydrostatic tensor, because the characteristics of shear and mean stresses for a soil become more evident. Equation 2.7 illustrates this relationship.

$$
\sigma_{i j}=S_{i j}+\frac{1}{3} \sigma_{n n} \delta_{i j}
$$

where $S_{\mathrm{ij}}=$ deviatoric tensor, $\sigma_{\mathrm{nn}}=$ hydrostatic stress $=\sigma_{11}+\sigma_{22}+\sigma_{33}, \delta_{\mathrm{ij}}=$ Kronecker delta.

Substitution of (2.7) into equation (2.1) leads to:

$$
\left[\begin{array}{lll}
\sigma_{11} & \sigma_{12} & \sigma_{13} \\
\sigma_{21} & \sigma_{22} & \sigma_{23} \\
\sigma_{31} & \sigma_{32} & \sigma_{33}
\end{array}\right]=\left[\begin{array}{lll}
S_{11} & S_{12} & S_{13} \\
S_{21} & S_{22} & S_{23} \\
S_{31} & S_{32} & S_{33}
\end{array}\right]+\left[\begin{array}{ccc}
\frac{\sigma_{n n}}{3} & 0 & 0 \\
0 & \frac{\sigma_{n n}}{3} & 0 \\
0 & 0 & \frac{\sigma_{n n}}{3}
\end{array}\right]
$$

Thus, 


$$
S_{i j}=\sigma_{i j}-\frac{1}{3} \sigma_{n n} \delta_{i j}=\sigma_{i j}-p \delta_{i j}
$$

where $\mathrm{p}=$ mean stress $=\sigma_{\mathrm{nn}} / 3$

Because the deviatoric stress tensor is also a symmetric tensor, the deviatoric stress invariants are obtained as follows.

$$
\begin{gathered}
J_{1}=S_{i i}=S_{11}+S_{22}+S_{33}=0 \\
J_{2}=\frac{1}{2} S_{i j} S_{i j}=\frac{1}{2}\left[S_{11}^{2}+S_{12}^{2}+S_{13}^{2}+S_{12}^{2}+S_{22}^{2}+S_{23}^{2}+S_{13}^{2}+S_{23}^{2}+S_{33}^{2}\right] \\
=\frac{1}{6}\left[\left(\sigma_{1}-\sigma_{2}\right)^{2}+\left(\sigma_{2}-\sigma_{3}\right)^{2}+\left(\sigma_{1}-\sigma_{3}\right)^{2}\right] \\
J_{3}=\frac{1}{3} S_{i j} S_{j m} S_{m i}=I_{3}-\frac{2}{3} I_{1} I_{2}+\frac{2}{27} I_{1}^{3}=0
\end{gathered}
$$

\subsection{Elastic Behavior of Soil}

\subsubsection{Elastic Stress-Strain Relationship}

This first step in describing elasto-plastic behavior is to define elastic behavior. A solid is called elastic if it completely recovers its original configuration when the forces applied on it are removed. According to the generalized form of Hooke's law, the linear elastic relationship between the stress tensor and strain tensor can be written as follows (Chen and Saleeb 1994).

$$
\sigma_{i j}=C_{i j k l} \varepsilon_{k l}
$$


Here $\mathrm{C}_{\mathrm{ijk}}$ is a fourth-order elastic stiffness tensor and has 81 constants. By using the symmetry of stress, strain and elastic stiffness tensors, 81 constants reduce to 21 constants (Chen and Saleeb 1994). Now (2.14) can be expressed in matrix form as:

$$
\left\{\begin{array}{l}
\sigma_{11} \\
\sigma_{22} \\
\sigma_{33} \\
\sigma_{23} \\
\sigma_{13} \\
\sigma_{12}
\end{array}\right\}=\left[\begin{array}{llllll}
C_{1111} & C_{1122} & C_{1133} & C_{1123} & C_{1113} & C_{1112} \\
C_{2211} & C_{2222} & C_{2233} & C_{2223} & C_{2213} & C_{2212} \\
C_{3311} & C_{3322} & C_{3333} & C_{3323} & C_{3313} & C_{3312} \\
C_{2311} & C_{2322} & C_{2333} & C_{2323} & C_{2313} & C_{2312} \\
C_{1311} & C_{1322} & C_{1333} & C_{1323} & C_{1313} & C_{1312} \\
C_{1211} & C_{1222} & C_{1233} & C_{1223} & C_{1213} & C_{1212}
\end{array}\right]\left\{\begin{array}{l}
\varepsilon_{11} \\
\varepsilon_{22} \\
\varepsilon_{33} \\
\gamma_{12} \\
\gamma_{23} \\
\gamma_{13}
\end{array}\right\}
$$

where $\varepsilon_{11}, \varepsilon_{22}$, and $\varepsilon_{33}$ are normal strains, and $\gamma_{12}, \gamma_{23}$, and $\gamma_{13}$ are shear strains, respectively.

In the most general form, an isotropic, fourth-order tensor can be given by:

$$
C_{i j k l}=\lambda \delta_{i j} \delta_{k l}+\mu \delta_{i k} \delta_{j l}+v \delta_{i l} \delta_{j k}
$$

Since $\mathrm{C}_{\mathrm{ijkl}}$ is symmetric and hence $\mu=v$, taking (2.15) into (2.14) leads to:

$$
\sigma_{i j}=\lambda \delta_{i j} \varepsilon_{k k}+2 \mu \varepsilon_{i j}
$$

where $\lambda$ and $\mu$ are Lame's constants. Here $\mu$ is the shear modulus, also known as G.

In order to express $\varepsilon$ in terms of $\sigma$, rewriting (2.16) leads to:

$$
\varepsilon_{i j}=\frac{1}{2 \mu} \sigma_{i j}-\frac{\lambda \delta_{i j}}{2 \mu(3 \lambda+2 \mu)} \sigma_{k k}
$$

Matrix $\mathrm{C}^{-1}$ becomes 


$$
C^{-1}=\frac{1}{\mu(3+2 \mu)}\left[\begin{array}{cccccc}
\lambda+\mu & -\frac{\lambda}{2} & \frac{-\lambda}{2} & 0 & 0 & 0 \\
-\frac{\lambda}{2} & \lambda+\mu & -\frac{\lambda}{2} & 0 & 0 & 0 \\
-\frac{\lambda}{2} & -\frac{\lambda}{2} & \lambda+\mu & 0 & 0 & 0 \\
0 & 0 & 0 & 3 \lambda+2 \mu & 0 & 0 \\
0 & 0 & 0 & 0 & 3 \lambda+2 \mu & 0 \\
0 & 0 & 0 & 0 & 0 & 3 \lambda+2 \mu
\end{array}\right]
$$

Young's modulus E, Poisson's ratio $v$, shear modulus G, and bulk modulus $\mathrm{K}$ can be defined as:

$$
\begin{gathered}
E=\frac{\mu(3 \lambda+2 \mu)}{(\lambda+\mu)} \\
v=\frac{\lambda}{2(\lambda+\mu)} \\
G=\mu=\frac{E}{2(1+v)} \\
K=\frac{\sigma_{k k}}{3 \varepsilon_{k k}}=\frac{E}{3(1-2 v)}
\end{gathered}
$$

These fundamental elastic terms discussed above will be used in developing a constitutive model that describes both resilient and permanent behavior in the finite element (FE) formulation in Chapter 7.

\subsection{Resilient Behavior of Subgrades}

\subsubsection{Introduction}

It is well known that subgrade soils show a nonlinear and time dependent elastoplastic response under traffic loading. As mentioned earlier, in the traditional theories of 
elasticity, the elastic properties of a material are defined by the elastic modulus $\mathrm{E}$ and Poisson's ratio $v$. A similar approach has been widely used in dealing with base material and subgrade soils. In this approach, the elastic modulus is replaced with the resilient modulus to represent the nonlinearity with respect to stress level (Lekarp et al. 2000). This resilient modulus is generally used as an input parameter for multi-layered elastic analysis. The resilient modulus is very meaningful to a pavement's life. To illustrate this condition, Elliott and Thornton (1988) reported the results of analyses using the ILLIPAVE algorithms on a flexible pavement subjected to a 9,000-pound wheel load. As the resilient modulus increased, the asphalt layer strain decreased and the subgrade stress ratio (load-induced deviator stress in subgrade divided by the unconfined compressive strength of the soil) also decreased.

From 1986, AASHTO required the use of the subgrade resilient modulus for the design of flexible pavements. Resilient modulus is an important material property, similar in concept to the modulus of elasticity. It differs from the modulus of elasticity in that it is obtained by a repeated-load triaxial test and is based only on the recoverable strains. Resilient modulus is defined as:

$$
M_{R}=\frac{\sigma_{d}}{\varepsilon_{r}}
$$

where $M_{R}$ is the resilient modulus; $\sigma_{d}$ is the repeated deviator stress; and $\varepsilon_{r}$ is the recoverable axial strain.

The current standard test method to determine the resilient modulus is described by AASHTO T 307-99 which has recently been upgraded from AASHTO T 294-94 and AASHTO T 274. Most literature is limited to AASHTO T 294-94 and AASHTO T 274 
but limited literature on the evaluation of AASHTO T 307-99 appears to be available. In AASHTO T 307-99, traffic conditions are simulated by applying a series of repeated deviator stresses, separated by rest periods and field conditions are simulated by conditioning and postconditioning (i.e. main testing). Conditioning consists of 500 to 1000 load applications at a confining stress of 6 psi and a deviator stress of 4 psi. In addition, main testing is performed at three levels of confining stresses $(2,4,6$ psi) for which each 5 levels of deviator stresses $(2,4,6,8$ and 10 psi) are applied, resulting in 15 steps of load applications. AASHTO T 307-99 classifies soil types into type 1 and type 2 materials. Granular soils and cohesive soils are categorized as type 1 and type 2, respectively. This test applies to the same procedure for both granular and cohesive subgrades and is done under drained conditions only. However, the research on the drainage condition has been quite limited and somewhat neglected. Although the test is done under drained conditions, considerably fast and repeated load applications (each cycle consists of 0.1 second loading and 0.9 second unloading) may lead to undrained or partially undrained condition, especially for cohesive subgrades.

\subsubsection{Resilient Behavior of Cohesive Subgrades}

In general, the resilient modulus of cohesive subgrades is affected by the following factors: a) Deviator stress; b) Method of compaction; c) Compaction water content and dry density; d) Thixotropy; e) Degree of saturation; and f) Freeze-thaw cycles. Deviator stress, compaction water content and dry density, and freeze-thaw cycles are the factors that most influence the resilient modulus of cohesive subgrades. Another factor that affects the resilient modulus is seasonal variation of moisture content. Seasonal variations, 
however, can be accounted for by variations in the degree of saturation. Therefore, seasonal variations will not be discussed further here.

\subsubsection{Deviator stress}

Results from several studies have shown that the resilient modulus of cohesive soils is greatly affected by the magnitude of the deviator stress. Wilson et al. (1990), Drumm et al. (1990) and Thompson and Robnett (1979) reported that at low levels of repeated deviator stress, the resilient modulus decreases significantly as the deviator stress increases. On the other hand, as shown in Figure 1, at greater levels of deviator stress, the resilient modulus either decreases slightly or reaches constant values. Figure 1 presents a subset of the tests that Wilson et al. (1990) performed on an A-6a cohesive subgrade, located in Jackson County, Ohio. In a different study, Thompson and Robnett, after thorough testing performed on Illinois soils, reported the existence of a breakpoint resilient modulus corresponding to the resilient modulus at a deviator stress of 6 psi with unconfined confining stress. This breakpoint characterizes the behavior of these soils under repeated loads. 


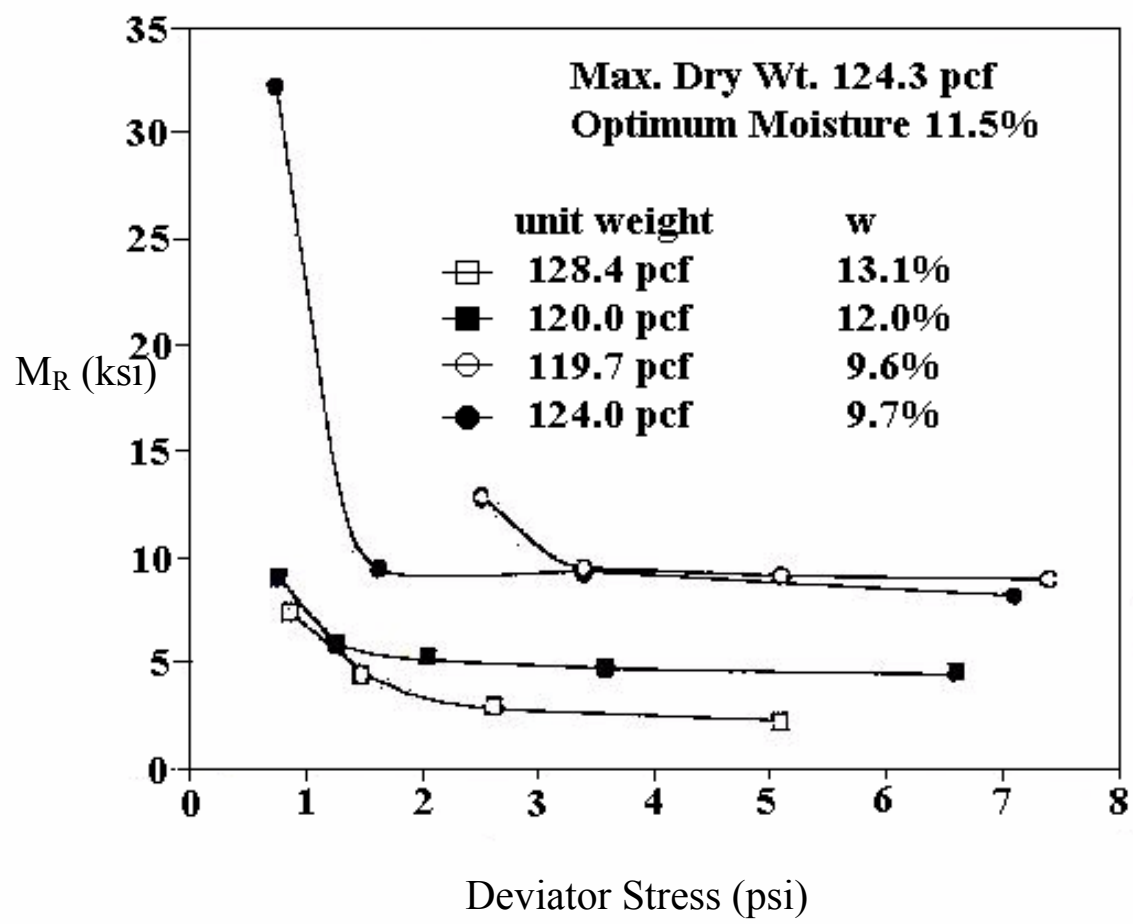

Figure 1. Effect of deviator stress on a A-7-6 subgrade soil (Wilson et al. 1990)

\subsubsection{Method of compaction}

Lee (1993) reported on the influence of the method of compaction on the resilient modulus of cohesive subgrades based on the results of past studies. For specimens compacted at low degrees of saturation, the method of compaction had little effect on the resilient modulus due to the flocculated arrangement of the clay particles. In contrast, when samples are compacted above optimum water content, compaction caused large changes, which was attributed to the dispersed arrangement of the clay particles. Seed and Chan (1959) concluded that the kneading and impact methods of compaction usually produce a flocculated particle arrangement for water contents dry of optimum and a dispersed arrangement at wet of optimum, while static compaction, at any level of moisture content generates a flocculated arrangement. They also reported that for clays 
compacted dry of optimum, the recoverable strains for samples prepared by kneading and static compaction were the same. However, for specimens compacted wet of optimum, the kneading compacted specimens experienced significantly larger recoverable strains.

\subsubsection{Compaction water content and dry density}

It is expected that as the compaction moisture content of a cohesive soil increases, the stiffness of the soil tends to decrease. As seen from Figures 2 and 3, the same trend has been observed for the resilient modulus. Figure 2 is from results of tests on cohesive subgrades conducted in Indiana by Lee et al. (1997). Figures 1 and 2 clearly show that as the moisture content increases, the resilient modulus decreases. It was noticed that specimens compacted wet of optimum exhibit significantly lower values of the resilient modulus. This observation agrees well with the aforementioned effect of the method of compaction. As seen from Figure 2, it is also observed that the resilient modulus increases as the dry density increases. As the density of any soil increases, less volume is occupied by the voids, and this consequently results in the increase of the strength of the soil. 


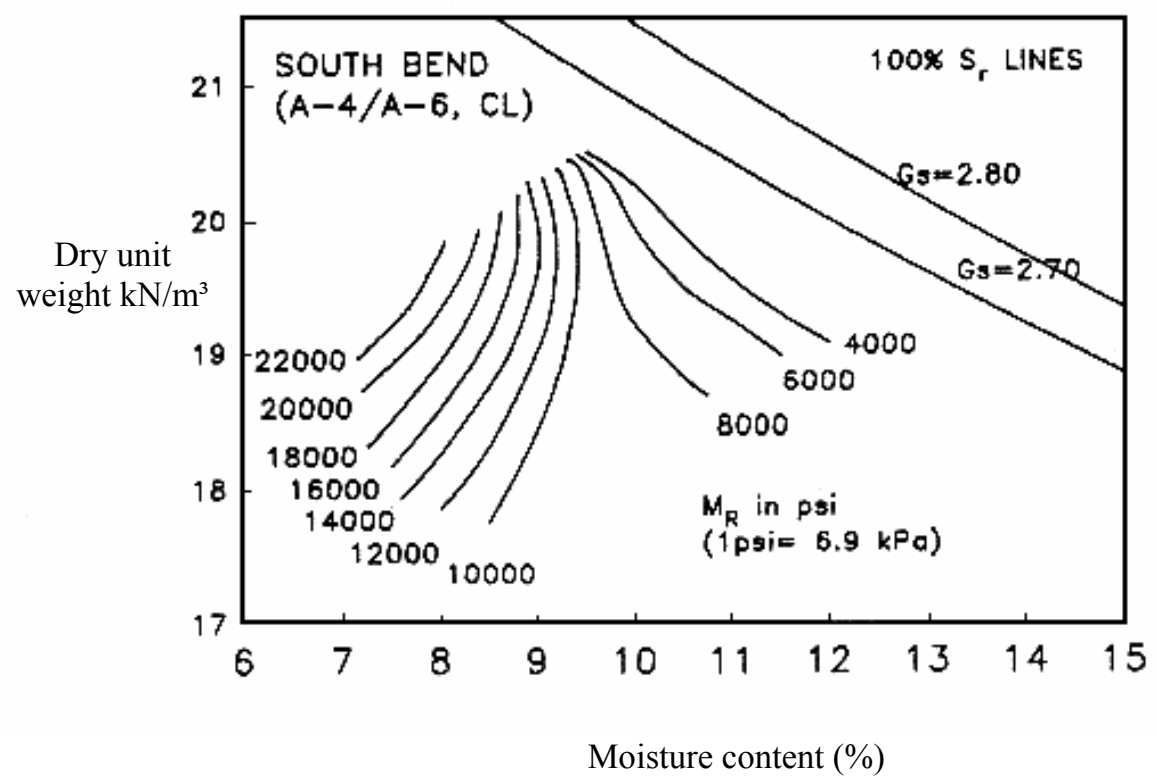

Figure 2. Effect of compaction water content and moisture density on a cohesive subgrade (Lee et al. 1997)

\subsubsection{Thixotropy}

Seed and Chan (1957) showed that when samples of cohesive soil are compacted at a high degree of saturation, they exhibit a significant increase in strength if they are allowed to rest before testing. Seed and Chan also reported that after a certain number of repeated loads (about 40,000 repetitions), thixotropy no longer affected the recoverable deformations. This situation could be attributed to the fact that the induced deformations were so large that they overcame the thixotropic strength of the samples.

\subsubsection{Degree of saturation}

The effect of the degree of saturation is similar to the effect of the water content on the resilient modulus. Figure 3 presents the variation of the resilient modulus with the degree of saturation of an A-7-5 subgrade soil, compacted wet of optimum. The results 
are from research that Drumm et al. (1997) carried out on Tennessee soils. A decrease in the resilient modulus is observed as the degree of saturation increases.

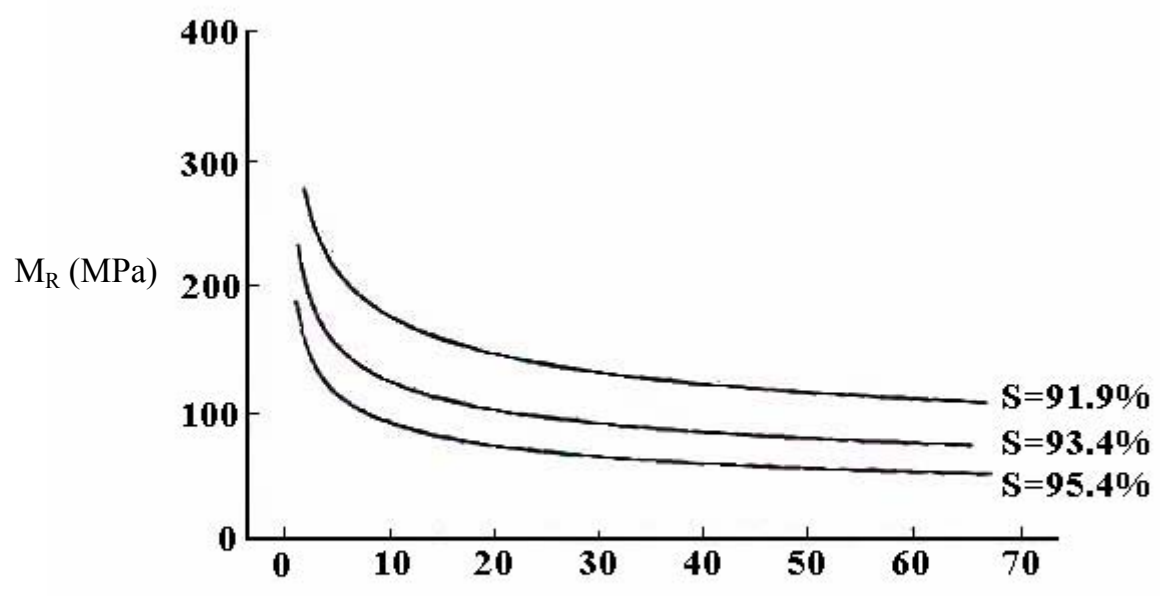

Deviator Stress (kPa)

Figure 3. Effect of post-compaction saturation on resilient modulus of an A-7-5 subgrade soil (Drumm et al. 1997)

\subsubsection{Freeze-thaw}

The effect of freeze-thaw on the resilient modulus of cohesive subgrades is significant. Elliott and Thornton (1988) mentioned a dramatic reduction in the resilient modulus following only one freeze-thaw cycle. In some Arkansas soils, this reduction was estimated to be about 50 percent. Lee (1993) also reported that Micleborough in 1970 examined the effect of freeze-thaw on the resilient properties of highly plastic glacial lake clay. After two and four freeze-thaw cycles, the results showed a reduction of the resilient modulus by 63 and 74 percent, respectively. 
2.4.2.7. Models for the resilient modulus of cohesive subgrades

During the last twenty years, many models have been proposed to predict the resilient modulus of cohesive subgrades. Some of them are stress-dependent and others are dependent on physical properties. There are also models that considered both physical and stress conditions of the subgrades. However, all these models seem to apply only to the subgrades that were used to develop these models. In most of the cases when the models were applied to other types of cohesive subgrades, the deviation was significant. This deviation is expected given the nature of the models. These models were developed for certain soils and then were examined to see if they were applicable to others. The results were not satisfactory because these soils had different physical and stress conditions. Therefore, it is worth noting that when using one of the models presented next, one must proceed with caution.

a. Pezo and Hudson (1994) suggested the following model for the resilient modulus.

$$
M r=F_{0} \cdot F_{1} \cdot F_{2} \cdot F_{3} \cdot F_{4} \cdot F_{5} \cdot F_{6}, R^{2}=0.803
$$

Factors $F_{0} \sim F_{6}$ depend on physical properties and the stress condition of the soil.

b. Thompson and Robnett (1979) introduced the following model.

$$
\begin{aligned}
& M r=k_{2}+k_{3} \cdot\left(k_{1}-\sigma_{d}\right), \text { if } \mathrm{k}_{1}>\sigma_{\mathrm{d}} \\
& M r=k_{2}+k_{4} \cdot\left(\sigma_{d}-k_{1}\right), \text { if } \mathrm{k}_{1}<\sigma_{\mathrm{d}}
\end{aligned}
$$

$\mathrm{k}_{1}-\mathrm{k}_{4}=$ material and physical property parameters.

c. Hall and Thompson (1994) proposed the model:

$$
M r(O P T)=6.90+0.0064 \cdot C+0.216 \cdot P I-1.970 \cdot C, R^{2}=0.76
$$


Mr (OPT): subgrade resilient modulus (ksi) at AASHTO T-99 optimum moisture content and 95 percent compaction

C: percent clay $(<2 \mu \mathrm{m})$

PI: plasticity index (percent)

OC: percent organic carbon

$\mathrm{R}^{2}$ : coefficient of determination

d. Lee et al. (1979) suggested the following model.

$$
M r=695.4 \cdot\left(S_{u 1.0 \%}\right)-5.93 \cdot\left(S_{u 1.0 \%}\right)^{2}, R^{2}=0.97
$$

Mr: resilient modulus (psi) at maximum axial stress of $6 \mathrm{psi}$, confining stress is $3 \mathrm{psi}$ $\mathrm{S}_{\mathrm{u} 1.0 \%}$ : stress (psi) causing 1\% strain in conventional unconfined compressive test e. Mohammad et al. (1999) performed CPT tests in two types of clay and suggested the model below.

$$
M r=a \cdot q_{c}^{n}+b \cdot f_{s}+c \cdot w+d \cdot \gamma_{d}+e, R^{2}=0.91-0.95
$$

Mr: resilient modulus (in $\mathrm{MPa}$ )

a, b, c, d, e: constants from regression analyses

$\mathrm{n}$ : integer $(1,2$, or 3$)$

$\mathrm{q}_{\mathrm{c}}$ : tip resistance $(\mathrm{MPa})$

$\mathrm{f}_{\mathrm{s}}$ : sleeve friction $(\mathrm{MPa})$

w:moisture content $(\%)$

$\gamma_{\mathrm{d}}$ : dry unit weight $\left(\mathrm{kN} / \mathrm{m}^{3}\right)$

f. Drumm et al. (1997) modeled the change of the resilient modulus with respect to postcompaction saturation and presented the following model. 


$$
M_{r(w e t)}=M_{r(o p t)}+\frac{d M_{r}}{d S} \cdot \Delta S
$$

$\mathrm{M}_{\mathrm{r}(\text { wet })}$ : resilient modulus $(\mathrm{MPa})$ at increased post-compaction saturation

$\mathrm{M}_{\mathrm{r}(\mathrm{opt})}$ : resilient modulus $(\mathrm{MPa})$ at optimum moisture content

$\mathrm{dM}_{\mathrm{r}} / \mathrm{dS}$ : gradient of resilient modulus (MPa), function of type of soil

$\Delta \mathrm{S}$ : change in post-compaction degree of saturation (decimal)

\subsubsection{Resilient Behavior of Cohesionless Subgrades}

In the case of cohesionless subgrades, the factors that influence the resilient modulus the most are, in approximate order of importance, the following: a) Dry density; b) Degree of saturation; c) Confining pressure; d) Aggregate gradation; e) Compaction method; f) Deviator stress.

\subsubsection{Deviator stress}

The influence of the deviator stress on the resilient modulus of cohesionless subgrades is similar to that of cohesive subgrades. Wilson et al. (1990) and Mohammad et al. (1995) reported a decrease of the resilient modulus as the deviator stress increased. Figure 4 illustrates that for an A-1 subgrade, there is a significant decrease of the resilient modulus with respect to the deviator stress for specimens compacted dry of the optimum water content. It can also be noticed that the resilient modulus of specimens compacted wet of optimum is smaller compared to the compacted dry of optimum specimens and decreases significantly with increasing deviator stress. 


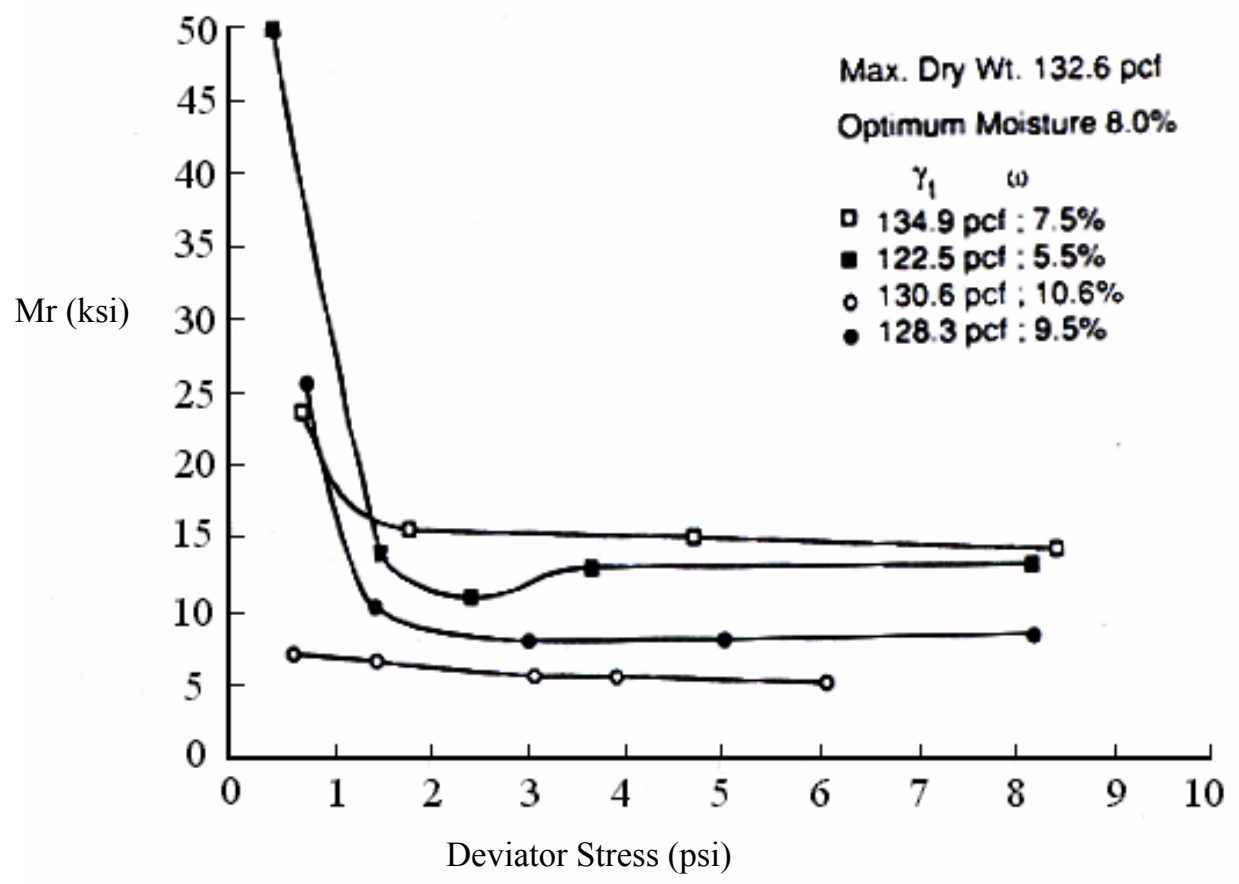

Figure 4. Effect of deviator stress on the resilient modulus of an A-1 subgrade soil (Wilson et al. 1990)

\subsubsection{Confining pressure}

The effect of confining pressure on granular subgrades is more pronounced than the effect of the deviator stress. Mohammad et al. (1995) and Hicks and Monismith (1971) reported that the resilient modulus of granular subgrades increases as the confining pressure increases.

\subsubsection{Dry density}

Dry density has a significant role in the resilient modulus of cohesionless subgrades. Lee et al. (1995) reported that specimens of dune sand exhibited higher values of resilient modulus as the dry density increased. Moreover, Hicks and Monismith (1971) concluded from tests performed on a granular subgrade (shown in Figure 5) that the resilient 
modulus increased as the relative dry density increased for both coarse-graded and finegrading subgrade. This conclusion is certainly due to the fact that increasing the dry density consequently decreases the volume of voids and as a result increases the strength properties of a granular subgrade.
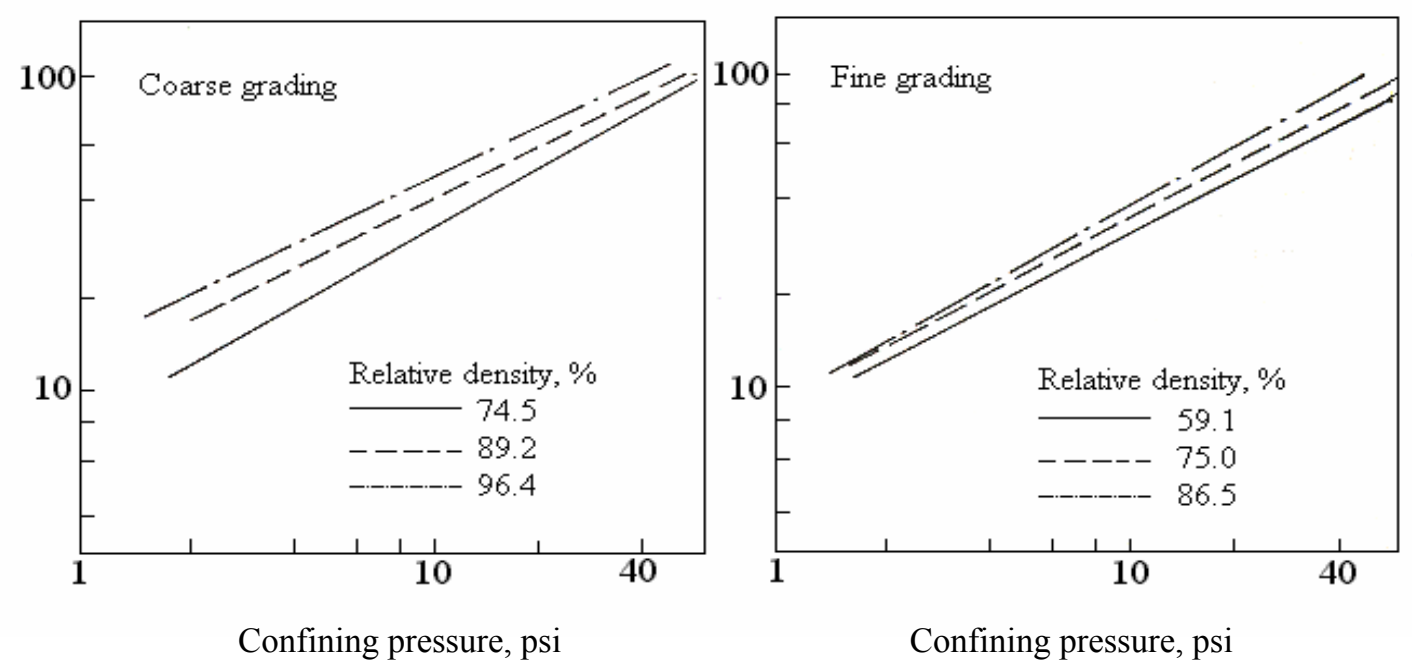

Figure 5. Influence of dry density on the resilient modulus of granular subgrades (Hicks and Monismith 1971)

\subsubsection{Degree of saturation}

The degree of saturation significantly affects the resilient modulus. As Lee (1993) reported, Haynes and Yoder, from tests conducted on both gravel and crushed stone base course material, found that the resilient modulus of the gravel at a degree of saturation of 97 percent was one half of that at a degree of saturation of 70 percent. In addition, Hicks and Monismith (1971) also found a decrease in the resilient modulus as the degree of saturation increased. 


\subsubsection{Aggregate gradation}

Hicks and Monismith (1971) examined the effect of aggregate gradation. As presented in Figure 5, as the percentage of fines increased in a granular subgrade, for the same level of confining pressure, a decrease of the resilient modulus was observed. As the percentage of fines increases in a granular soil, the degree of interlocking decreases which results in the decrease of the strength of the soil.

\subsubsection{Method of compaction}

Lee et al. (1995) from their testing on dune sand found that, as seen in Figure 6, the resilient modulus of an impact-compacted specimen is lower than that of a vibratorycompacted one; despite the fact that the impact compacted specimen has slightly higher density and lower water content.

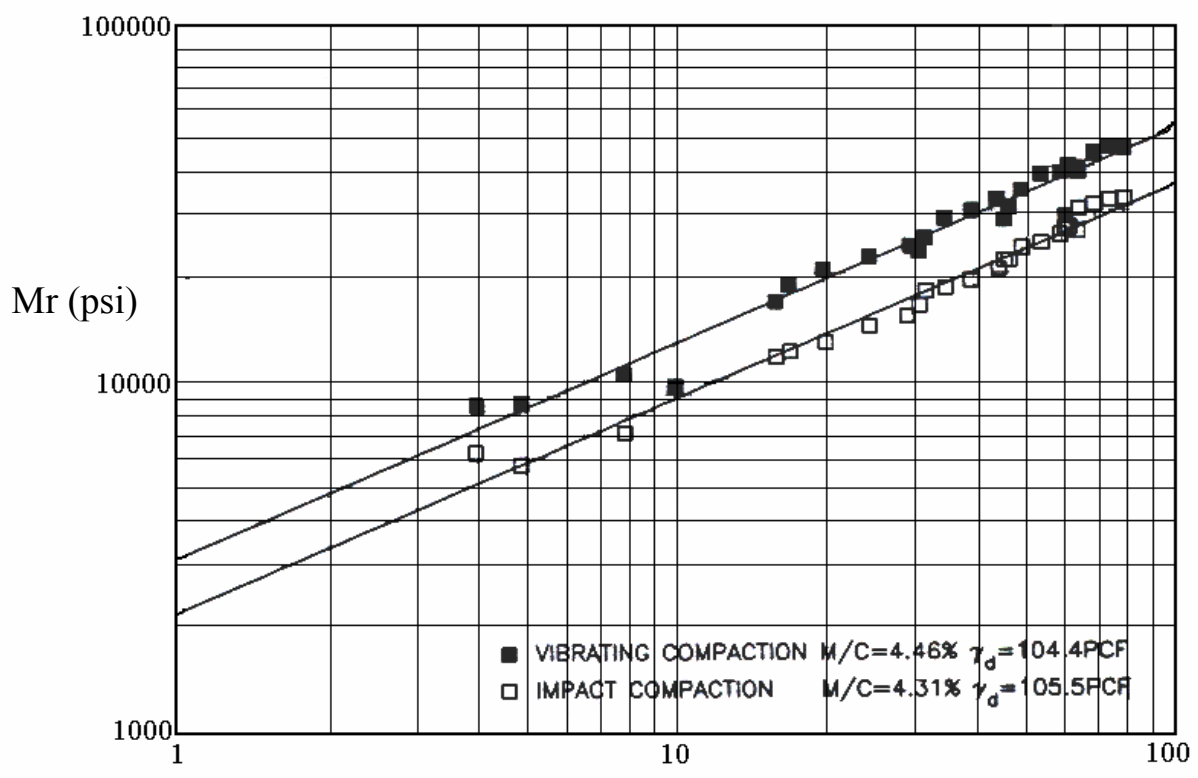

Sum of principal stresses (psi)

Figure 6. Effect of method compaction (Lee et al. 1997) 
2.4.3.7. Models for the resilient modulus of cohesionless subgrades

The models proposed to predict the resilient modulus of granular subgrades do not fit well to soils other than those for which the models were developed. One example is the case of Puppala et al. (1996) who used three models to predict the resilient modulus of sand. Among those three models, the triaxial model provided predictions closer to the measured data. The other two models deviated significantly from the measured data. The following are some examples of models used to predict the resilient modulus of granular subgrade.

a. Lee et al. (1995) from their tests on dune sand proposed the following model.

$$
M r=(-20,163+232.886 \cdot R C) \cdot \theta^{0.595}
$$

$\mathrm{M}_{\mathrm{R}}$ : resilient modulus $(\mathrm{kPa})$

$\mathrm{RC}$ : relative compaction $=$ dry density $/ 17.17 \mathrm{kN} / \mathrm{m}^{3}$

$\theta$ : sum of principal stresses $(\mathrm{kPa})$

b. Puppala et al. (1996), in their study to predict the resilient modulus of a sand, used the following three equations.

(Bulk stress model)

$$
\begin{gathered}
M r=a \cdot \theta^{b} \\
\log a=-0.85+0.06 \cdot \gamma_{d}-0.27 \cdot w, R^{2}=0.98 \\
b=-1.23+0.002 \cdot \gamma_{d}+0.11 \cdot w, R^{2}=0.96
\end{gathered}
$$


(Octahedral stress model)

$$
\begin{gathered}
\frac{M r}{\sigma_{a t m}}=k_{1} \cdot\left(\frac{\sigma_{o c t}}{\sigma_{a t m}}\right)^{k_{2}} \cdot\left(\frac{\tau_{o c t}}{\sigma_{a t m}}\right)^{k_{3}} \\
\log k_{1}=2.56+0.013 \cdot \gamma_{d}-0.08 \cdot w, R^{2}=0.96 \\
k_{2}=-34.9+0.31 \cdot \gamma_{d}-0.003 \cdot w, R^{2}=0.72 \\
k_{3}=28.1-0.25 \cdot \gamma_{d}+0.07 \cdot w, R^{2}=0.68
\end{gathered}
$$

(Triaxial stress model)

$$
\begin{gathered}
\frac{M r}{\sigma_{a t m}}=k_{4} \cdot\left(\frac{\sigma_{3}}{\sigma_{a t m}}\right)^{k_{5}} \cdot\left(\frac{\sigma_{d}}{\sigma_{a t m}}\right)^{k_{6}} \\
\log k_{4}=-9.61+0.12 \cdot \gamma_{d}-0.08 \cdot \mathrm{w}, R^{2}=0.69 \\
k_{5}=-19.6+0.17 \cdot \gamma_{d}-0.05 \cdot \mathrm{w}, R^{2}=0.69 \\
k_{6}=15.2-0.14 \cdot \gamma_{d}+0.06 \cdot \mathrm{w}, R^{2}=0.68
\end{gathered}
$$

Mr: resilient modulus $(\mathrm{kPa})$

$\sigma_{\text {oct }}$ octahedral normal stress $(\mathrm{kPa})$

$\tau_{\text {oct }}$ octahedral shear stress $(\mathrm{kPa})$

$\sigma_{\text {atm: }}$ atmospheric pressure $(\mathrm{kPa})$

$\gamma_{d}$ : dry unit weight (pcf)

w: moisture content 


\subsection{Permanent Behavior of Subgrades}

\subsubsection{Permanent Deformations of Cohesive Subgrades}

The factors that most affect the permanent deformation of cohesive subgrades are a) Shear stress level; b) Stress history; c) Thixotropy; d) Frequency of load; e) Moisture content; f) Freeze-thaw cycles and; g) Overconsolidation ratio.

\subsubsection{Shear Stress level}

The shear stress level is the most influential factor on the development of permanent deformations in cohesive subgrades. Muhanna et al. (1998) tested an A-6 subgrade soil under repeated load tests. This soil had a maximum dry density of $17.52 \mathrm{kN} / \mathrm{m}^{3}$ at optimum water content of 15.7 percent. The stress levels (SL) were expressed as a percentage of the deviator stress at failure from unconsolidated undrained (UU) tests, while the confining pressure was kept constant. Results are presented in Figures 7 - 9 and are for specimens compacted at 2.5 percent below optimum moisture content, optimum, and 2.5 percent above optimum, respectively. It is evident that at any stress level, as the number of load repetitions increases, permanent deformations increase. Also, permanent deformations increase significantly when the stress level increases. For specimens compacted dry of optimum, permanent deformations become constant as the number of cycles increase. Only in the case of specimens compacted above optimum water content, for $\mathrm{SL}=75 \%$, are permanent deformations very large, and do not reach a constant value as the number of cycles increase. Shear failure occurs in these cases. 


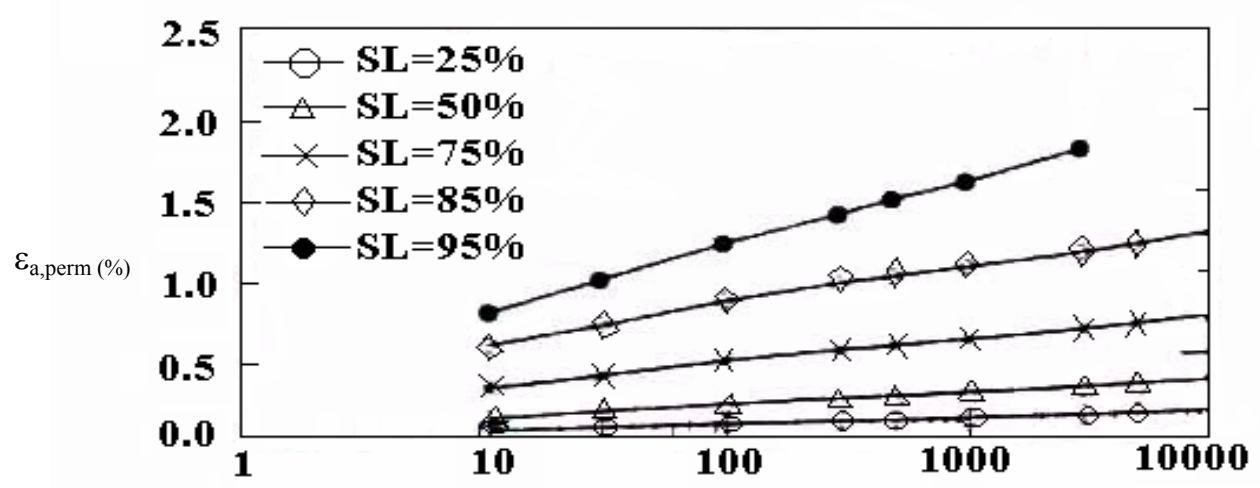

Figure 7. Results from tests on compacted at dry of optimum A-6 subgrade soil (Muhanna et al. 1998)

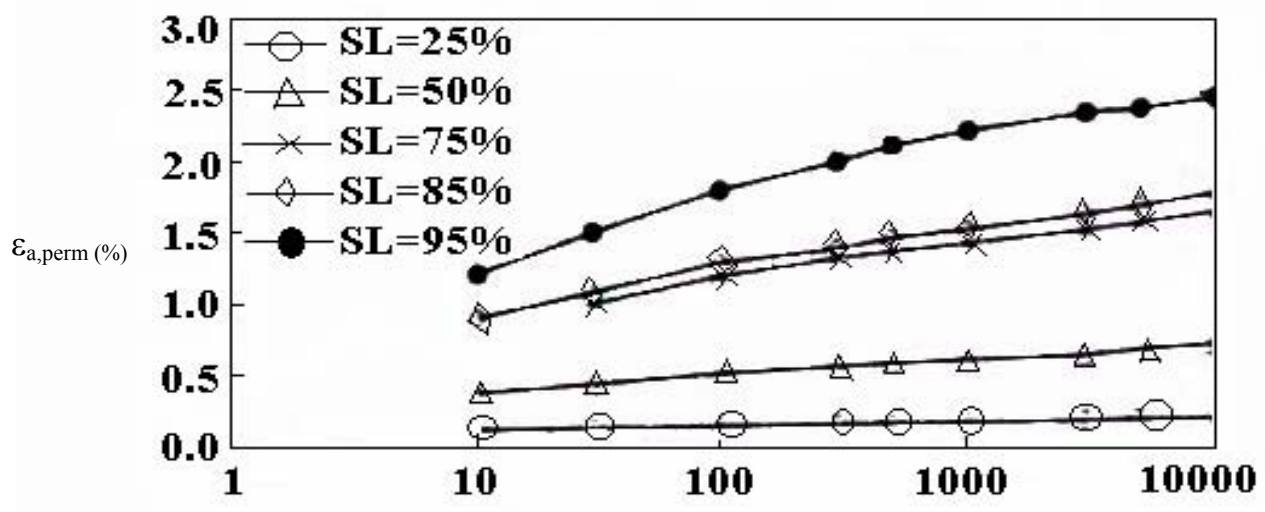

Number of Cycles, $\mathrm{N}$

Figure 8. Results from tests on compacted at optimum A-6 subgrade soil (Muhanna et al. 1998) 


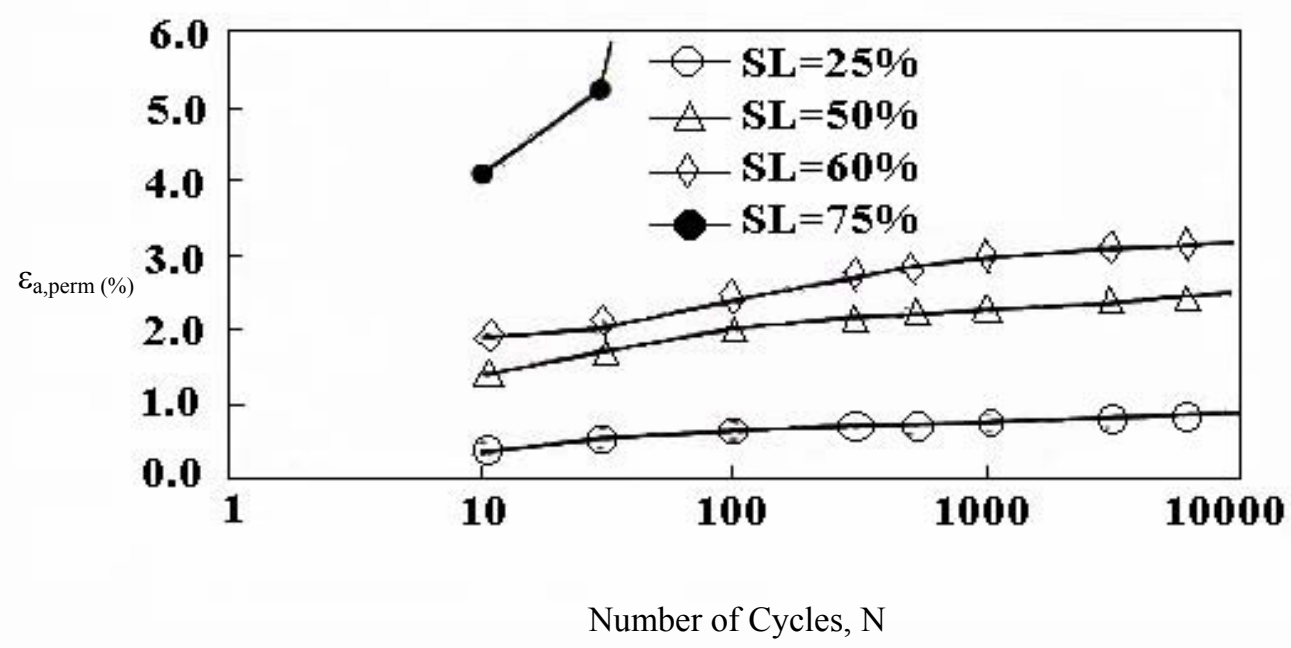

Figure 9. Results from tests on compacted at wet of optimum A-6 subgrade soil (Muhanna et al. 1998)

Raad and Zeid (1990) developed a model of permanent strains under repeated loads for an A-6 silty clay subgrade. The maximum dry density and optimum moisture content given by modified AASHTO compaction were $131.5 \mathrm{lb} / \mathrm{ft}^{3}$ and 8.5 percent. The ratio $\mathrm{q}_{\mathrm{r}}$ is the ratio of repeated deviator stress to the strength obtained from a standard triaxial test at a strain rate of $0.5 \% / \mathrm{min}$. Results are illustrated in Figures 10 and 11. Permanent strains were measured at two levels of confining pressure ( 0 and $14.5 \mathrm{psi})$ and water content ( 7 and 10 percent). For stress levels of $\mathrm{q}$ up to 0.80 , permanent deformations initially increase, but eventually stabilize with an increasing number of repetitions. In contrast, for $q \geq 0.90$ permanent strains continuously increase. Therefore, it can be concluded that there exists a "threshold stress level", below which the accumulation of permanent axial strains stops, leading to a stable response, and above which progressive accumulation of 
axial strains occurs and causes unstable response and ultimately failure. In the case of Raad and Zeid, the "threshold stress level" was between 0.80 and 0.90 . For the tests of Muhanna et al. (1998), the "threshold stress level" appeared only for specimens compacted wet of optimum and it was for values of SL between 60 and 75 percent.

The effect of the confining pressure on the tests that Raad and Zeid performed is very significant. As confining pressure was increased, a stiffening of the soil was observed, consequently resulting in lower axial strains.

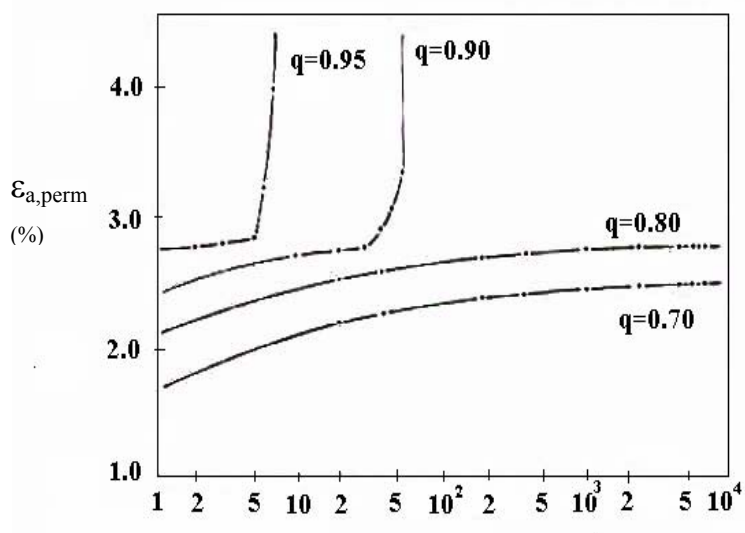

Number of stress repetitions $\mathrm{N}$

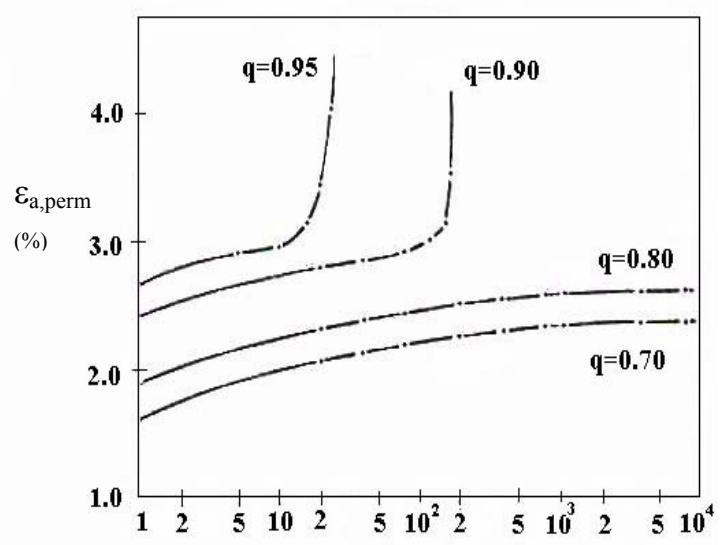

Number of stress repetitions $\mathrm{N}$

Figure 10. Results from tests on silty clay; left: $\sigma_{3}=0 \mathrm{psi}, \gamma_{\mathrm{d}}=129.5 \mathrm{lb} / \mathrm{ft}^{3}, \mathrm{~m}=7 \%$ right: $\sigma_{3}=14.5 \mathrm{psi}, \gamma_{\mathrm{d}}=129.5 \mathrm{lb} / \mathrm{ft}^{3}, \mathrm{~m}=7 \%$ (Raad and Zeid 1990) 

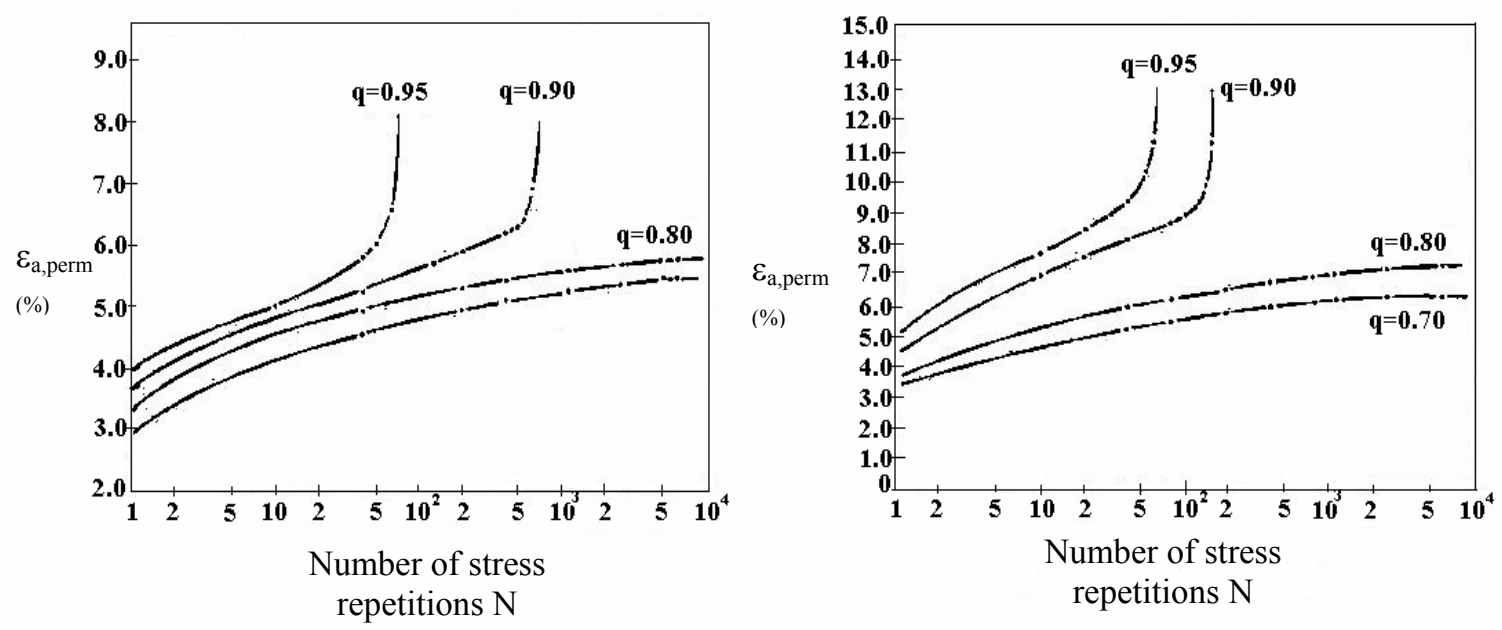

Figure 11. Results from tests on silty clay; left: $\sigma_{3}=0 \mathrm{psi}, \gamma_{\mathrm{d}}=129.5 \mathrm{lb} / \mathrm{ft}^{3}, \mathrm{~m}=10 \%$ right: $\sigma_{3}=14.5 \mathrm{psi}, \gamma_{\mathrm{d}}=129.5 \mathrm{lb} / \mathrm{ft}^{3}, \mathrm{~m}=10 \%$ (Raad and Zeid 1990)

Raymond et al. (1979) reported the existence of the "threshold stress level" for Leda clay. This clay is very sensitive and saturated, having a natural water content of $91 \%$, a liquid limit of $66 \%$ and a plastic limit of $20 \%$. Drained triaxial tests were performed under a constant confining pressure of $35 \mathrm{kPa}$ to simulate a typical subgrade stress. The repeated deviator stress was a percentage of the principal stress difference at failure, $66 \mathrm{kPa}$, from drained triaxial tests (at $35 \mathrm{kPa}$ confining pressure). Here, the "threshold stress level" was about 54 to 60 percent of the deviator stress at failure.

\subsubsection{Stress history}

Monismith et al. (1975) performed a series of undrained triaxial compression tests on a silty clay (liquid limit $=35$, plasticity index $=15$ ). Specimens were prepared at dry 
densities from 90 to 95 percent of the maximum value obtained in the modified AASHTO compaction test and at water contents from 16 to 20 percent. The effect of stress history on permanent strain accumulation is presented in Figure 12. These are the results of repeated load tests of specimens at a constant confining pressure of 5 psi and at repeated deviator stresses of 10 and 20 psi. In two of the cases, the specimens were subjected to 10,000 applications of these stresses, followed by an unloading and a reload to the same number and level of stress applications. The data shows that specimens with previous stress applications exhibited lower axial permanent strains than specimens that were not previously subjected to stress applications. This result is attributed to a considerable stiffening and a consequent increase in resistance to deformation that is generated by the previous stress applications.

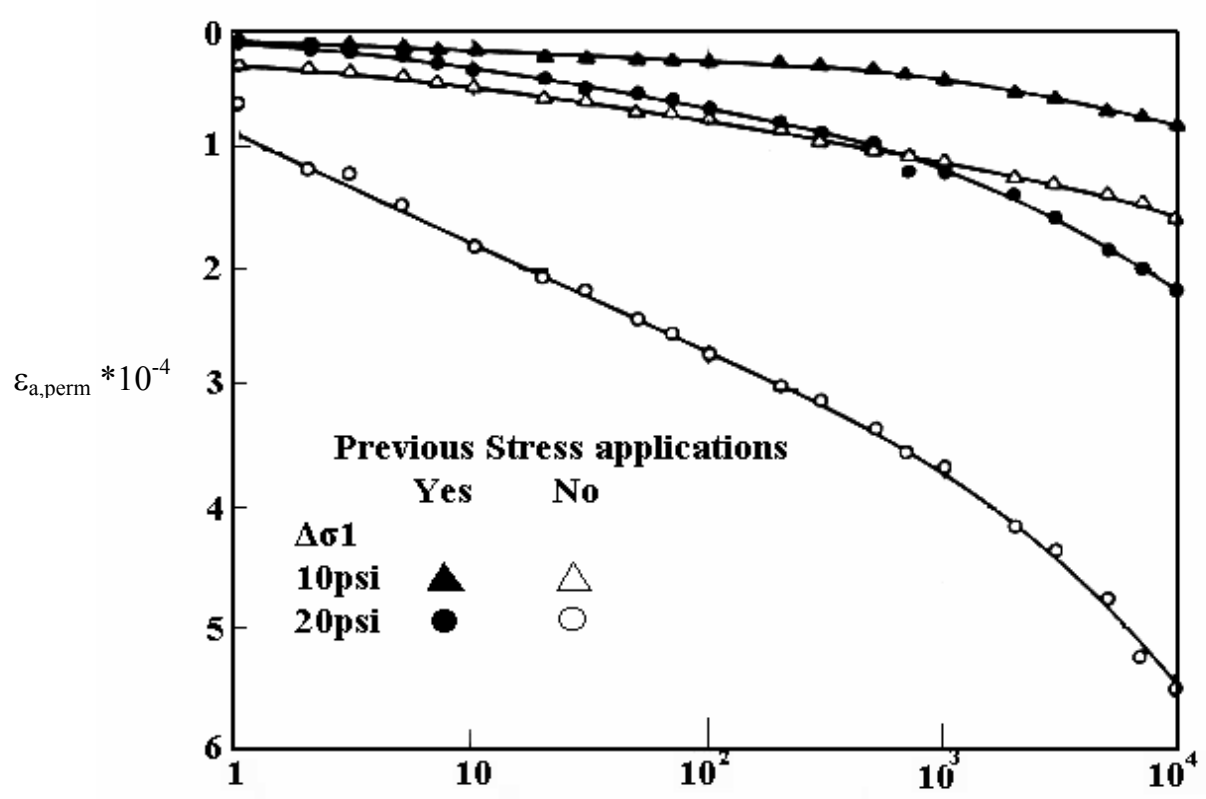

Number of Stress Applications

Figure 12. Influence of stress history on permanent strains (Monismith et al. 1975) 
Seed and Chan (1958) made similar observations when they tested a silty clay (liquid limit 37 and plastic limit 23). They concluded that this stress stiffening was probably due to changes in the structural arrangements of the clay particles that compressed as water dissipated under repeated loads.

\subsubsection{Thixotropy}

Seed and Chan (1958) investigated the effects of thixotropy (strength gain with time in saturated clays) on axial strain. This investigation was accomplished by testing specimens six weeks after compaction, thereby allowing the specimens to gain considerable thixotropic strength. Figure 13 presents the results for specimens with an initial degree of saturation of 95 percent. For specimens tested six weeks after compaction, axial strains were significantly lower than for samples tested immediately after they were compacted. In contrast, Figure 14 shows the results for specimens at an initial degree of saturation of 70 percent. The period of rest did not influence the accumulation of axial strains. Therefore, saturated clay subgrades are affected significantly by the period of rest. In particular, between long intervals of load applications, saturated clays regain more thixotropic strength than at short intervals (high frequencies). 
Number of stress applications

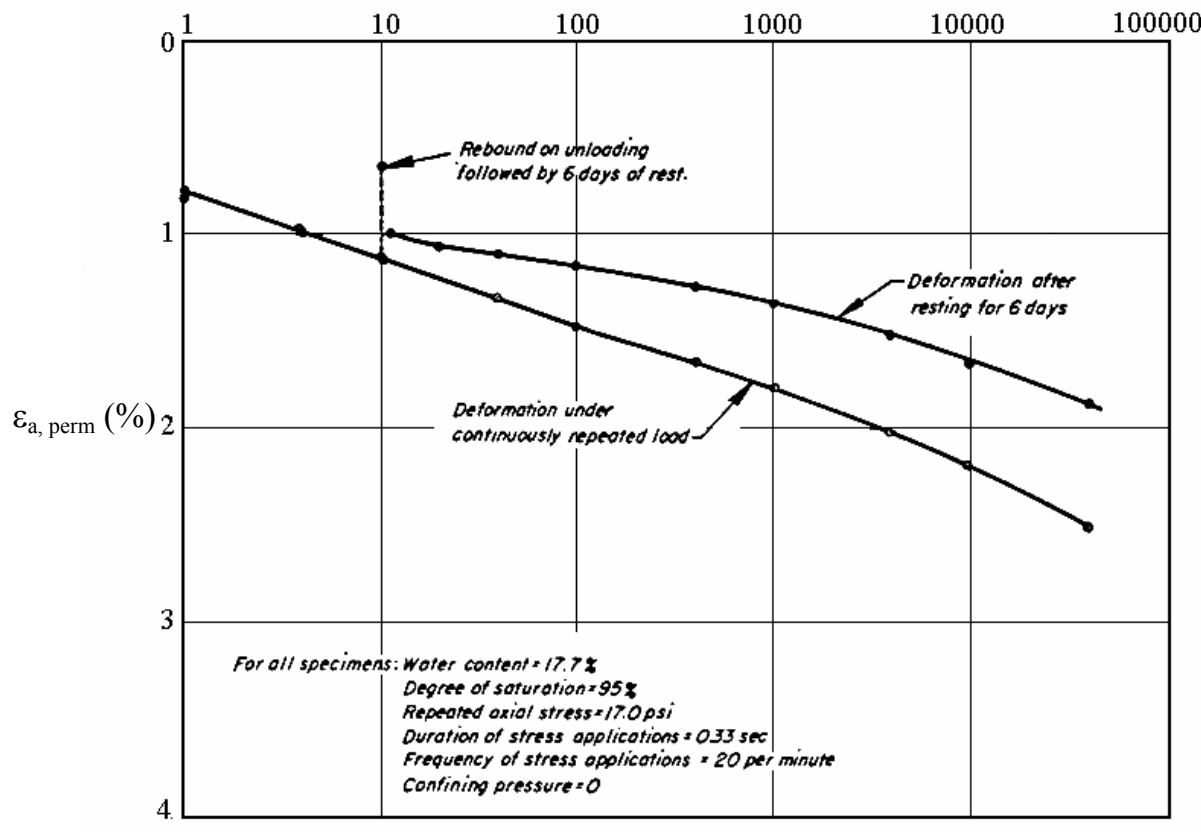

Number of stress applications

Figure 13. Effect of period of rest on deformation under repeated loading of silty clay with high degree of saturation (Seed and Chan 1958) 


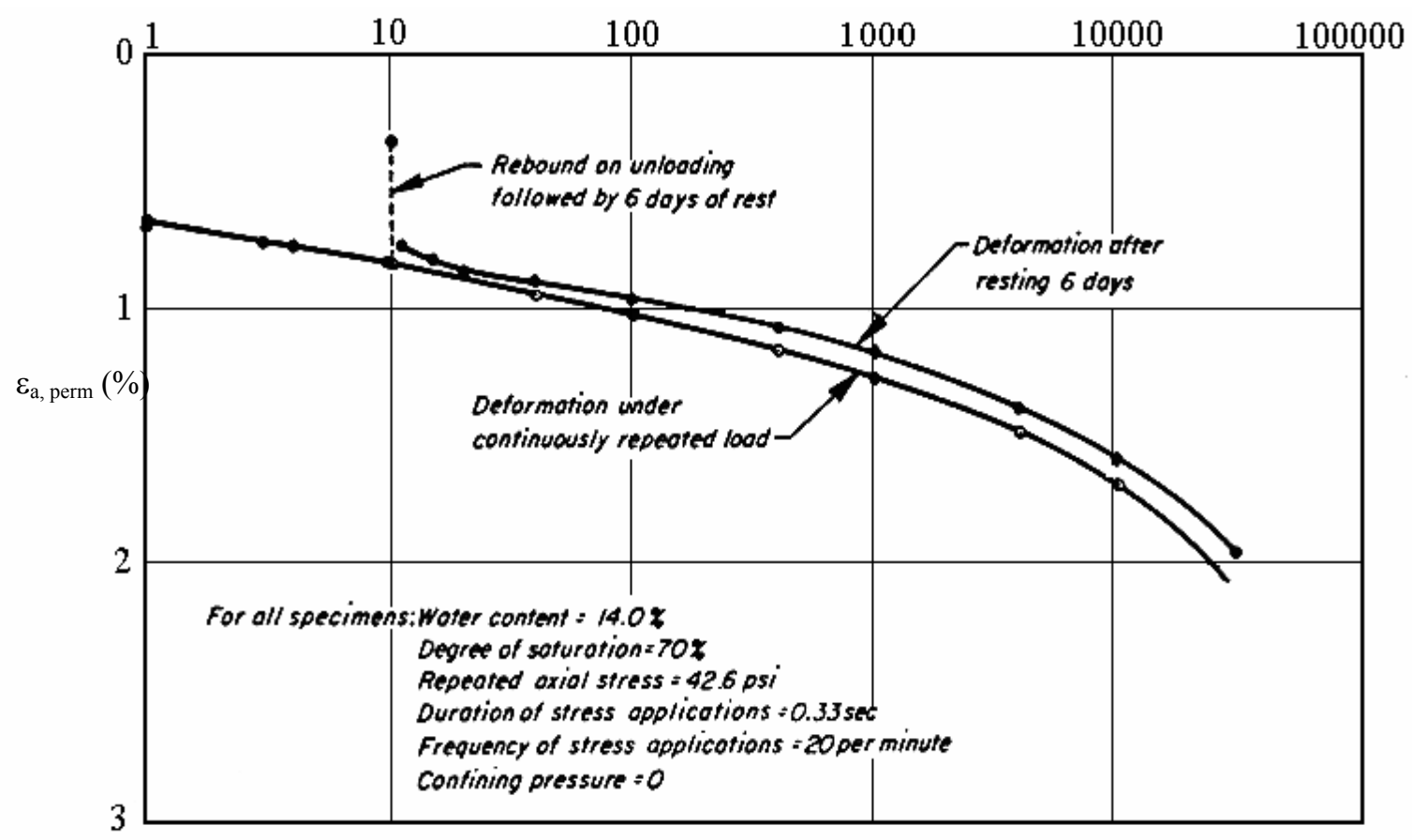

Figure 14. Effect of period of rest on deformation under repeated loading of silty clay with low degree of saturation (Seed and Chan, 1958)

\subsubsection{Frequency of load}

Seed and Chan (1958) thoroughly examined this matter. They found that the influence of the frequency of load was significant on clays with high degrees of saturation, which are very thixotropic. Clays with low degrees of saturation (less thixotropic) were not influenced at all. Figure 15 presents the effect of the load frequency using stress controlled tests for identical silty clay specimens compacted to an initial degree of saturation of 95 percent and subjected to repeated stress applications of the same magnitude and duration, but with varying frequencies. There is large difference in the number of applications required to cause a certain amount of strain. Specimens 
subjected to high load frequencies developed a certain amount of axial strain sooner than specimens subjected to low load frequencies.

Figure 16 shows that for specimens compacted at an initial degree of saturation of 63 percent and tested at a wide range of frequencies, the accumulation of axial strains was the same and the frequency had no influence at all. This difference was due to the thixotropic behavior of clays with high degree of saturation as mentioned earlier.

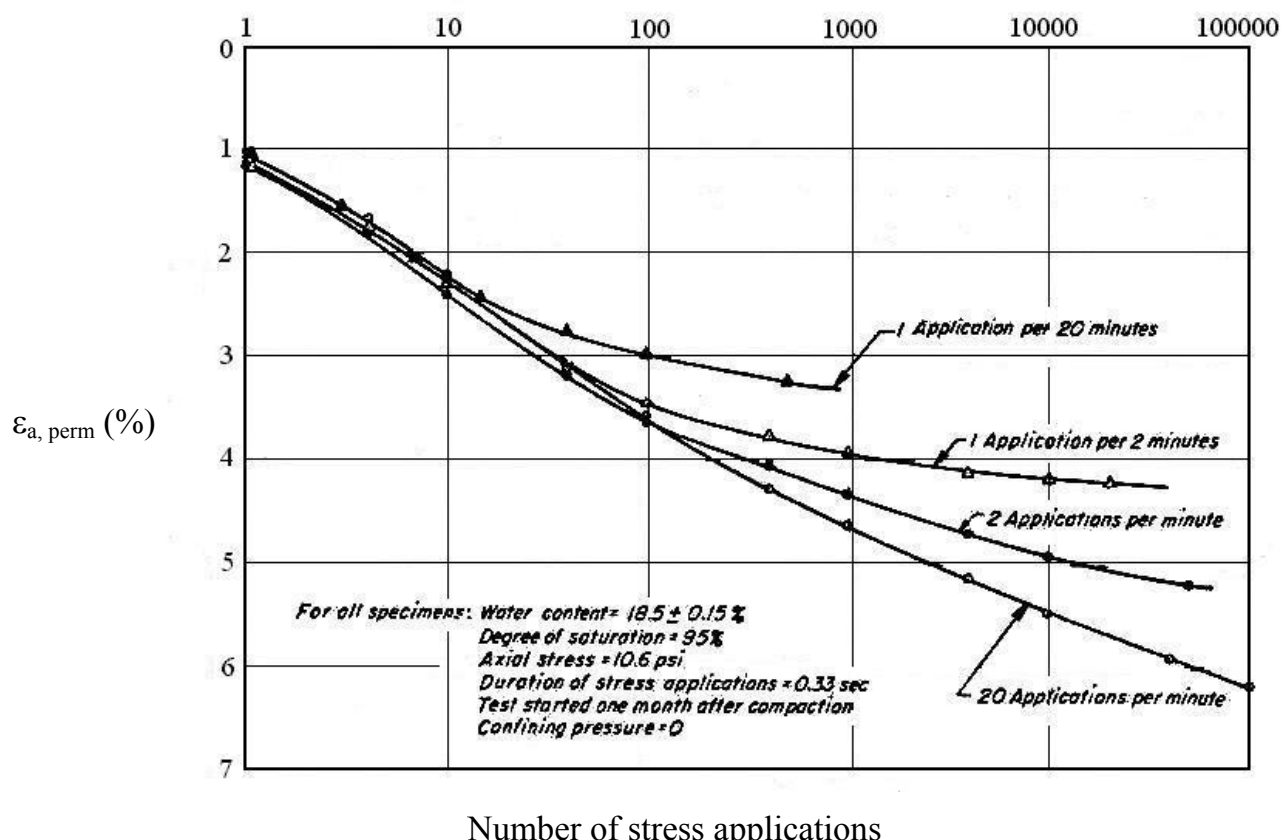

Figure 15. Effect of frequency of stress application on deformation of silty clay with high degree of saturation (Seed and Chan 1958) 


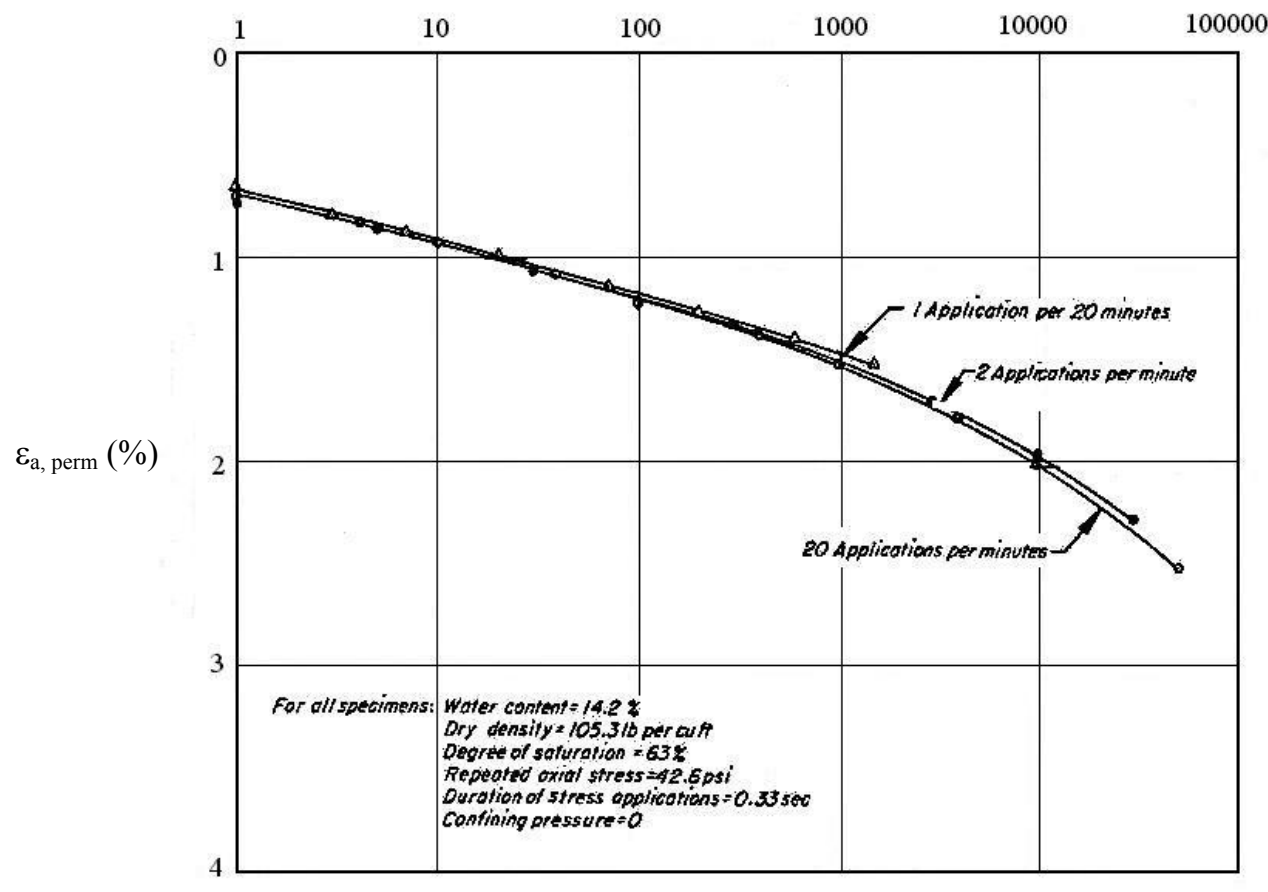

Number of stress applications

Figure 16. Effect of frequency of stress application on deformation of silty clay with low degree of saturation (Seed and Chan 1958)

\subsubsection{Moisture content}

The influence of moisture content is illustrated in Figures 1 - 4. In all of these figures, it is apparent that as the moisture content increases, the permanent strains also increase. Elliott et al. (1999) examined the influence of moisture content on the permanent deformations of four representative Arkansas cohesive subgrade soils and found that as moisture content increased (especially for specimens compacted above optimum), for the same deviator stress, permanent strains increased. This result is 
expected since the presence of water results in a decrease of the resistance to deformation and therefore strains (irrecoverable, or permanent) consequently increase.

\subsubsection{Freeze-thaw}

Elliott et al. (1999) investigated the effect of freeze-thaw cycles on the permanent strains. The effect of freeze-thaw was significant, even for one cycle. They reported that for one freeze-thaw cycle, permanent strains increased up to 100 percent, depending on the type of subgrade tested.

\subsubsection{Overconsolidation ratio}

Hyde (1974) examined the effect of overconsolidation ratio (OCR) on Keuper Marl soil. This soil had a liquid limit of $32 \%$, plastic limit of $18 \%$ and plasticity index of $14 \%$. The percentage of clay was found to be $18 \%$. Keuper Marl was subjected to repeated load tests at a constant confining pressure of $40 \mathrm{kN} / \mathrm{m}^{2}$. The results of these tests for values of OCR $=4,10$, and 20 , showed that as the overconsolidation ratio increased, permanent strain decreases (for a certain deviator stress). This result is expected since an increasing OCR leads to an increase in the strength of clays.

\subsubsection{Models for the permanent strains of cohesive subgrades}

Not many models have been suggested to predict the accumulation of permanent strains in cohesive subgrades under repeated loads. The few models found appear to reasonably predict the permanent strains for the soil used for the models, but fail to predict the permanents strains of other soils. These models consider, in general, the 
number of load repetitions, physical properties and the stress conditions. Several major models found in the literature are presented.

a. Monismith et al. (1975) proposed the following model

$$
\varepsilon_{p}=A \cdot N^{b}
$$

$\varepsilon_{\mathrm{p}}$ : permanent strain

$\mathrm{N}$ : number of stress applications

A, b: experimentally determined coefficients.

Poulsen and Stubstad (1987) used this model to predict the permanent strains of the subgrades in six countries and they concluded that it did not represent adequately the behavior of the investigated soils.

b. Muhanna et al. (1998) proposed the following model

$$
\log \left[\sum \varepsilon_{p}^{*} /\left(S L^{7 / 4} \cdot e^{3}\right)\right]=1.3+2.476 \cdot\left(w-w_{0}\right) / w_{0}
$$

$\Sigma \varepsilon_{\mathrm{p}}{ }^{*}:$ accumulated plastic strain $(\%)$ at the state of apparent shakedown (shake down can be defined as the switch of material response from plastic to purely elastic behavior after a few cycles of loading)

SL: stress level

e: void ratio obtained by $\mathrm{T}-99$ compaction at $\mathrm{w}$ w: molding water content (\%) $\mathrm{w}_{0}$ : T-99 optimum moisture content (\%) 
c. Raad and Zeid (1990) suggested the following models for stress levels lower than the "threshold stress level".

$$
q=\frac{\varepsilon_{a}}{a_{L}+s_{L} \cdot \log N}
$$

q: stress level

$\varepsilon_{\mathrm{a}}:$ permanent axial strain $(\%)$

$\alpha_{L}, s_{L}:$ material parameters

For stress levels above the "threshold stress level"

$$
\begin{gathered}
q_{r}=\frac{\varepsilon_{a}}{a_{h}+b_{h} \cdot \varepsilon_{a}} \\
b_{h}=B_{h}+S_{h} \cdot \log N
\end{gathered}
$$

$\mathrm{q}_{\mathrm{r}}$ : stress level

$\varepsilon_{\mathrm{a}}$ : permanent axial strain $(\%)$

$\alpha_{\mathrm{h}}, \mathrm{B}_{\mathrm{h}}, \mathrm{S}_{\mathrm{h}}:$ material parameters

\subsubsection{Permanent Deformations of Cohesionless Subgrades}

Pavements are considered to have failed when the permanent deformations (irrecoverable deformations) of their components are so large that they cause an intolerably uneven riding surface, or the recoverable strains induce cracking of the surfacing material. Thus, the objective of a pavement design should focus on how to limit the stresses and strains induced by the traffic on the pavement's materials, so that rutting (accumulation of permanent deformations) and fatigue failure do not occur. Since subgrade soils may contribute greatly to the rutting of a pavement, permanent 
deformations of subgrade soils under repeated loads are important. Traffic is simulated by triaxial tests, and suitable devices measure permanent deformations. The permanent deformations of cohesive and cohesionless subgrades will be described in different sections, due to their differing behaviors.

The factors affecting most permanent deformations of cohesionless subgrades are the following: a) Stress level; b) Dry unit weight; and c) Moisture content.

\subsubsection{Stress level}

The level of the deviator stress and confining pressure of repeated triaxial tests has a significant role in the accumulation of permanent strains under repeated loads. Gaskin et al. (1979) conducted repeated stress tests on a Sydenham sand, which had a Standard Proctor maximum dry density of $17.7 \mathrm{kN} / \mathrm{m}^{3}$. The confining pressure was kept constant at $35 \mathrm{kPa}$ (5 psi). As seen in Figure 17, the repeated stress was expressed as the ratio $\mathrm{X}$ of the applied stress to the shear strength obtained by a standard triaxial test. For a dry density of $15.8 \mathrm{kN} / \mathrm{m}^{3}$, this shear strength was $130 \mathrm{kPa}$. Permanent strains for any stress level increased until $10^{4}$ cycles, and at high values of $\mathrm{X}$, permanent strains continued to increase. In particular, the sample with $X=0.90$ failed in shear at about the $500,000^{\text {th }}$ cycle. The other samples were considered to approach this failure by excessive deformation. For values of $\mathrm{X}$ less than 0.50 , permanent strains leveled off and reached a constant value. At this state, the sand had reached an equilibrium and behaved almost elastically. As seen in the case of the cohesive subgrades, the existence of a "threshold stress level" was observed. For the case of the Sydenham sand, this level is approximately at a value of $\mathrm{X}=0.50$. 


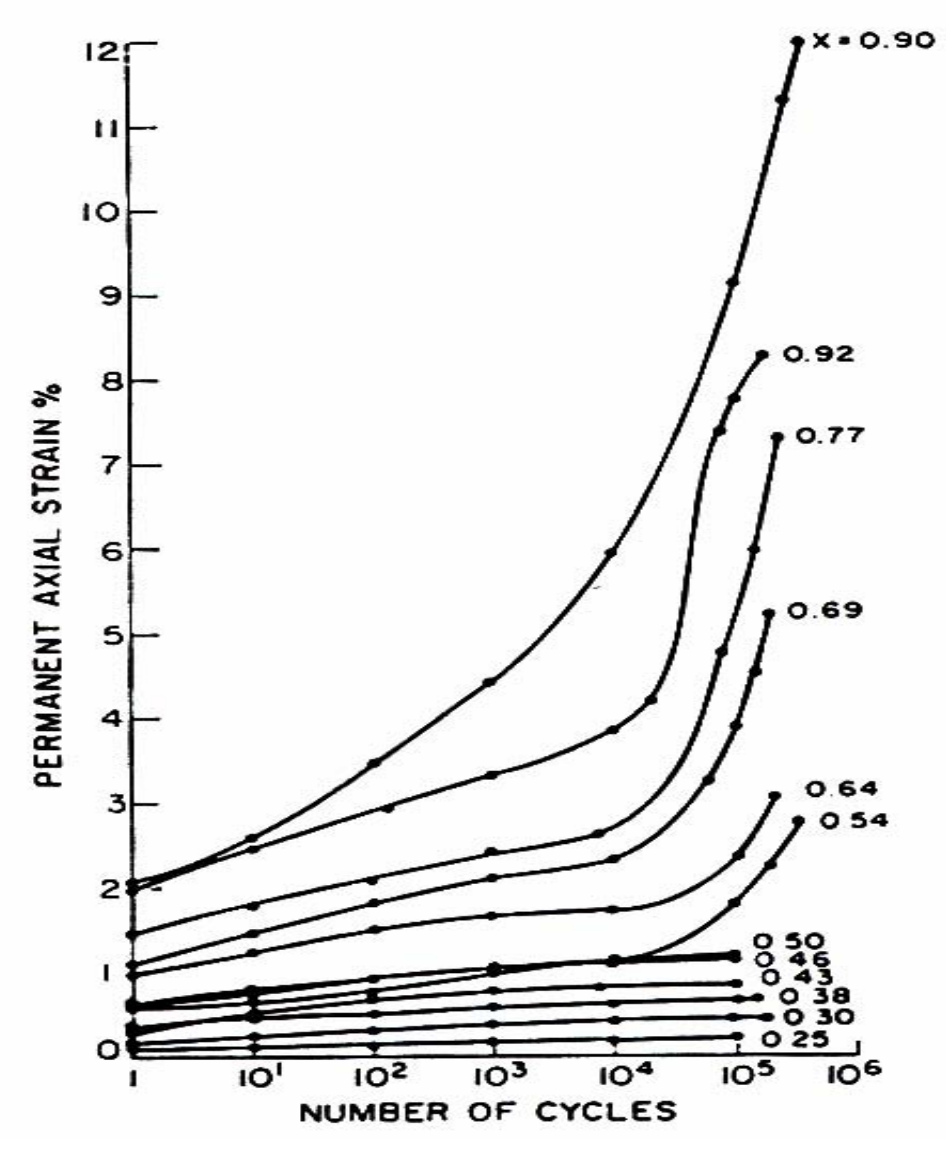

Figure 17. Permanent axial strains for Sydenham sand (Gaskin et al. 1979)

Diyaljee and Raymond (1983) performed repeated load tests on a Coteau Balast. The confining pressure was kept constant at 5 psi. The repeated deviator stress was again expressed as the ratio $\mathrm{X}$ of the repeated deviator stress to the failure deviator stress under static loading. The results are presented in Figure 18. At any stress level, it is noteworthy that permanent strains increase. However, it seems that for values of $\mathrm{X}$ up to 0.70 , 
permanent strains tend to reach a constant value, while for $\mathrm{X}=0.82$ permanent strains continue to increase. Thus, in this case, the "threshold stress level" is estimated at a value of $\mathrm{X}$ between 0.70 and 0.82 .

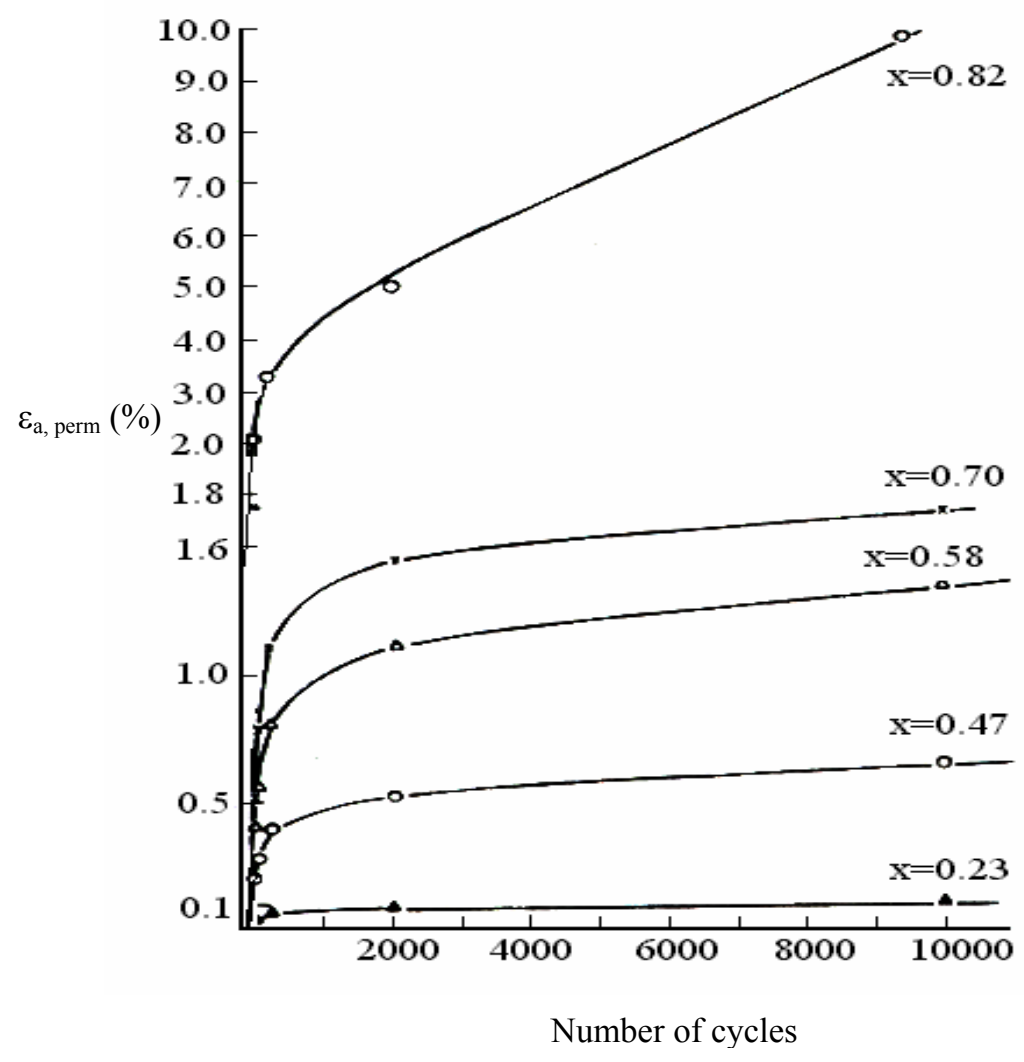

Figure 18. Plastic axial strains for Coteau Balast (Diyaljee and Raymond 1983)

Pumphrey and Lentz (1986) carried out tests on a Florida subgrade sand with a maximum dry unit weight of 110 pcf and optimum water content of 11 percent (AASHTO T-180). The repeated deviator stress was a percentage of the peak static soil strength determined from samples tested at similar dry unit weight and moisture content. For tests where the confining pressure was constant at 50 psi, they reported (for any of 
the tested stress levels) a continuous increase of the permanent strain as the number of cycles increased. Thus, they did not report a "threshold stress level" for this sand. They also examined the influence of the confining pressure on the permanent strain as shown in Figure 19. It was observed that for low stress levels, the effect of the confining pressure was minor. For the highest stress level, however, permanent strain decreased with increasing confining pressure. This observation might be the result of aggregate interlock since the degree of interlock exceeded that observed for the other stress levels. Notice that for high levels of confining pressure, the difference in the permanent strain between stress ratios of 0.40 and 0.75 was not significant. This may be explained by the fact that higher confining pressures led to increasing inter-particle friction, resulting in less movement, for any stress level. 


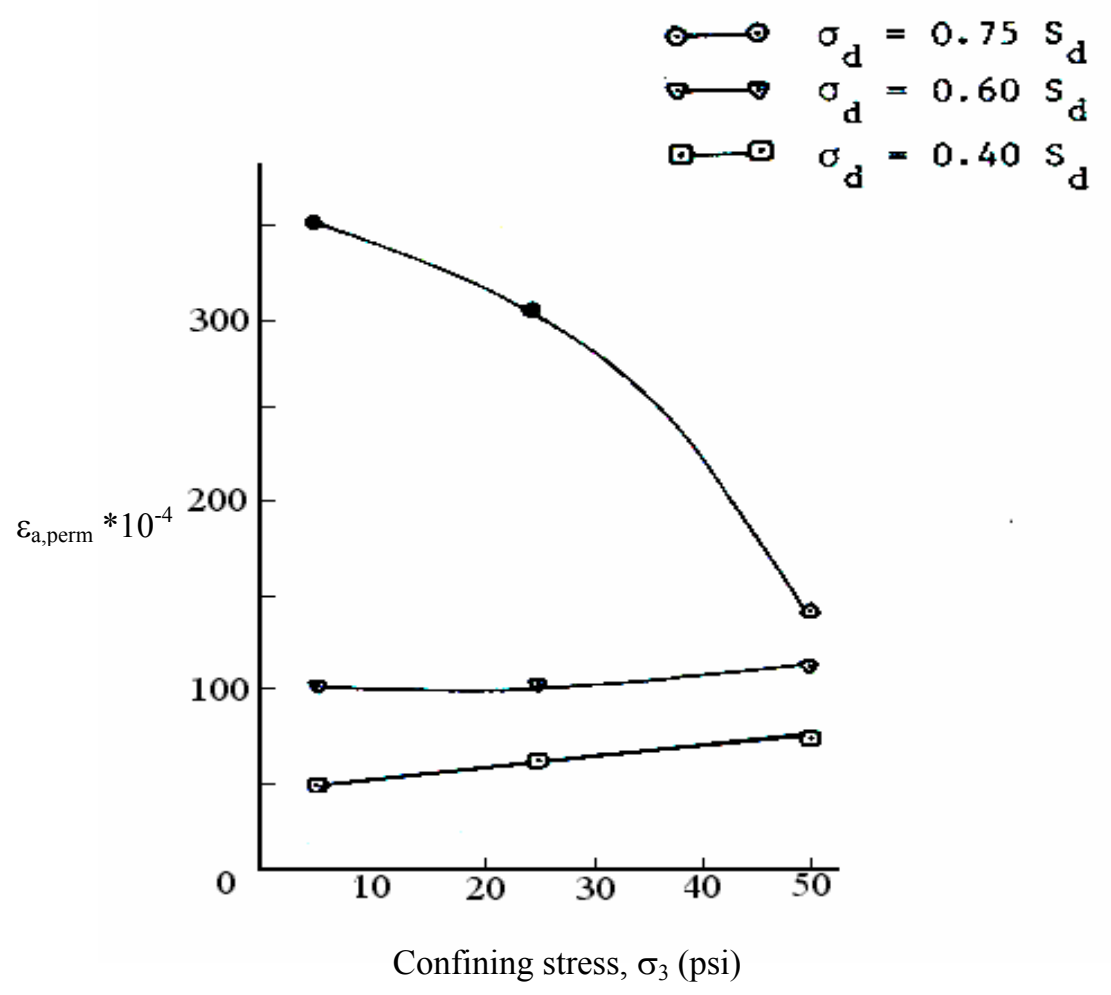

Figure 19. Effect of confining stress on permanent strain at $\mathrm{N}=10,000$ for the Florida subgrade sand (Pumphrey and Lentz 1986)

In both cohesive and cohesionless subgrades, there exists a "threshold stress level". Below this level, subgrades reach an equilibrium state and their behavior becomes almost elastic. Above this level, the behavior of subgrades under repeated loads is unstable and, as a consequence, shear failure occurs due to excessive deformations. Therefore, it is essential to subgrade stability to keep the stresses induced by the traffic below this level. Unfortunately, this level is not unique and it depends on the soil type. In general, the "threshold stress level" is greater than 50 - 60 percent of the principal stress difference at failure obtained from static triaxial tests. 


\subsubsection{Dry unit weight}

Pumphrey and Lentz (1986) examined the influence of the dry unit weight on permanent strain. For samples compacted below and at optimum moisture content, Figure 20 shows the variation of the permanent strain for the $10,000^{\text {th }}$ cycle with the dry unit weight. As expected, permanent strain decreased as the dry unit weight increased. This result is reasonable, because with higher dry unit weight the volume of voids becomes less, resulting in more particle contacts and greater aggregate interlock.

\subsubsection{Moisture content}

As shown in Figure 20, Pumphrey and Lentz (1986) investigated the effects of moisture content on permanent strain. For samples compacted at optimum moisture content, permanent strains at the $10,000^{\text {th }}$ cycle are greater than for samples compacted below optimum. Generally, this is attributed to the fact that less water volume during compaction allows for a denser soil structure. 


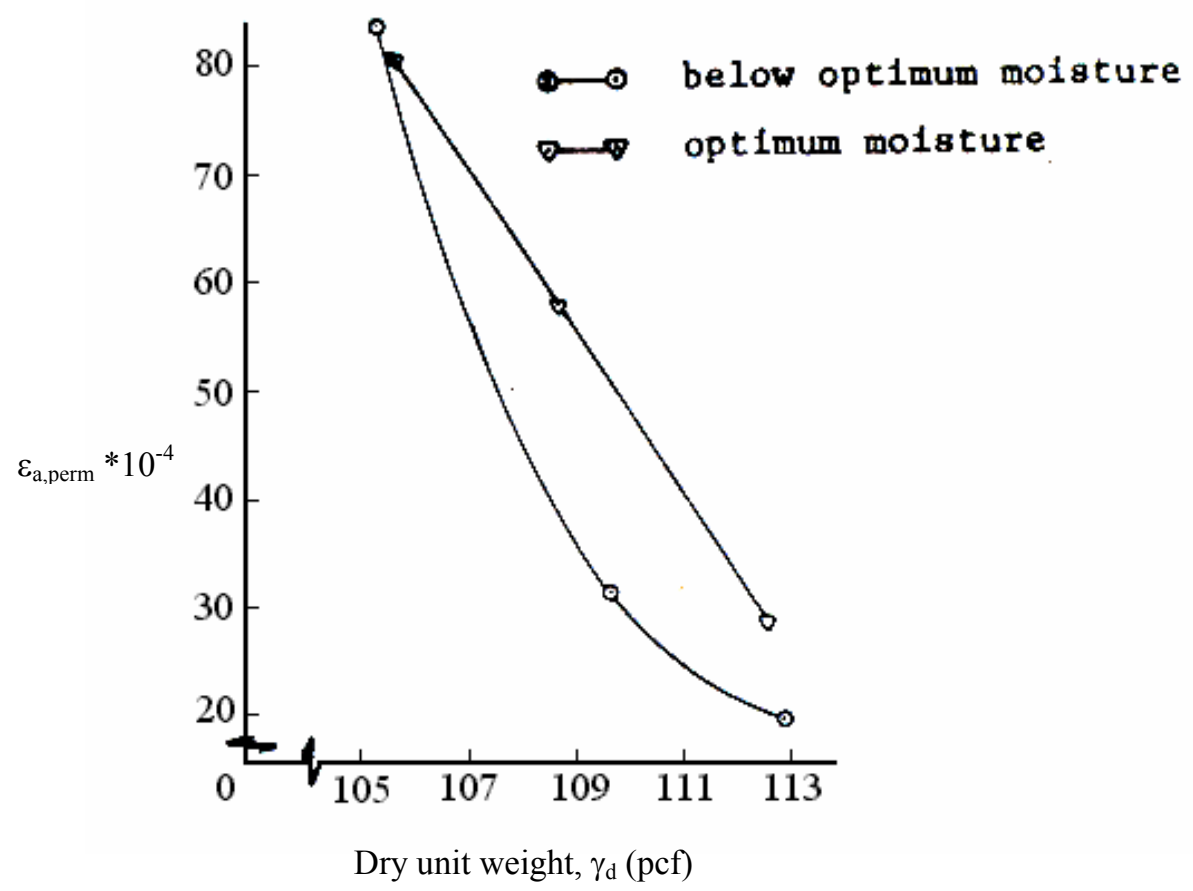

Figure 20. Effect of dry unit weight and moisture content on permanent strainat $\mathrm{N}=10,000$ (Pumphrey and Lentz 1986)

\subsubsection{Models for the permanent strains of cohesionless subgrades}

For cohesionless subgrades, some models have been developed to predict permanent strains under repeated loads. These models were found to reasonably predict the permanent strains of the soils that were developed, but for the reasons stated earlier, failed to predict the accumulation of permanent strains for different cohesionless subgrades. The following are some examples of models that have been suggested. a. Lentz and Baladi (1981) performed tests on a uniform, medium sand and developed the following model, which was based on results from static triaxial tests. 


$$
\begin{gathered}
\varepsilon_{p}=\left[\varepsilon_{0.95 S_{d}} \cdot \ln \left(1-\frac{\sigma_{d}}{S_{d}}\right)^{-0.15}\right]+\left[\frac{\left(\frac{\sigma_{d}}{S_{d}}\right) \cdot n}{1-m \cdot\left(\frac{\sigma_{d}}{S_{d}}\right)}\right] \cdot \ln N \\
n=\left(0.809399+0.003769 \cdot \sigma_{3}\right) \cdot 10^{-4} \\
m=0.856355+0.049650 \cdot \ln \sigma_{3}
\end{gathered}
$$

$\varepsilon_{\mathrm{p}}:$ permanent strain

$\varepsilon_{0.95 \mathrm{Sd}}:$ static strain at 95 percent of static strength

$\sigma_{\mathrm{d}}:$ repeated deviator stress $(\mathrm{psi})$

$\mathrm{S}_{\mathrm{d}}$ : static strength $(\mathrm{psi})$

$\mathrm{n}, \mathrm{m}$ : regression constants

$\sigma_{3}$ : confining pressure (psi)

$\mathrm{N}$ : number of cycle

Lekarp and Dawson (1998) mentioned that Sweere used this model for both sands and granular base course materials and the results were not satisfactory.

b. Diyaljee and Raymond (1983) developed the following general model for the permanent strain of cohesionless subgrades.

$$
\varepsilon_{p}=B \cdot e^{n \cdot X} \cdot N^{m}
$$

$B$ : value of strain at $X=0$ for the first cycle

$\mathrm{n}, \mathrm{m}$ : experimentally derived parameters

$\mathrm{N}$ : number of cycles

$\mathrm{X}$ : repeated deviator stress level 
c. Other models can be found in the paper by Lekarp and Dawson (1998). However, most of these models were developed for base materials. 


\section{CHAPTER 3. REVIEW OF THE NEW M-E DESIGN GUIDE}

\subsection{Introduction}

With the release of the Mechanistic-Empirical Design Guide for New and Rehabilitated Pavement Structures or the M-E Design Guide, highway agencies are required to implement the new design methodology appropriately. The M-E Design Guide requires a large number of design inputs related to subgrades, materials, environment, traffic, drainage, and other pavement elements that need to be considered to be able to analyze and design pavement (Kim and Zia 2004). In order to fully implement the M-E Design Guide with greater accuracy, a designer's knowledge of both design inputs and pavement performance is required. Successful implementation can be accomplished by an integrated collaboration between traffic engineers, materials engineers, geotechnical engineers, and pavement structural engineers (Nantung et al. 2005).

The major objective of this chapter is to provide an extensive review of subgrade design in the M-E Design Guide. Several design examples for subgrade layers will be provided in Chapter 8 in accordance with the New Mechanistic-Empirical Design Guide.

\subsubsection{Major Differences between the AASHTO Design Guide and M-E Design Guide}

TABLE 1 shows the major differences in the design features and philosophies for subgrades between the existing AASHTO Design Guide and the new M-E Design Guide. 
In order to design a subgrade with the M-E Design Guide, a pavement designer needs to use computer software included in the M-E Design Guide (NCHRP 2004) rather than using the Design Guide book. As designers are required to run the software for pavement design and the pavement design results and analysis are provided by the software, it is still necessary to fully understand the principles and features embedded in the software to achieve rational designs.

In the structural analysis associated with stress and strain developed in the layers subjected to traffic loadings, the existing AASHTO Design Guide is based on linear elastic analysis (LEA), while the new M-E Design Guide offers two types of analyses, LEA and 2-D Finite Element Analysis (FEA). LEA assumes a constant representative resilient modulus (Mr) for each layer, whereas FEA employs a stress-dependent resilient modulus for the Level 1 design. According to the NCHRP report on this new M-E Design Guide (NCHRP 2004), the FEA needs further calibration before it can be implemented.

The M-E Design Guide incorporates unsaturated soil conditions under an assumption that the subgrade layer will largely be in the unsaturated condition during the design life period. The unsaturated soil condition is taken into account using the soil water characteristic curve (SWCC) suggested by Fredlund and Xing (1994). Given the fact that most geotechnical designs for foundations and slope stability have generally been done under fully saturated condition of soils for the purpose of conservative design, the consideration of unsaturated soil conditions is a significant development for a realistic design of pavement.

Although the existing AASHTO Design Guide recommends the use of Mr monthly variations, its application was quite limited. The new M-E Design Guide, however, 
further improves the features to consider the monthly variations by incorporating Enhanced Integrated Climatic Module (EICM).

Table 1. Major differences in subgrade design between the AASHTO Guide design guide and M-E design guide

\begin{tabular}{|c|c|c|c|}
\hline & $\begin{array}{l}\text { The AASHTO Design } \\
\text { Guide }\end{array}$ & M-E Design Guide & \\
\hline Design tool & Design manual & M-E Design software & \\
\hline $\begin{array}{l}\text { Structural Analysis } \\
\text { type }\end{array}$ & Linear Elastic Analysis & $\begin{array}{l}\text { Linear Elastic Analysis } \\
\text { (LEA) and 2-D Finite } \\
\text { Element Analysis } \\
\text { (FEA) for Level } 1 \\
\text { hierarchical inputs to } \\
\text { characterize the non- } \\
\text { linear moduli response } \\
\text { of any unbound } \\
\text { materials (bases, } \\
\text { subbase and/or } \\
\text { subgrades) }\end{array}$ & $\begin{array}{l}\text { FEA approach } \\
\text { has not been } \\
\text { calibrated. }\end{array}$ \\
\hline Input parameters & Not applicable & $\begin{array}{l}\text { Numerous inputs } \\
\text { parameter depending } \\
\text { on the design level }\end{array}$ & \\
\hline $\begin{array}{l}\text { Unsaturated soil } \\
\text { condition }\end{array}$ & Not applicable & $\begin{array}{l}\text { Unsaturated properties } \\
\text { such as Soil Water } \\
\text { Characteristic Curve } \\
\text { (SWCC) included }\end{array}$ & \\
\hline $\begin{array}{l}\text { Monthly variation of } \\
\text { resilient modulus }\end{array}$ & $\begin{array}{l}\text { Simple monthly } \\
\text { variation } \\
\text { was considered }\end{array}$ & $\begin{array}{l}\text { More advanced } \\
\text { monthly variation is } \\
\text { considered based on } \\
\text { temperature, freeze- } \\
\text { thaw, degree of } \\
\text { saturation }\end{array}$ & \\
\hline Design level & Not applicable & $\begin{array}{l}\text { Hierarchical design } \\
\text { input levels: Level 1, } \\
\text { Level } 2, \text { Level } 3\end{array}$ & \\
\hline
\end{tabular}




\subsection{Review of Subgrade Design in M-E Design}

\subsubsection{Hierarchical Design Inputs - Level 1, Level 2, Level 3}

The M-E Design Guide employs hierarchical design approach to the pavement design and analysis input parameters. It consists of Level 1, Level 2 and Level 3 inputs, in the order of importance and accuracy. The highest level of design accuracy, Level 1, requires an agency a capability of performing rigorous laboratory tests as indicated in the manual. Different level inputs can be chosen for each input parameter for a given design.

Level 1 inputs result in the highest level of design accuracy, leading to the lowest level of uncertainty error. For Level 1 inputs, laboratory testing or field testing, such as the resilient modulus testing of subgrade or non-destructive testing (NDT) such as the Falling Weight Deflectometer (FWD) is necessary. Consequently, Level 1 inputs demand much more time and resources than Level 2 and Level 3 inputs. Level 1 design is suitable to be implemented in major highways where heavy traffic is expected and roadway functional classification is very critical to the transportation system. Level 2 design provides an intermediate level of accuracy and can have similar results as in the existing AASHTO Guide. Level 2 design can be used in place of Level 1 design in the case of unavailability of testing equipment. Level 3 inputs offer the lowest level of accuracy.

\subsubsection{Input Parameters for Unbound Materials and Sugrades}

Three major categories for the material parameters required for unbound granular materials and subgrades in the M-E Design Guide are as follows (NCHRP 1994): 
- Pavement response model material inputs: resilient modulus $(\mathrm{Mr})$ and Poisson's ratio;

- ECIM material inputs: Plasticity Index (PI), Sieve Analysis (percent passing No. 200 sieve, percent passing No. 4 sieve, D 60 (mm)), degree of saturation;

- Other unbound material parameters: coefficient of lateral pressure $\left(\mathrm{k}_{\mathrm{o}}\right)$.

These design inputs in the M-E Design Guide are shown in Figures 21 and 22.

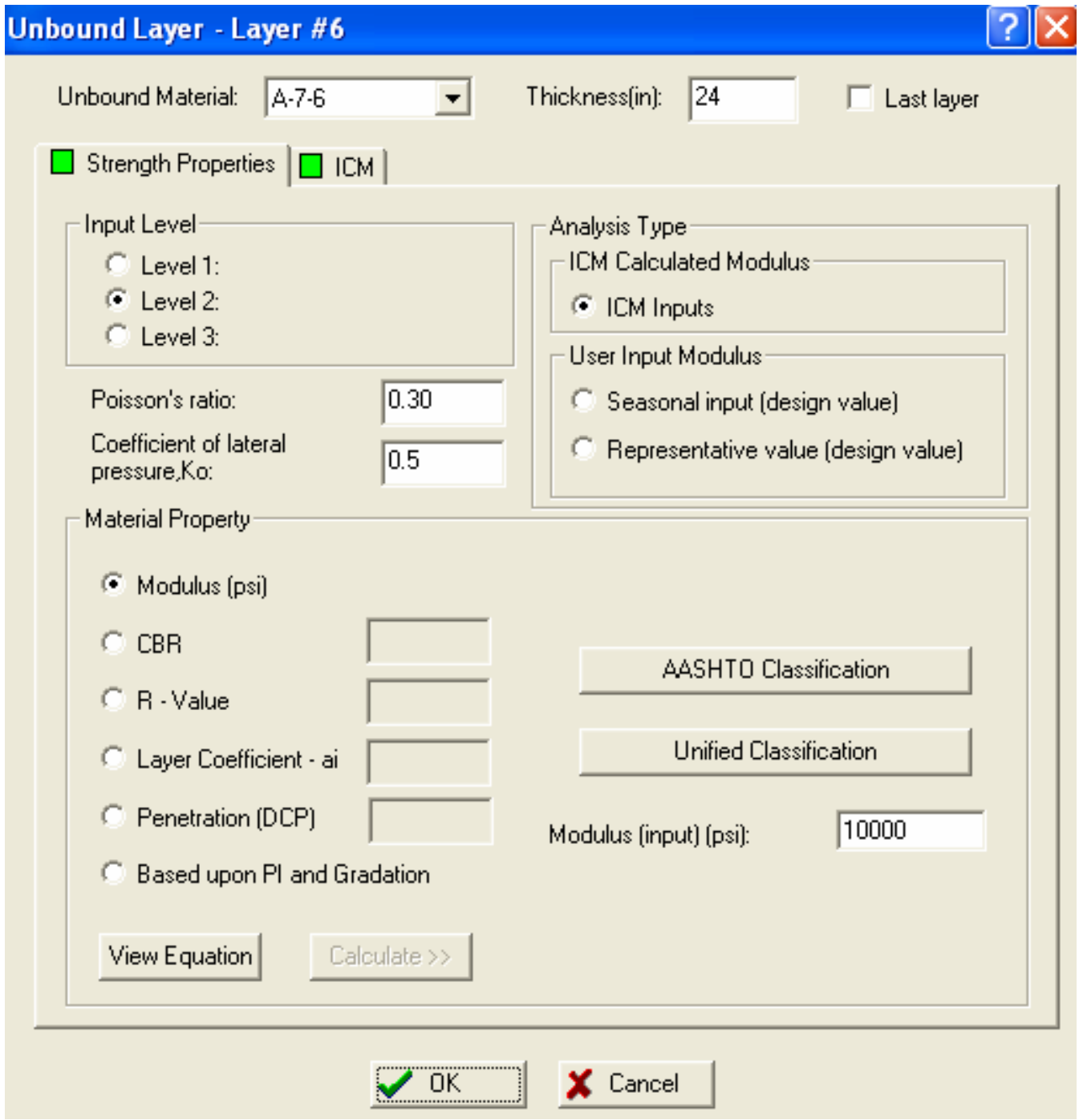

Figure 21. Design inputs for unbound layers-response model 


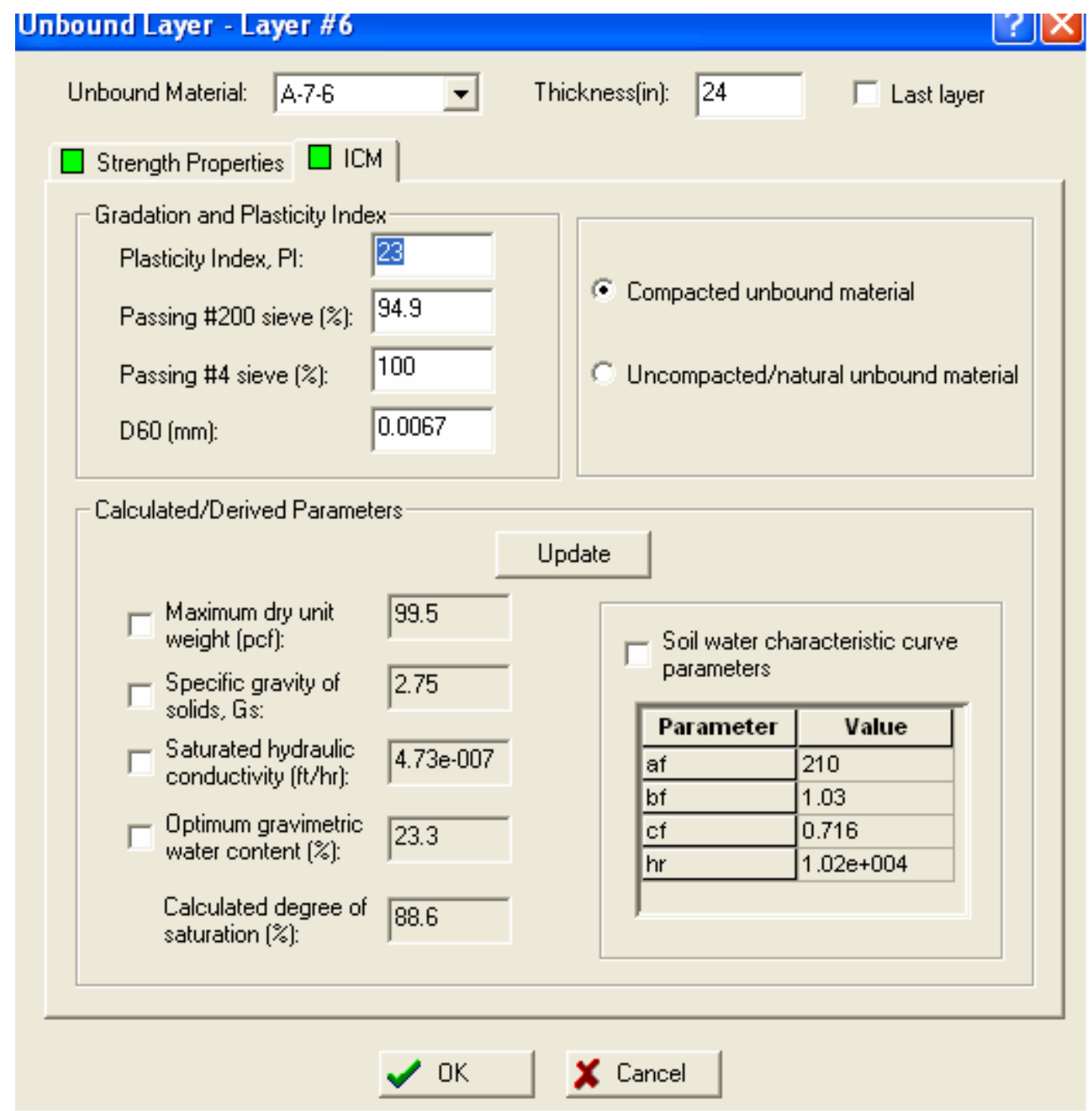

Figure 22. Design inputs for unbound layers-ECIM inputs

\subsubsection{Resilient Modulus-Level 1 design: Laboratory testing}

Level 1 design is based on laboratory resilient modulus testing. The NCHRP report on the new M-E Design Guide (NCHRP 2004) recommends Mr to be obtained from the repeated triaxial testing or resilient modulus testing following NCHPR 1-28 A, "Harmonized test methods for laboratory determination of resilient modulus for flexible 
pavement design" or AASHTO T307, "Determining the resilient modulus of soil and aggregate materials".

Many researchers have proposed numerous predictive models to capture the resilient behavior of soils. The first model for granular materials is the K- $\theta$ model (Seed et al. 1967) as follows:

$$
M r=k_{1} \theta^{k_{2}}
$$

where $\mathrm{k}_{1}$ and $\mathrm{k}_{2}$, $=$ regression coefficients; $\theta=$ sum of principal stresses. This model describes the resilient behavior of soils only as a function of confining stress, and the effect of deviator stress is not considered.

The another model for cohesive material is the $\mathrm{K}-\sigma_{\mathrm{d}}$ model is given by:

$$
M r=k_{1} \sigma_{d}^{k_{2}}
$$

where $\sigma_{\mathrm{d}}$ is deviator stress. The $\mathrm{K}-\sigma_{\mathrm{d}}$ model is only associated with the deviator stress.

In order to account for both the confining and deviator stresses, Uzan (1985) suggested a universal model, which is a more advanced model than both the K- $\theta$ model and the $\mathrm{K}-\sigma_{\mathrm{d}}$ model. The predicted Mr values can be obtained from the following equation:

$$
M r=k_{1} p_{a}\left(\frac{\theta}{p_{a}}\right)^{k_{2}}\left(\frac{\sigma_{d}}{p_{a}}\right)^{k_{3}}
$$

where, $\mathrm{k}_{1}, \mathrm{k}_{2}, \mathrm{k}_{3}$, $=$ regression coefficients; $\theta=$ sum of principal stresses; $\mathrm{p}_{\mathrm{a}}=$ reference pressure $=100 \mathrm{kpa} \approx 1 \mathrm{kgf} / \mathrm{cm}^{2} \approx 2000 \mathrm{psf} \approx 14.5 \mathrm{psi}$; and $\sigma_{\mathrm{d}}=$ deviator stress in the same unit as $\mathrm{p}_{\mathrm{a}}$.

In the M-E design Guide (NCHRP 2004), resilient modulus is predicted using a similar model to the equation (3.3), as shown below in equation (3.4): 


$$
M r=k_{1} p_{a}\left(\frac{\theta}{p_{a}}\right)^{k_{2}}\left(\frac{\tau_{o c t}}{p_{a}}+1\right)^{k_{3}}
$$

where $\tau_{\text {oct }}$ is the octahedral shear stress. The regression coefficients of the predictive model can be calculated by performing a regression analysis for the laboratory $\mathrm{Mr}$ test data following AASHTO T 307.

3.2.2.2. Resilient Modulus-Level 2 design: Correlations with other material properties

Level 2 design can be selected when laboratory Mr testing is not available. The value of resilient modulus can be obtained using typical correlations between resilient modulus and physical soil properties (dry unit weight, Atterberg limits, specific gravity) or between resilient modulus and strength properties (i.e., CBR, unconfined compressive strength). The following correlations are suggested in the M-E Design Guide:

$$
\begin{gathered}
\mathrm{CBR}=28.09\left(\mathrm{D}_{60}\right) \\
\mathrm{CBR}=75 /(1+0.728(\mathrm{wPI}) \\
\mathrm{CBR}=292 / \mathrm{DCP}^{1.12} \\
\mathrm{Mr}=2555(\mathrm{CBR})^{0.64}
\end{gathered}
$$


Where $\mathrm{D}_{60}=$ diameter at $60 \%$ passing from the grain size distribution $(\mathrm{mm})$; wPI is weighted plasticity index; $\mathrm{CBR}=$ California Bearing Ratio $(\%) ; \mathrm{Mr}=$ resilient modulus (psi); DCP = DCP index ( $\mathrm{mm} / \mathrm{blow})$. When estimating $\mathrm{Mr}$, the material property is first related to $\mathrm{CBR}$ and then $\mathrm{CBR}$ is related to $\mathrm{Mr}$.

For level 2 design, the M-E Design Guide software allows users the following two options.

- Input a representative value of $\mathrm{Mr}$ and use EICM to adjust it for the effect of seasonal climate (i.e., the effect of freezing, thawing, etc.);

- Input Mr for each month (season) of the year.

\subsubsection{Resilient Modulus-Level 3 design: Typical Values}

For design Level 3, only a typical representative Mr value at optimum moisture content is required. EICM is used to adjust the representative $\mathrm{Mr}$ for the seasonal effect of climate. Pavement designers may select the representative Mr value without the results being affected by EICM.

\subsubsection{Assumptions Related to Subgrade Compactions in the M-E Design}

The M-E Design Guide assumes that the compacted subgrades are compacted near or at optimum moisture content (OMC) with maximum dry density (the peak point in a compaction curve) and during the design life of the pavement, they will experience changes in moisture content without any major variation in dry density (See Figure 23). It is also assumed that the initial degree of saturation, $\mathrm{S}_{\mathrm{opt}}$ (degree of saturation at $\mathrm{OMC}$ ), will be in equilibrium depending on drainage properties and environmental conditions 
(calculated by the EICM) with time, resulting in the final degree of saturation, $\mathrm{S}_{\text {equil }}$. These assumptions are based on the fact that most of the soils will be compacted to the OMC in the field, and most of the resilient modulus tests available in the literature were done on specimens compacted at OMC.

In order to simulate the variation in the lab, the NCHRP report (2004) recommends, first, compacting the specimens at the optimum moisture content and maximum dry density and then varying the moisture content (by soaking or drying) until the desired moisture content is achieved. It appears quite difficult, practically, to achieve the desired water content with this method. Moreover, the assumption in regards that all compacted subgrade layers as being compacted at OMC may lead to quite unconservative subgrade design as the compacted subgrade may meet the compaction specification even compacted at the dry densities much less than the maximum dry density. This is a common problem, as in practice, the compaction specification usually approves compaction of subgrade soils greater than 90 or $95 \%$ of the maximum dry density $\left(\gamma_{\mathrm{dmax}}\right)$. According to Kim and Zia's study (2004), the difference in resilient modulus between the wet of optimum and dry of optimum may be very significant. 


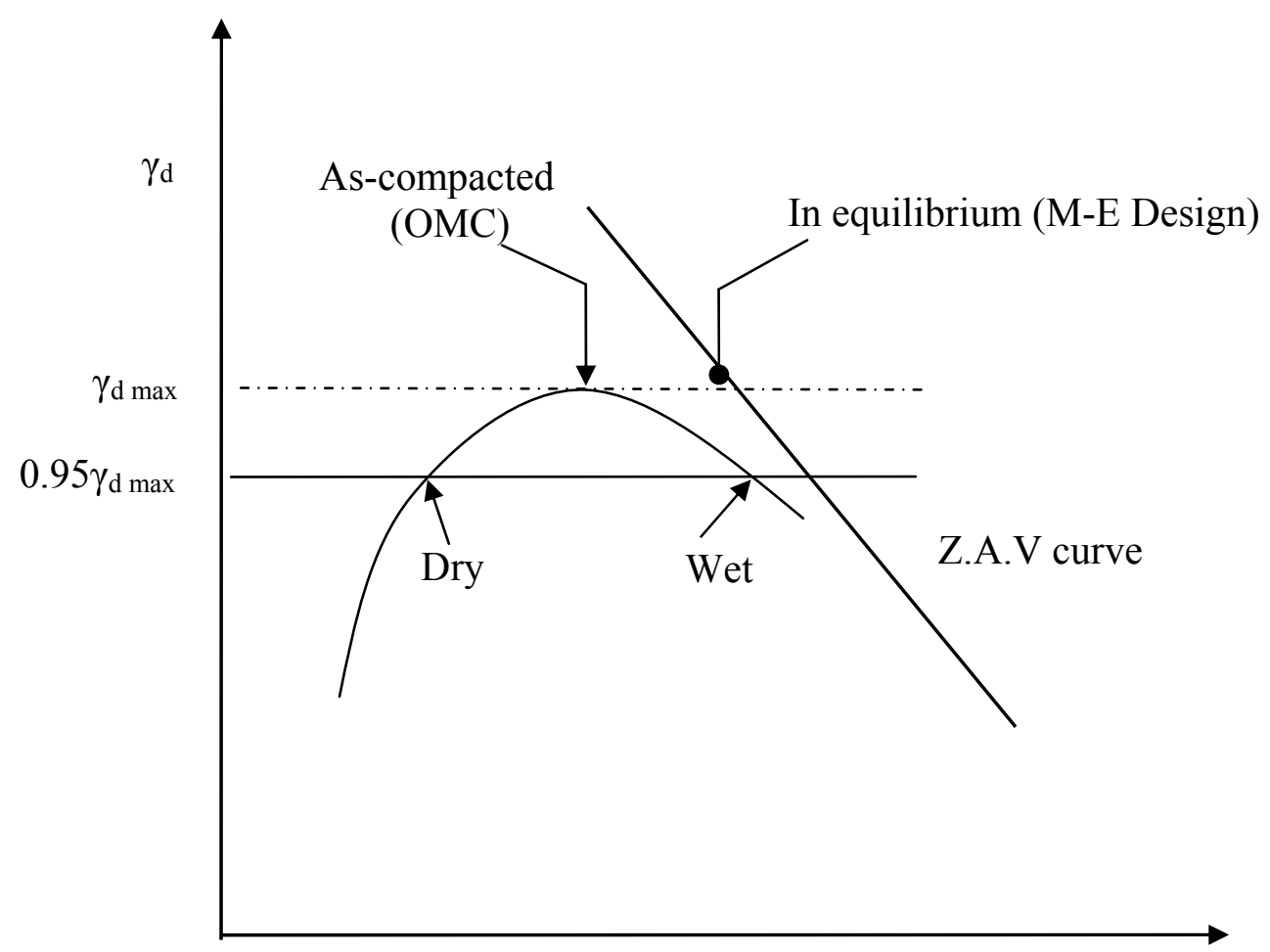

Moisture content (\%)

Figure 23. Variation in moisture contents for the compacted subgrade 


\subsubsection{Climatic and Environmental Effects in the M-E Design}

Moisture and temperature are two key factors that significantly affect the pavement layer and subgrade properties and its load carrying capacity. Effects of these factors on resilient modulus are considered in the M-E Design Guide.

\subsubsection{The Enhanced Integrated Climatic Model (EICM)}

In the M-E Design Guide, variation in temperature and moisture in subgrade soils are considered throughout the design life through the Enhanced Integrated Climatic Model (EICM). The EICM is composed of the following three components (NCHRP 2004):

- The Climatic-Materials-Structure Model (CMS Model)

- The CRREL Frost-Heave and Thaw Settlement Model (CRREL Model)

- The Infiltration and Drainage Model (ID Model)

Input parameters required by the climatic model are general information, such as weather related information, ground water related information, drainage and surface properties, pavement structure and material characteristics. The EICM calculates temperature, resilient modulus adjustment factors $\left(\mathrm{F}_{\mathrm{F}}, \mathrm{F}_{\mathrm{R}}, \mathrm{F}_{\mathrm{U}}\right)$, pore water pressure, frost and thaw depth, frost heave, and drainage performance over the design period. It is noted in the M-E Design that one of the important factors required from EICM is a set of adjustment factors for unbound material layers that account for the effect of 
environmental parameters and conditions such as changes in moisture content, freezing, thawing, and recovery from thawing. The environmental factor, $\mathrm{F}_{\mathrm{env}}$ is a composite factor, which could generally represent a weighted average of the factors appropriate for possible conditions.

- Frozen: frozen material - $\mathrm{F}_{\mathrm{F}}$ (factor for frozen material, calculated based on the temperature)

- Recovering: thawed material that is recovering to its state before freezing occurred- $\mathrm{F}_{\mathrm{R}}$ (factor of recovering materials)

- Unfrozen/ fully recovered/normal: for materials that were never frozen or are fully recovered- $\mathrm{F}_{\mathrm{U}}$ (factor for unfrozen materials)

Since the resilient modulus in the M-E Design Guide depends on stress, moisture and free/thaw effects, the values of the resilient modulus at any location and time within a given pavement structure are calculated as a function of those factors. The resilient modulus Mr at any time or location is then expressed as follows:

$$
M r=F_{e n v} \times M r_{\text {opt }}
$$

where $\mathrm{F}_{\text {env }}$ is an adjustment factor and $\mathrm{Mr}_{\mathrm{opt}}$ is the resilient modulus at optimum conditions (maximum dry density and optimum moisture content) and any state of stress.

The EICM accounts for unsaturated soil conditions based on the soil-water characteristic curve (SWCC) suggested by Fredlund and Xing (1994), saturated and unsaturated hydraulic conductivity, a climatic database containing hourly data from 800 weather stations across the United States for sunshine, rainfall, wind speed, air 
temperature and relative humidity (NCHRP 2004). The SWCC is generally used in unsaturated soil mechanics and defined as variation of water storage capacity within the macro-and micro-pores of a soil, with respect to suction. This relationship is generally plotted as variation of water content (gravimetric, volumetric, or degree of saturation) with soil suction. The SWCC is used to calculate the degree of saturation in equilibrium, $\mathrm{S}_{\text {equil }}$ as given by:

$$
S_{\text {equil }}=C(h) \times \frac{1}{\left[\ln \left[E X P(1)+\left(\frac{h}{a_{f}}\right)^{b_{f}}\right]\right]^{c_{f}}}, C(h)=1-\frac{\ln \left(1+\frac{h}{h_{r}}\right)}{\ln \left(1+\frac{1.45 \times 10^{5}}{h_{r}}\right)}
$$

where $\mathrm{h}=$ distance from the point in question to ground water table and $\mathrm{a}_{\mathrm{f}}, \mathrm{b}_{\mathrm{f}}, \mathrm{c}_{\mathrm{f}}$, and $\mathrm{h}_{\mathrm{r}}=$ input parameters obtained from regression analyses.

\subsubsection{Resilient modulus as function of soil moisture}

Moisture content is an important factor affecting resilient behavior of soils. Generally, for a given soil with the same dry density, the higher the moisture content, the lower the resilient modulus. The M-E Design Guide incorporates a predictive equation within the EICM to predict changes in modulus due to changes in moisture. The resilient modulus as a function of soil moisture in the M-E Design Guide is as follows:

$$
\log \frac{M r}{M r_{o p t}}=a+\frac{b-a}{1+E X P\left(\ln \frac{-b}{a}+k_{m}\left(S-S_{o p t}\right)\right)}
$$


where, $\mathrm{Mr} / \mathrm{Mr}_{\mathrm{opt}}=$ resilient modulus ratio; $\mathrm{Mr}$ is the resilient modulus at a given time and $\mathrm{Mr}_{\mathrm{opt}}$ is the resilient modulus at the optimum moisture content; $\mathrm{a}=$ minimum of $\log$ $\left(\mathrm{Mr} / \mathrm{Mr}_{\mathrm{opt}}\right) ; \mathrm{b}=$ maximum of $\log \left(\mathrm{Mr} / \mathrm{Mr}_{\mathrm{opt}}\right) ; \mathrm{k}_{\mathrm{m}}=$ regression parameter; $\left(\mathrm{S}-\mathrm{S}_{\mathrm{opt}}\right)=$ variation in degree of saturation expressed in decimal.

The M-E Design Guide (NCHRP 2004) suggests that the modulus ratio, $\mathrm{Mr} / \mathrm{Mr}_{\mathrm{opt}}$, is in the range of 2 to 0.5 for coarse-grained soils, while it is between 2.5 to 0.5 for finegrained soils. This means that the fine-grained soils are more influenced by the moisture content than the coarse-grained soils. Generally, the degree of saturation of subgrades (especially for fine-grained subgrades) increases with time, the resilient modulus will decrease over the design period due to the increase in moisture content and reach the minimum resilient modulus. It is noted that $\mathrm{Mr}$ values of Indiana subgrade soils were reported by Kim and Zia (2004) for a confining stress of 2 psi and a deviator stress of 6 psi. The average $\mathrm{Mr} / \mathrm{Mr}_{\mathrm{opt}}$ is 0.28 , which is considerably lower than 0.5 .

\subsubsection{Resilient Modulus for Frozen/ Thawed Unbound Materials}

In the M-E Design Guide, a significant literature search was done to study the behavior of unbound materials under freezing/thawing conditions. It presents absolute values of moduli for frozen material, termed $\mathrm{Mr}_{\text {frz }}$ and the ratio of Mr just after thawing, termed $\mathrm{Mr}_{\text {min }}$, to the $\mathrm{Mr}$ of natural, unfrozen material, termed $\mathrm{Mr}_{\text {unfrz. }}$. The ratio is used as a reduction factor, termed RF. Since some of the data from the literature produced RF values based on $\mathrm{Mr}_{\text {unfrz }}$ as a reference and some were based on $\mathrm{Mr}_{\text {opt }}$ as a reference, it adopted a conservative interpretation of using the smaller of $\mathrm{Mr}_{\text {unfrz }}$ and $\mathrm{Mr}_{\mathrm{opt}}$ as a reference. The definitions are as follows: 


$$
\begin{aligned}
& \mathrm{Mr}_{\mathrm{frz}}=\mathrm{Mr}_{\text {max }}=\mathrm{Mr} \text { for frozen material } \\
& \mathrm{Mr}_{\mathrm{unfrz}}=\text { the normal } \mathrm{Mr} \text { for unfrozen material } \\
& \mathrm{Mr}_{\text {min }}=\mathrm{Mr} \text { just after thawing } \\
& \mathrm{RF}=\text { modulus reduction factor }=\mathrm{Mr}_{\text {min }} / \text { smaller of }\left(\mathrm{Mr}_{\mathrm{unfz}}, \mathrm{Mr}_{\mathrm{opt}}\right)
\end{aligned}
$$

The M-E Design Guide recommends $\mathrm{Mr}_{\mathrm{frz}}$, ave $=3,000,000$ psi for coarse grained materials, $\mathrm{Mr}_{\text {frz_ave }}=2,000,000$ psi for fine grained silt and silty sands, $\mathrm{Mr}_{\mathrm{frz} \_ \text {ave }}=$ 1,000,000 psi, as a conservative value for clays. Note that Lee et al. (1993) recommends resilient modulus ranging from 27000 to 46000 psi for typical Indiana soils based on their test results, which are considerably smaller values than $\mathrm{Mr}_{\mathrm{frz}}$ ave.

\subsubsection{Summary}

With the advent of the new M-E Design Guide, highway agencies are encouraged to implement an advanced design following its philosophies. As part of implementation of the M-E Design Guide, the present study reviews the features embedded in this new design guide for unbound materials, especially subgrades.

The following can be summarized:

- The M-E Design Guide assumes that the subgrade is compacted to optimum moisture content, leading to unconservative design. In order to ensure a 
conservative design for subgrades, the use of the average moisture content between OMC and wet of optimum (95\% compaction) is recommended;

- When laboratory testing for evaluating thawed $\mathrm{Mr}$ is not available, the use of Mr for wet of optimum would be reasonable;

- Caution needs to be taken to use the unconservative frozen $\mathrm{Mr}$ value suggested in M-E Design Guide.

In characterizing subgrade in Indiana, Mr testing program for both design inputs Level 2 and Level 1 are desirable. In addition, the following initiatives will be conducted to enhance characterization of subgrade:

- Mr monthly variation laboratory testing to simulate freeze-thaw in the subgrade;

- Mr long term laboratory simulation to consider permanent strain for pavement rehabilitation;

- Correlation between Mr and FWD data for non-destructive testing evaluation;

- Laboratory evaluation on unsaturated soil properties such as soil water characteristic curve (SWCC). 


\section{CHAPTER 4. LABORATORY TESTING PROGRAM}

\subsection{Soils Used in the Study}

A total of fourteen fine-grained soils and five coarse-grained soils encountered in Indiana were used in the testing program. The testing program consisted of sieve analysis, Atterberg limit tests, standard Proctor tests, unconfined compressive tests, and resilient modulus tests. Figure 24 shows the particle size distribution and Table 2 presents material properties of these soils.

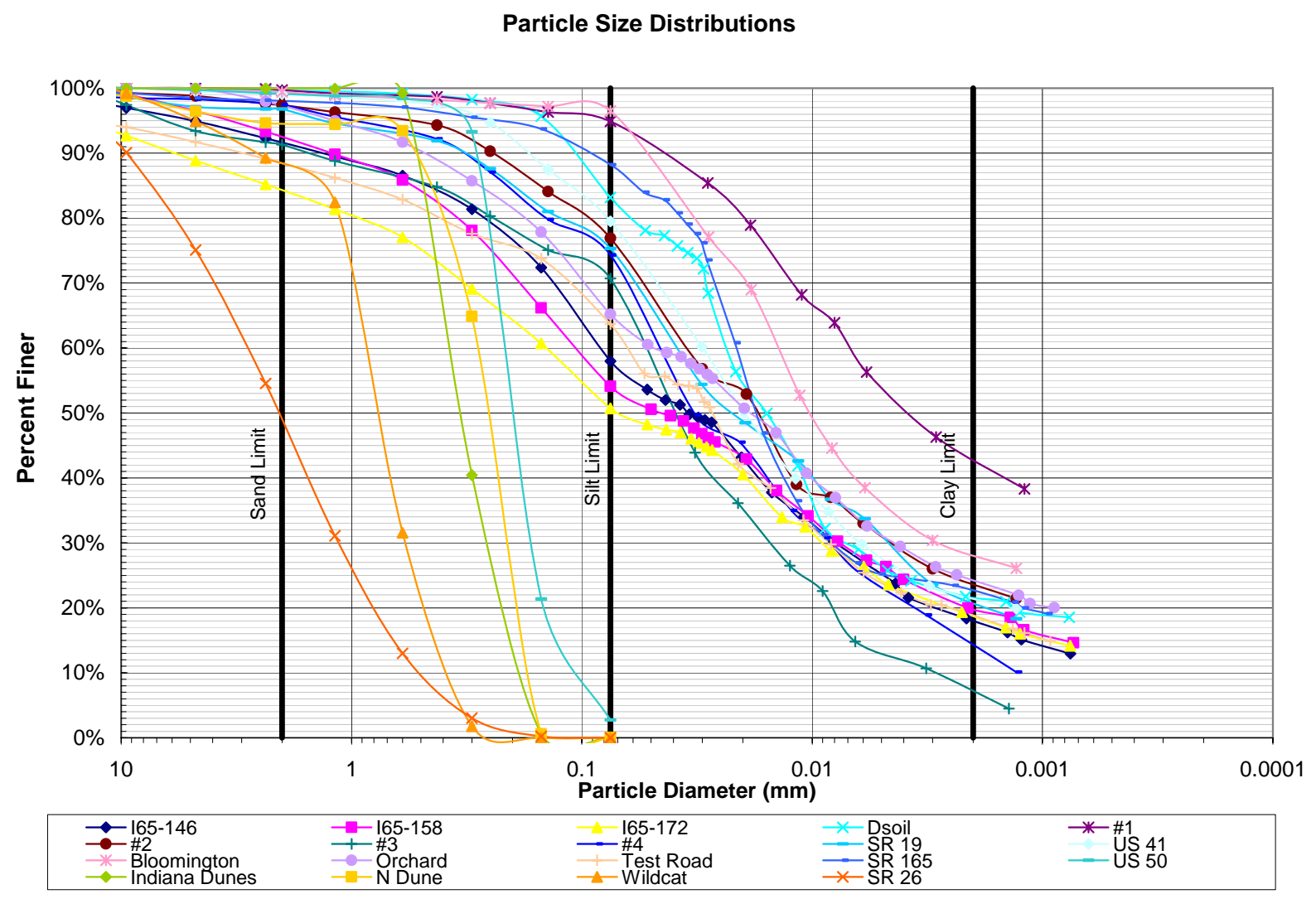

Figure 24. Particle size distribution for soils used 
Table 2. Material properties for soils used

\begin{tabular}{l|l|l|l|l|l|l|l|l}
\hline \hline soil & $\begin{array}{l}\% \\
\text { Gravel }\end{array}$ & $\begin{array}{l}\% \\
\text { Sand }\end{array}$ & $\begin{array}{l}\% \\
\text { Silt }\end{array}$ & $\begin{array}{l}\% \\
\text { clay }\end{array}$ & LL & PI & AASHTO & USCS \\
\hline I65-146 & 8 & 34 & 40 & 18 & 18.5 & 5.2 & A-4 & $\begin{array}{l}\text { CL- } \\
\text { ML }\end{array}$ \\
\hline I65-158 & 8 & 38 & 44 & 10 & 18.2 & 4.6 & A-4 & $\begin{array}{l}\text { CL- } \\
\text { ML }\end{array}$ \\
\hline I65-172 & 16 & 33 & 33 & 18 & 24.2 & 14.7 & A-6 & CL \\
\hline Dsoil & 0 & 17 & 61 & 22 & & 6.2 & A-4 & $\begin{array}{l}\text { CL- } \\
\text { ML }\end{array}$ \\
\hline \#1soil & 0.3 & 4.8 & 52.3 & 42.6 & 50 & 23 & A-7-6 & CH \\
\hline \#2soil & 2.6 & 20.5 & 52.7 & 24.2 & 39 & 16 & A-6 & CL \\
\hline \#3soil & 8.7 & 20.6 & 62.6 & 8.1 & 40 & 15 & A-6 & CL \\
\hline \#4soil & 2.5 & 23.2 & 59.8 & 14.5 & 43 & 21 & A-7-6 & CL \\
\hline SR19 & 3.2 & 21.5 & 55.4 & 19.9 & 33 & 16 & A-6 & CL \\
\hline US41 & 0.9 & 19.6 & 58.1 & 21.4 & 28 & 9 & A-4 & CL \\
\hline Bloomington & 0.3 & 3.2 & 60.6 & 35.9 & 46 & 26 & A-7-6 & CL \\
\hline Orchard & 3 & 32 & 41 & 24 & 29.8 & 12 & A-6 & CL \\
\hline Test road & 11.5 & 24.5 & 45 & 19 & 30.5 & 9.1 & A-4 & CL \\
\hline SR 165 & 2 & 10 & 65 & 23 & 31 & 8.5 & A-4 & CL \\
\hline US 50 & 1 & 96 & 3 & 0 & - & - & A-3 & SP \\
\hline Indiana & 0 & 100 & 0 & 0 & - & - & A-3 & SP \\
Dunes & & & & & & & & \\
\hline N Dune & 5.5 & 94.5 & 0 & 0 & - & - & A-3 & SP \\
\hline Wildcat & 12 & 88 & 0 & 0 & - & - & A-1-b & SP \\
\hline SR 26 & 51 & 49 & 0 & 0 & - & - & A-1-b & GP \\
\hline \hline
\end{tabular}

\subsection{Specimen Preparation}

For each soil, three samples were made at three different water contents which are dry of optimum (95\% relative compaction), optimum (100\% relative compaction), and wet of optimum ( $95 \%$ relative compaction). Throughout the report, dry of optimum, optimum and wet of optimum correspond to 95 percent relative compaction (Dry side), 100 percent compaction, 95 percent relative compaction (Wet side), respectively. A wide 
range of water content was used to account for the possible range of lower and upper bounds of $\mathrm{Mr}$ values. Note that the percent relative compaction is defined as the percentage of the dry unit weight $\left(\gamma_{d}\right)$ to the maximum dry unit weight $\left(\gamma_{d m a x}\right)$ in the compaction curve.

For preparation of a specimen for a Mr testing, a compaction mold, specially constructed, with a diameter of 2.8 " was used. Five layers of compaction were done with the same compaction energy as the standard Proctor compaction test. Compaction curves for all of the soils tested are shown in Figure 25. As can be in Figure 25, for silty sandy soils the dry unit weight is in the range of 115 to $125 \mathrm{pcf}$ and the optimum water content ranges between 9 and 13 percent, while for clayey soils the dry unit weight ranges from 95 to 115 pcf and the optimum water content ranges between 12 and 23 percent. The poorly graded sands (US 50, Indiana Dunes and N Dune) tend to show lower dry densities than the good graded sand (SR 26). All of sands are in the medium range of dry densities of fine-grained soils. 


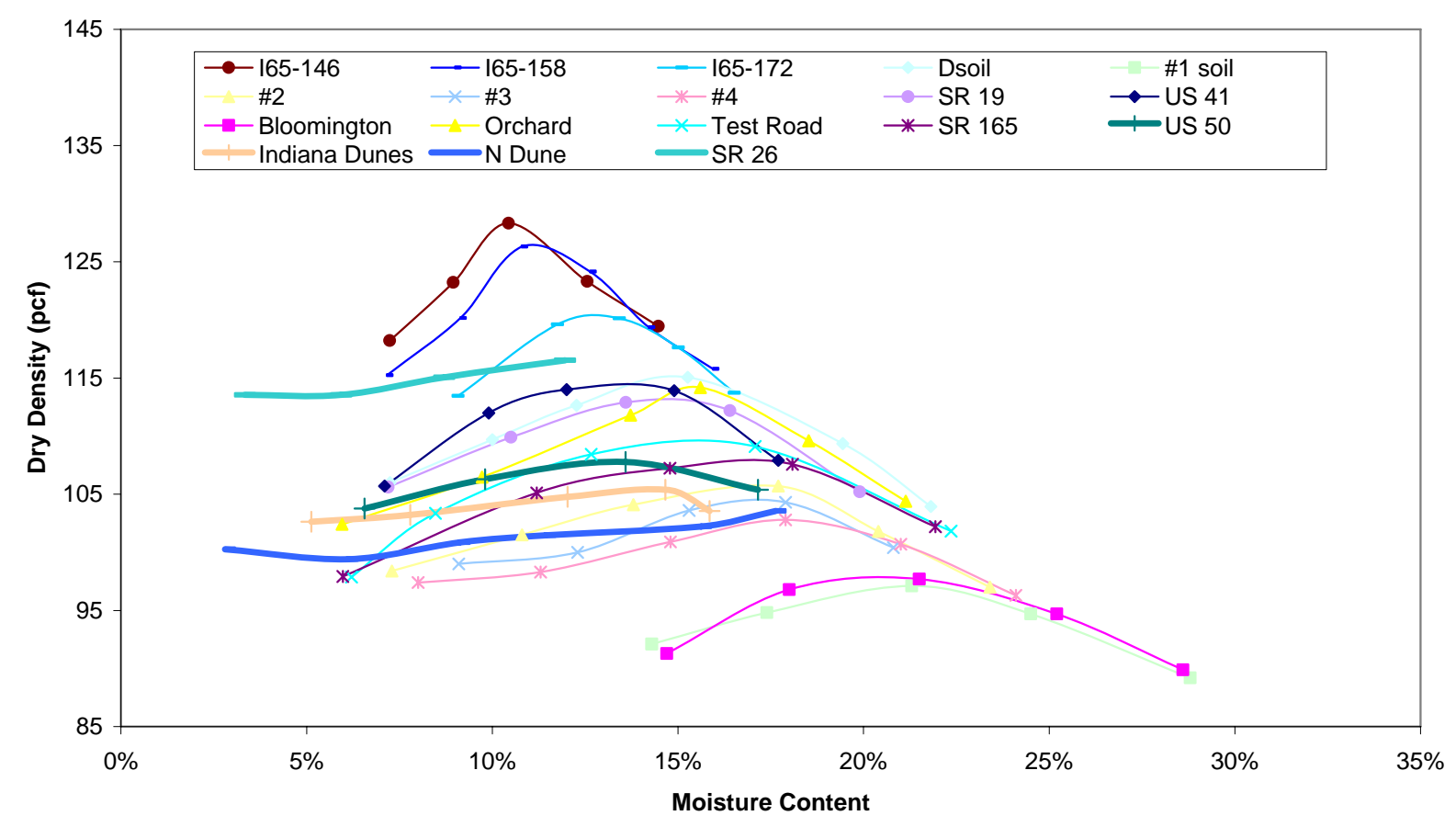

Figure 25. Compaction curves for soils used

\subsection{Resilient Modulus Test}

An automated resilient modulus testing device made by Geocomp Corp. was used for Mr testing. Figure 26 shows the testing equipment used in the study. Air was used to apply the confining pressure. The Mr testing is completed after a series of loading combinations as specified in AASHTO T307 (see Table 3). Figure 27 shows the example of the load pulse of the resilient modulus testing. In addition, long-term resilient modulus tests were conducted to evaluate both the long-term resilient modulus and permanent deformation. 


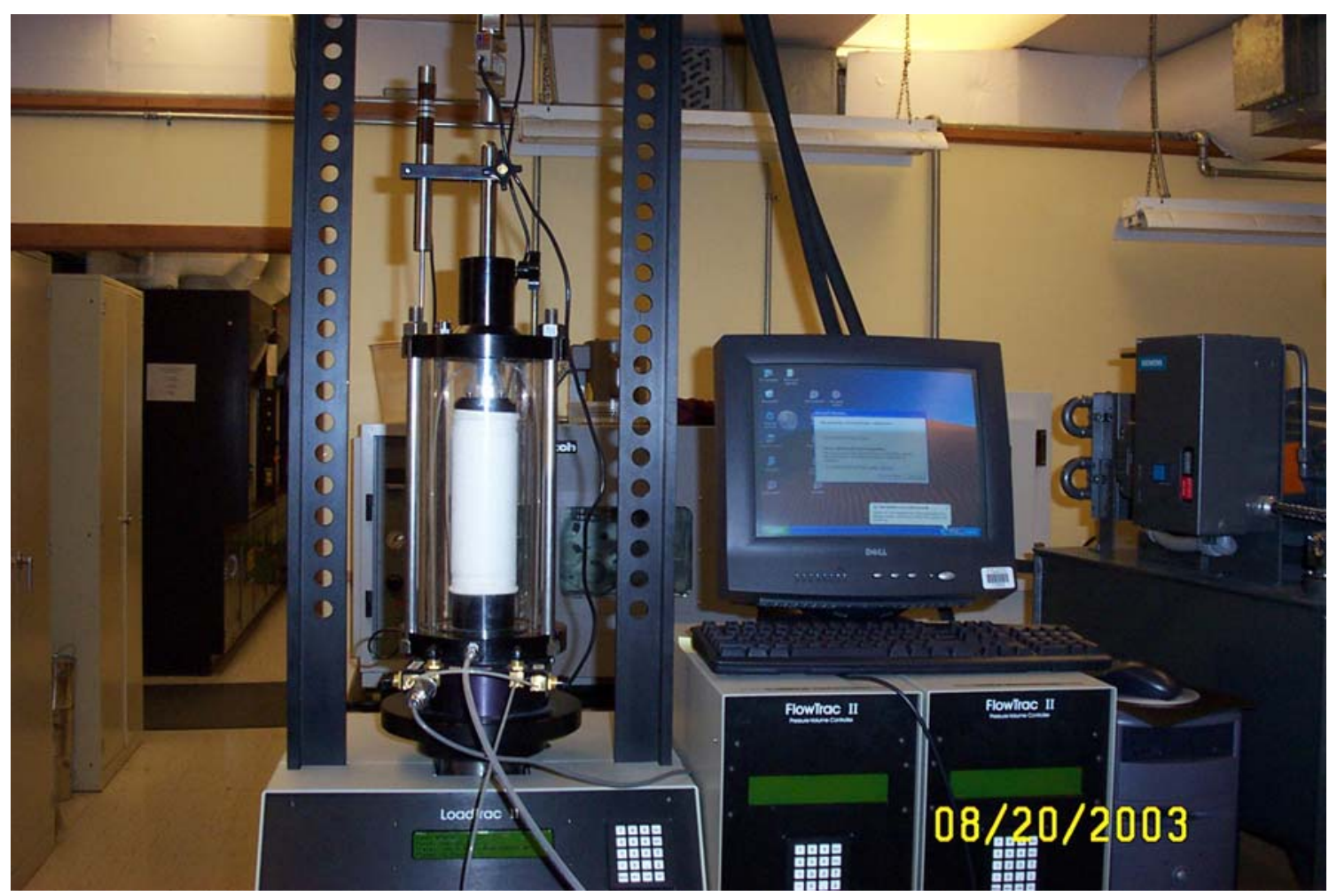

Figure 26. Resilient modulus test equipment 
Table 3. AASHTO T307-99 for Type 1 and Type 2

\begin{tabular}{c|c|c|c}
\hline \hline Sequence & $\begin{array}{c}\text { Confining } \\
\text { Stress (psi) }\end{array}$ & $\begin{array}{c}\text { Deviator Stress } \\
(\mathrm{psi})\end{array}$ & $\begin{array}{c}\text { No. of Load } \\
\text { Application }\end{array}$ \\
\hline Conditioning & 6 & 4 & $500-1000$ \\
\hline 1 & 6 & 2 & 100 \\
\hline 2 & 6 & 4 & 100 \\
\hline 3 & 6 & 6 & 100 \\
\hline 4 & 6 & 8 & 100 \\
\hline 5 & 6 & 10 & 100 \\
\hline 6 & 4 & 2 & 100 \\
\hline 7 & 4 & 4 & 100 \\
\hline 8 & 4 & 6 & 100 \\
\hline 9 & 4 & 8 & 100 \\
\hline 10 & 4 & 10 & 100 \\
\hline 11 & 2 & 2 & 100 \\
\hline 12 & 2 & 4 & 100 \\
\hline 13 & 2 & 6 & 100 \\
\hline 14 & 2 & 8 & 100 \\
\hline 15 & 2 & 10 & 100 \\
\hline \hline
\end{tabular}

\section{Load Pulse in Resilient Modulus test}

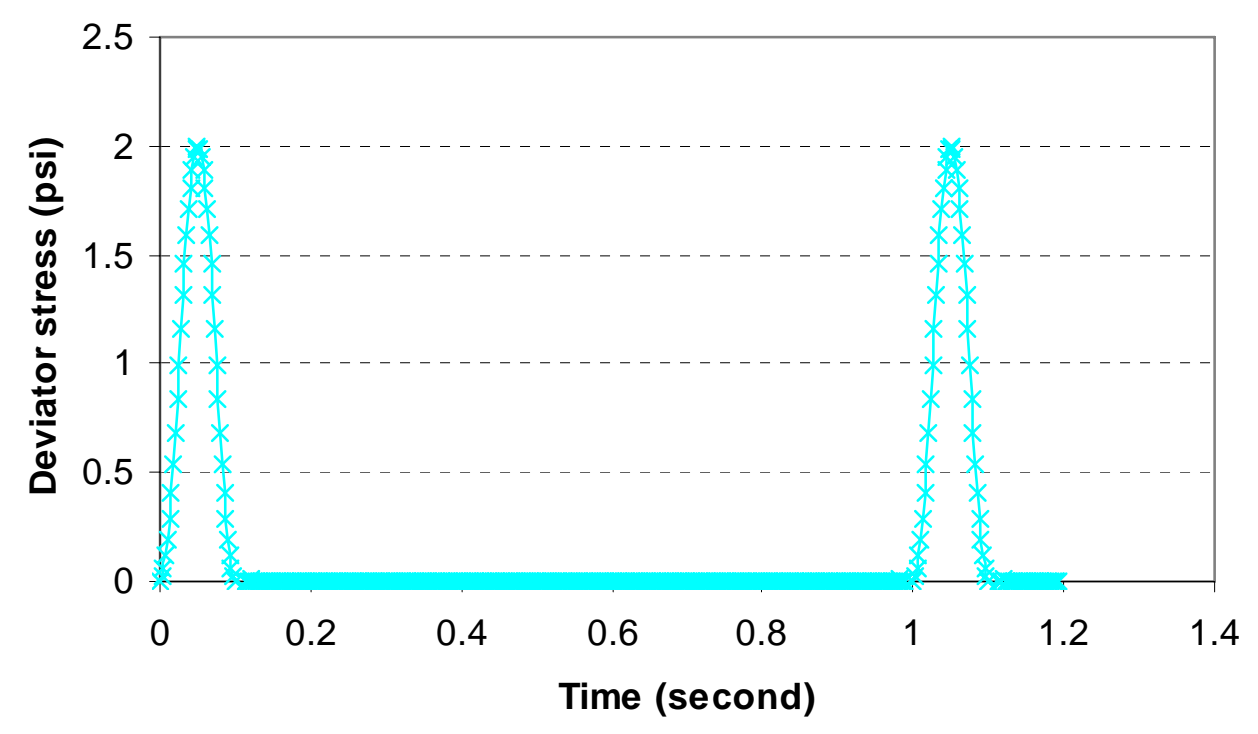

Figure 27. Load pulse at a deviator stress of $2 \mathrm{psi}$ 


\subsection{Dynamic Cone Penetration (DCP) Tests}

The dynamic cone penetration test used in this experiment was performed in the laboratory to produce any possible correlations between the DCP index and the resilient modulus. Specimens were compacted in a 6" diameter and 9" high mold (CBR mold) using the standard Proctor compaction energy, requiring significant amount of soil and time consuming compaction effort. This was achieved using 8 soil layers and 37 blows using a standard proctor hammer on each layer. The DCPT was performed on dry and OMC samples for five soils (Bloomington, Orchard, Test Road, Exit 172, SR 165). It was not possible to perform the test on wet soil samples, as the weight of the apparatus caused the cone to penetrate the soil, giving the wet samples a penetration index of infinity. The other soils were penetrated to an approximate depth of 6 " to reduce the effect of confinement from the bottom of the mold on the results. 


\section{CHAPTER 5. DISCUSSION OF THE TEST RESULTS}

\subsection{Resilient modulus test}

\subsubsection{Results of Resilient Modulus Test on Cohesive Subgrade Soils}

\subsubsection{Multi-layered Elastic Analyses}

In order to evaluate the range of confining and deviator stresses generated in the subgrade, several multilayered elastic analyses were performed on four typical pavement cross-sections (See Kim 2002). The cross-sections consist of a 4 to 6 inches of asphalt layer, a 6 to 8 inches of base layer and a 12 inches of compacted clay or sand subgrade layer followed by a infinite layer. A single axle load of 18 kips with an inflation pressure of 100 psi was applied to the surface of the pavement. For an extreme scenario, a super single tire loading with an inflation pressure of 125 psi (Kim 2002) was also applied. Figure 28 shows the evaluation points in the subgrade layer. Analysis results showed that the confining stresses induced in the subgrades for four typical Indiana cross-sections range from 2 psi to 6 psi and deviator stresses range from 2 to 18 psi. One of the analyses

on the deviator stresses induced in the subgrade is shown in Figure 29. The 15 psi would be the highest deviator stresses that the subgrade ever experiences (except for supersingle load). Note that the highest deviator stress is a little higher than 10 psi specifed in AASHTO T 307. 
18 kips load \& Super-single load

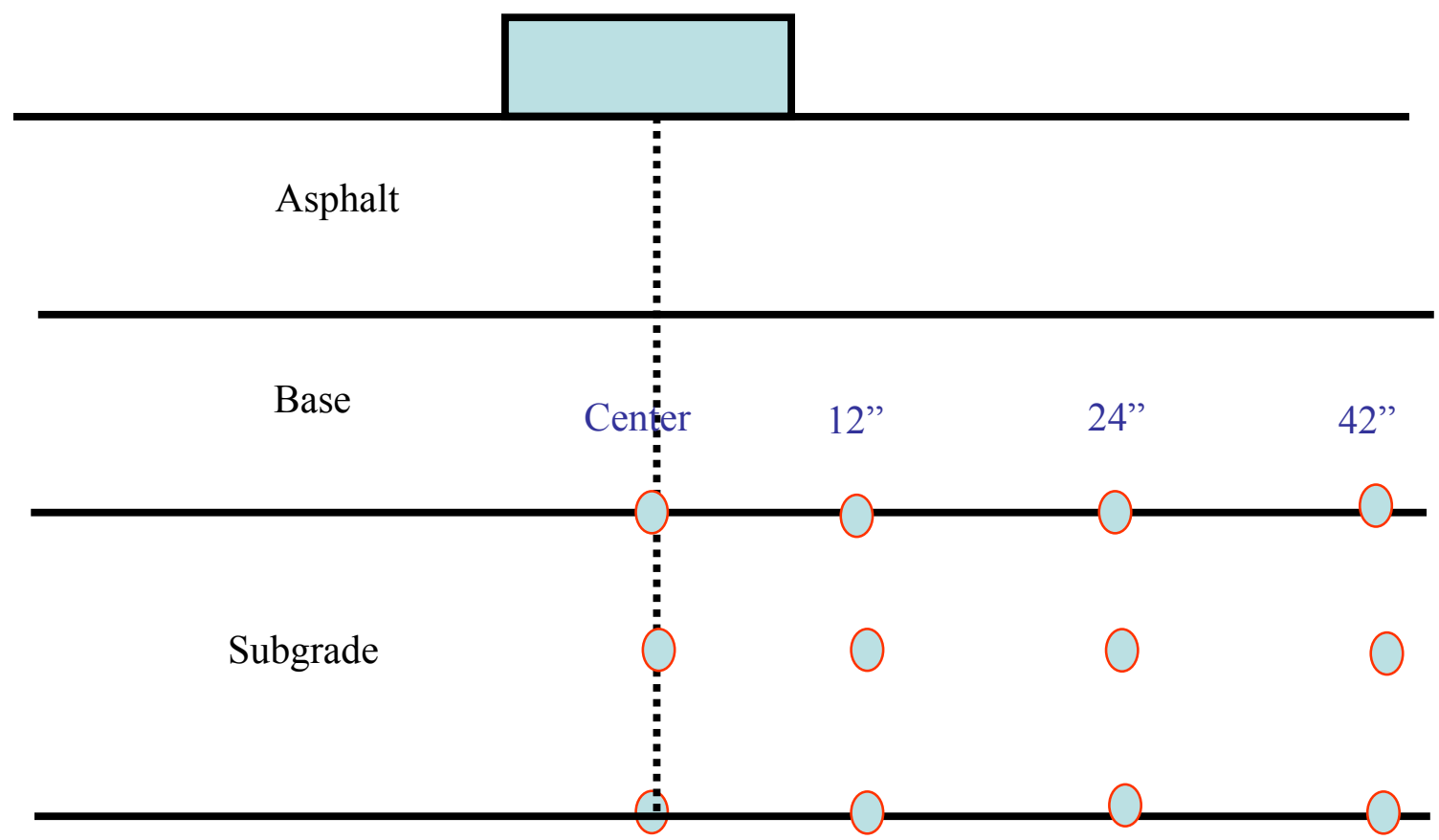

Semi-infinite

Figure 28. Evaluation points of multi-elastic analyses for typical Indiana subgrades 


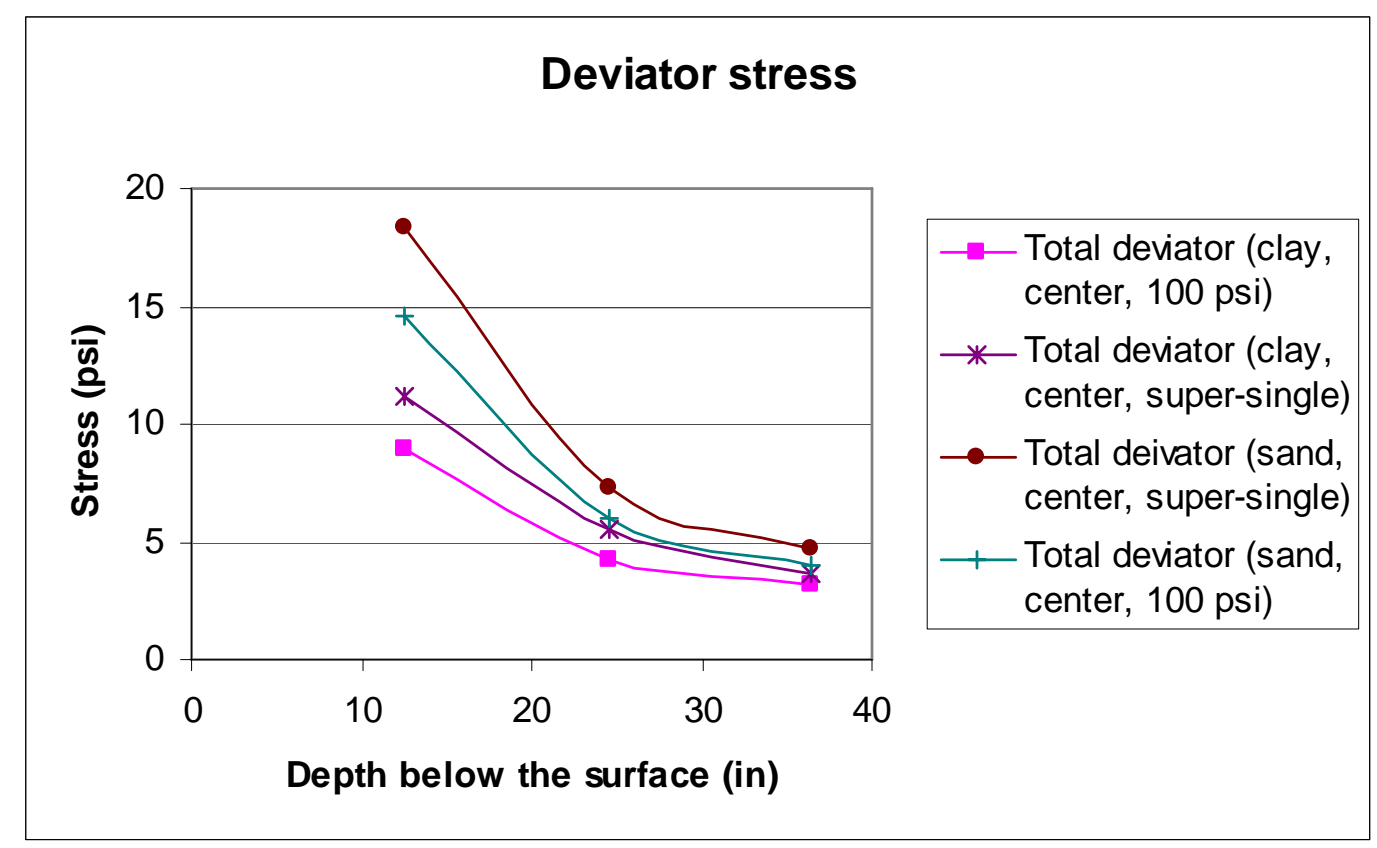

Figure 29. Deviator stresses induced in the subgrade

\subsubsection{Simplified Procedure vs. AASHTO T307}

As mentioned previously, the current AASHTO T307 calls for 15 steps of repeated loading. The primary reason for that is to apply the traffic loading in a wide range covering the typical loadings. In the design of pavements, resilient modulus values of subgrades corresponding to the representative stress levels on top of the subgrades are important because these values should be used for design parameters. Generally, the level of confining stress on top of the subgrades induced by 18 kips Equivalent Single Axle 
Load (ESAL) would be around 2 - 3 psi (Elliot et al. 1988). In our study, the multilayered elastic analyses for typical cross-sections using ELSYM5 showed the 2 psi as a minimum confining pressure for typical Indiana roads. Therefore, one attempt was made to make the procedure quicker and easier. As a consequence, it was determined that a confining stress of 2 psi and deviator stresses of 2, 4, 6, 8, 10 and 15 psi were appropriate for the simplified Mr procedure.

Figures 30 and 31 show the comparisons of the Mr values between the simplified and the AASHTO procedures, where those soils were compacted at optimum moisture contents for I65-158 and I65-172. It is clearly seen in Figures 30 and 31 that the higher the confining stress, the higher the resilient modulus value, which is the typical behavior of subgrade soils. In Figure 30 the number of repetition in the conditioning stage and the main testing was the same as the one in the AASHTO T307, while in Figure 31 the number of repetitions both in the conditioning stage and the main testing stage was reduced by half the number as per AASHTO T307. The Mr values obtained from the two methods are almost identical for most of the soils used in this study. This means that the simplified procedure can be appropriately used for estimation of Mr values in place of the current Mr testing method, AASHTO T 307. 


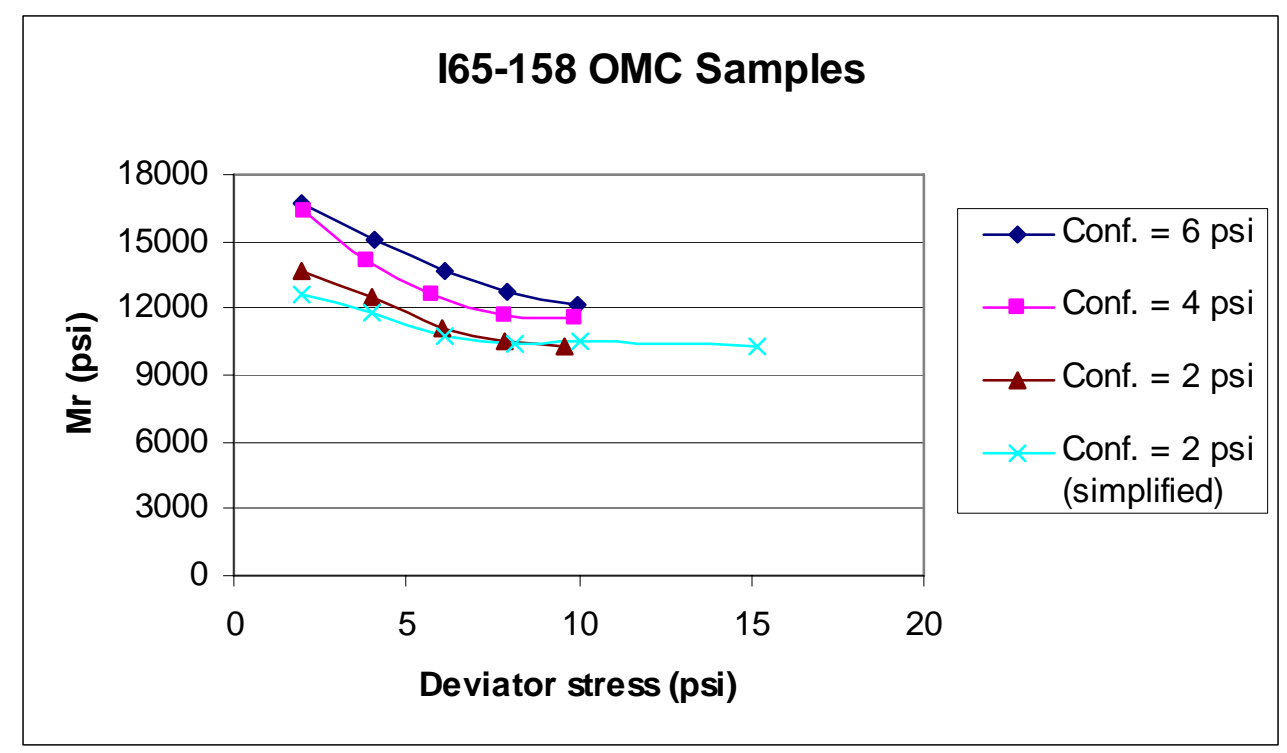

Figure 30. Comparison of $\mathrm{Mr}$ between the Simplified (500 repetitions for conditioning and 100 repetitions for main testing) and the AASHTO procedures

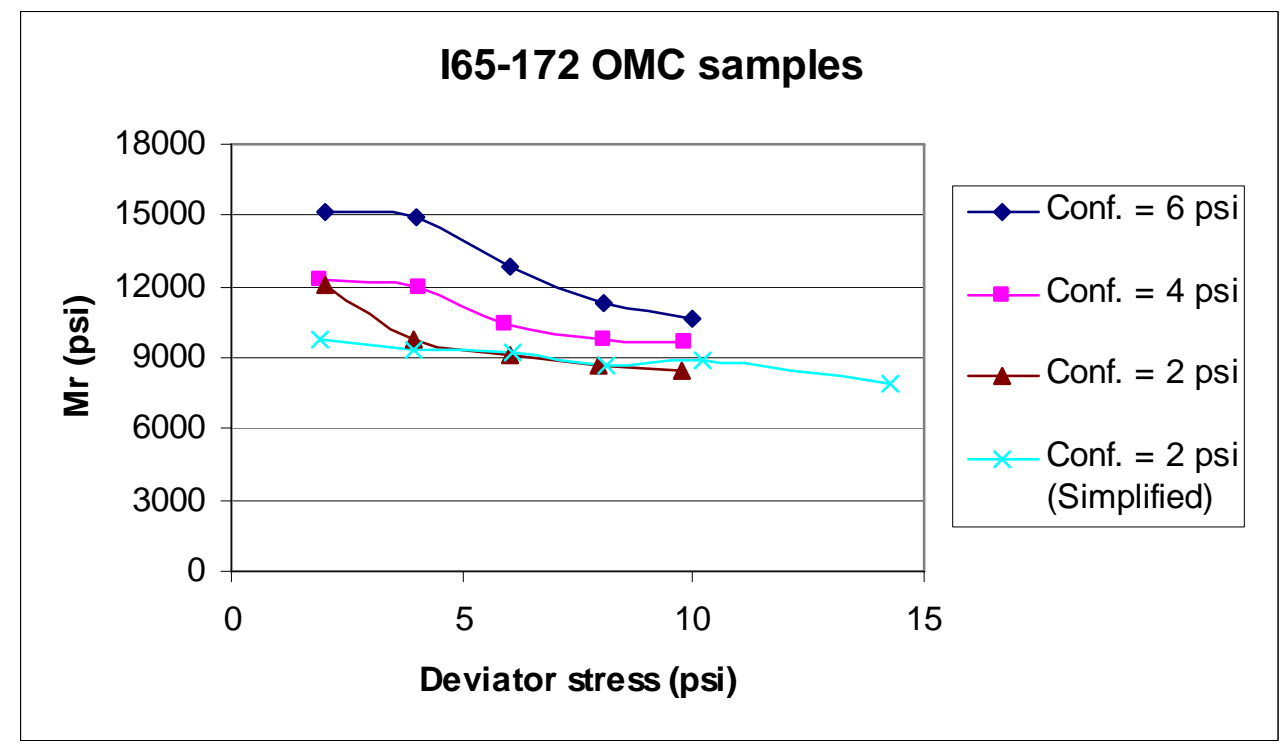

Figure 31. Comparison of Mr between the Simplified (250 repetitions for conditioning and 50 repetitions for main testing) and the AASHTO procedures between the Simplified 


\subsubsection{Mr values for Dry, OMC and Wet Water Contents}

In general, $\mathrm{Mr}$ testing is performed at optimum moisture content (OMC) or \pm 2 percent of the OMC. In the field, however, compaction control is conducted by the percent relative compaction with respect to the standard Proctor compaction curve. Ninety-five percent relative compaction is usually incorporated for compaction control of subgrades, which allow some cases where water contents exist dry of optimum or wet of optimum. In order to account for such field conditions, Mr testing was performed on soils compacted dry of optimum, optimum and wet of optimum. It should be noted that the difference in water contents between them is considerably large, approximately 5 to 12 percent, which is dependent on the shape of the compaction curve.

It is very important to distinguish the meaning of stiffness from strength of the soil. Resilient modulus is not strength but stiffness. For instance, a soil having a higher strength than the other does not necessarily show higher stiffness; may be either higher or lower. Table 4 shows the measured $\mathrm{Mr}$ values for soils compacted dry of optimum, optimum and wet of optimum at a confining stress of 2 psi and a deviator stress of 6 psi. As indicated in Table 4, for all of the four silty sandy clay soils tested, the highest $\mathrm{Mr}$ value is observed in the soils compacted dry of optimum, and the lowest Mr value in soils compacted wet of optimum. Although the dry unit weight of the Dry sample is smaller than the OMC sample, the value of $\mathrm{Mr}$ is higher. This appears to be caused by capillary suction and lack of lubrication. Capillary suction contributes to increase in the effective stress by pulling particles towards one another and thus increasing particle contact force, resulting in higher Mr values. 
Table 4. Measured Mr values for Dry, OMC and Wet samples $\left(\sigma_{\mathrm{c}}=2 \mathrm{psi}, \sigma_{\mathrm{d}}=6 \mathrm{psi}\right)$

\begin{tabular}{|c|c|c|c|c|}
\hline \multirow{2}{*}{\multicolumn{2}{|c|}{ Soil Type and Source }} & \multicolumn{3}{|c|}{ Mr values (psi) } \\
\hline & & Dry & $\mathrm{OMC}$ & Wet \\
\hline \multirow{4}{*}{$\begin{array}{l}\text { Silty sandy } \\
\text { clay soils }\end{array}$} & I65-146 & 13,641 & 3,327 & 2,946 \\
\hline & I65-158 & 15,867 & 11,104 & 3,970 \\
\hline & I65-172 & 16,710 & 9,631 & 2,605 \\
\hline & Dsoil & 12,278 & 9,310 & 1,996 \\
\hline \multirow{10}{*}{ Clay soils } & \#1soil & 16,617 & 12,587 & 7,235 \\
\hline & $\# 2$ soil & 13,444 & 17,563 & 2,430 \\
\hline & \#3soil & 14,439 & 18,813 & 1,633 \\
\hline & \#4soil & 11,440 & 10,697 & 1,717 \\
\hline & SR19 & 25,047 & 22,896 & 1,884 \\
\hline & US41 & 24,209 & 14,489 & 2,376 \\
\hline & Bloomington & 13,725 & 13,488 & 2,026 \\
\hline & Orchard & 12,587 & 14,322 & 2,913 \\
\hline & Test road & 13,857 & 12,523 & 3,325 \\
\hline & SR 165 & 11,276 & 9,409 & 2,405 \\
\hline
\end{tabular}

\subsubsection{Silty Sandy Clay soils}

Figures 32-35 present the unconfined compressive test results for OMC, Dry and Wet samples for I65-146, I65-158, I65-172 and Dsoil, respectively. Unconfined compressive (UC) tests were done to understand why the permanent strain (which will be discussed in a later section) occurs excessively for some Wet samples, and to understand if there is any indication of effect of peak strength, stiffness of UC test and permanent strain on resilient behavior. For all of the four silty sandy clay soils, the highest stiffness is observed in the Dry samples and the peak strength is also observed in the Dry samples, 
except for I65-158 OMC sample. From Figures 33 and 34, Dry samples of I65-158 and Dsoil show slightly larger stiffness than OMC samples. The same trend in the Mr testing is also evidenced in Table 4.

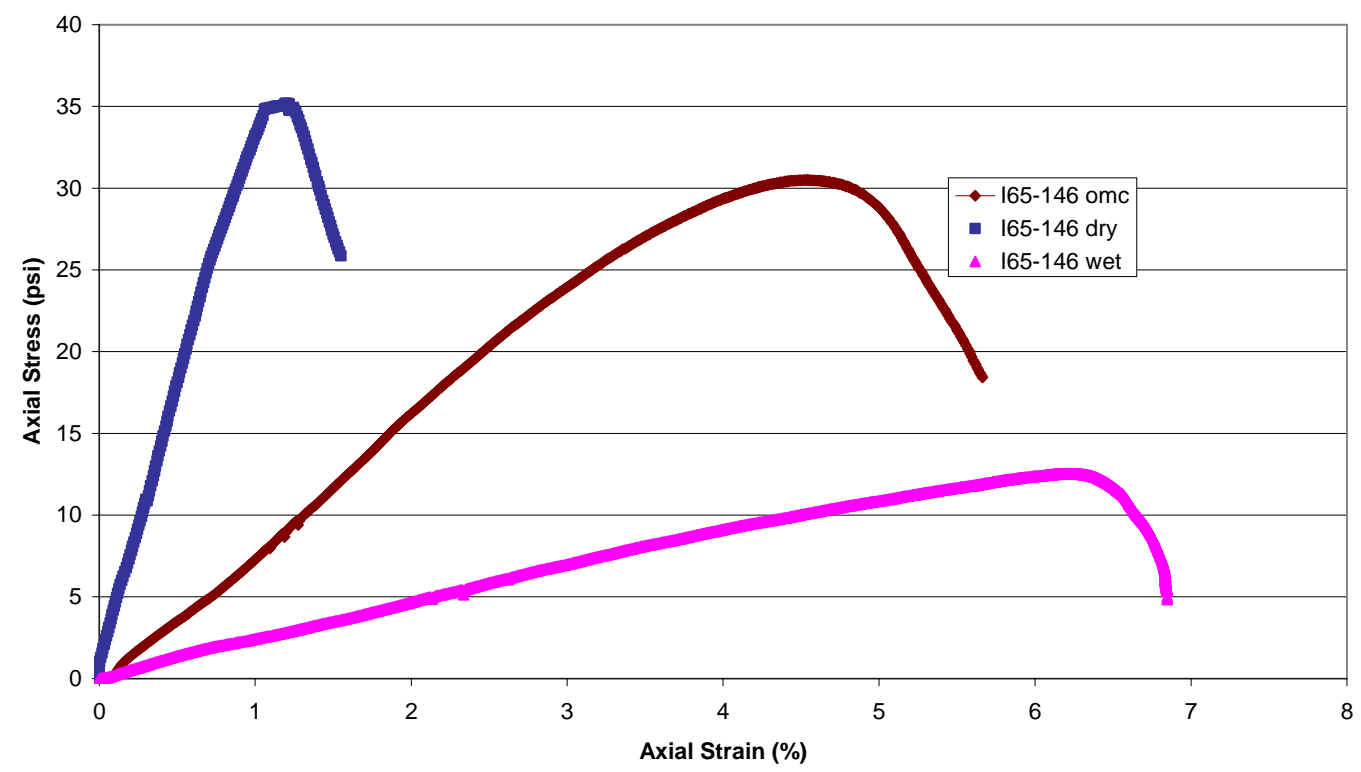

Figure 32. Unconfined compressive test results for Dry, OMC, Wet samples for I65-146 


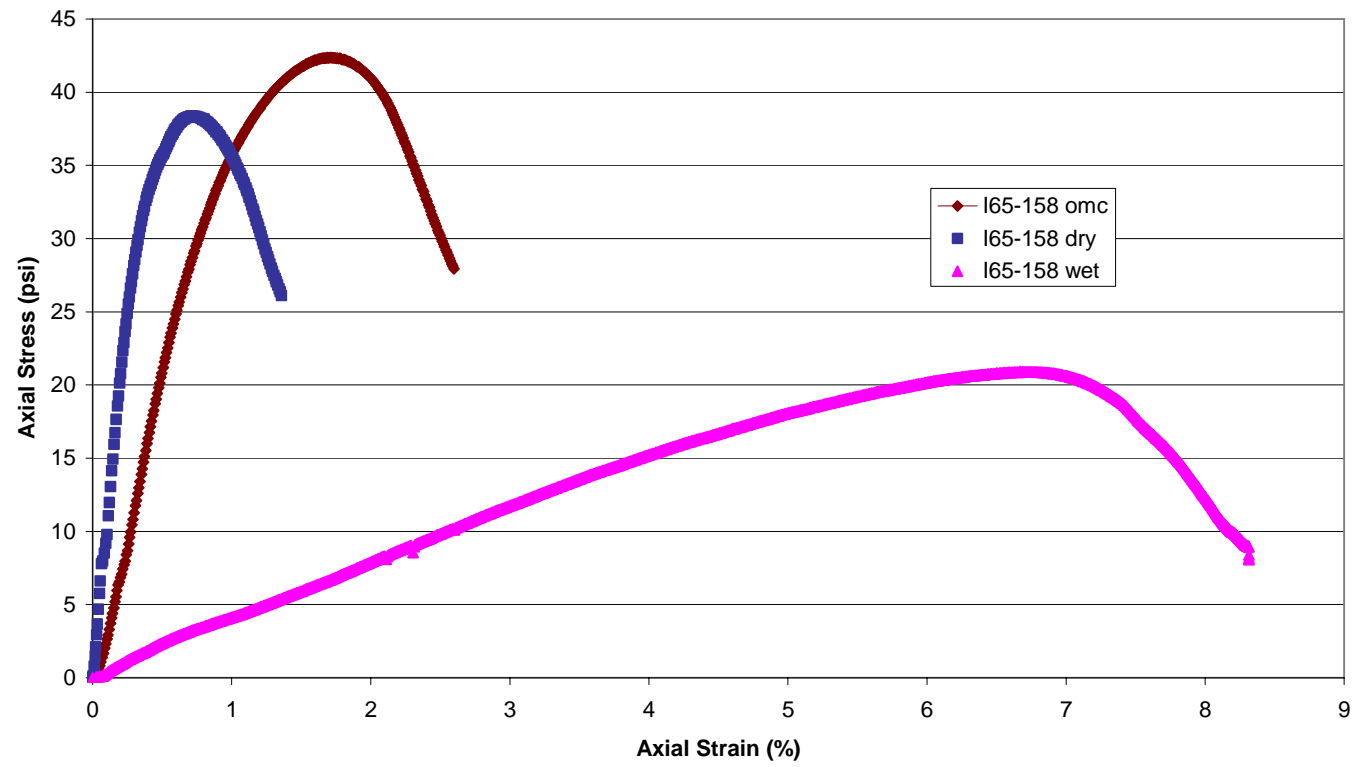

Figure 33. Unconfined compressive test results for Dry, OMC, Wet samples for I65-158

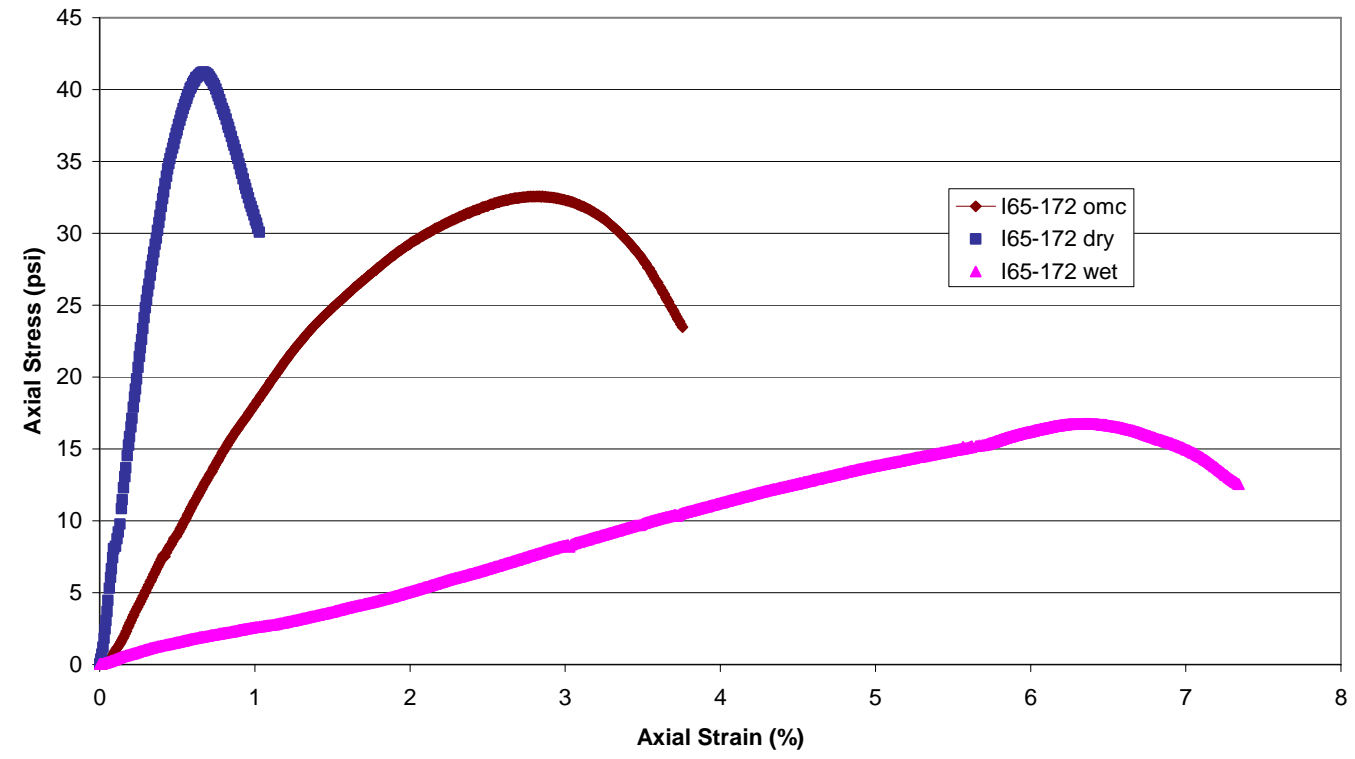

Figure 34. Unconfined compressive test results for Dry, OMC, Wet samples for I65-172 


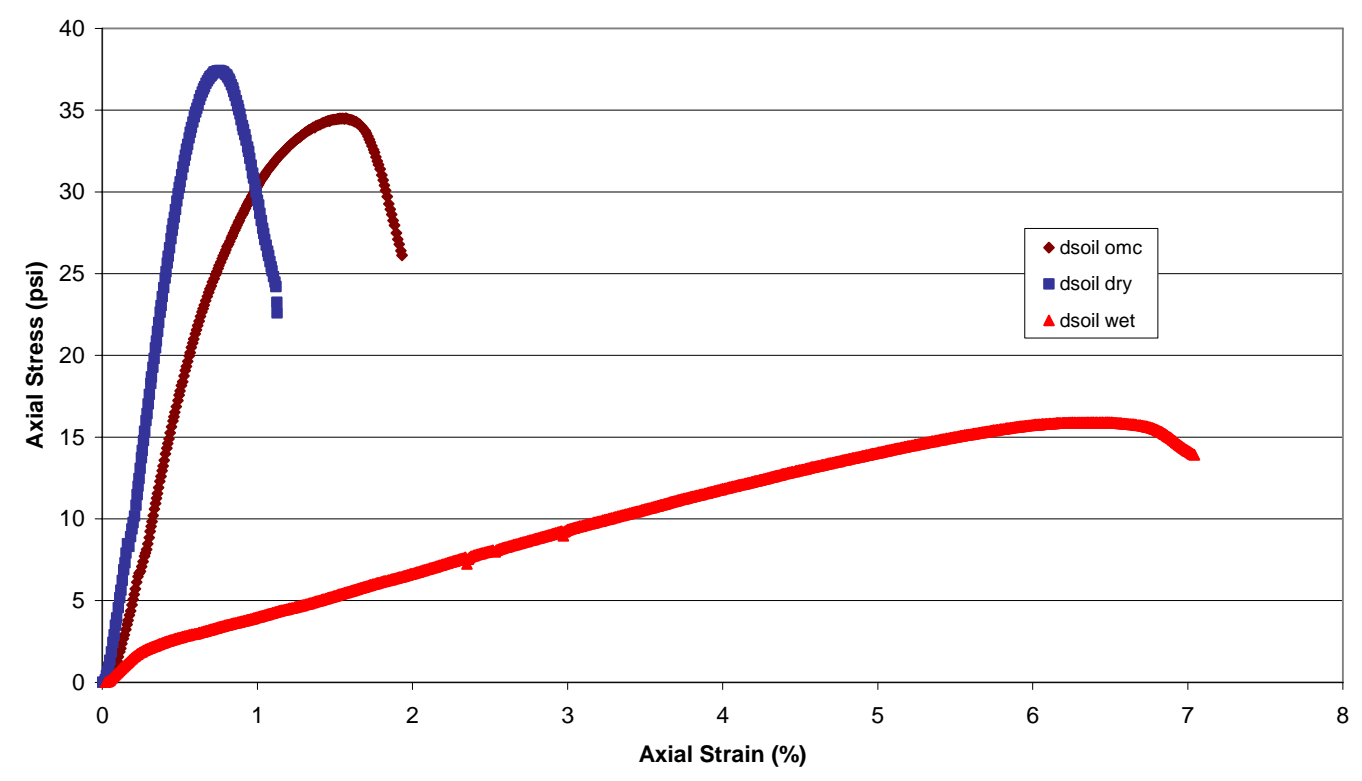

Figure 35. Unconfined compressive test results for Dry, OMC, Wet samples for Dsoil

\subsubsection{Clay soils}

As shown in Table 4, the seven fine-grained soils have a slightly different resilient behavior compared with the silty sandy clay soils soils. The difference in Mr for clay soils between Dry samples and OMC specimens are smaller than that for silty sandy clay soils. Some OMC specimens show higher Mr values than Dry samples. This indicates that the effect of dry unit weight on resilient behavior in the clay soils becomes more pronounced than in the silty sandy clay soils and the effect of suction appears to increase in the clay soils. Similarly observed in the silty sandy clay soils, the wet samples in the clay soils show considerably lower Mr values than Dry and OMC samples, which means that the soils are very weak due to the higher degree of saturation and thus can be used for the lowest limit (i.e., spring) of Mr values for subgrades. 


\subsubsection{Permanent Deformation Behavior}

Permanent deformation behavior is not considered in the calculation of $\mathrm{Mr}$ values. This is because the permanent strain is very small for most of the subgrade soils. For most of the soils tested, the small permanent deformations occurred, especially for Dry and OMC samples. However, some samples compacted wet of optimum exhibited an excessive permanent deformation while performing a $\mathrm{Mr}$ testing. This caused a significant difficulty to run a Mr testing up to the final step. Sometimes it was impossible to run a Mr testing to the end because of the sudden failure of the sample. Most of the failure was observed to be bulging failure, not shear failure. As can be seen in Figures 32-35, the peak strengths of the wet samples occur at a permanent strain of about seven percent and the stress ratio of the highest deviator stress (i.e., $10 \mathrm{psi}$ ) in $\mathrm{Mr}$ testing to the peak strength are in the range of 50 to 70 percent. This explains why the permanent strain occurs excessively in the Wet samples. The AASHTO T307 calls for shear test for samples greater than 5 percent permanent strain. However, it is not practical not to evaluate Mr values for the soils. The maximum permanent strain was set as 20 percent so that $\mathrm{Mr}$ values can be obtained even for those soils with excessive permanent strain.

Figures 36 and 37 are the results of Mr testing for I65-146 wet sample in the conditioning stage and in the $5^{\text {th }}$ step, respectively. It was observed in Figure 36 that even in the conditioning stage the permanent strain occurred to about 10 percent. From Figure 37, the permanent strain approached to about 18 percent and the testing was terminated in the $5^{\text {th }}$ step. A comparison was made of the resilient modulus between using the original length and using the deformed length for I65-158 soil, as shown in Figure 38. The 
permanent strain of about 10 percent occurred in the $\mathrm{Mr}$ testing and the difference in $\mathrm{Mr}$ values using the original and deformed lengths are approximately eight percent. This suggests that it would be more accurate to calculate the Mr values using the deformed length.

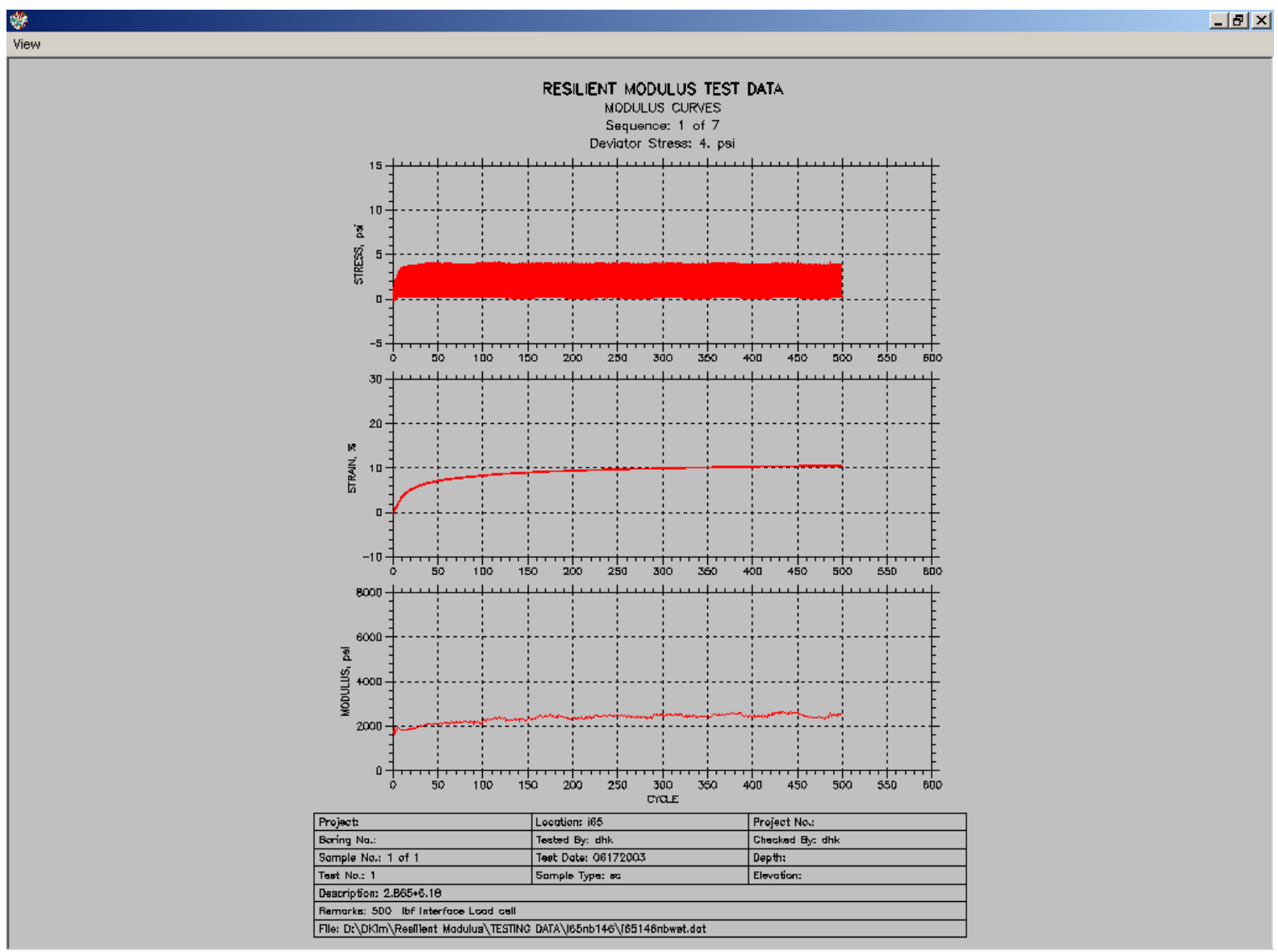

Figure 36. Permanent strains for I65-146 wet sample in the conditioning stage 


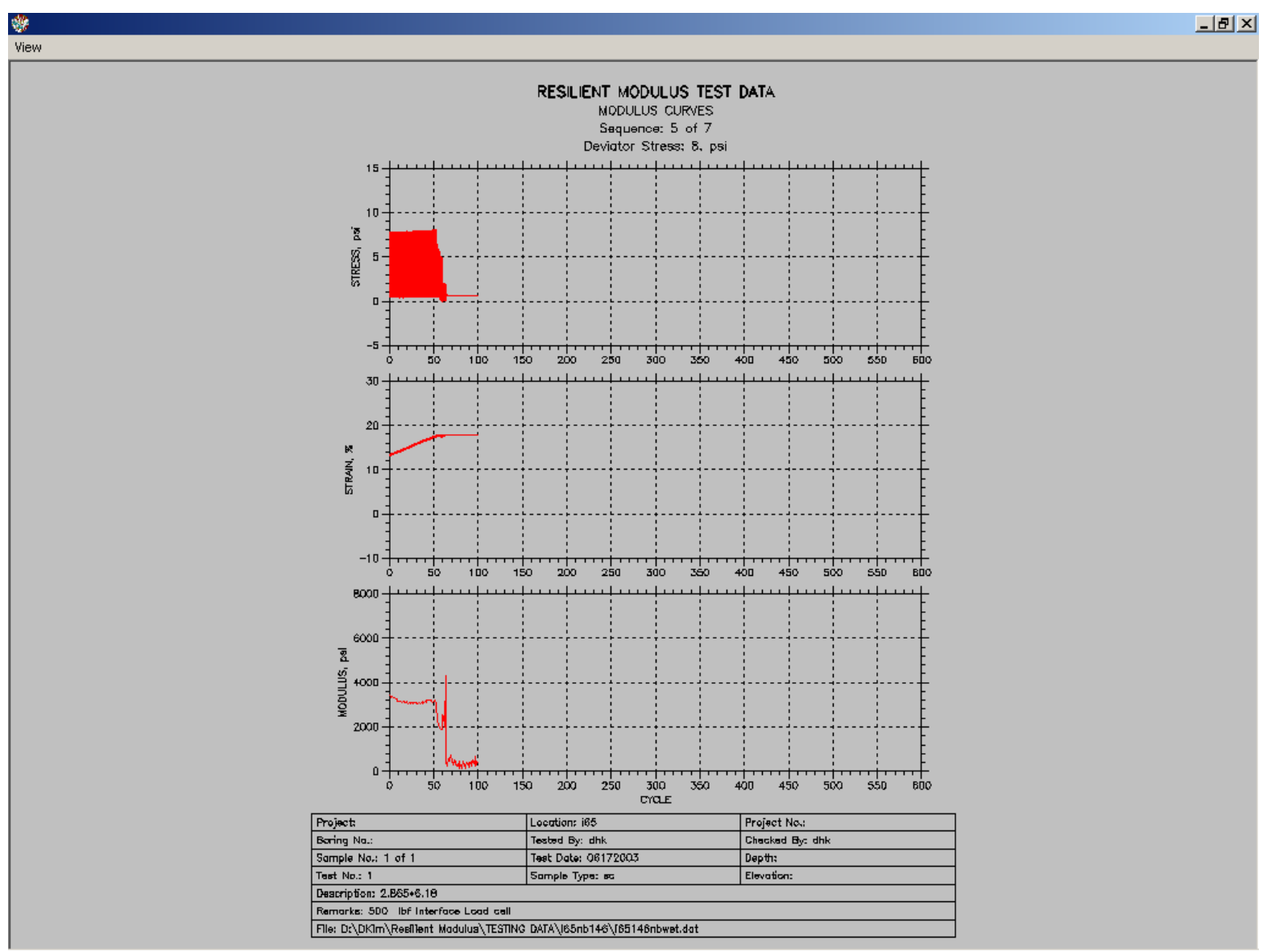

Figure 37. Permanent strains for I65-146 wet sample in the $5^{\text {th }}$ step

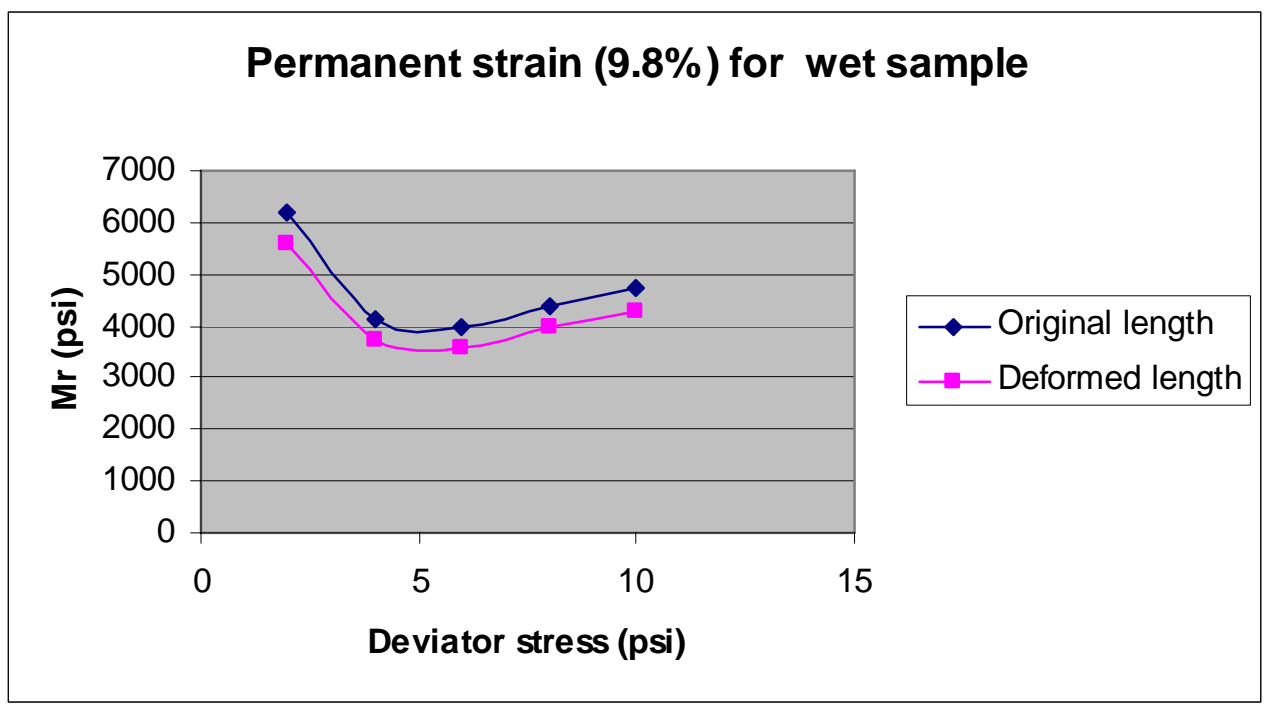

Figure 38. Mr values for original length and deformed length 


\subsubsection{Correlation between Unconfined Compressive Test Results and $\mathrm{Mr}$}

Some researchers (Lee et al. 1997, Thompson and Robnett 1979) suggested using the unconfined compressive strength at $1 \%$ strain to estimate the resilient modulus, but it was found that this is not appropriate for our study. Based on the results of unconfined compressive tests, the three equations were formed primarily using the relationships, shown in Figure 39:

$$
\mathrm{Mr}=\mathrm{k}_{1} * \mathrm{f}(\mathrm{E})+\mathrm{k}_{2} * \mathrm{e}_{3}^{(\mathrm{k} * \text { failure strain })}+\mathrm{k}_{4} * \ln \left(\mathrm{q}_{\mathrm{u}}\right)+\mathrm{k}_{5}
$$

Where $\mathrm{f}(\mathrm{E})=\mathrm{aE} \mathrm{E}^{3}+\mathrm{bE}^{2}+\mathrm{cE}+\mathrm{d}, \mathrm{k}_{1}=0.708, \mathrm{k}_{2}=3171, \mathrm{k}_{3}=-20, \mathrm{k}_{4}=1284, \mathrm{k}_{5}=-32416$, $a=0.00000008, b=-0.0014, c=7.711$ and $d=2436$

$$
\mathrm{Mr}=\mathrm{k}_{1} * \ln (\mathrm{E})+\mathrm{k}_{2} * \ln \left(\mathrm{q}_{\mathrm{u}}\right)+\mathrm{k}_{3} / \text { failure strain }+\mathrm{k}_{4}
$$

Where $\mathrm{k}_{1}=4720, \mathrm{k}_{2}=-1189, \mathrm{k}_{3}=-23.04$ and $\mathrm{k}_{4}=-16983$

$\mathrm{Mr}=\mathrm{k}_{1} * \ln (\mathrm{E})+\mathrm{k}_{2} * \ln \left(\mathrm{q}_{\mathrm{u}}\right)+\mathrm{k}_{3} /$ failure strain $+\mathrm{k}_{4} * \ln \left(\mathrm{E}_{\mathrm{f}}\right)+\mathrm{k}_{5} * \ln \left(\mathrm{q}_{\mathrm{f}}\right)+\mathrm{k}_{6} /$ yield strain $+\mathrm{k}_{7}$

where $\mathrm{k}_{1}=11267, \mathrm{k}_{2}=3217, \mathrm{k}_{3}=-76.9, \mathrm{k}_{4}=-8725, \mathrm{k}_{5}=-2587$, $\mathrm{k}_{6}=127.4, \mathrm{k}_{7}=-135134, \mathrm{E}=$ tangent elastic modulus, $\mathrm{q}_{\mathrm{u}}=$ unconfined compressive strength, $\mathrm{E}_{\mathrm{f}}=$ secant modulus at failure and $\mathrm{Mr}=$ resilient modulus at a confining stress of 2 psi and a deviator stress of 6 psi. 
As shown in Figure 39, each of the six variables was plotted with respect to resilient modulus in order to determine the relationships that best correlates to the data. Within the three types of variables, stresses, strains, and moduli, the relationships were very similar (e.g. failure stress and peak stress are both best related using a logarithmic equation). In order to reduce the redundancy of using similar variables, one from each group was chosen for equations (5.1) and (5.2) after observing the trends on the graph, and choosing the strongest. Elastic Modulus, peak stress, and failure strain were chosen.

Equation (5.1) uses a third order function of E, the natural logarithm of peak stress, and an exponential function of failure strain. The function of $\mathrm{E}$ and the exponential function of failure strain each require additional constants to be found in order to relate them to the resilient modulus. The constants for these functions $\left(a, b, c, d, k_{3}\right)$ in the equation were approximated from the best fit lines shown in Figure 39. The constants in the final equation $\left(\mathrm{k}_{1}, \mathrm{k}_{2}, \mathrm{k}_{4}, \mathrm{k}_{5}\right)$ were found using a linear regression analysis. Equation (5.1) has the highest $\mathrm{R}^{2}$ value, and the lowest standard error. However, the functions are far more complex and require more constants to be approximated empirically. Also, the third order polynomial is not preferable, it is possible that this function, despite its good correlation with the data, would not model other soils as consistently.

Equation (5.2) provides a much simpler relationship between the $\mathrm{Mr}$ and the three variables. By replacing the third order polynomial with a logarithmic function and replacing the exponential function with an inverse function, the number of required constants is reduced by five. This also increases the likelihood that the relationship will accurately model soils, as it is more logical. Statistical analysis shows that this 
relationship is not as strong as that of equation (5.1), but its simplicity makes it an attractive alternative.

Equation (5.3) uses all six variables, but uses the relationships used in Equation (5.2) to relate them to the resilient modulus. It requires seven constants, like Equation (5.2), but still maintains a more intuitive model for each variable, and the constants are more simply obtained using a regression. Equation (5.3) has a comparable squared error to equation (5.1), but has a standard error similar to equation (5.2).

The use of equation (5.2) or (5.3) is recommended. Equation (5.1) is too complex and too dependent on inconsistent data. Equation (5.2) is simple, and logical, but does not provide as accurate results as equations (5.1) and (5.3). Equation (5.3) is also logical, however it is more complicated. It is, however, more accurate than equation (5.2). FIGURE 3 shows the comparison between predicted and measured $\mathrm{Mr}$ values using equation (5.3), showing that they are in good agreement. 

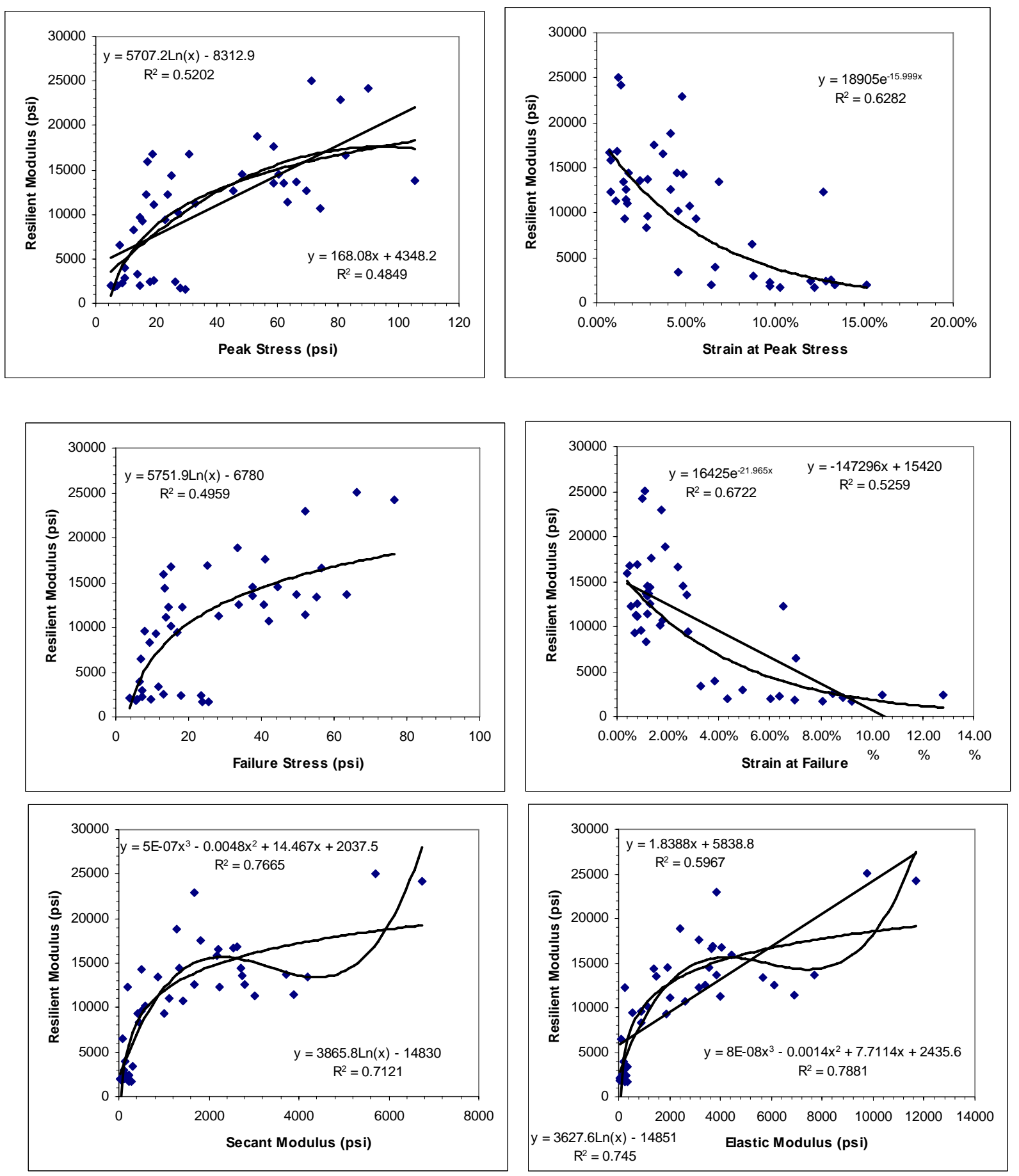

Figure 39. Correlations between $\mathrm{Mr}$ and properties obtained from unconfined compressive tests 


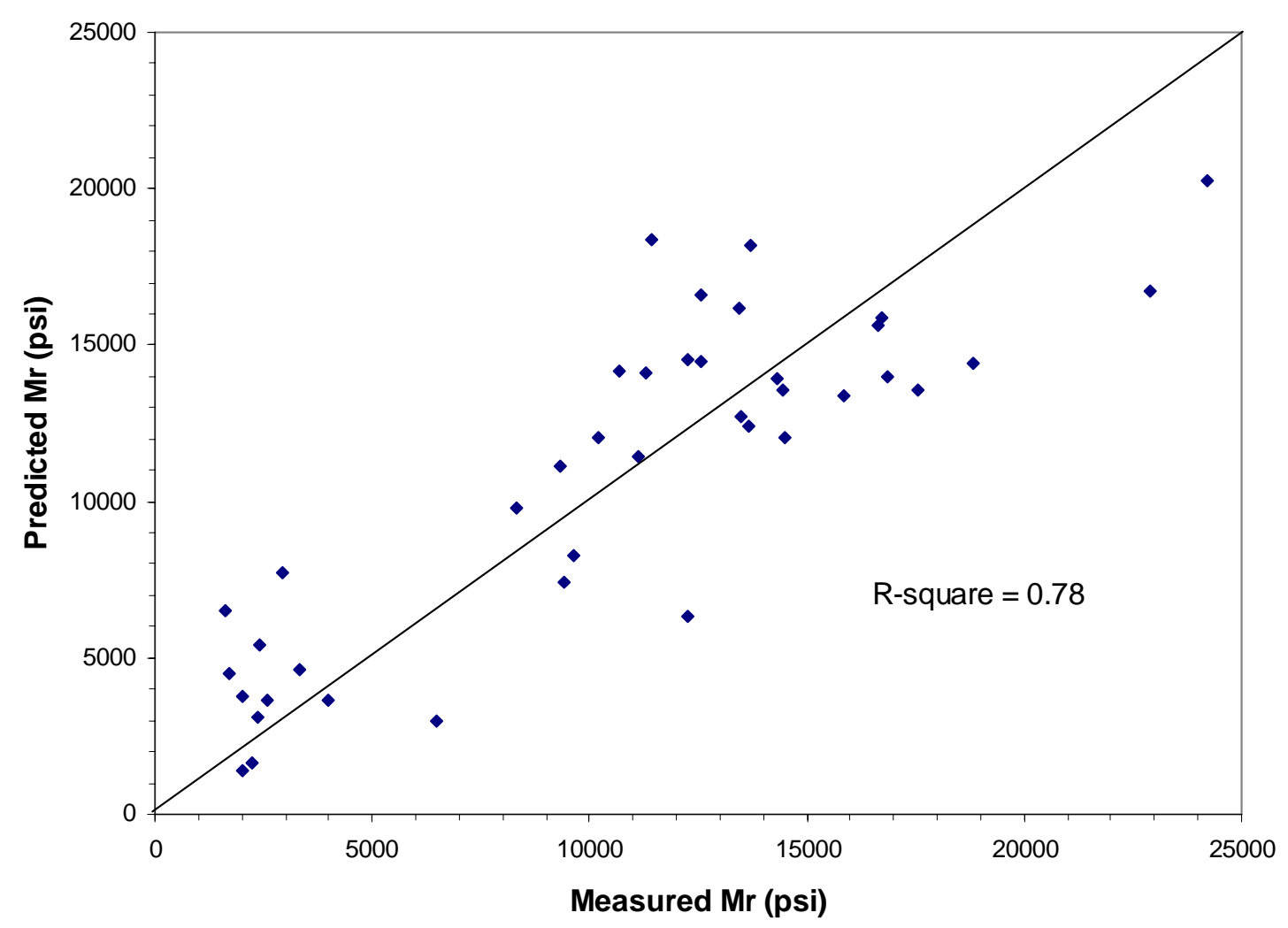

Figure 40. Comparison between predicted and measured resilient moduli using equation (5.3)

5.1.1.8. Development of a Predictive Model for the Estimation of Material Coefficients $\mathrm{k}_{1}$, $\mathrm{k}_{2}$, and $\mathrm{k}_{3}$ for Level 1 Design

In Level 1 design, non-linear coefficients $\mathrm{k}_{1}, \mathrm{k}_{2}$, and $\mathrm{k}_{3}$ are required. In order to generate a predictive model for $\mathrm{Mr}$, the fourteen compacted subgrade soils were analyzed. The following regression coefficients were obtained, shown below. Dependent variables should not be used in the statistical analysis. Note that the moisture content (MC) is the 
actual moisture content of the specimen and $\mathrm{OMC}$ is the optimum moisture content moisture content of the soil and moisture content ratio (MCR) is MC/OMC. We tested three specimens (dry of optimum, optimum, wet of optimum) for each soil. As seen previously, the resilient modulus of subgrade is significantly dependent on whether the moisture content of the subgradel is wet of optimum, optimum and dry of optimum. The predictive models were developed to better estimate the different resilient modulus depending on the relative moisture content and where the moisture contents exist (i.e., dry of optimum, OMC and wet of optimum). Although these three variables appear to be dependent variables, they need to be treated as independent variables due to the reasons above mentioned. The resilient modulus can be calculated by inserting the regression coefficients into equation (3.4):

$\log \mathrm{k}_{1}=-20.62-0.0594 \times \mathrm{OMC}+0.02689 \times \mathrm{MC}-1.1974 \times \mathrm{MCR}+0.18322 \times \mathrm{MDD}-$ $0.1689 \times$ DD $+23.5925 \times \%$ COMP $-0.4651 \times$ SATU $-0.007 \times \%$ SAND $-0.0047 \times$ \%SILT - 0.0028 x \%CLAY + 0.04087 x LL - 0.0244 x PI

$\mathrm{k}_{2}=11.9183-0.0948 \times \mathrm{OMC}+0.08235 \times \mathrm{MC}-2.19 \times \mathrm{MCR}-0.0867 \times \mathrm{MDD}+0.12727$ x DD - $14.03 \times \%$ COMP + $1.02965 \times$ SATU $-0.0302 \times \%$ SAND -0.012 x \%SILT $0.0278 \times$ x \% CLAY + 0.05654 x LL - $0.0384 \times$ PI

$\mathrm{k}_{3}=-131.46+0.30203 \times \mathrm{OMC}-0.7234 \times \mathrm{MC}+7.13189 \times \mathrm{MCR}+1.22272 \times \mathrm{MDD}-$ $1.1918 \times \mathrm{DD}+122.713 \times \%$ COMP $+3.61448 \times$ SATU $-0.0796 \times \%$ SAND $-0.0185 \times$ 
$\%$ SILT $+0.00251 \times$ \% CLAY $+0.03458 \times$ LL $+0.08488 \times$ PI $(5.4)$

where OMC (Optimum Moisture Content), MC (Moisture Content), MCR (Moisture Content Ratio $=$ Moisture Content/ Optimum Moisture Content), DD (Dry Density), \%COMP (Percent Compaction = Dry Density/ Maximum Dry Density), SATU (Degree of Saturation), \%SAND (Percent Sand in Particle Size Distribution Curve), \%SILT (Percent Silt in Particle Size Distribution Curve), \%CLAY (Percent Clay in Particle Size Distribution Curve), LL (Liquid Limit) and PI (Plasticity Index).

Measured and predicted resilient moduli using equation (3.4) are presented in Figure 41. It is shown that the predicted resilient moduli compare well with the measured ones.

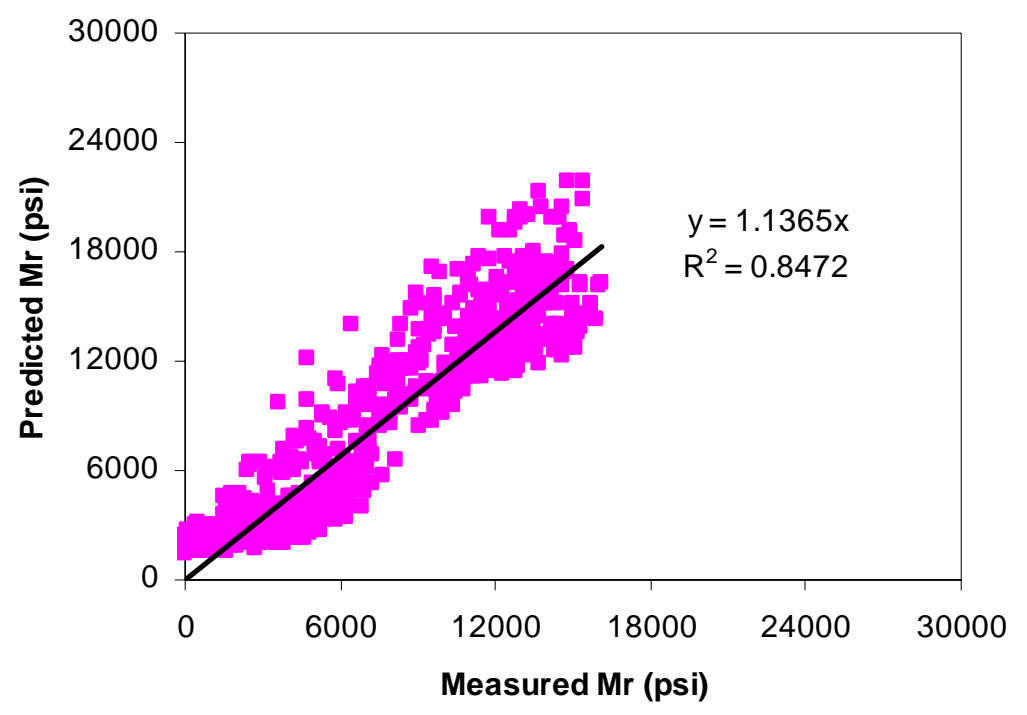


Figure 41.Comparison between predicted and measured resilient moduli using equation (5.4)

\subsubsection{Permanent Strain Behavior of Compacted Subgrades}

The standard resilient modulus test, AASHTO 307, is designed to model the behavior of soils under variable loadings similar to those they will experience in the subgrade. This test limits the number of repetitions to 2000 , in order to conserve time and energy. This is far lower than the amount soil would experience over the design period. With the low number of repetitions used, this method is not capable of describing changes in resilient behavior of the soil that may occur due to long term repeated loading, such as those experienced by subgrades. In order to model the impact of high traffic volumes on subgrades, a long term resilient modulus test is necessary. For this experiment, the number of cycles was increased from 2,000 to 20,000 . In order to determine the maximum change in resilient modulus, and to observe the greatest amount of permanent deformation, the maximum deviator stress (10 psi) and minimum confining stress (2 psi) used in the standard test were used throughout the entirety of the long term test. This will result in a conservative estimate, and magnify the potential deterioration of the soil properties shown in the standard test. Figures 42 and 43 show the changes in long-term resilient modulus. After about 5,000 repetitions, the resilient modulus shows a constant value except for the wet Orchard clay, which experienced the excessive permanent deformation and failed in the initial loading.

Figure 44 shows the long term permanent strain behavior for SR 165 Soil. Compared to wet soil, soils compacted at OMC and dry of optimum exhibit a negligible amount of permanent strain. All soils tend to plateau when placed under a consistent stress level, 
often after approximately 500 repetitions. This supports the number of the repetitions of the conditioning stage used for the test, however it is likely that soil will experience the different plateau under a different stress condition. It was desired to determine a relationship between the coefficients of the logarithmic regression and some soil properties. Due to the small data sample size, a predictive model has not been developed and needs to be further investigated.

While the permanent deformation obtained from the long term test closely follows a logarithmic function, due to the variation of loadings used in the standard test, the permanent strain curve can not be modeled by a continuous function, as seen in Figure 45. The standard permanent strain curve shows that the amount of permanent strain decreases at the point in the sequence when the confining pressure is decreased. The cause of this phenomenon may be related to a temporary relaxation of an axial load that is continuously present during the test, despite attempts to completely unload the sample during each cycle, or the suction of the air pressure removal system. The permanent deformation of the standard resilient modulus test follows a logical and expected pattern within each individual confining pressure grouping. The slope of the curve increases with increasing deviator stress. However, the slope for each deviator stress decreases as the confining pressure is decreased. This can be partially attributed to the order of the sequences, as the sample is more highly compacted during the stages using smaller confining pressures, causing the sample to be more resistant to deformation. 


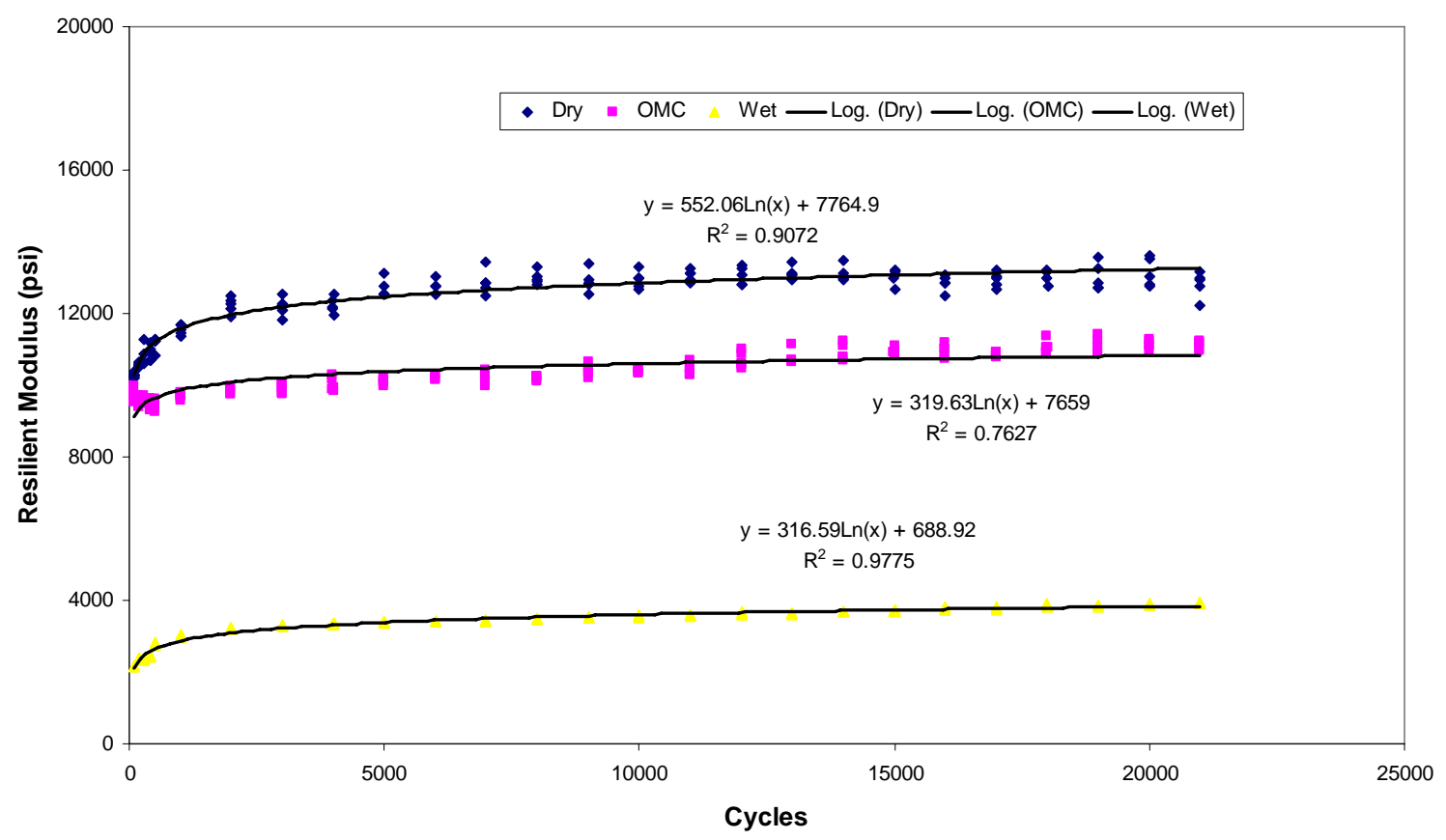

Figure 42. Long-term resilient modulus testing for SR165

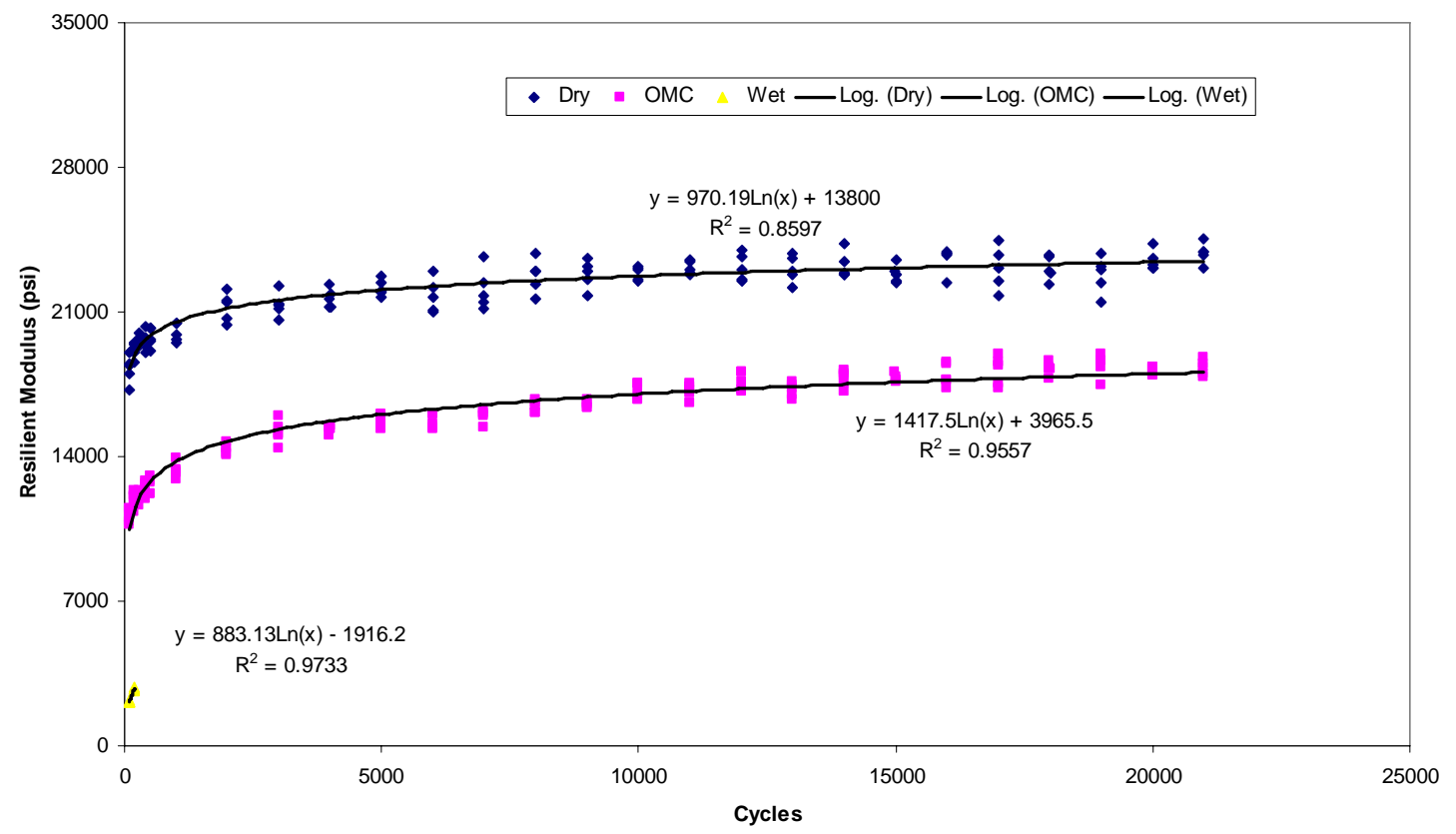

Figure 43. Long-term resilient modulus testing for Orchard clay 


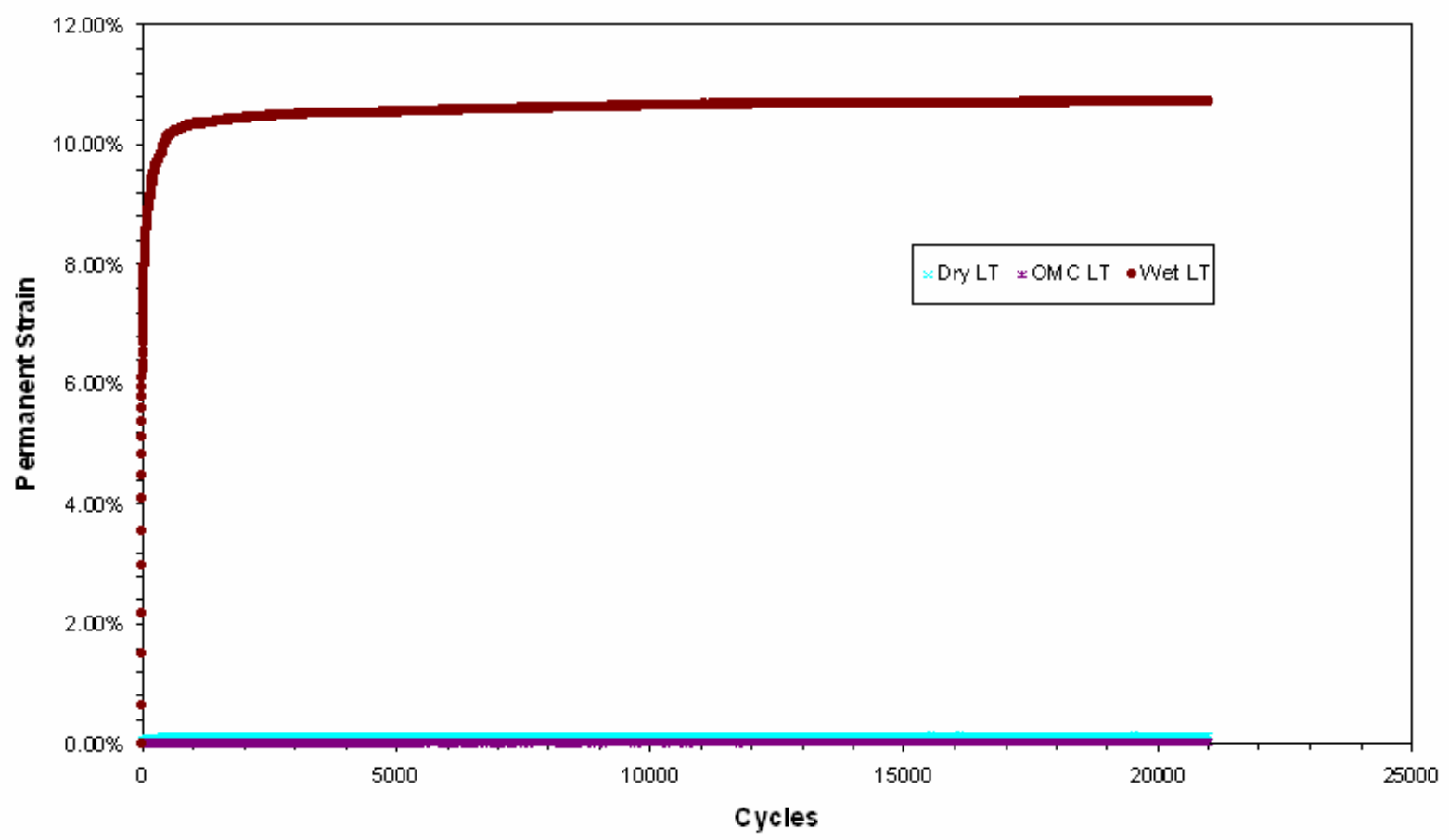

Figure 44. Permanent Strain of SR 165 Soil (long term Mr test)

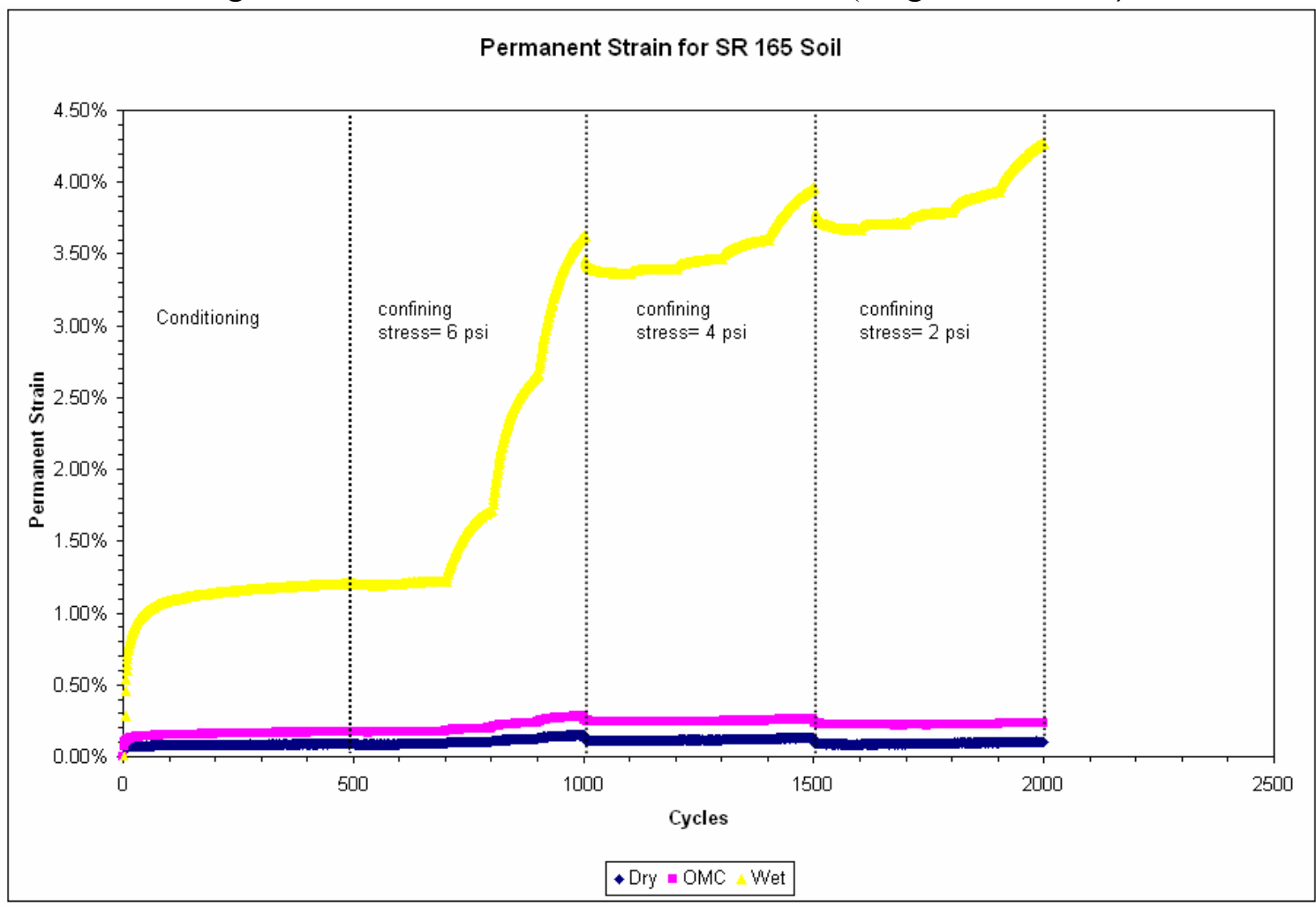


Figure 45. Permanent strain of SR 165 Soil (standard test)

\subsubsection{Results of Resilient Modulus Test on Cohesionless Subgrade Soils}

Cohesionless subgrade samples were compacted at optimum moisture contents with standard Proctor energy. The results of resilient modulus tests for five soils tested are presented in Figures 46-50. Note that the effect of moisture contents of cohesionless subgrade soils on resilient modulus is generally negligible due to high permeability of these soils (Lee et al. 1993). The resilient moduli of cohesionless subgrade soils shown in Figures 46-50 are slightly higher than those observed in cohesive subgrade soils although they are poorly graded. As cohesive subgrade soils are more predominant in Indiana than cohesionless subgrade soils, further investigation has not been conducted. 


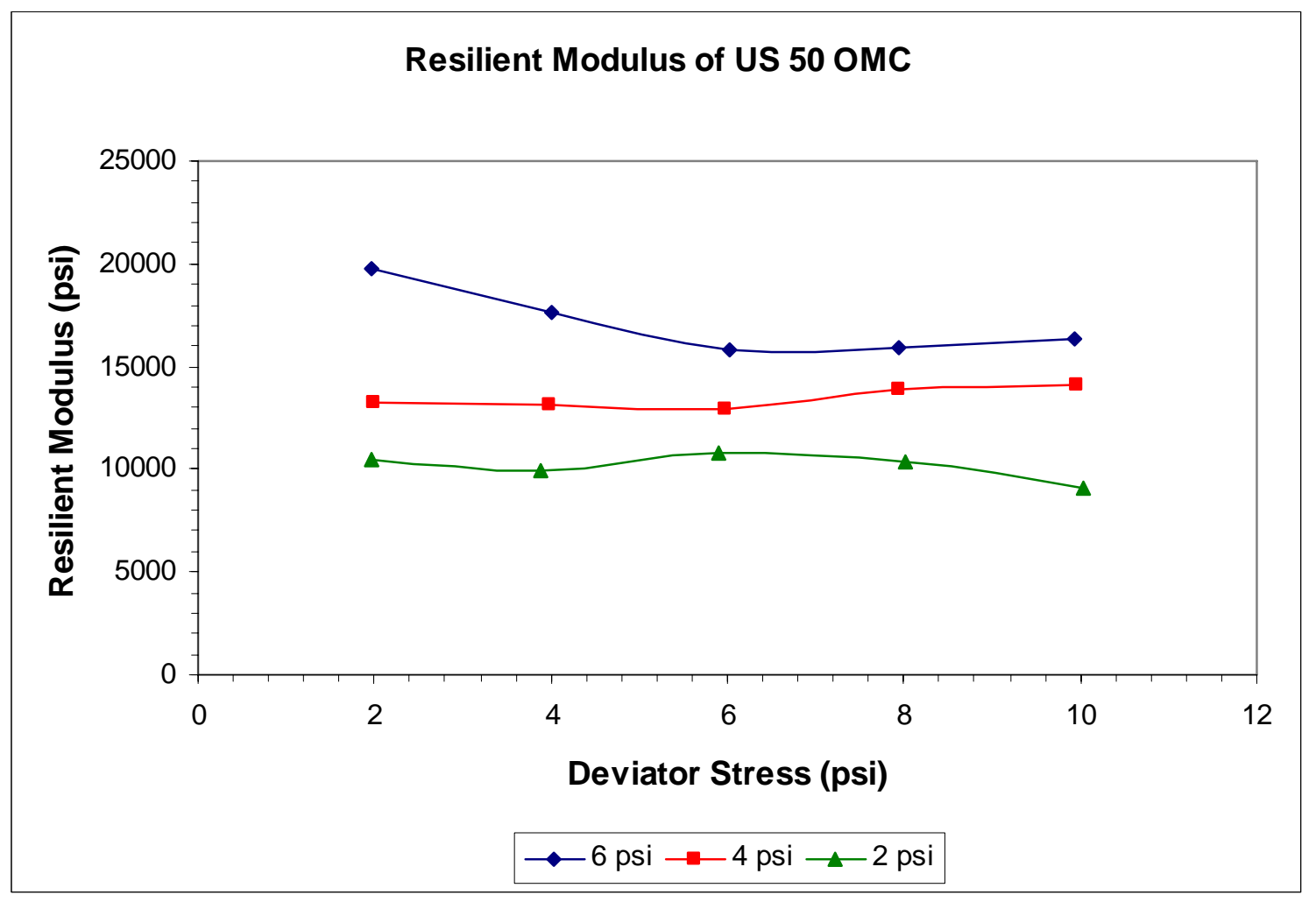

Figure 46. Resilient modulus for US 50

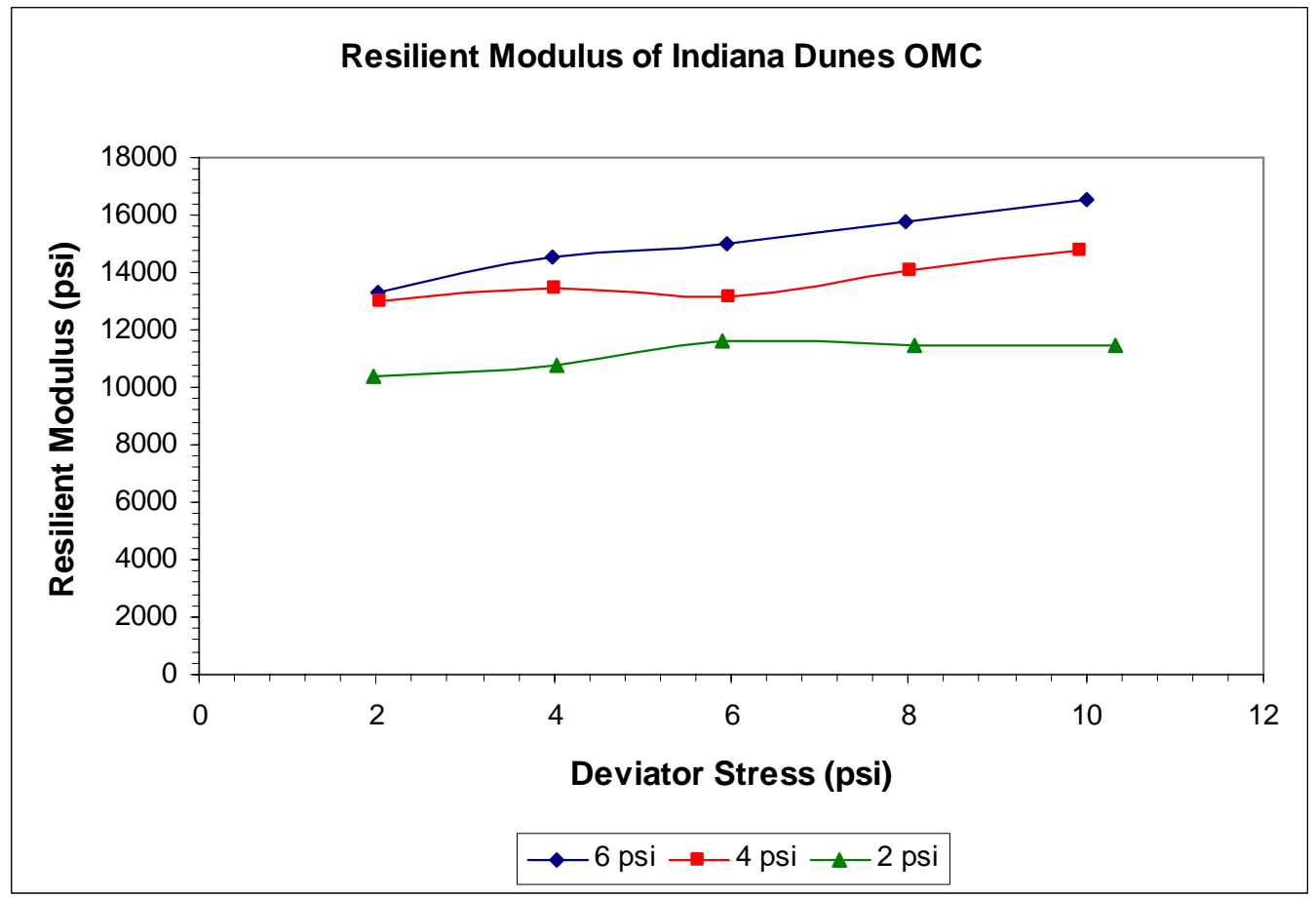

Figure 47. Resilient modulus for Indiana dunes 


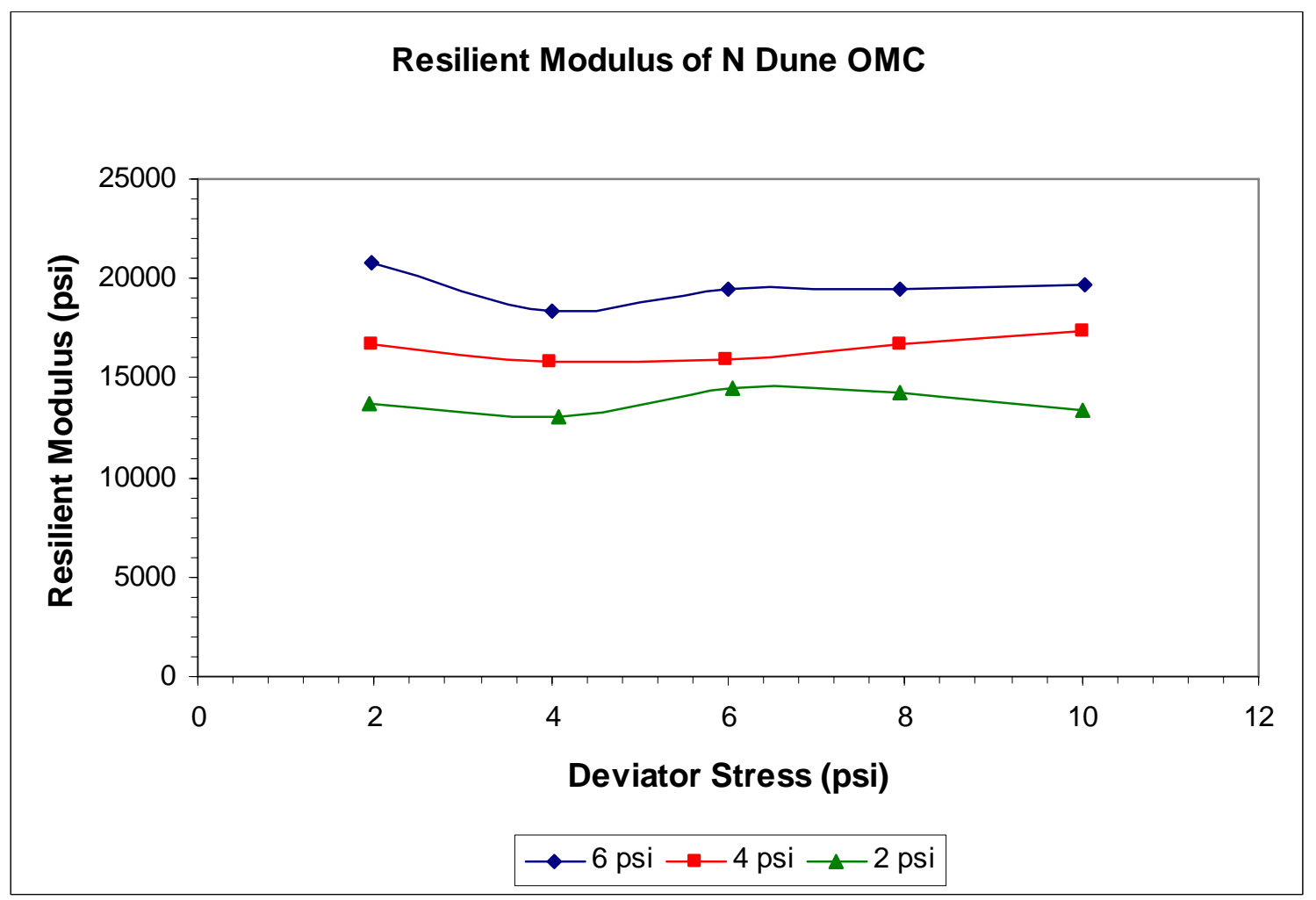

Figure 48. Resilient modulus for N Dune

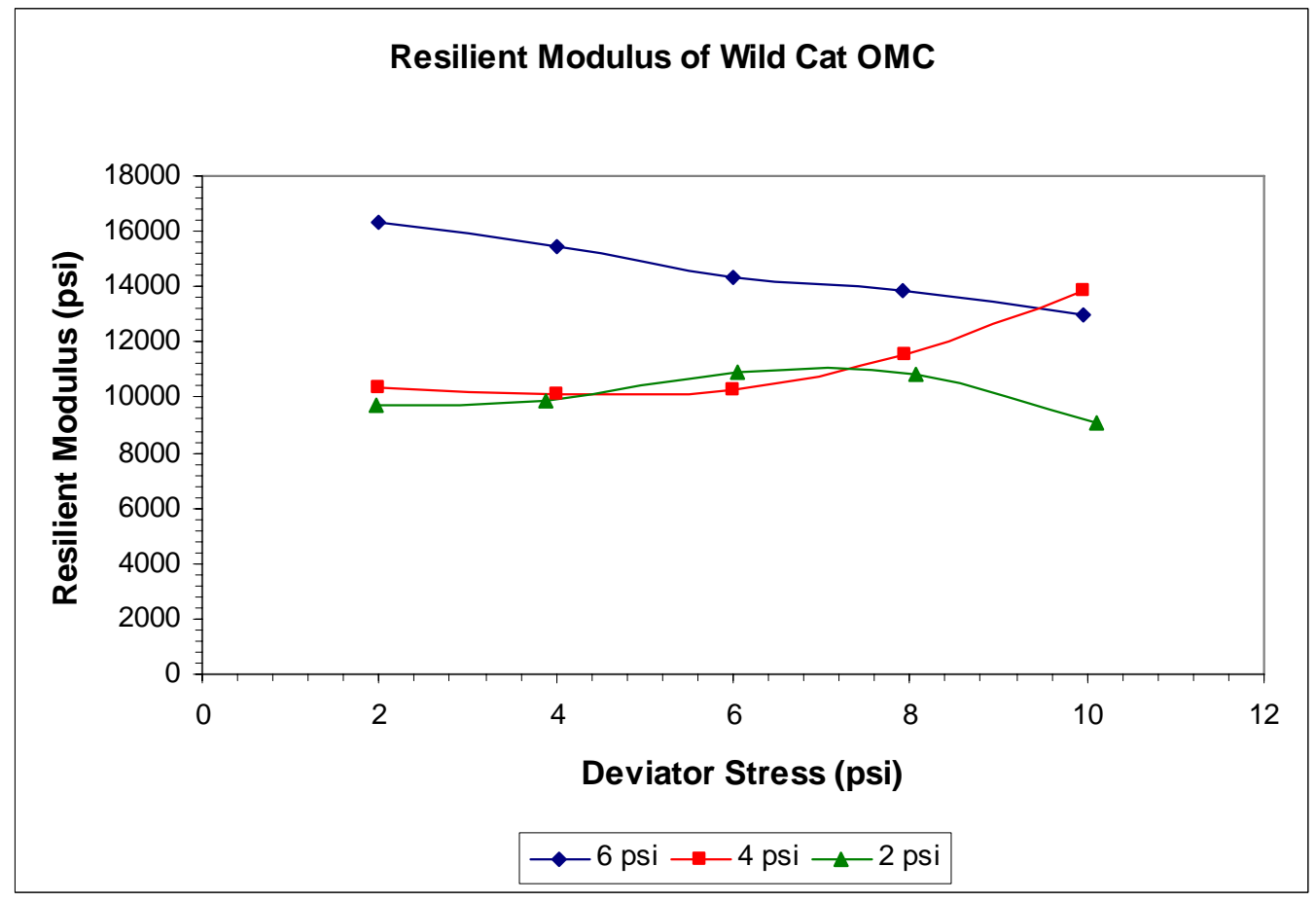

Figure 49. Resilient modulus for Wild Cat 


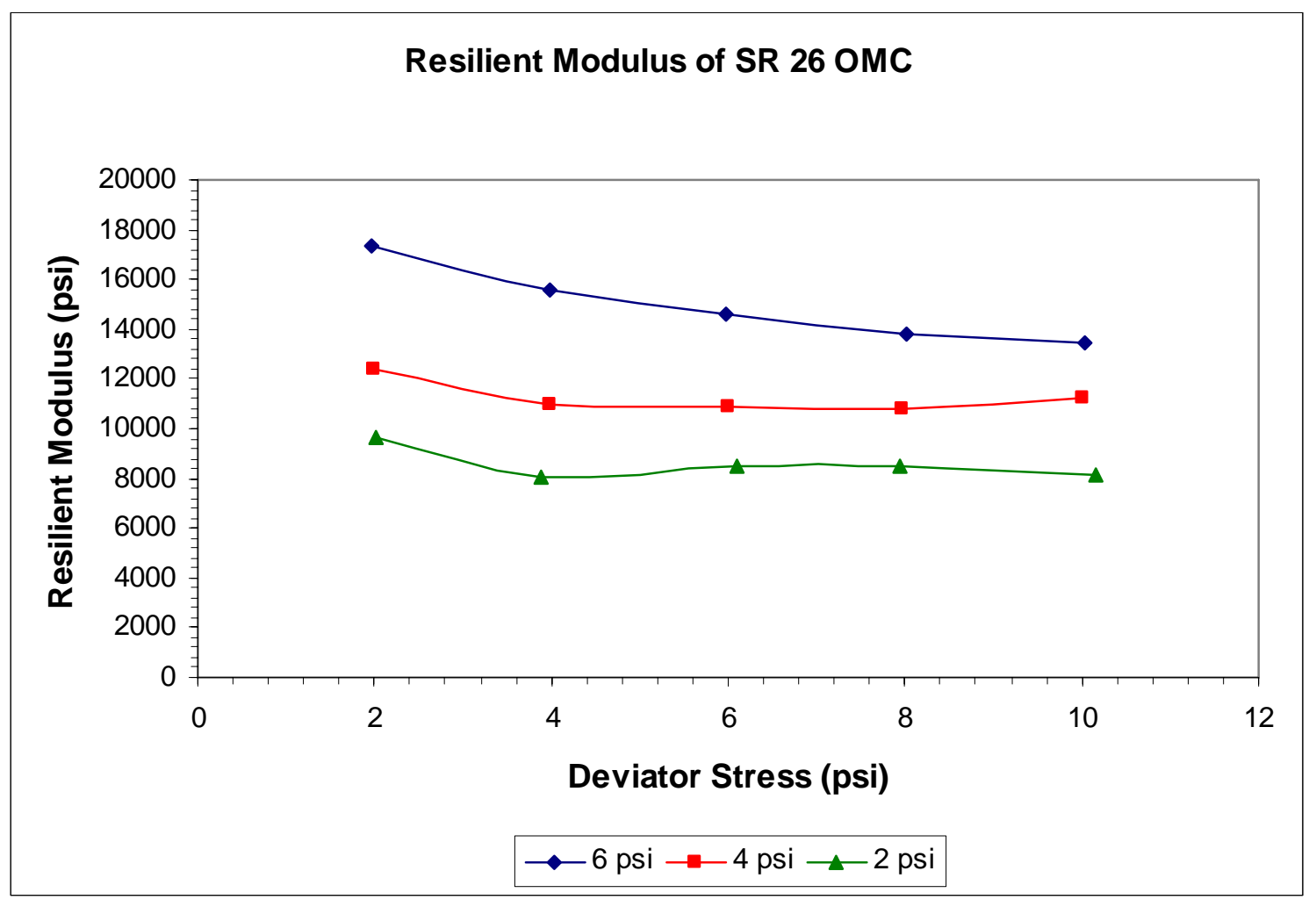

Figure 50. Resilient modulus for SR 26

\subsection{Preliminary Dynamic Cone Penetrometer (DCP) Test}

\subsubsection{Regression Analysis}

As stated earlier, it should be noted that DCPT tests were done for limited samples. An attempt was made to correlate the penetration index obtained from the DCPT to the resilient modulus at a confining stress of 2 psi and a deviator stress of 6 psi. Figure 51 presents the relationship between the penetration index vs. the resilient modulus. No obvious trend was visible from this graph. A $2^{\text {nd }}$ order polynomial better fits the data, however it is not a logical model for the behavior normally seen with these two properties. Penetration Index should show an inverse trend with the resilient modulus. A linear 
regression is also shown on the graph below. There is no significant linear relationship between these variables.

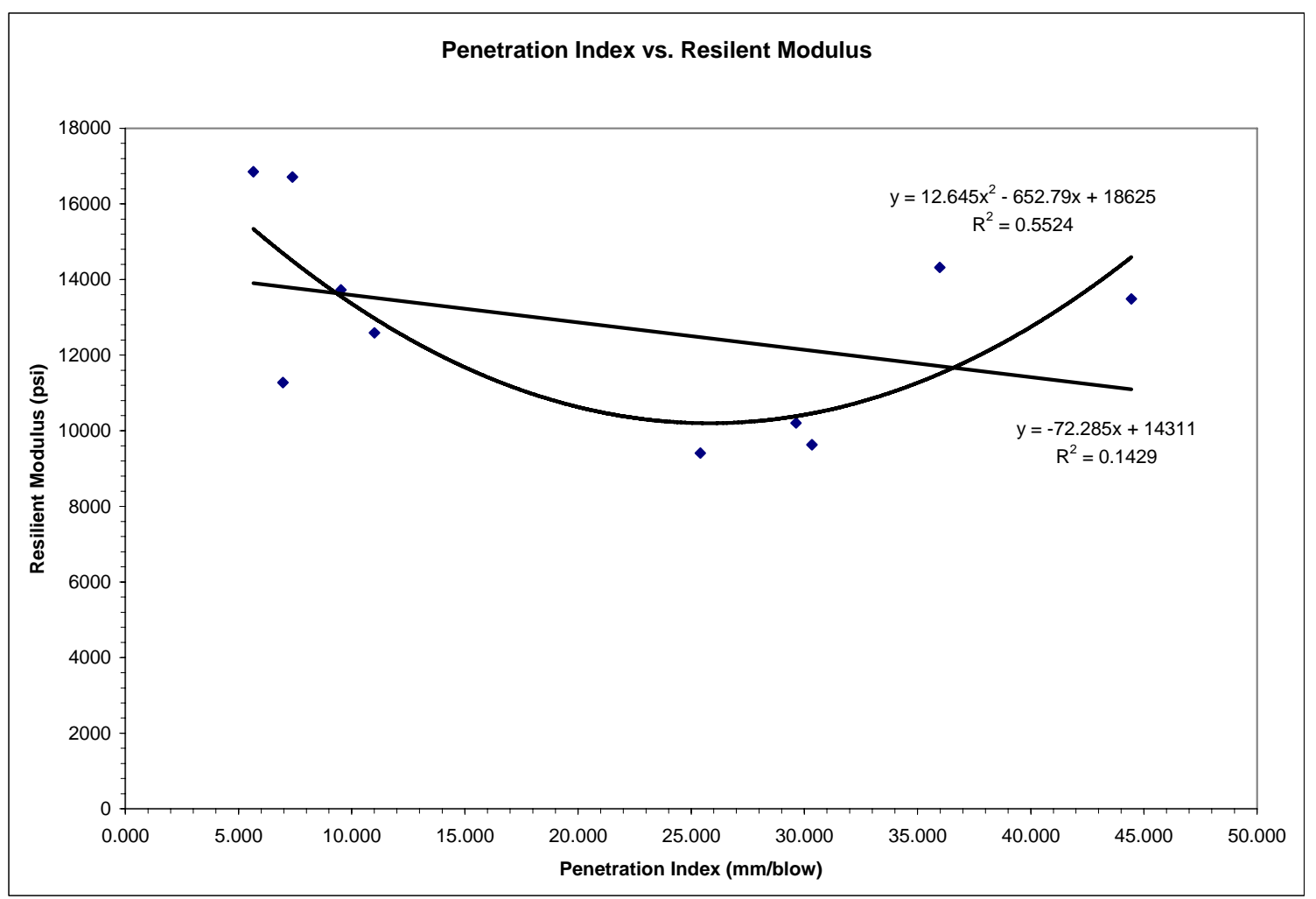

Figure 51. Penetration Index vs. resilient modulus

The penetration index was then altered to provide a linear relationship. As shown in Figures 52 and 53, the inverse and the square of the inverse were each plotted vs. the resilient modulus. These regressions provided a reasonable model for the data; however the accuracy of the model is very low. The relationship using the square of the inverse of the penetration index provides the best results, with the highest $\mathrm{R}^{2}$ value, making it the preferred regression. 


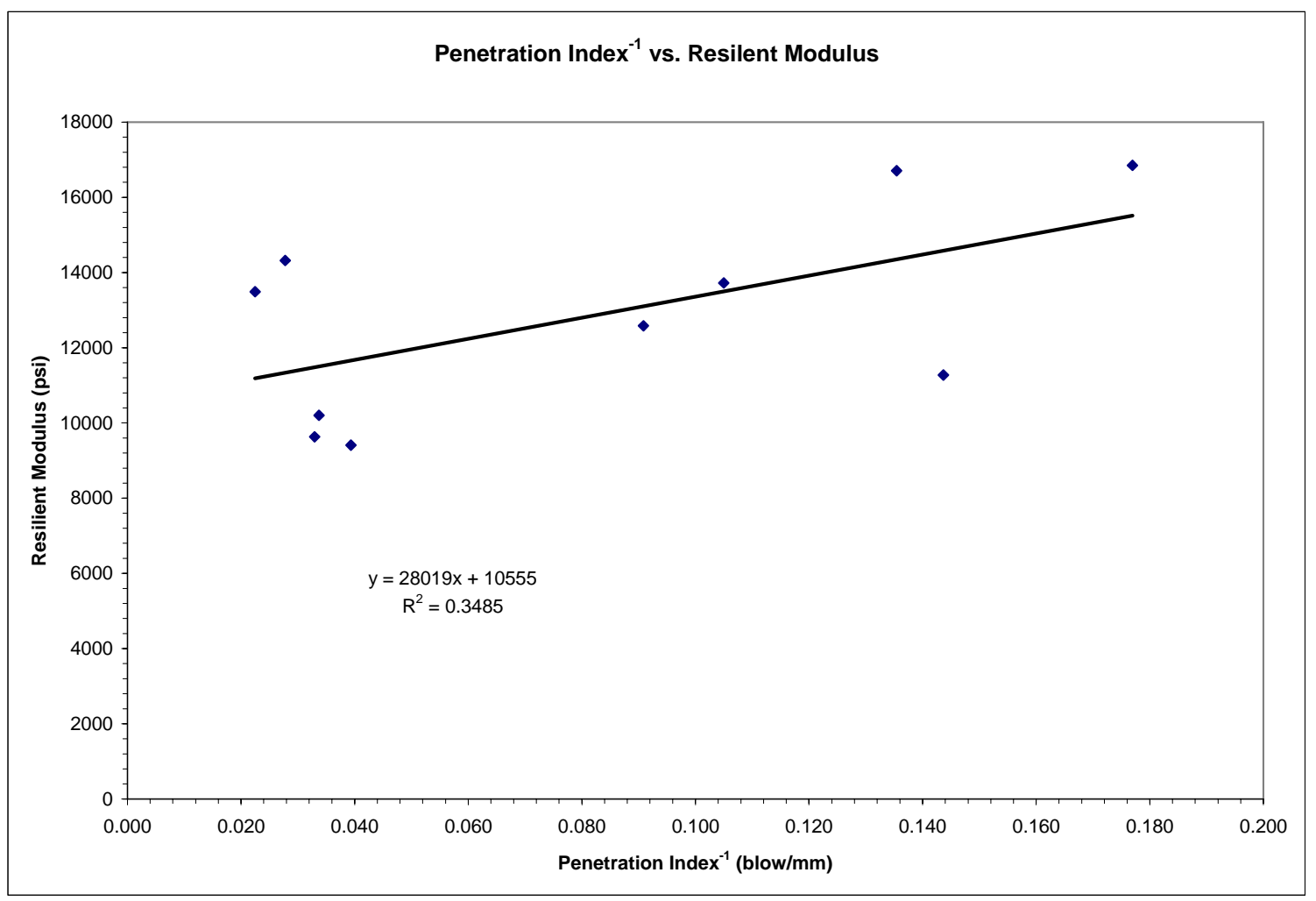

Figure 52. Penetration Index ${ }^{-1}$ vs. resilient modulus 


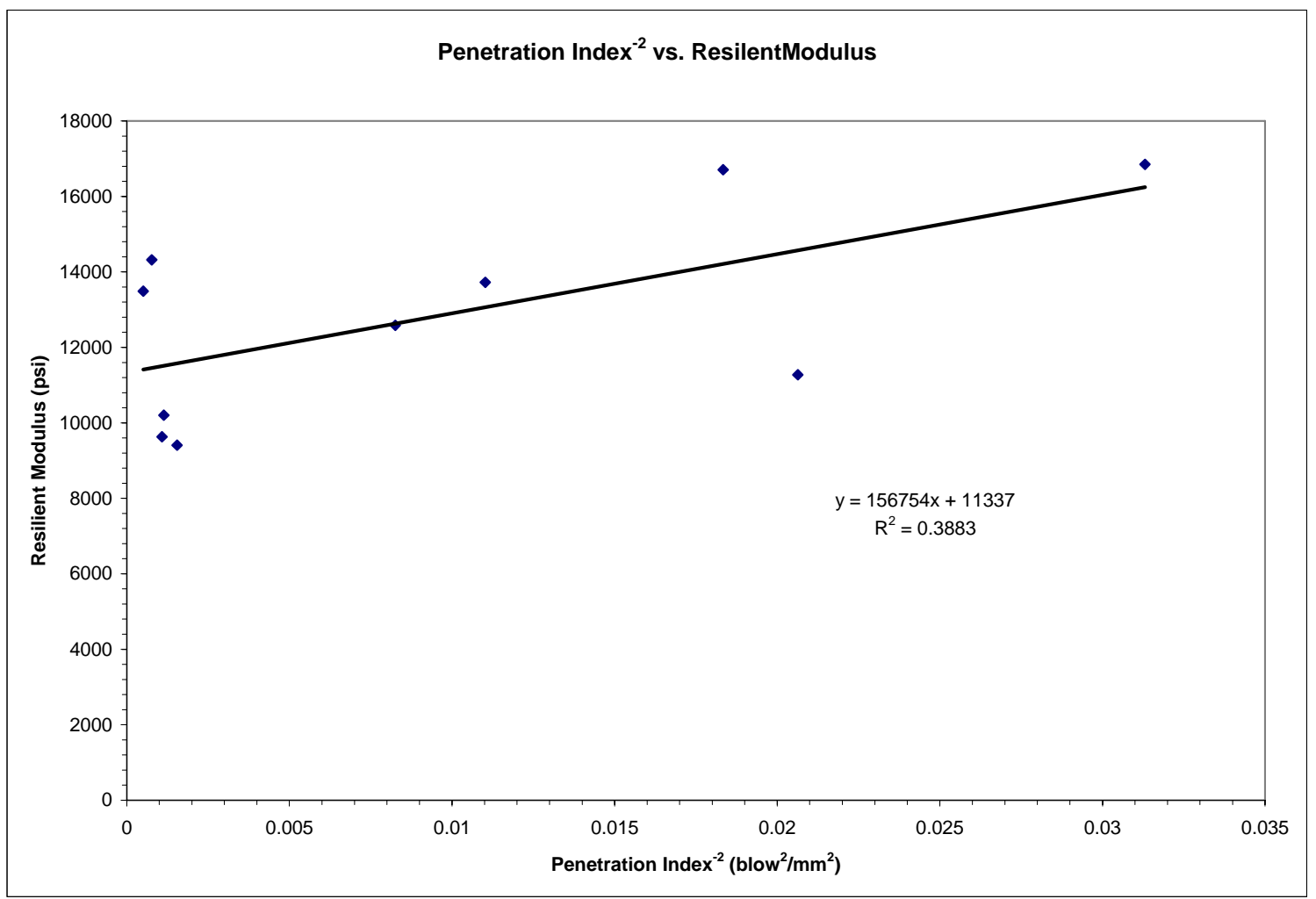

Figure 53. Penetration Index ${ }^{-2}$ vs. resilient modulus

Adding soil properties to the model in order to provide a better relationship is difficult, considering the small amount of available data points. In order to avoid simply solving a system of equations, additional variables must be kept to a minimum. This has not yielded a desirable result at this time. In summary, further investigation is needed to find a relationship between DCPT blow count and the resilient modulus. 


\section{CHAPTER 6. RESILIENT BEHVAIOR OF LIME AND LKD TREATED SUBGRADES}

\section{$\underline{6.1 . \text { Introduction }}$}

This chapter summarizes the resilient modulus tests of soils treated with Lime Kiln Dust (LKD) that were previously conducted for an INDOT implementation project. This chapter is mainly based on the paper presented at TRB annual meeting (Kim and Zia 2004).

When a given soil is too weak for a certain specification, one way to improve the soil so that it satisfies certain engineering properties is to blend it with other natural materials (Hausmann 1990). Over the past decades, lime treatment has been extensively used for road construction purposes. Treatment results in increased bearing capacity of weak subgrades, allowing a reduction in the thickness of the base layer (Bergado et al. 1996, Hausmann 1990). The asphalt or base layer would be thicker if the subgrade had a very low strength in a pavement structure. The thickness of the asphalt or base layer can be reduced if the subgrade soil is appropriately treated.

The Indiana Department of Transportation (INDOT) has increased the pace of improving the current highway network in the past several years. This desire to improve and expand existing roads is attributed to the importance of mobility for economic growth, aging of the existing roadway network, etc. (INDOT 2002). To some degree, chemical-soil modification has become a viable, economic, and minimally disruptive alternative to in-place modification and/or stabilization. Chemicals such as lime, cement, 
and flyash are either used to stabilize (increased strength accounted for in pavement design) or modify (workable to meet compaction) natural soils that are not appropriate for immediate subgrade construction due to high water contents and low strengths (INDOT 2002). INDOT has recently made considerable efforts to achieve effective roadbed improvement and revised subgrade specifications recently to allow contactors to choose appropriate subgrade construction methods based on soil types, economy, traffic limitations, and environmental considerations.

In subgrade improvement using lime, quicklime $(\mathrm{CaO})$ or hydrated lime $\left(\mathrm{Ca}(\mathrm{OH})_{2}\right)$ is generally used to facilitate subgrade construction in INDOT. Treated soils with lime exhibit improved plasticity, workability, and volume change characteristics. Quicklime (calcium oxide) is formed as a coarse-grained powder. Lime is primarily used for the treatment of fine grained soils (i.e. such as A-4, A-6 and A-7 following the AASHTO classfication), especially clayey soils. The short-term reactions of the soil-lime mixture in the presence of water result in hydration and flocculation (ion exchange) due to the clay minerals. In a favorable environment such as temperature, the lime is a source of free calcium. The long-term reactions are related to cementation. Quicklime reacts with water very quickly in the soil. This drying action is particularly beneficial in the treatment of moist clays. When lime is mixed with clay, sodium and other cations absorbed to the clay mineral surfaces are exchanged with calcium. This cation exchange affects the way the structural components of the clay minerals are linked together. Lime causes clay to coagulate, aggregate, or flocculate. The plasticity of clay is reduced, making it more workable and potentially increasing its stiffness and strength. Cementation is the main contributor to the strength of the stabilized soil. The higher the surface area of the soil, 
the more effective is this process. Note that lime is not suitable for improving clean sands or gravels. Practical lime admixtures range from 2 to $8 \%$. Thus, lime has some advantages in clay subgrade stabilization, which increases strength of clay soils, and reduces shrinkage and swelling.

Although LKD has recently been permitted to be used in soil modification by INDOT, unlike lime, it has not been approved for subgrade stabilization due to limited experience with it. Also, the increased strength of LKD treated soils is not considered in design and the material parameters of the original natural soils are applied in design practice for a conservative design. Therefore, the objective of this study was to evaluate the mechanical benefits of the LKD for use in soil modification and stabilization under similar environmental conditions.

\subsection{Engineering Properties of Soils Treated with LKD and LIME}

LKD (Lime Kiln Dust) is a by-product collected in dust collection systems from the manufacture of lime. LKD is mainly composed of calcium oxide, but contains varying amounts of calcium sulphate (depending on the sulfur level of the fuel), fly ash, and limestone (Francis 2003). Lime is manufactured from limestone $\left(\mathrm{CaCO}_{3}\right)$ by heating it to a high temperature (about $\left.2000^{\circ} \mathrm{F}\right)$ to separate and drive off the carbon dioxide $\left(\mathrm{CO}_{2}\right)$.

Although extensive research on lime and Cement Kiln Dust (CKD) has been done, mechanical evaluation studies on LKD are quite limited (Parson 1995, Ciesielski and Collins 1995, Henkel 1997, Daita et al. 2005). Due to the limited data available for LKD, it would be helpful to study the characteristics of lime-treated soils. The behavior of lime treated soils is primarily dependent on soil types, lime contents, temperature, curing time (TRB 1987). 
Moisture-density relationships of lime treated soils change constantly. Maximum dry density and Optimum Moisture Content (OMC) are two important parameters used to characterize compaction. Maximum dry density decreases as optimum moisture increases when a lime-soil mixture is allowed to cure (TRB 1987, Daita et al. 2005). It is important to realize that this density reduction is not due to poor compaction but rather to the fact that the material is changing. Based on the study done by Heckel (1997), LKD also reduces the maximum dry density and increases the $\mathrm{OMC}$, which is similarly observed in lime-soil mixtures.

Improvement of the uncured unconfined compression strength, CBR, plasticity of the soil-lime mixture was observed by many studies (Thompson 1966, Thompson 1969, Neubauer and Thompson 1972). This immediate improvement helps expedite construction when soft, highly plastic, cohesive soils create mobility problems for wheeled equipments (TRB 1987). According to Heckel (1987), it is also noted that LKD creates an increase in unconfined strength. One important factor of the lime-treated soils is hardening resulting from curing with time. It should be noted that considerable improvement of strength continues over 10 years in some cases (TRB 1987). Soil-lime mixtures lead to substantial increases in cohesion resulting from cementation, but not in the internal angle of friction.

\subsection{Experimental Program}

6.2.1. LKD and Hydrated Lime used in the study

According to INDOT specification, hydrated lime or quick lime and LKD can be used in the range of $4 \pm 0.5 \%$ and $5 \pm 1 \%$ by weight of soil for modification, respectively. 
For subgrade modification, a $\mathrm{pH}$ test is generally performed to determine the amount of lime or LKD. In our study, $5 \%$ LKD and $5 \%$ hydrated lime contents were used. The LKD contained $60 \%$ of calcium and magnesium oxides and the hydrated lime contained $90 \%$ of calcium and magnesium hydroxides/ oxides.

\subsubsection{Soils used in the study}

Five typical fine-grained soils in Indiana which are appropriate for lime treatment were collected from I-94, US-41, SR-37, and SR-46. For distinction, each soil is designated as, for example, A-4 (US-41) indicating an A-4 soil collected from US-41. Figure 54 shows the grain size distribution and Table 5 represents the index test results for soils used in the experimental program. The soils are classified as A-4, A-6, and A-76 under the AASHTO classification; ML, CL and CH under the USCS classification; and as Si, Si-LO, CL-LO, and CL under INDOT textural Soil Classification (Figure 55). Gradation and Atterberg limits tests were performed following AASHTO T-89 and AASHTO T-90. Standard Proctor tests were performed according to AASHTO T-99.

Figure 56 shows the compaction curves for determining maximum dry density and optimum moisture content. As seen in Figure 56, the maximum dry density and optimum moisture content are in the range of $98-115$ pcf $\left(15.4-18 \mathrm{kN} / \mathrm{m}^{3}\right)$ and $12-23 \%$, respectively. In our study, three samples of each soil (i.e. untreated, $5 \%$ lime treated and $5 \%$ Lime Kiln Dust (LKD)) were prepared. In addition, untreated and treated soils were prepared with $90 \%, 95 \%$ (compacted at dry of optimum) and $100 \%$ compaction to assess the unconfined compression strength, CBR, swell potential and resilient modulus. 
As mentioned previously, the dry density and water content changes with time due to the curing. It should be noted that curing effect with time was not considered in our study because the focus was specifically on comparing the short-term engineering properties of LKD-soil mixture with those of lime-soil mixture rather than on evaluating curing properties. All the tests (except for the CBR test) were performed 5 hours after mixing lime or LKD with the soils as consistent as possible. At 5 hours the curing effect would be negligible as all the tests would take less than two hours (e.g. resilient modulus testing).

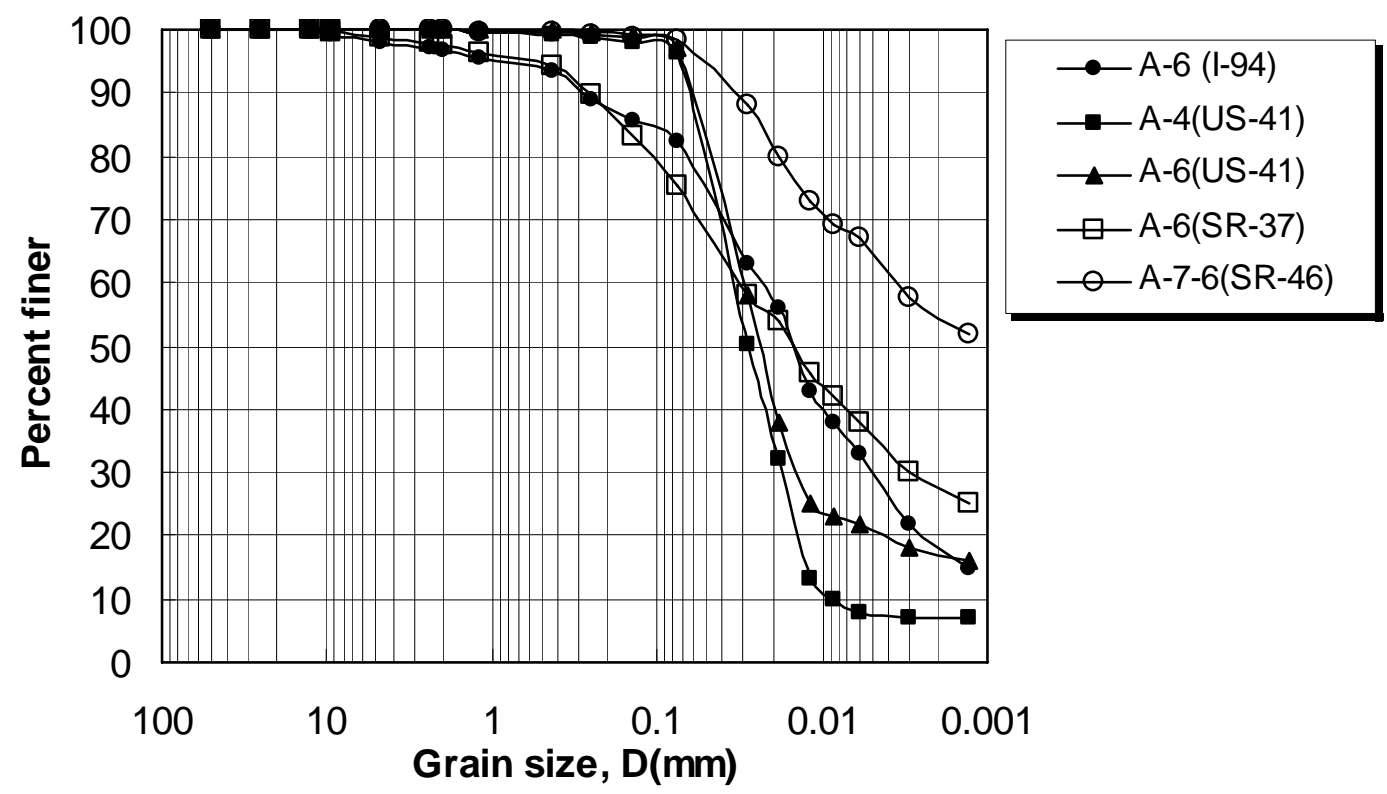

Figure 54. Particle size distribution for soils used 
Table 5. Index properties

\begin{tabular}{|c|c|c|c|c|c|c|c|}
\hline $\begin{array}{l}\text { Soil } \\
\text { Classification }\end{array}$ & $\begin{array}{l}\% \\
\text { Gravel }\end{array}$ & $\%$ Sand & $\begin{array}{l}\% \\
\text { Silt }\end{array}$ & $\begin{array}{l}\% \\
\text { clay }\end{array}$ & $\begin{array}{l}\text { Liquid } \\
\text { Limit }\end{array}$ & $\begin{array}{l}\text { Plastic } \\
\text { Limit }\end{array}$ & $\begin{array}{l}\text { Plasticity } \\
\text { Index }\end{array}$ \\
\hline A-6 (I-94) & 3.4 & 14.1 & 64.4 & 18.1 & 30 & 18 & 12 \\
\hline A-4 (US-41) & 0 & 3.6 & 90.2 & 6.2 & 30 & 21 & 9 \\
\hline A-6 (US-41) & 0 & 2.8 & 80.2 & 17 & 37 & 22 & 15 \\
\hline A-6 (SR-37) & 1.2 & 23.5 & 48 & 27.3 & 40 & 16 & 24 \\
\hline A-7-6 (SR-46) & 0 & 1.7 & 44.5 & 53.8 & 79 & 25 & 54 \\
\hline
\end{tabular}

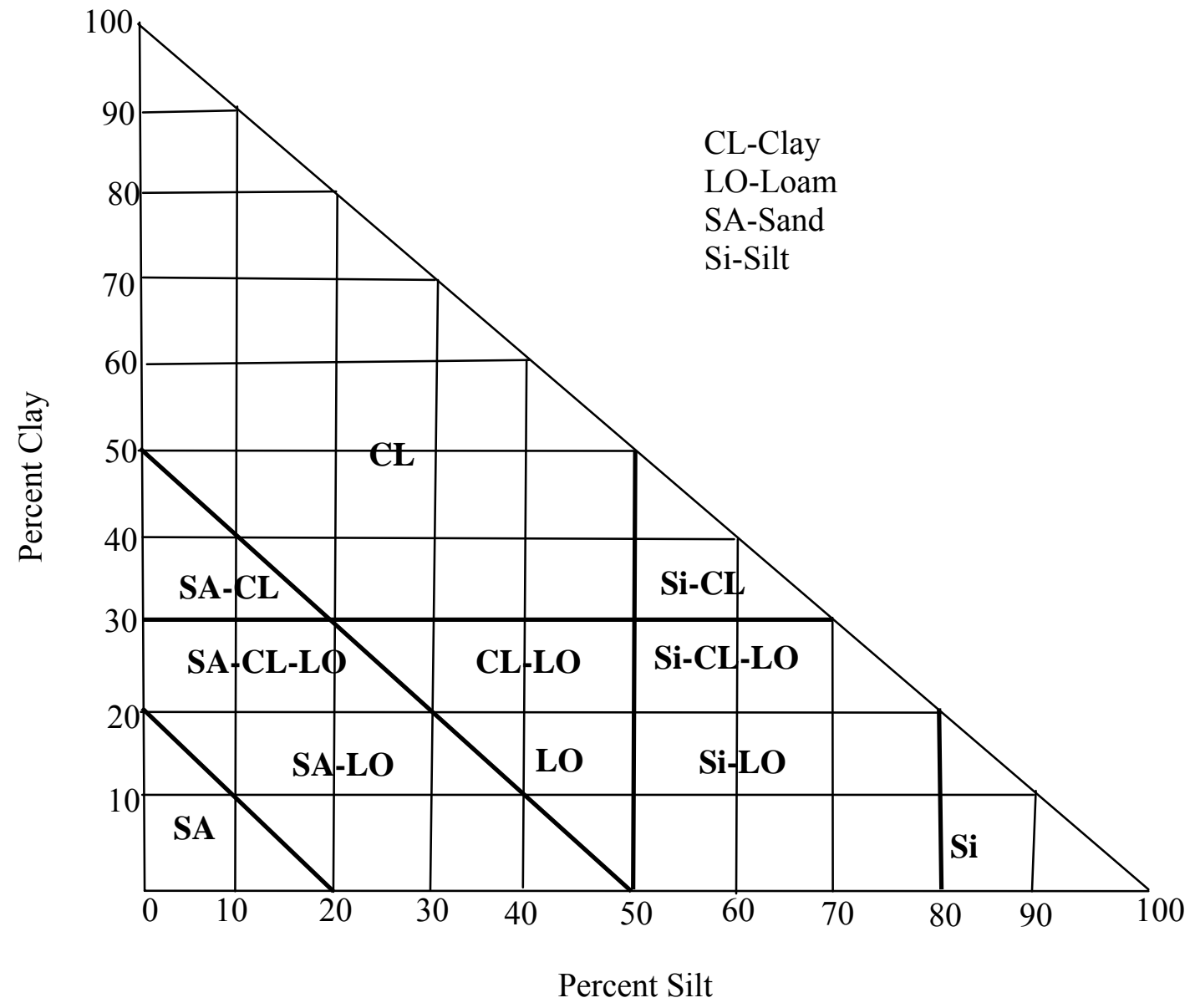

Figure 55. INDOT textural soil classification 


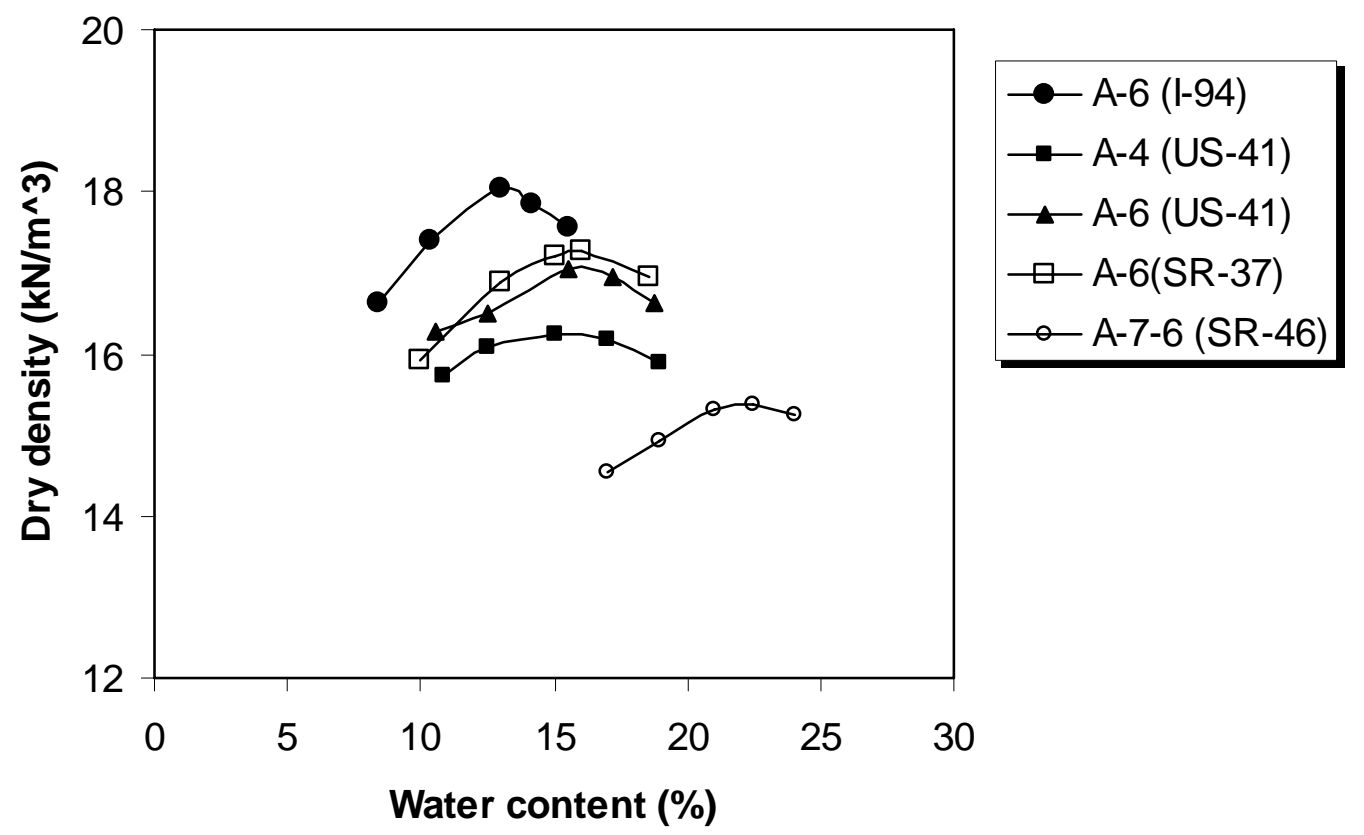

Figure 56. Compaction curves for soils used

\subsection{Discussion of the Test Results}

\subsubsection{Unconfined Compression Strength}

Unconfined compression strength is an important parameter by which INDOT evaluates the mechanical characteristics of a subgrade (Zia and Fox 2000). Unconfined compression tests were performed to asses how much the strength of soils treated with 5 $\%$ LKD and $5 \%$ lime would be increased. Figures 57 and 58 illustrate the comparison of unconfined strengths between untreated and treated soils with LKD and lime for A-4 (US-41) and A-6 (SR-37). As can be seen in the figures, the unconfined strength 
increases considerably for both $5 \%$ LKD and $5 \%$ lime treated soils. For A-4 (US-41) and A-6 (SR-37) soils, almost the same amount of increase in unconfined strength for both $5 \%$ LKD and $5 \%$ lime occurs and ranges from $60 \%$ to $400 \%$. All other soils not shown in this paper also showed a similar trend of increase in the unconfined strengths. This indicates that LKD is comparable to lime and can be used as an alternative to lime. Figures 57 and 58 also show that the higher the percentage of compaction, the higher the unconfined strength, indicating the importance of compaction of the subgrade, regardless of the materials.

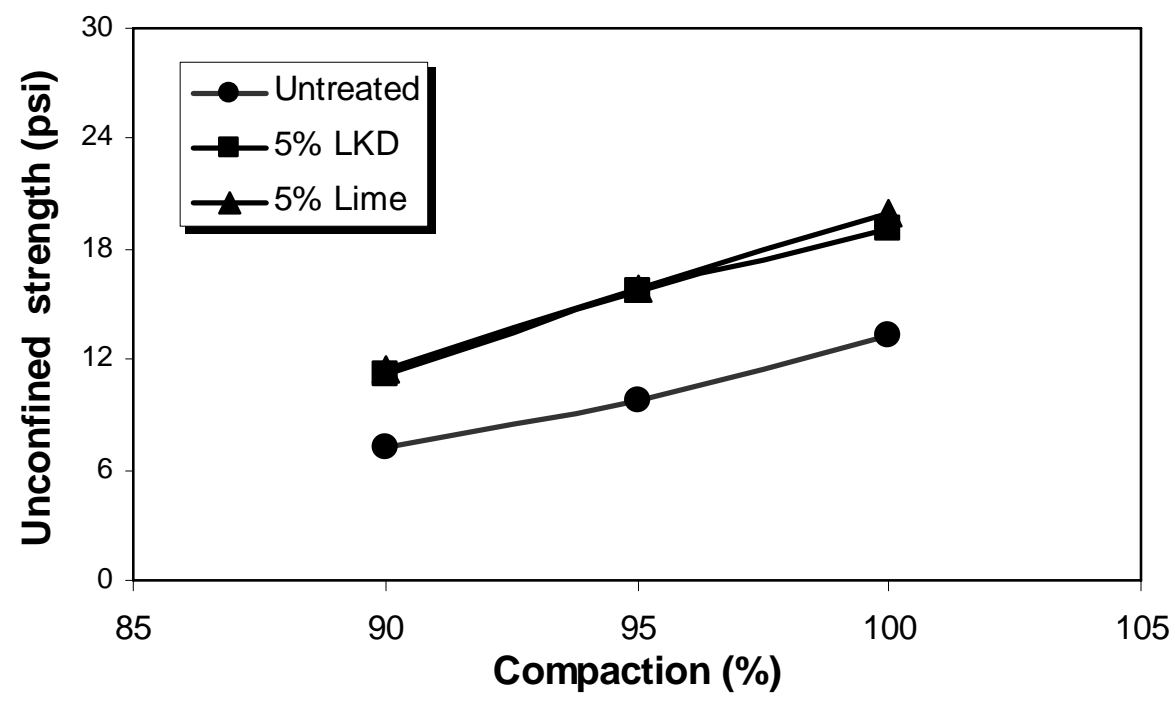

Figure 57. Unconfined strength vs. \% compaction for A-4 (US-41) 


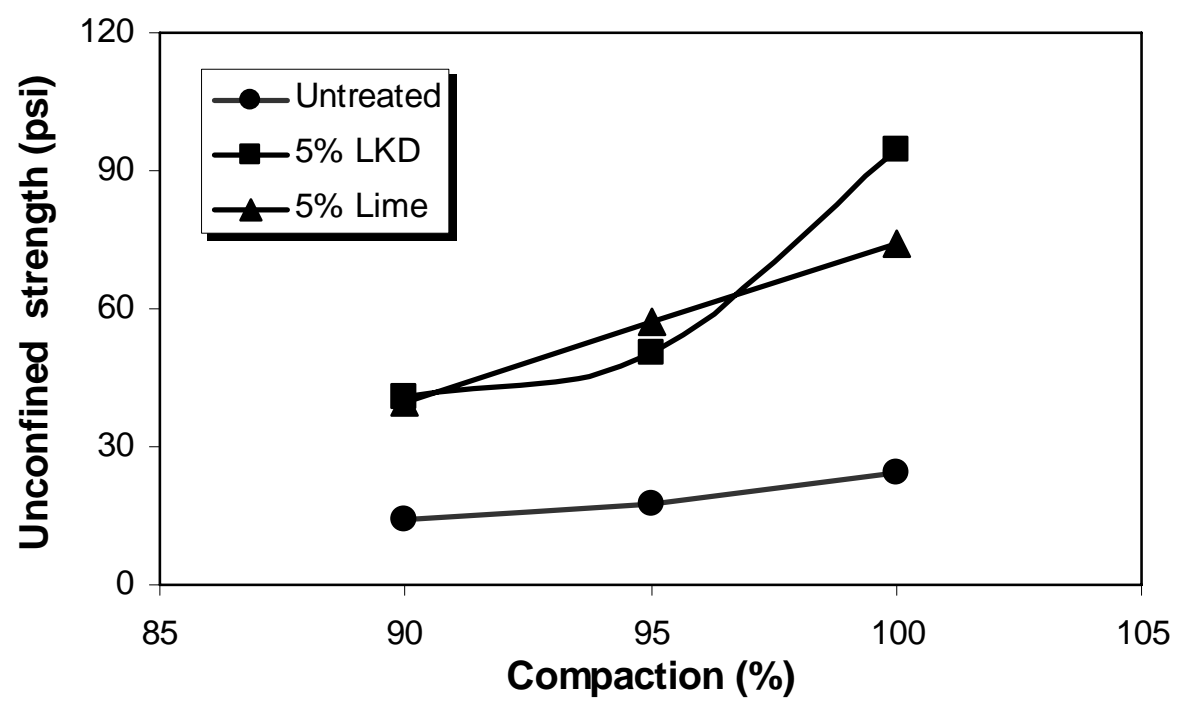

Figure 58. Unconfined strength vs. \% compaction for A-6 (SR-37)

\subsubsection{CBR and Swell Potential}

Although it has already been recommended to use the resilient modulus value for characterizing subgrade materials, CBR values are still used in design practice due to the limited availability of resilient modulus values for soils. Table 6 presents CBR values and the amount of swell measured after 4 days of soaking for untreated and untreated soils compacted at optimum moisture content. As seen in Table 6, the maximum dry densities become smaller and optimum moisture contents become larger for treated soils than those for untreated soils. It is noted that much larger CBR values are achieved for both $5 \%$ lime and $5 \%$ LKD soil mixtures than those for untreated soils. Except for A-7-6 (SR-37), the largest $\mathrm{CBR}$ values are were achieved for $5 \%$ LKD treated soils. CBR values for treated soils were in the range of 25 to 70 while those for untreated soils ranged from 3 to 18. It should be noted that the swell potential would vary for different percent 
compactions; the smaller the water contents, the higher the swell potential due to a greater portion of air trapped in the soil. For this reason, a larger amount of swell was observed at $90 \%$ and $95 \%$ compaction compared with $100 \%$ compaction. It is apparent that blending with $5 \%$ lime and $5 \%$ LKD causes the swell potential to decrease remarkably. As can be seen in the table, a higher reduction in swell potential was observed more often in the $5 \%$ lime treated soils than that in the $5 \%$ LKD treated soils. LKD treated soils, however, also showed substantial improvement in swell potential, compared with untreated soils. This implies that soils having high clay contents can decrease in the swell potential when mixed with $5 \%$ LKD. For A-4 (US-41) soil, interestingly the swell potential of LKD treated soil increased slightly. This appears to be due to the negligible swell potential of the untreated soil as it has a fairly high silt content as shown in Table 5. 
Table 6. CBR and swell potential for untreated and $5 \%$ LKD and $5 \%$ lime treated soils compacted at $\mathrm{OMC}$

\begin{tabular}{|c|c|c|c|c|c|c|c|c|}
\hline Soil & Condition & $\begin{array}{l}\text { Maximum } \\
\text { density } \\
\left(\mathrm{kN} / \mathrm{m}^{3}\right) \\
\end{array}$ & $\begin{array}{c}\text { OMC } \\
(\%) \\
\end{array}$ & $\begin{array}{l}\text { Molded } \\
\text { density } \\
\left(\mathrm{kN} / \mathrm{m}^{3}\right) \\
\end{array}$ & $\begin{array}{l}\text { Molded } \\
\text { water } \\
\text { content } \\
(\%) \\
\end{array}$ & $\begin{array}{l}\text { Percent } \\
\text { maximum } \\
\text { density } \\
(\%) \\
\end{array}$ & $\begin{array}{l}\text { Swell } \\
\text { day } 4\end{array}$ & CBR \\
\hline \multirow[t]{3}{*}{ A-6 (I-94) } & Untreated & 18.1 & 13 & 18.0 & 13.5 & 99.5 & 0.22 & 3.1 \\
\hline & $5 \%$ LIME & 17.3 & 17 & 17.1 & 17 & 98.8 & 0.17 & 45.3 \\
\hline & $5 \%$ LKD & 17.3 & 17 & 17.6 & 16 & 102.1 & 0.19 & 68.7 \\
\hline \multirow[t]{3}{*}{ A-4 (US-41) } & Untreated & 16.3 & 15 & 16.4 & 14.8 & 100.3 & 0.07 & 17.3 \\
\hline & $5 \%$ LIME & 16.3 & 17 & 16.5 & 16.9 & 101.3 & 0.04 & 32.3 \\
\hline & $5 \%$ LKD & 16.2 & 17 & 16.2 & 17.5 & 100.1 & 0.26 & 52.4 \\
\hline \multirow[t]{3}{*}{ A-6 (US-41) } & Untreated & 17.1 & 16 & 17.1 & 16.8 & 99.9 & 0.33 & 11.3 \\
\hline & $5 \%$ LIME & 16.5 & 19 & 16.0 & 19.5 & 97.2 & 0.04 & 39.1 \\
\hline & $5 \%$ LKD & 16.3 & 18 & 16.8 & 18.6 & 102.6 & 0.22 & 64.5 \\
\hline \multirow[t]{3}{*}{ A-6 (SR-37) } & Untreated & 17.3 & 16 & 17.4 & 16.1 & 100.6 & 1.77 & 5.9 \\
\hline & $5 \%$ LIME & 17.7 & 18 & 17.4 & 18.2 & 98.1 & 0.17 & 63.1 \\
\hline & $5 \%$ LKD & 17.4 & 13 & 17.4 & 12.5 & 99.9 & 0.68 & 68 \\
\hline \multirow[t]{3}{*}{ A-7-6 (SR-46) } & Untreated & 15.4 & 23 & 15.6 & 23 & 101.5 & 3.53 & 2.8 \\
\hline & $5 \%$ LIME & 15.2 & 27 & 14.8 & 27.6 & 97.1 & 0.79 & 44 \\
\hline & $5 \%$ LKD & 15.1 & 25 & 14.8 & 26 & 98.0 & 1.72 & 25.3 \\
\hline
\end{tabular}

\subsubsection{Resilient Behavior of Soil-LKD and Soil-Lime Mixtures}

Since the AASHTO design guide in 1986 recommended highway agencies use resilient modulus (Mr) in the design of pavements, resilient modulus has been used to characterize subgrade. Resilient modulus testing was performed according to the stress sequence of AASHTO T-307. In Mr testing, confining stresses of 2, 4, and 6 psi were applied and deviator stresses of 2, 4, 6, 8 and 10 psi were used for each confining stress. Specimens for $\mathrm{M}_{\mathrm{r}}$ testing were prepared and wrapped with a vinyl bag for 5 hours like the other tests to maintain the mixing water content before testing. Generally, the resilient behaviors of fine- grained soils are primarily dependent on the confining pressure; the higher the confining stress, the higher the resilient modulus (Lee et al. 1997, Thompson 
and Robnett 1979). On the contrary, as the deviator stress increases, resilient modulus generally decreases due to the degradation of the stiffness.

Figures 59, 60 and 61 present the resilient modulus vs. deviator stress for A-6 (SR-37) with respect to confining stresses of 2, 4 and 6 psi. It is clearly seen in Figure 59 that the higher the confining stress, the higher the resilient modulus value, which is the typical behavior of cohesive soils. For the deviator stresses, although the untreated soil shows decreasing Mr values with increasing deviator stresses, $5 \%$ LKD and $5 \%$ lime treated soils shows unclear deviator stress effect on resilient modulus values. It appears that such behavior is similar to what is typically observed in coarse grained soils, which may be due to an increase in stiffness. There is, however, a considerable confining stress effect on the resilient modulus as well.

In the design of pavements, the resilient modulus values of subgrades corresponding to the representative stress levels on top of the subgrades are important because these values should be used for design parameters. In general, the level of confining stress on top of the subgrades induced by 18 kips $(80 \mathrm{kN})$ Equivalent Single Axle Load (ESAL) is approximately 2 - 3 psi (Elliot and Thompson 1988). In our study, several multi-layered elastic analyses using ELSYM5 showed 2 psi to be a minimum confining pressure for typical Indiana roads. Figures 62 and 63 are diagrams of Mr vs. deviator stress in terms of a confining stress of 2 psi, which would be conservative for design purposes. As seen in the figures, the $5 \%$ soil-lime mixture has a higher resilient modulus than the $5 \%$ soil LKD mixture. It is interesting to note that LKD treated soils show considerably lower resilient modulus values than $5 \%$ lime treated soils, although their CBR values were close to those for treated soils as seen previously. This is probably 
due to curing effect in the CBR. However, as seen in Figures 64 and 65, no improvement of Mr values for A-4(US-41) and A-6 (US-41) is observed in the lime and LKD treated soils. This may be attributed to the low clay contents of these silty soils. For this reason, the cementation between LKD or lime and soils might be damaged under the dynamic loading. This indicates that Mr values for treated soils having low clay contents should be used with caution in design. However, it should be noted that the curing effect was not considered in our study. The resilient modulus values of treated soils are expected to increase considerably if permitted to cure with time (Daita et al. 2005).

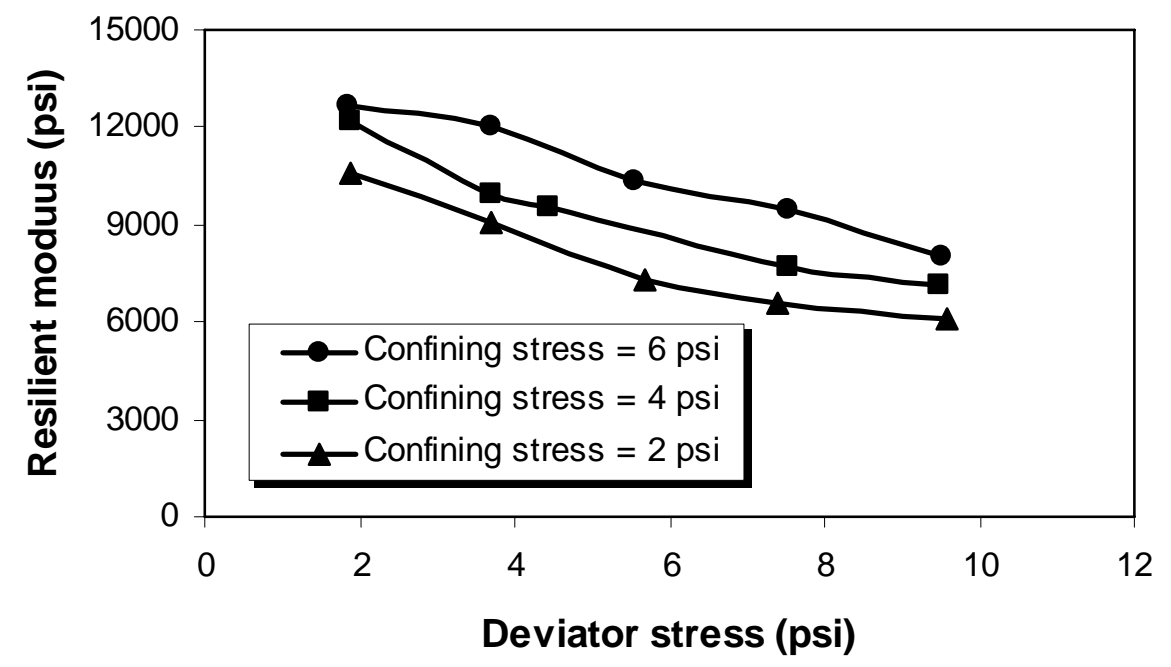

Figure 59. Resilient modulus vs. deviator stress for untreated soils for A-6 (SR-37) 


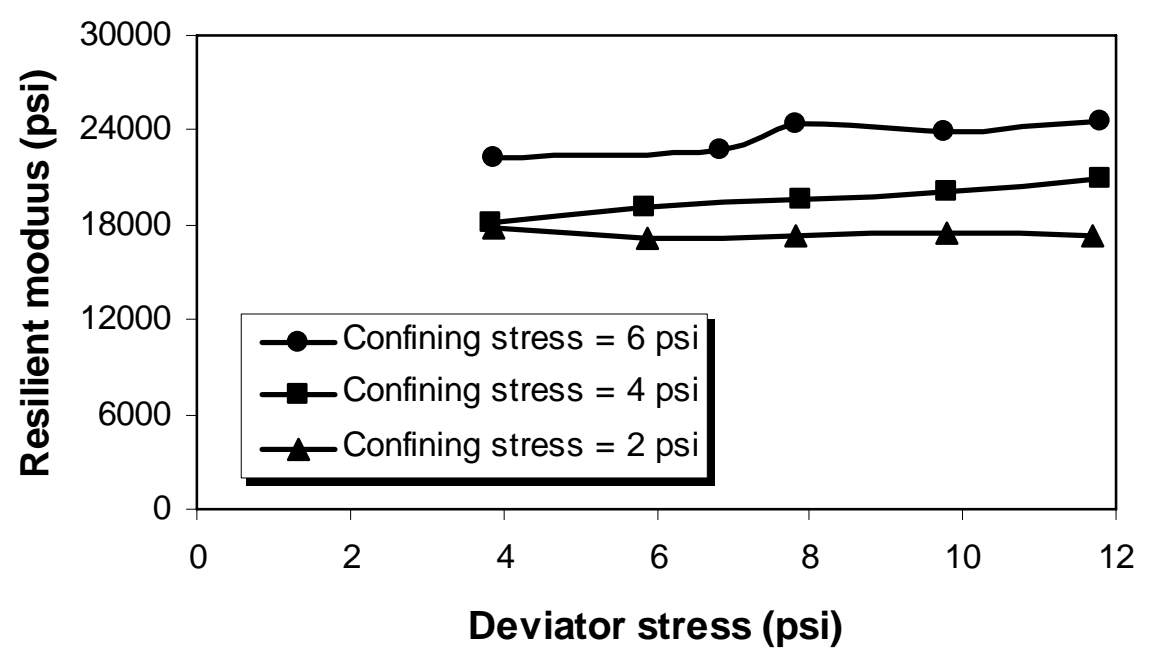

Figure 60. Resilient modulus vs. deviator stress for $5 \%$ LKD treated soils for A-6 (SR-37)

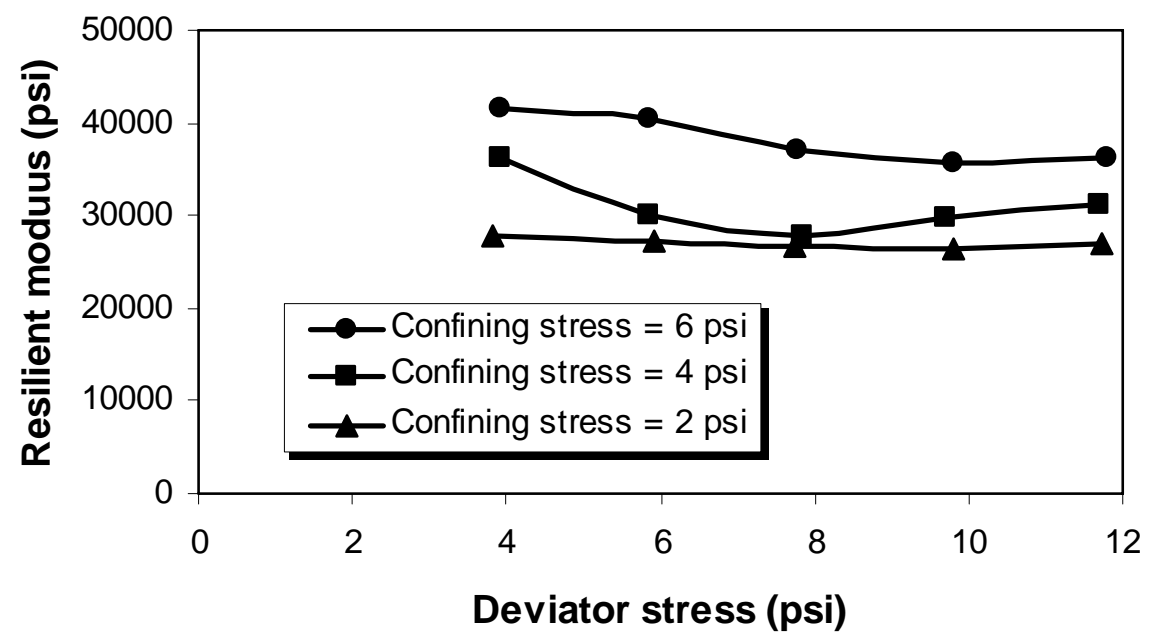

Figure 61. Resilient modulus vs. deviator stress for $5 \%$ Lime treated soils for A-6 (SR37) 


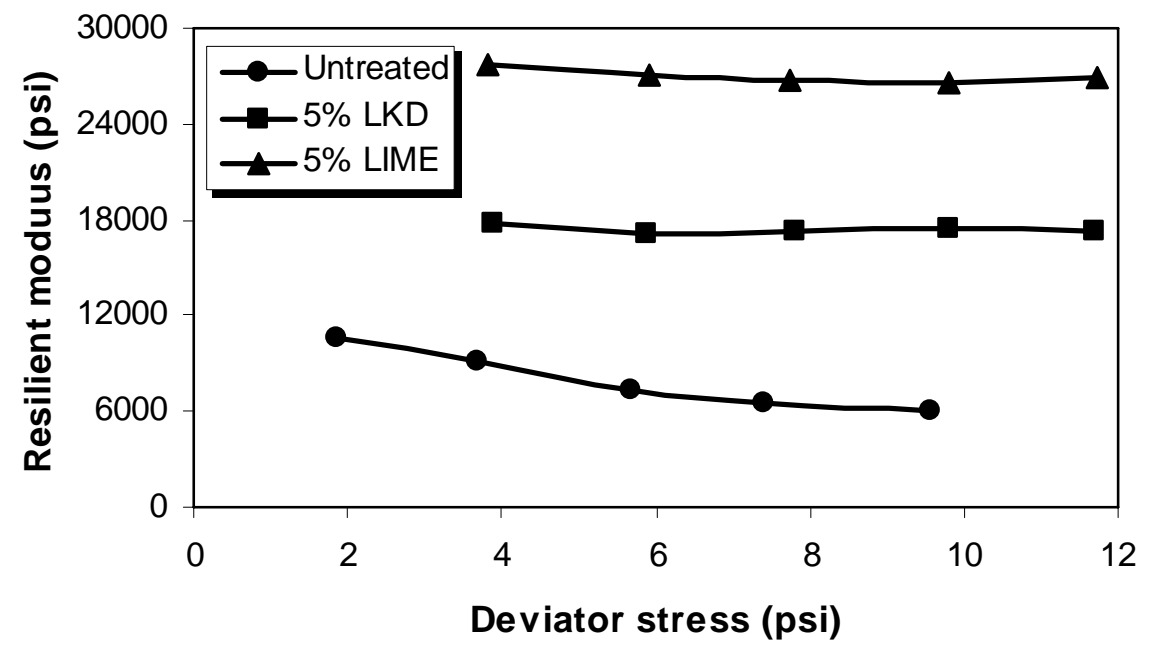

Figure 62. Resilient modulus vs. deviator stress for A-6 (SR-37) in terms of confining stress of 2 psi

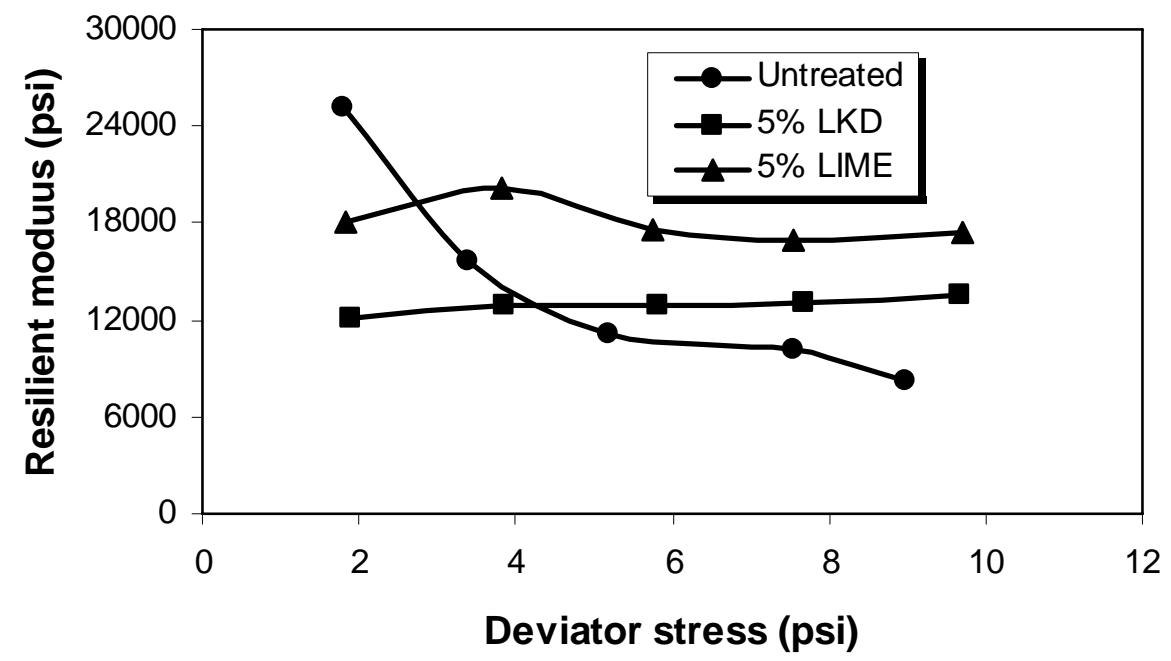

Figure 63. Resilient modulus vs. deviator stress for A-7-6 (SR-46) in terms of confining stress of $2 \mathrm{psi}$ 


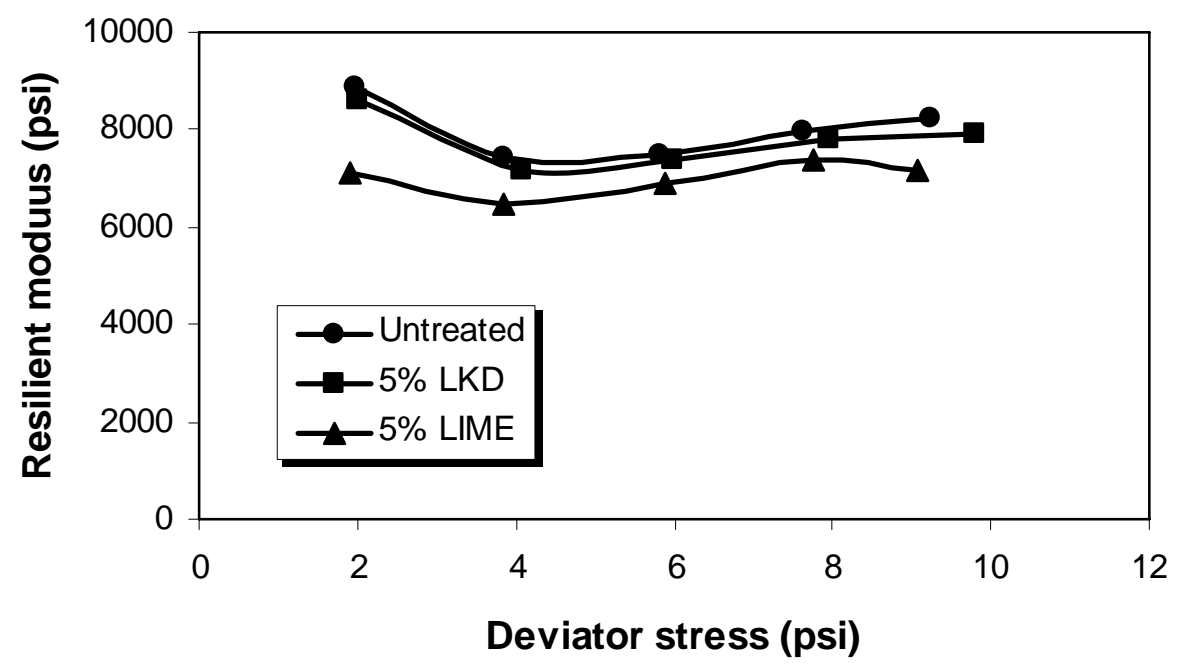

Figure 64. Resilient modulus vs. deviator stress for A-4 (US-41) in terms of confining stress of 2 psi

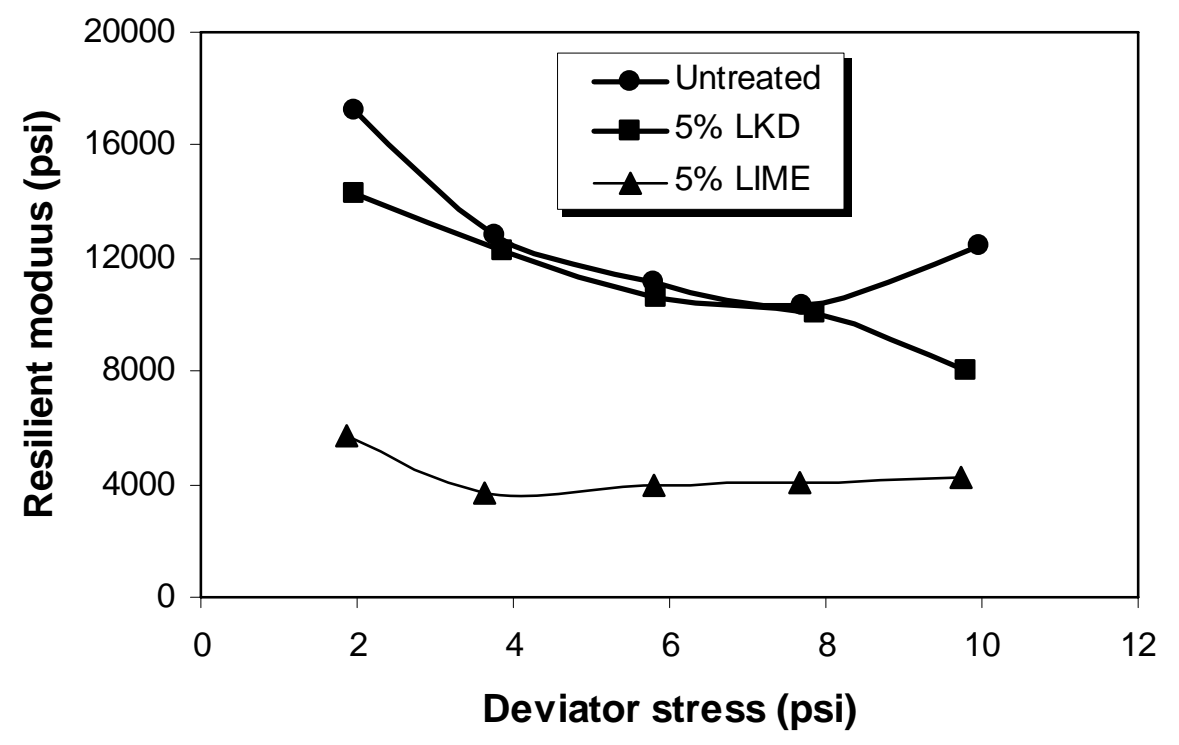

Figure 65. Resilient modulus vs. deviator stress for A-6 (US-41) in terms of confining stress of 2 psi 
Generally, resilient behavior of subgrade soils can be described by the Uzan model (Uzan 1985), also known as the universal model, taking into account confining and deviator stresses (Santa 1994). The predicted Mr values were obtained from the following equation:

$$
M r=k_{1} p_{a}\left(\frac{\theta}{p_{a}}\right)^{k_{2}}\left(\frac{\sigma_{d}}{p_{a}}\right)^{k_{3}}
$$

where, $\mathrm{k}_{1}, \mathrm{k}_{2}, \mathrm{k}_{3}$, $=$ regression coefficients; $\theta=$ sum of principal stresses; $\mathrm{p}_{\mathrm{a}}=$ reference pressure $=100 \mathrm{kpa} \approx 1 \mathrm{kgf} / \mathrm{cm}^{2} \approx 2000 \mathrm{psf} \approx 14.5 \mathrm{psi}$; and $\sigma_{\mathrm{d}}=$ deviator stress in the same unit as $\mathrm{p}_{\mathrm{a}}$.

It is noted that use of equation (6.1) for different soils cannot produce satisfactory correlation. In order to develop predictive models that account for the soil properties based on the all the Mr testing data for five untreated and treated soils, three equations, shown in Table 7 (shown only for untreated soils), to estimate the regression coefficient $\mathrm{k}_{1}, \mathrm{k}_{2}$, and $\mathrm{k}_{3}$ were developed through multiple regression analyses in terms of 12 soil variables which can be easily obtained in the Sieve Analysis, Atterberg's Limit test, and Standard Proctor compaction test. The variables are the following: OMC, MC (moisture content), MCR (Moisture Content Ratio = Moisture content/ Optimum Moisture Content), MDD (Maximum dry density), DD (dry density), SATU (Degree of saturation), \%Compaction, \%sand (percent sand in Particle size distribution curve), \%Silt (percent sand in Particle size distribution curve), \%CLAY (percent sand in Particle size distribution curve), LL (Liquid Limit) and PI (Plastic Index).

Figures 66, 67 and 68 show a plot of measured $\mathrm{Mr}$ vs. predicted $\mathrm{Mr}$ for the five LKD and five lime treated soils tested in this study. The predicted and measured $\mathrm{Mr}$ 
values based on soil properties are satisfactorily correlated for both untreated and treated soils. This suggests the predictive models using the soil properties could be developed constitutive models used to describe the resilient behavior of untreated and treated soils. Note that these equations do not consider effects of cementation with time after the 5 hours.

Table 7. Regression coefficient for the untreated, $5 \%$ LKD treated, $5 \%$ lime treated soils

\begin{tabular}{|c|}
\hline MDD $+0.037667 \times$ DD $-0.615328 \times \%$ comp $-1.16865 \times$ SATU +0.0 \\
\hline $\begin{array}{l}\mathrm{k} 2=1.448989-0.562096 \times \mathrm{OMC}+0.038833 \times \mathrm{MC}-1.076241 \times \mathrm{MCR}+0.007293 \times \\
\mathrm{MDD}+0.027179 \times \mathrm{DD}-0.353534 \times \% \text { comp }-1.719342 \times \mathrm{SATU}+0.051245 \times \\
\% \text { sand }+0.037536 \times \% \text { SILT }-0.17828 \times \% \text { CLAY }+0.048949 \times \mathrm{LL}+0.254824 \times \mathrm{PI}\end{array}$ \\
\hline $\begin{array}{l}\mathrm{k} 3=0.986459-0.077286 \times \mathrm{OMC}-0.096477 \times \mathrm{MC}+1.177117 \times \mathrm{MCR}-0.10423 \times \\
\text { MDD }-0.010463 \times \mathrm{DD}+0.202627 \times \% \text { comp }-0.354245 \times \text { SATU }+0.017843 \times \\
\% \text { sand }+0.011723 \times \% \text { SILT }+0.049246 \times \% \text { CLAY }+0.049337 \times \text { LL- } 0.073874 \times \mathrm{PI}\end{array}$ \\
\hline
\end{tabular}

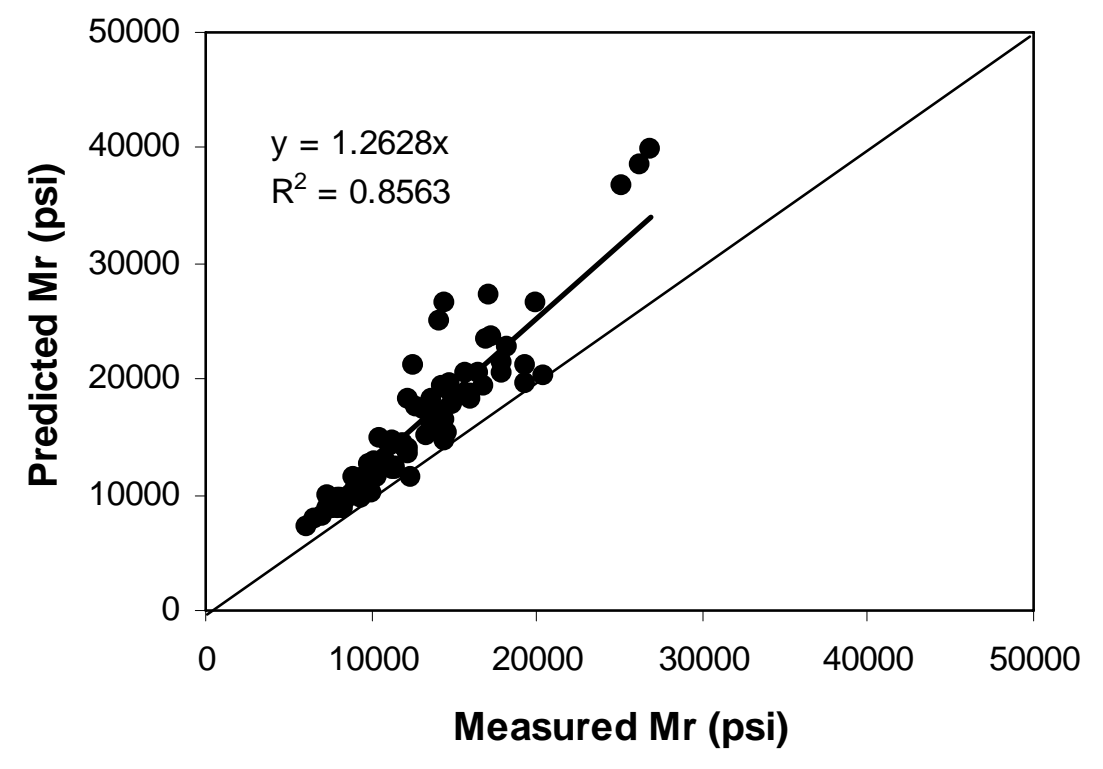


Figure 66. Measured vs. predicted Mr for untreated soils

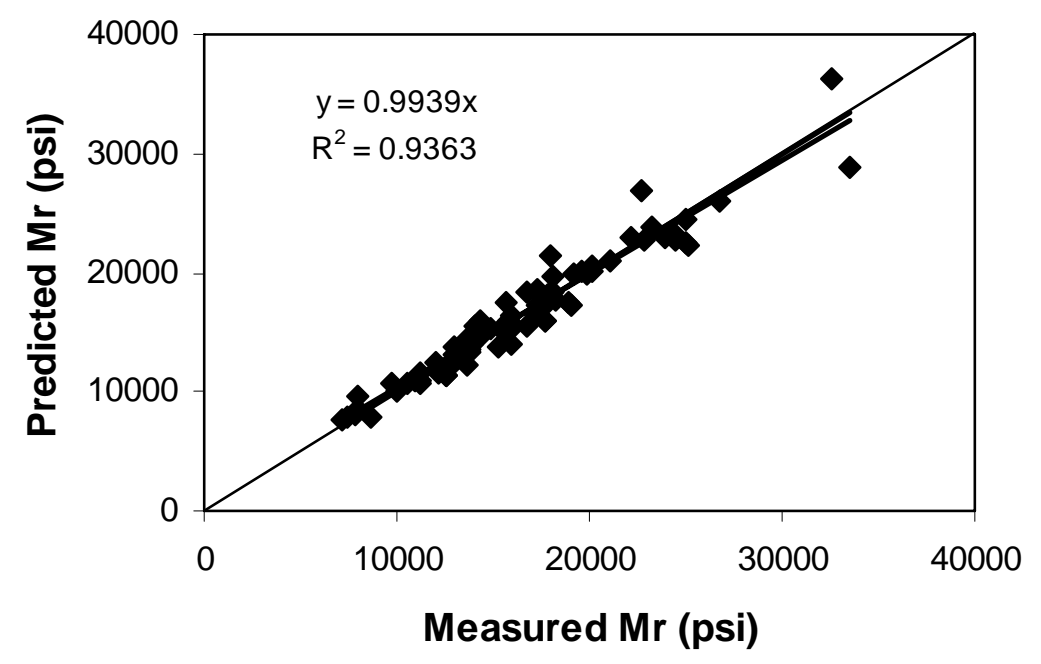

Figure 67. Measured vs. predicted Mr for $5 \%$ LKD treated soils

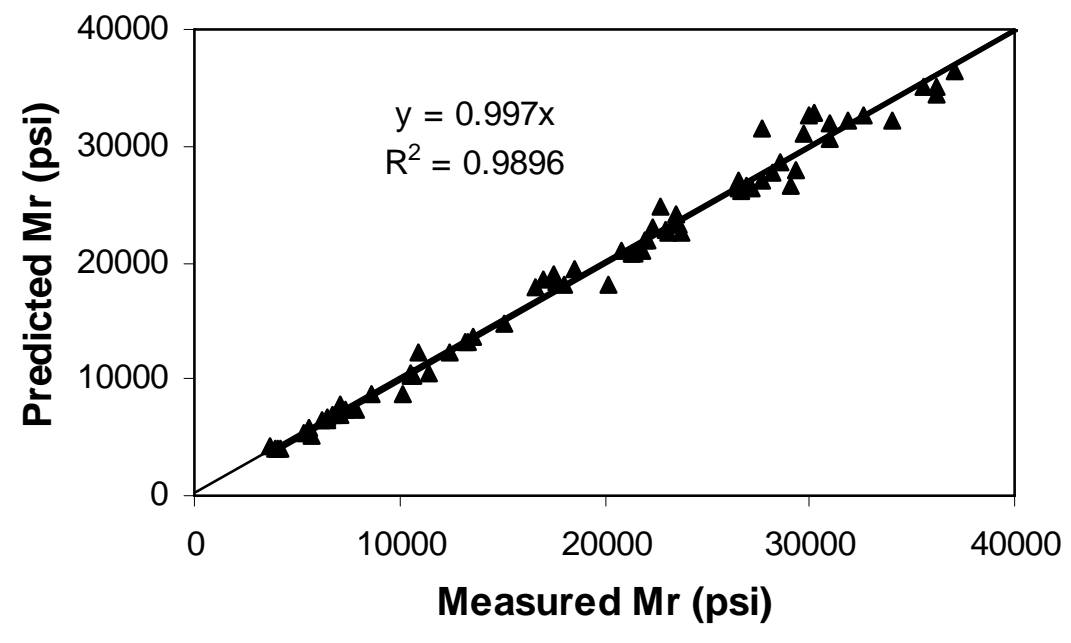

Figure 68. Measured vs. predicted Mr for $5 \%$ Lime treated soils 


\subsection{Summary}

Laboratory evaluation was done to identify possible benefits of Lime Kiln Dust for subgrade modification and stabilization. $5 \%$ LKD and $5 \%$ hydrated lime were added to typical fine-grained soils encountered in Indiana. Unconfined strength, CBR and resilient modulus tests were performed on untreated, $5 \%$ LKD treated, and $5 \%$ lime treated samples with $90 \%, 95 \%$ and $100 \%$ compactions. As a result of the laboratory tests, the following conclusions can be drawn. It is noted that conclusions based on five hours of curing may differ from conclusions that can be made after 7 day, 14 day. or during the life of the pavement.

- Mixtures of fine grained soils with $5 \%$ lime or $5 \%$ LKD substantially improve unconfined strength up to $60 \%-400 \%$. For both untreated and treated soils, as the percentage of compaction increases, the unconfined compression strength increases. This suggests the importance of compaction of the subgrade, regardless of the materials.

- CBR values are remarkably improved with LKD and lime treatment and swell potential is generally reduced. Larger CBR values are achieved by $5 \%$ LKD treatment than by 5 $\%$ lime treatment. Therefore, use of LKD for subgrade improvement is as promising as lime. 
- Resilient behavior of LKD and lime treated soils shows a similar tendency to finegrained soils in terms of confining stresses. However, unlike untreated soils, the effect of deviator stress on the resilient modulus is negligible for treated soils. This would be attributed to the increased stiffness in the treated soils compared with the untreated soils.

- Although the CBR values for soils treated with LKD and lime were higher, resilient modulus values for treated soils for A-4 (US-41) and A-6 (US-41) were lower than those for untreated soils. It appears that this may be due to the low clay contents of these silty soils, or to the presence of cementation in the CBR test by soaking of the specimens, and to the different mechanisms of the CBR test (static test) and resilient modulus test (dynamic repeated test). Therefore, soils with high clay contents are advisable when mixed with LKD or lime, as evidenced by A-6 (SR-37) and A-7-6(SR-46). More resilient modulus testing for LKD and lime treated soils needs to be done to draw a complete conclusion on the resilient modulus behavior of these treated soils in conjunction with more CBR tests.

- Regression equations were developed for untreated, $5 \%$ LKD and $5 \%$ lime treated soils following the Uzan model considering the soil physical parameters to estimate $\mathrm{Mr}$ values. Predicted Mr values are well correlated with measured Mr values for 5 hours of curing.

In Indiana, LKD has been used for subgrade modification, but not for stabilization due to the limited available data for implementation. The improved properties such as unconfined, CBR, resilient modulus values achieved by the modification have not been taken into account in design. Results of the unconfined strength, CBR, resilient modulus 
tests for untreated, $5 \%$ LKD and $5 \%$ lime treated soils suggest that LKD could be effectively used as an alternative to lime. This leads to the beneficial impact on the use of LKD for both subgrade modification and stabilization. Further study on the resilient behavior is recommended to accumulate typical resilient modulus values for different types of soils with LKD and Lime treatment for more realistic design. 


\section{CHAPTER 7. THEORETICAL INVESTIGATION OF BEHAVIOR OF SUBGRADES}

\subsection{Mathematical Expression of the Loading Cycles in AASHTO T307}

The basic principle of the loading adopted in AASHTO T 307 is the simulation of a typical moving load in a sinusoidal form. The peak point of the loading is analogous to the loading condition where the traffic is immediately above the subgrade. A soil sample subjected to resilient modulus testing can be simply modeled as a one-dimensional forced vibration of a spring-mass system, as shown in equation (7.1).

$$
m Y^{\prime \prime}+c Y^{\prime}+k Y=F(t)
$$

Where $\mathrm{m}=\mathrm{W} / \mathrm{g}, \mathrm{W}=$ weight $($ Unit: $\mathrm{kN}), \mathrm{g}=$ gravity acceleration, $\mathrm{c}=$ damping ratio (non-dimensional), $\mathrm{Y}=$ vertical displacement and $\mathrm{F}(\mathrm{t})=$ the applied load. For simplicity, mass of top cap and ram in equation (7.1) is neglected.

Fourier series can be used to represent a given periodic function $F(t)$ in terms of cosine and sine functions. If a function $\mathrm{F}(\mathrm{t})$ of period $\mathrm{p}=2 \mathrm{~L}$ has a Fourier series, we can express this series as follows:

$$
F(t)=a_{0}+\sum_{n=1}^{\infty}\left(\left(a_{n} \cos \left(\frac{n \pi}{L} t\right)+b_{n} \sin \left(\frac{n \pi}{L} t\right)\right)\right.
$$




$$
\begin{gathered}
a_{0}=\frac{1}{2 L} \int_{-L}^{L} f(t) d t \\
a_{n}=\frac{1}{2 L} \int_{-L}^{L} f(t) d t \cos \frac{n \pi t}{L} d t \quad \mathrm{n}=1,2 \ldots, \\
b_{n}=\frac{1}{2 L} \int_{-L}^{L} f(t) d t \sin \frac{n \pi t}{L} d t \quad \mathrm{n}=1,2 \ldots .,
\end{gathered}
$$

An example of the schematic load pulse for a deviator stress of 2 psi in AASHTO 307 is shown in Figure 69. As can be seen in Figure 69, for 0.1 second the deviator stress is applied and for 0.9 second, no load is applied, and then this is repeated for a certain level of stress. The load pulse shown in Figure 69 can be expressed as:

$$
\begin{array}{cc}
f(t)=\sigma_{\max }\left(\frac{1-\cos (20 \pi t)}{2}\right) & 0<\mathrm{t}<0.1 \mathrm{~s} \\
f(t)=0 & 0.1 \mathrm{~s} \ll \mathrm{t}<1 \mathrm{~s}
\end{array}
$$

$$
\text { As } \mathrm{p}=2 \mathrm{~L}=1 \text { second, } \mathrm{L}=1 / 2 \text { second }
$$

Substituting equations (7.6), (7.7) and (7.8) into equation (7.2) allows $F(t)$ to be obtained. The plot of $F(t)$ is shown in Figure 70. After substituting the obtained $F(t)$ into equation (7.1) and solving the $2^{\text {nd }}$ order differential equation (7.1), (assuming $\mathrm{c}=0.2$ ), one can obtain the vertical displacement of a soil sample as a function of the weight of sample and the spring constant as given by: 
$\left.Y=\frac{1}{50} \times \frac{(-1+50 \times F(t)}{k}+C_{1} \times \sin \left(\frac{k}{m}\right)^{\frac{1}{2}} \times t\right)-\frac{1}{50} \times\left(\frac{-1+50 \times F(t)}{k}\right) \times \cos \left(\left(\frac{k}{m}\right)^{\frac{1}{2}} \times t\right)$

(7.9)

Figure 71 presents the plot of the relationship between the displacement and time. This was done assuming the typical values such as length of the diameter, stiffness and density. Therefore, we can calculate the resilient modulus by dividing the deviator stress by the vertical strain.

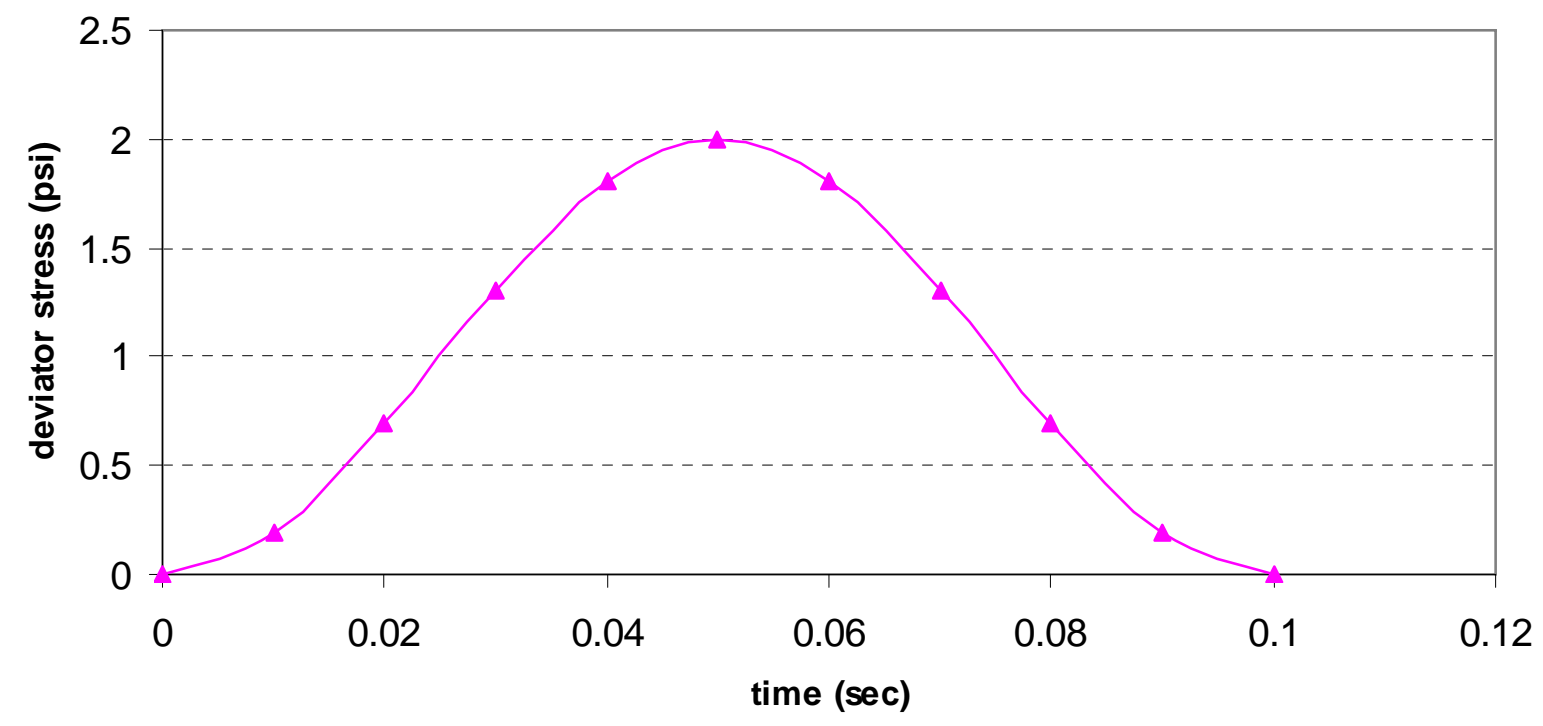

Figure 69. Loading cycle in AASTHO 307 test 


\section{Load Pulse in Resilient Modulus test}

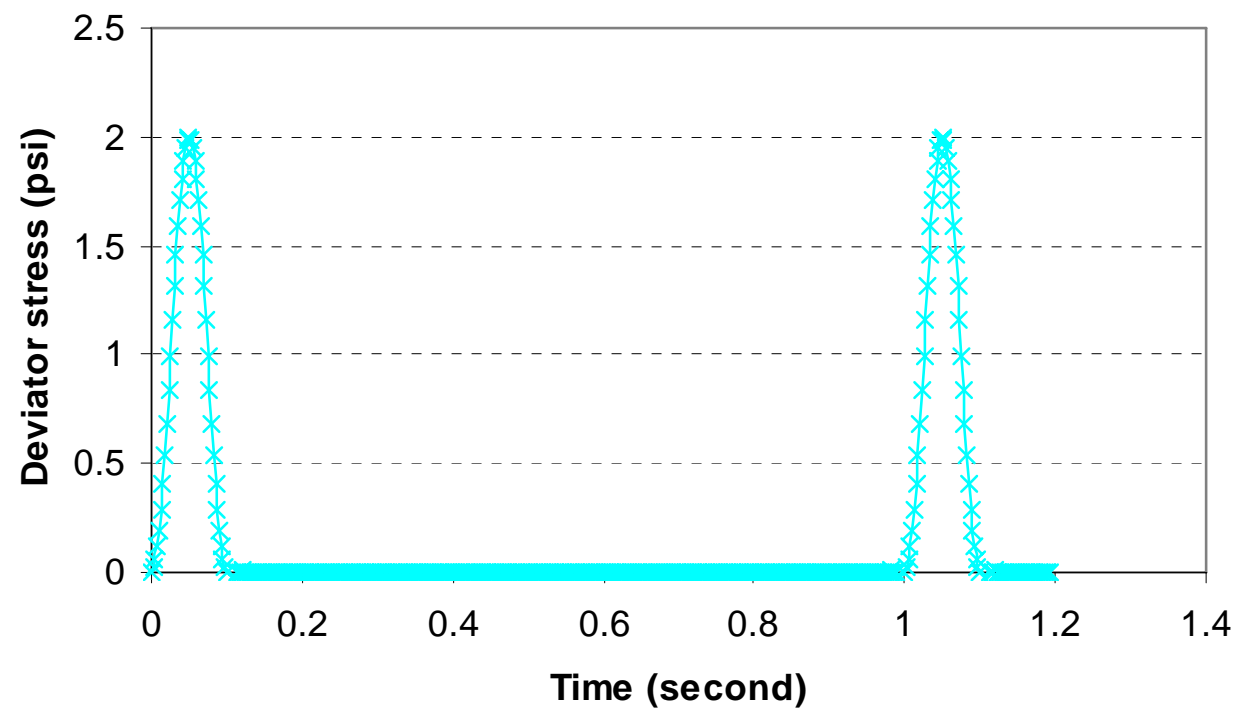

Figure 70. Plot of $\mathrm{F}(\mathrm{t})$ as a function of time at a deviator stress of 2 psi

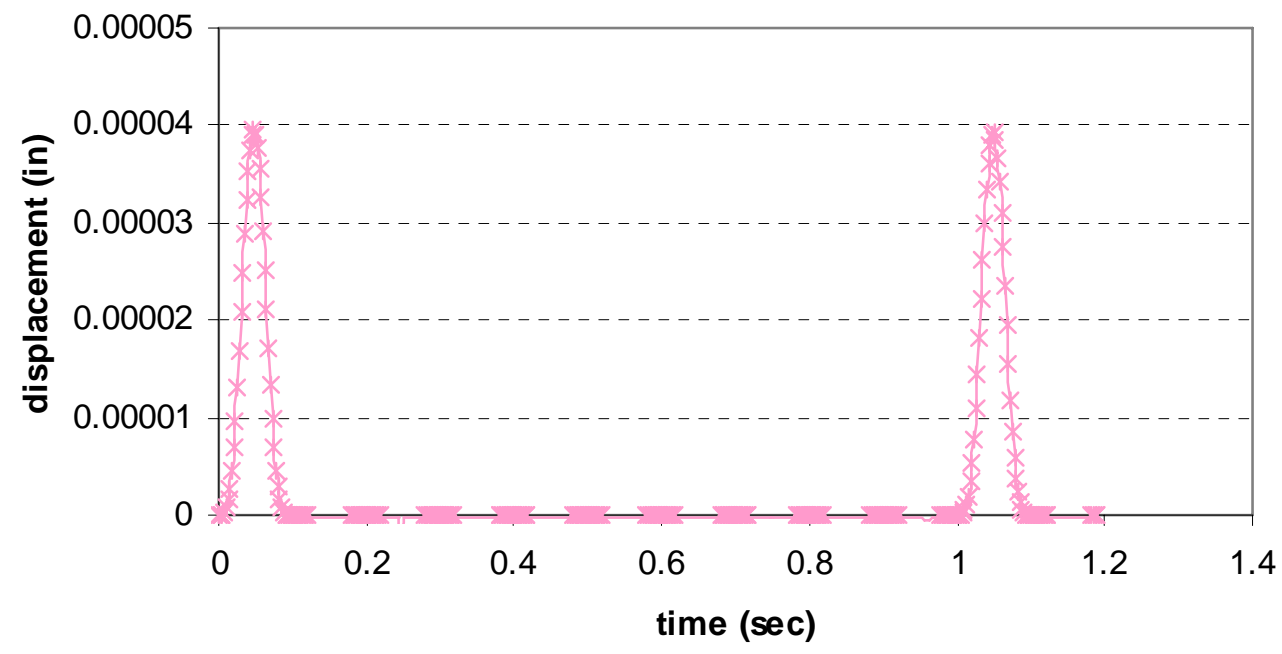

Figure 71. Change in displacement with respect to time 


\subsection{Development of a Constitutive Model for a soil having Permanent Strain Subjected} to the Resilient Modulus Test

Generally, the permanent strain of subgrade soils is not taken into consideration in the resilient modulus test. This is due to the assumption that the subgrade would be in the elastic state. However, as discussed previously, subgrade soils may exhibit the permanent strain even at a much smaller load than that causing shear failure. It is fairly necessary to develop a constitutive model that describes the realistic behavior of subgrade soils.

The permanent strain at small loads cannot be modeled using classical plasticity constitutive models such as the Drucker-Prager model or the Mohr-Coulomb model, as the stress state of soils with those models will always be elastic. In the modeling of subgrade, as the plastic deformation occurs during the Mr testing, a simple classical plasticity theory that does not require the shear strength parameters (cohesion and friction angle) can be employed to consider both the resilient behavior and the permanent behavior. Soil plasticity consists of the three parts: a yield criterion, a flow rule, and a hardening rule.

\subsubsection{Yield Criterion}

A yield function $\mathrm{F}$ can be defined as a function of stresses $\{\sigma\}$ and $\mathrm{W}_{\mathrm{p}}$ associated with the isotropic hardening rule. Yielding occurs when the following condition is satisfied: 


$$
F\left(\sigma, W_{P}\right)=0
$$

$$
\text { Where } W_{p}=\int\{\sigma\}^{T}\left\{d \varepsilon^{p}\right\}=\text { plastic work }
$$

Throughout this paper, \{\} is defined as a column matrix and [] is as a rectangular or a square matrix.

\subsubsection{Flow Rule}

We define a plastic potential Q, which has units of stress and is a function of stresses, $Q=Q\left(\sigma, W_{p}\right)$. With $\mathrm{d} \lambda$, a scalar called plastic multiplier, plastic strain increments are given by:

$$
\left\{d \varepsilon^{p}\right\}=\left\{\frac{\partial Q}{\partial \sigma}\right\} d \lambda
$$

An incremental stress-strain, analogous to the relation $\{\sigma\}=[C]\{\varepsilon\}$ of elasticity but valid into the elasto-plastic regime, can be derived as follows. $[C]$ is a three-dimensional elastic tangent stiffness matrix, which is symmetric, as given by: 
$[C]=\frac{E}{(1+v)(1-2 v)}\left[\begin{array}{cccccc}(1-v) & v & v & 0 & 0 & 0 \\ v & (1-v) & v & 0 & 0 & 0 \\ v & v & (1-v) & 0 & 0 & 0 \\ 0 & 0 & 0 & \frac{(1-2 v)}{2} & 0 & 0 \\ 0 & 0 & 0 & 0 & \frac{(1-2 v)}{2} & 0 \\ 0 & 0 & 0 & 0 & 0 & \frac{(1-2 v)}{2}\end{array}\right]$

Differentiation of eq. (7.10) leads to

$$
d F=\left\{\frac{\partial F}{\partial \sigma}\right\}^{T}\{d \sigma\}+\frac{\partial F}{\partial W_{P}} d W_{P}=0
$$

From eq. (7.11) $d W_{p}=\{\sigma\}^{T}\left\{d \varepsilon^{p}\right\}$

$$
\{d \sigma\}=[C]\left\{d \varepsilon^{e}\right\}=[C]\left(\{d \varepsilon\}-\left\{d \varepsilon^{p}\right\}\right)
$$

Plugging (12) into (15) and rearranging (15) in terms of $\mathrm{d} \lambda$ becomes:

$$
d \lambda=\{D\}^{T}\{d \varepsilon\}
$$

$$
\text { where }\{D\}^{T}=\frac{\left\{\frac{\partial F}{\partial \sigma}\right\}^{T}[C]}{\left\{\frac{\partial F}{\partial \sigma}\right\}^{T}[C]\left\{\frac{\partial Q}{\partial \sigma}\right\}-\frac{\partial F}{\partial W_{P}}\{\sigma\}^{T}\left\{\frac{\partial Q}{\partial \sigma}\right\}}
$$

Finally, substituting eq. (7.12) into eq. (7.15) gives: 


$$
\{d \sigma\}=[C]\left\{\{d \varepsilon\}-\left\{\frac{\partial Q}{\partial \sigma}\right\} d \lambda\right) \text { or }\{d \sigma\}=\left|C_{e p}\right|\{d \varepsilon\}
$$

where $\left[C_{e p}\right]=[C]-[C]\left\{\frac{\partial Q}{\partial \sigma}\right\}\{D\}^{T}=$ elasto-plastic tangent stiffness matrix or Jacobian matrix, $\left\lfloor C_{e p}\right\rfloor=6 \times 6$ matrix, $\left\{\frac{\partial Q}{\partial \sigma}\right\}=6 \times 1$ matrix, $\left\{\frac{\partial F}{\partial \sigma}\right\}^{T}=1 \times 6$ matrix, $\{D\}^{T}=1 \times 6$ matrix, and $\{\sigma\}^{T}=1 \times 6$ matrix.

\subsubsection{Implementation Process}

1) Material parameters needed: $v, k_{1}, k_{2}$ and $k_{3}$

$$
M_{r}=k_{1} p_{a}\left(\frac{\theta}{p_{a}}\right)^{k_{2}}\left(\frac{\tau_{o c t}}{p_{a}}+1\right)^{k_{3}}
$$

where $\theta=\sigma_{11}+\sigma_{22}+\sigma_{33}$ and $\tau_{o c t}=\frac{1}{3} \sqrt{\left(\left(\sigma_{1}-\sigma_{2}\right)^{2}+\left(\sigma_{1}-\sigma_{3}\right)^{2}+\left(\sigma_{2}-\sigma_{3}\right)^{2}\right.}$

In order to incorporate the non-linearity of resilient behavior of soils, E in equation (7.13) is substituted by $\mathrm{Mr}$ in equation (7.19). Unlike the Mohr-Coulomb or the Drucker-Prager model, the yield criterion requires only a hardening rule, and hence the stress-strain relation obtained from a resilient modulus test is sufficient to model both the resilient and the permanent behavior of a soil.

\section{2) Failure criterion}

The yield criterion determines the stress level at which plastic deformation begins and can be written in the general form: 


$$
\mathrm{F}(\sigma, \mathrm{Wp})=\mathrm{q}(\sigma)-\mathrm{g}(\mathrm{Wp})=0
$$

where $\mathrm{q}=$ Mises equivalent stress

$$
q=\sqrt{3 / 2 S_{i j} S_{i j}}=\sqrt{\frac{1}{2}\left\{\left(\sigma_{11}-\sigma_{22}\right)^{2}+\left(\sigma_{22}-\sigma_{33}\right)^{2}+\left(\sigma_{33}-\sigma_{11}\right)^{2}+6\left({\sigma_{12}}^{2}+{\sigma_{23}}^{2}+\sigma_{13}{ }^{2}\right)\right\}}
$$

and $g\left(W_{p}\right)=1.4687 \ln (W p)+17.028$

$$
\frac{\partial F}{\partial W_{p}}=\frac{1.4687}{\exp \left(\frac{\sigma_{d}-17.028}{1.4687}\right)}
$$

As shown above, the hardening rule is dependent on the deviator stress. The effect of the number of repeated loading is internally taken into account. The hardening rule is based on the long-term resilient modulus test data for Orchard clay.

3) Assuming the associate flow rule, $\left\{\frac{\partial Q}{\partial \sigma}\right\}=\left\{\frac{\partial F}{\partial \sigma}\right\}$

$$
\frac{\partial F}{\partial \sigma_{11}}=\frac{1}{2 \sqrt{\left.\frac{1}{2}\left\{\left(\sigma_{11}-\sigma_{22}\right)^{2}+\left(\sigma_{22}-\sigma_{33}\right)^{2}+\left(\sigma_{33}-\sigma_{11}\right)^{2}\right)+6\left({\sigma_{12}}^{2}+{\sigma_{23}}^{2}+\sigma_{13}{ }^{2}\right)\right\}}}\left(2 \sigma_{11}-\sigma_{22}-\sigma_{33}\right)
$$$$
\frac{\partial F}{\partial \sigma_{22}}=\frac{1}{2 \sqrt{\left.\frac{1}{2}\left\{\left(\sigma_{11}-\sigma_{22}\right)^{2}+\left(\sigma_{22}-\sigma_{33}\right)^{2}+\left(\sigma_{33}-\sigma_{11}\right)^{2}\right)+6\left({\sigma_{12}}^{2}+{\sigma_{23}}^{2}+\sigma_{13}{ }^{2}\right)\right\}}}\left(-\sigma_{11}+2 \sigma_{22}-\sigma_{3}\right)
$$$$
\frac{\partial F}{\partial \sigma_{33}}=\frac{1}{2 \sqrt{\left.\frac{1}{2}\left\{\left(\sigma_{11}-\sigma_{22}\right)^{2}+\left(\sigma_{22}-\sigma_{33}\right)^{2}+\left(\sigma_{33}-\sigma_{11}\right)^{2}\right)+6\left(\sigma_{12}{ }^{2}+\sigma_{23}{ }^{2}+\sigma_{13}{ }^{2}\right)\right\}}}\left(-\sigma_{11}-\sigma_{22}+2 \sigma_{3}\right)
$$ 


$$
\begin{aligned}
& \frac{\partial F}{\partial \sigma_{12}}=\frac{1}{2 \sqrt{\left.\frac{1}{2}\left\{\left(\sigma_{11}-\sigma_{22}\right)^{2}+\left(\sigma_{22}-\sigma_{33}\right)^{2}+\left(\sigma_{33}-\sigma_{11}\right)^{2}\right)+6\left({\sigma_{12}}^{2}+{\sigma_{23}}^{2}+\sigma_{13}{ }^{2}\right)\right\}}}\left(6 \sigma_{12}\right) \\
& \frac{\partial F}{\partial \sigma_{13}}=\frac{1}{2 \sqrt{\left.\frac{1}{2}\left\{\left(\sigma_{11}-\sigma_{22}\right)^{2}+\left(\sigma_{22}-\sigma_{33}\right)^{2}+\left(\sigma_{33}-\sigma_{11}\right)^{2}\right)+6\left({\sigma_{12}}^{2}+{\sigma_{23}}^{2}+{\sigma_{13}}^{2}\right)\right\}}}\left(6 \sigma_{13}\right) \\
& \frac{\partial F}{\partial \sigma_{23}}=\frac{1}{2 \sqrt{\left.\frac{1}{2}\left\{\left(\sigma_{11}-\sigma_{22}\right)^{2}+\left(\sigma_{22}-\sigma_{33}\right)^{2}+\left(\sigma_{33}-\sigma_{11}\right)^{2}\right)+6\left({\sigma_{12}}^{2}+{\sigma_{23}}^{2}+{\sigma_{13}}^{2}\right)\right\}}}\left(6 \sigma_{23}\right)
\end{aligned}
$$

The constitutive model discussed above was implemented in ABAQUS, a general Finite Element (FE) program, to account for both the resilient behavior and the permanent strain behavior. The detailed program code for user material is provided in Appendix. For a simple Finite Element (FE) analysis, a sample with a height of 6.0" and a diameter of 2.8 " for a resilient modulus test was modeled as axis-symmetric condition. The sample is subjected to a confining stress of 2 psi and deviator stress of 6 psi. As discussed previously, when modeling this specimen with the Drucker-Prager or the Mohr-Coulomb model, the permanent strain will not occur. Figure 72 shows the comparison between measured and predicted permanent strains induced by 10 times of the repeated loading. It is observed from Figure 72 that the measured permanent strain caused by the first loading is larger than that from the FE analysis. This results from the incomplete contact of the sample at the first loading. As the loading continues, the total magnitude of permanent strain increases with the decrease in the rate of permanent strain in each loading cycle. This agrees well with the observation from a resilient modulus test, as the specimen is compacted due to the continued loading. As can be seen in Figure 72, the measured and predicted $\mathrm{Mr}$ values are reasonably in good agreement. 


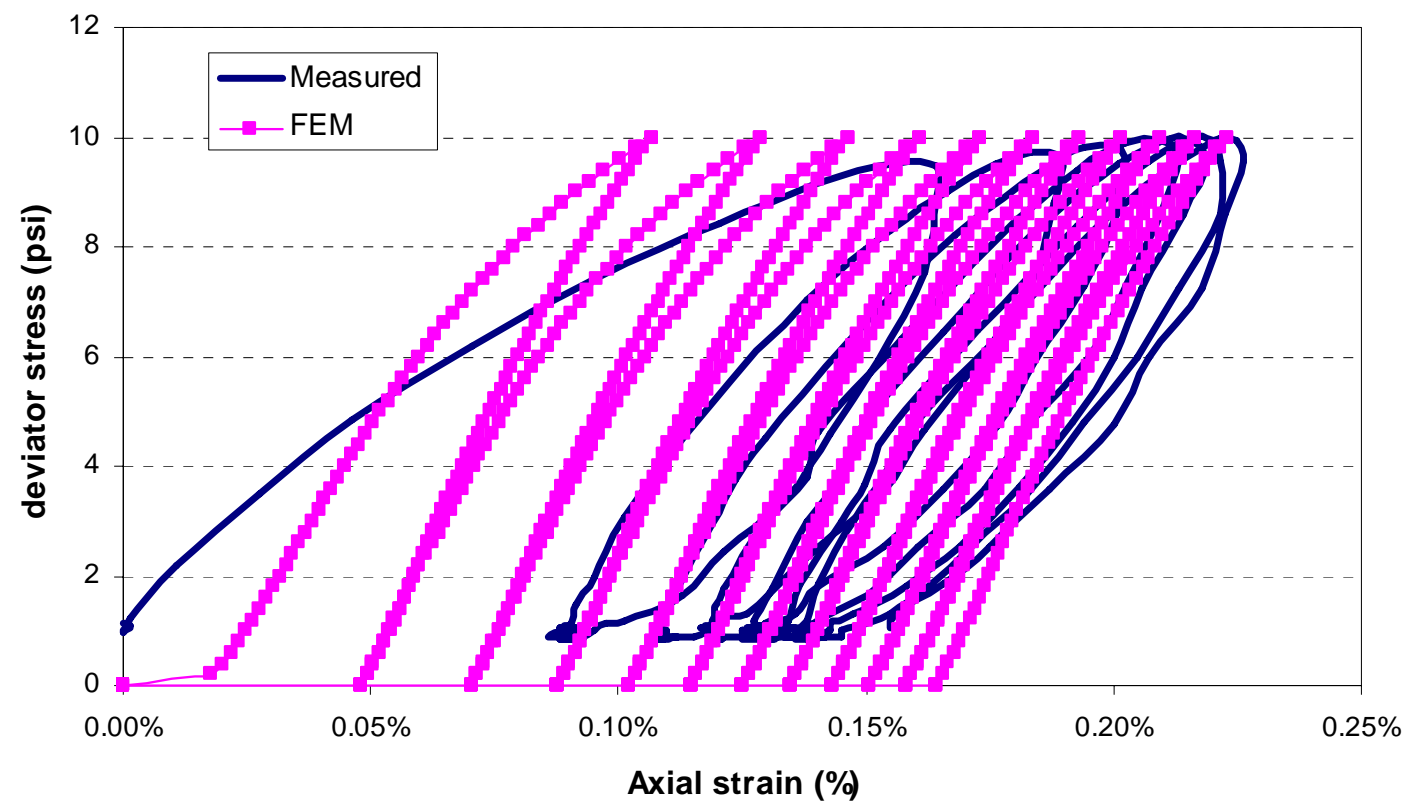

Figure 72. Comparison between the measured and predicted stress-strain relationship 


\section{CHAPTER 8. CONCULUSIONS AND RECOMMENDATION}

\section{$\underline{\text { 8.1. Conclusions }}$}

The objectives of this study were to simplify the resilient modulus testing procedure specified in AASHTO T307 based on the prevalent conditions in Indiana, to generate database of Mr values following the existing resilient modulus test method (AASHTO T307) for Indiana subgrades, to develop useful predictive models for use in Level 1 and Level 2 input of subgrade Mr values following the New M-E Design Guide, to develop a simple calculation method, and to develop a constitutive model based on the Finite Element Method (FEM) to account for both the resilient and permanent behavior of subgrade soils. The following conclusions can be drawn from this study.

1) Resilient modulus test results showed that it may be possible to simplify the complex procedures required in the existing Mr testing (AASHTO T307) to a single step with a confining stress of 2 psi and deviator stresses of 2, 4, 6, 8, 10 and 15 psi. The simplified procedure suggested compared well with the existing Mr testing procedure. The simplified procedure can be used for estimation of resilient modulus rather than performing the complex procedure with good accuracy. However, it should be noted that one of the disadvantages to use the simplified procedure is that it considers only one confining stress level that is the most conservative. If automatic equipment were available, it would be more desirable to use the wide range of stresses in existing standard 
resilient modulus test. This is because the additional steps do not require additional efforts to prepare the specimen and measure the data, and a number of data can be obtained to use different stress levels.

2) For some soils, excessive permanent strains occurred during resilient modulus testing. It turns out that this is because the stress ratio of the deviator stress to the peak strength of those soils and the permanent strains to reach the peak strengths were significant large.

3) The current $\mathrm{Mr}$ testing uses the original length of the specimen, but it is recommended that the deformed length during testing be used for more accurate calculation of $\mathrm{Mr}$.

4) The largest Mr values are observed in the Dry samples for silty sandy clay soils due to the capillary suction while the largest $\mathrm{Mr}$ values are observed either in the Dry or OMC sample for clay soils. The smallest Mr values obtained from Wet samples. The resilient modulus for Wet samples can be used as the limit of $\mathrm{Mr}$ in spring and further study needs to be done.

5) Three predictive models based on unconfined compressive tests, and resilient modulus tests were developed for use in subgrade design inputs. Comparisons of predicted moduli with measured ones show satisfactory agreement. These predictive models can be used for the estimation of design resilient modulus inputs for Level 1 or Level 2 design inputs.

6) A predictive model to estimate material coefficients $\mathrm{k}_{1}, \mathrm{k}_{2}$, and $\mathrm{k}_{3}$ using 12 soil variables obtained from the soil property tests and the standard Proctor tests was developed. The predicted resilient moduli using all the predictive models 
compared satisfactorily with measured ones. These predictive models can be used for the estimation of design resilient modulus inputs for Level 1 or Level 2 design inputs.

7) A mathematical expression using Fourier series for the repeated loading on a soil was derived and this can be used as a simple calculation for obtaining the resilient modulus;

8) Although the permanent strain occurs during the resilient modulus test, the permanent behavior of subgrade soils is currently not taken into consideration. In order to capture both the permanent and the resilient behavior of subgrade soils, a constitutive model based on the Finite Element Method (FEM) was proposed. The predictive permanent strains are comparable to the measured ones. The proposed constitutive model can allow capturing the permanent behavior of subgrade soils subjected to a much smaller load (e.g. the load used in resilient modulus testing) than that causing shear failure, which cannot be modeled by classical constitutive models such as the Mohr-Coulomb or the Drucker-Prager model. A comparison of the measured permanent strains with those obtained from the Finite Element (FE) analysis showed a reasonable agreement.

9) The current Mr testing cannot take into account the long term Mr values due to a limited number of repeated loadings applied to the specimen. The long term Mr values are especially needed for rehabilitation. The long-term resilient modulus tends to level off after 5,000 repetitions of repeated loading and the long-term permanent strain tends to plateau under a consistent stress level, 
often after approximately 500 repetitions. This supports the number of the repetitions of the conditioning stage used for the standard resilient modulus test, however it is likely that soil may experience a different plateau under a different stress condition.

10) An extensive review of the M-E design for subgrades was done. Based on the test results and review of the M-E Design, implementation initiatives can be proposed in the next section.

\subsection{Implementation of Unbound Material Design Inputs}

\subsubsection{Subgrade Design Input Level 3}

In Level 3 design, a modulus value for unbound material is required. There are two options to determine the modulus: ICM Calculated Modulus, and User Input Modulus (i.e., Representative Modulus). The ICM Calculated Modulus allows seasonal variation in the moduli for different months while the User Input Modulus remains constant for the entire design period. Therefore, it is desirable to use the ICM input module. In addition, a general equation between the $\mathrm{Mr}$ and $\mathrm{CBR}$ values is provided. Typical CBR values for most of untreated fine-grained soils in Indiana are in the range of 3 to $15 \%$ corresponding to $\mathrm{Mr}$ values from 4,940 to $12,970 \mathrm{psi}$. This range of $\mathrm{Mr}$ appears to be reasonable in the design input Level 3.

\subsubsection{Subgrade Design Input Level 2}

In Level 2 design, the following properties: $\mathrm{Mr}, \mathrm{CBR}$, R-value, Dynamic Cone Penetration Test (DCPT), layer coefficient and Plasticity Index (PI) and gradation can be 
selected. As discussed earlier, there are two design input options: EICM input and representative $\mathrm{Mr}$ input, and seasonal input. Several analyses revealed that similar outputs are observed in both Level 3 and Level 2 when a resilient modulus is selected using the Integrated Climatic Model (ICM) module. For seasonal design input option, monthly resilient moduli are required.

For Level 2 design, as shown previously, the following equation based on the results of unconfined compressive tests can be used.

$$
\begin{aligned}
& \mathrm{Mr}=11267.7 \times \ln \left(\mathrm{E}_{\mathrm{f}}\right)+3217.239 \times \ln \left(\mathrm{q}_{\mathrm{u}}\right)-76.9 / \varepsilon_{\mathrm{y}}+-8725.31 \times \ln \left(\mathrm{E}_{\mathrm{f}}\right) 2587.73 \times \ln \left(\mathrm{q}_{\mathrm{y}}\right) \\
& +127.5 / \varepsilon_{\mathrm{y}}-13513.9
\end{aligned}
$$

Where $\mathrm{E}=$ tangent elastic modulus, $\mathrm{q}_{\mathrm{u}}=$ unconfined compressive strength, $\mathrm{E}_{\mathrm{f}}=$ Secant modulus at failure, $\varepsilon_{\mathrm{y}}=$ strain at yield stress, $\mathrm{Mr}=$ Resilient modulus at a confining stress of $2 \mathrm{psi}$ and a deviator stress of 6 psi.

All the tested soils were prepared at dry of optimum $(95 \%$ of the maximum dry density), optimum, and wet of optimum ( $95 \%$ of the maximum dry density). As shown in Figure 40, predicted resilient moduli using equation (8.1) were reasonably comparable with the measured resilient moduli. When State DOTs are not capable of performing a resilient modulus test, this type of equation based on the unconfined compressive test would be quite useful to predict the resilient modulus. 


\subsubsection{Subgrade Design Input Level 1}

In Level 1 design, non-linear coefficients $\mathrm{k}_{1}, \mathrm{k}_{2}$, and $\mathrm{k}_{3}$ are required. In order to generate a Mr predictive model, testing data for fourteen compacted cohesive subgrade soils were analyzed. As discussed previously, the following non-linear regression coefficients were obtained.

$\log \mathrm{k}_{1}=6.660876-0.22136 \times \mathrm{OMC}-0.04437 \times \mathrm{MC}-0.92743 \times \mathrm{MCR}-0.06133 \times \mathrm{DD}+$ $10.64862 \times \%$ COMP $+0.328465 \times$ SATU $-0.04434 \times \%$ SAND -0.04349 x \%SILT $-0.01832 \times$ \%CLAY $+0.027832 \times$ LL $-0.01665 \times$ PI

$$
\begin{aligned}
\mathrm{k}_{2}= & 3.952635-0.33897 \times \mathrm{OMC}+0.076116 \times \mathrm{MC}-2.45921 \times \mathrm{MCR}-0.06462 \times \mathrm{DD}+ \\
& 6.012966 \times \% \mathrm{COMP}+1.559769 \times \mathrm{SATU}+0.020286 \times \% \text { SAND }+0.002321 \times \\
& \% \mathrm{SILT}+0.011056 \times \% \mathrm{CLAY}+0.077436 \times \mathrm{LL}-0.05367 \times \mathrm{PI}
\end{aligned}
$$

$\mathrm{k}_{3}=2.634084+0.124471 \times \mathrm{OMC}-0.09277 \times \mathrm{MC}+0.366778 \times \mathrm{MCR}-0.01168 \times \mathrm{DD}-$ $1.32637 \times \%$ COMP $+1.297904 \times$ SATU -0.01226 x \%SAND $-0.00512 \times \%$ SILT $0.00492 \times$ \%CLAY $-0.05083 \times$ LL +0.018864 x PI $(8.2)$

where; OMC (Optimum Moisture Content), MC (Moisture Content), MCR (Moisture Content Ratio $=$ Moisture Content/ Optimum Moisture Content), DD (Dry Density), \%COMP $($ Percent Compaction $=$ Dry Density/ Maximum Dry Density), SATU (Degree of Saturation), \%SAND (Percent Sand in Particle Size Distribution Curve), \%SILT 
(Percent Silt in Particle Size Distribution Curve), \%CLAY (Percent Clay in Particle Size Distribution Curve), LL (Liquid Limit) and PI (Plasticity Index).

The resilient modulus can be calculated by inserting the regression coefficient into the following equation (8.3) which is recommended by M-E Design Guide (NCHRP 2004):

$$
M r=k_{1} p_{a}\left(\frac{\theta}{p_{a}}\right)^{k_{2}}\left(\frac{\tau_{o c t}}{p_{a}}+1\right)^{k_{3}}
$$

where, $\mathrm{k}_{1}, \mathrm{k}_{2}, \mathrm{k}_{3}$, $=$ regression coefficients; $\theta=$ sum of principal stresses; $\mathrm{p}_{\mathrm{a}}=$ reference pressure $=100 \mathrm{kpa} \approx 1 \mathrm{kgf} / \mathrm{cm}^{2} \approx 2000 \mathrm{psf} \approx 14.5 \mathrm{psi} ; \sigma_{\mathrm{d}}=$ deviator stress in the same unit as $\mathrm{p}_{\mathrm{a}}$, and $\tau_{\text {oct }}$ is the octahedral shear stress.

If a resilient modulus testing can be done, it is the best way to obtain the nonlinear regression coefficients through a laboratory Mr test data obtained from AASHTO T 307.

\subsubsection{Design Example - Level 1, Level 2}

Two design examples are presented in the following case studies. A pavement section consists of 4 inches of hot-mix asphalt surface and intermediate layers, 3 inches of hot-mix asphalt permeable base, 3 inches of hot-mix asphalt base layer on 24 inches of subgrade layer, and a semi-infinite layer, top to bottom. The pavement location is in Northwest Indiana and the climatic data available for South Bend station were selected.

In order to design the subgrade, the following physical and mechanical tests are needed: sieve analysis, Atterberg limit tests, compaction test, unconfined compressive 
tests on samples compacted at OMC and wet of optimum, resilient modulus tests on samples compacted at OMC and wet of optimum. The results of the subgrade soil are presented from Figure 73 to Figure 77 and in Table 8.

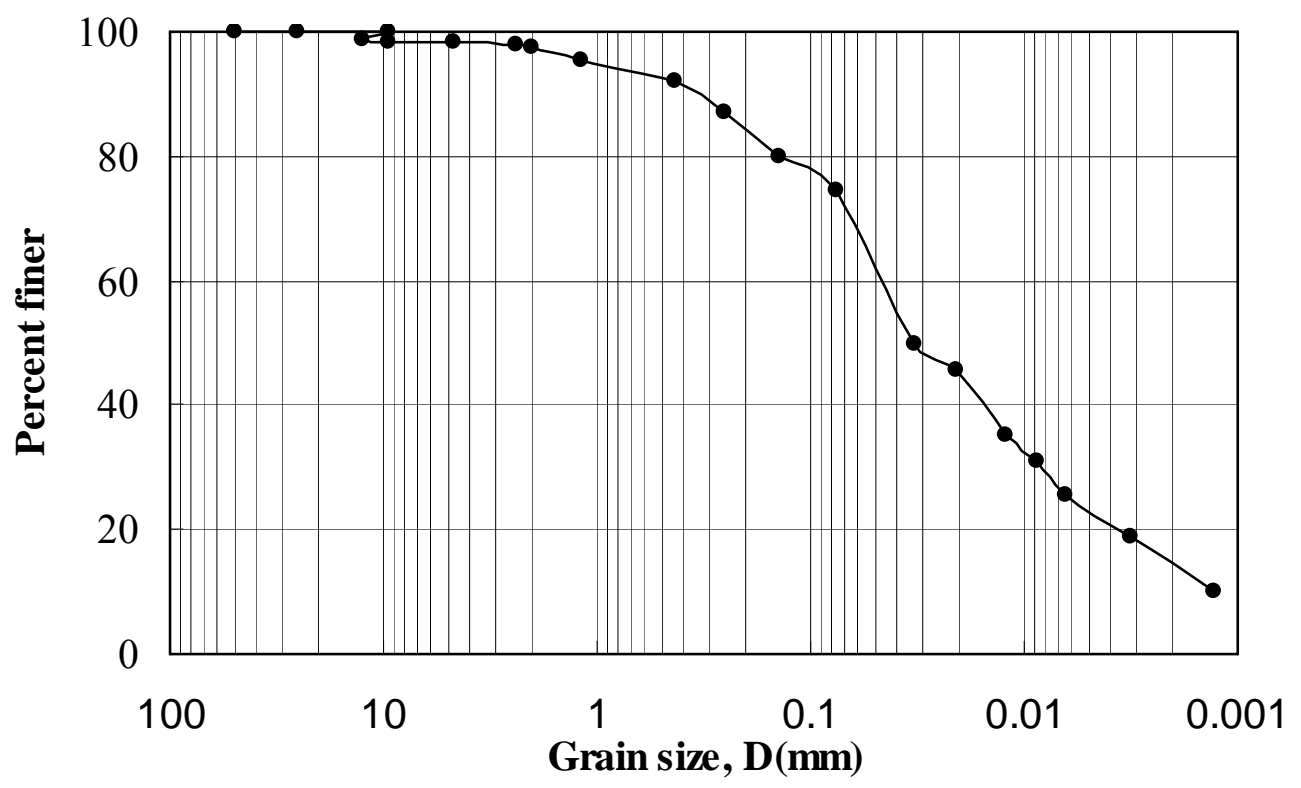

Figure 73. Particle size distributions

Table 8. Material properties for a design example

\begin{tabular}{l|l|l|l|l|l|l|l|l}
\hline \hline soil & $\%$ & $\%$ & $\%$ & $\%$ & & & & \\
& Gravel & Sand & Silt & $\begin{array}{l}\% \\
\text { clay }\end{array}$ & LL & PI & AASHTO & USCS \\
\hline \#4soil & 2.5 & 23.2 & 59.8 & 14.5 & 43 & 21 & A-7-6 & CL \\
\hline \hline
\end{tabular}




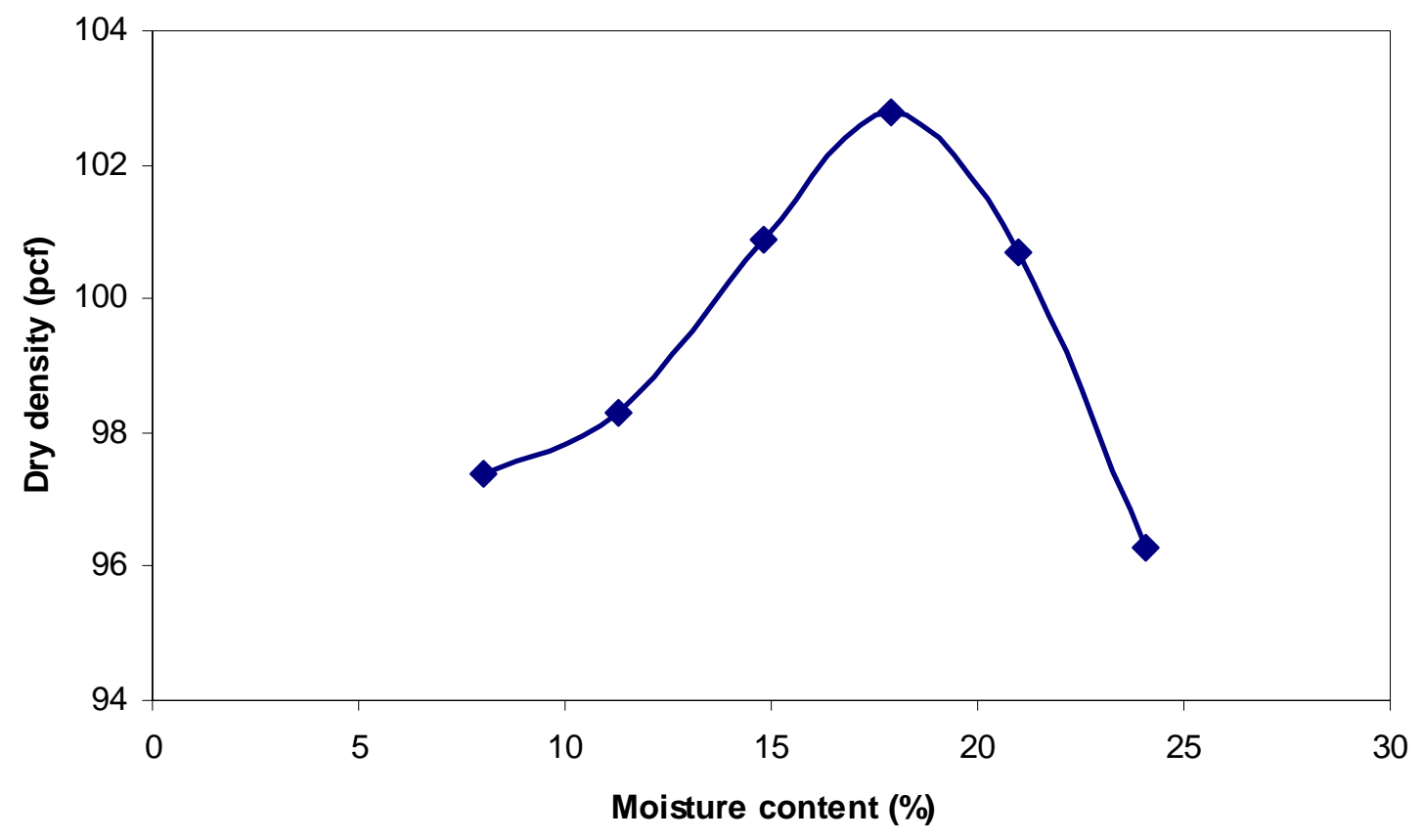

Figure 74. Compaction curve following AASHTO T 99

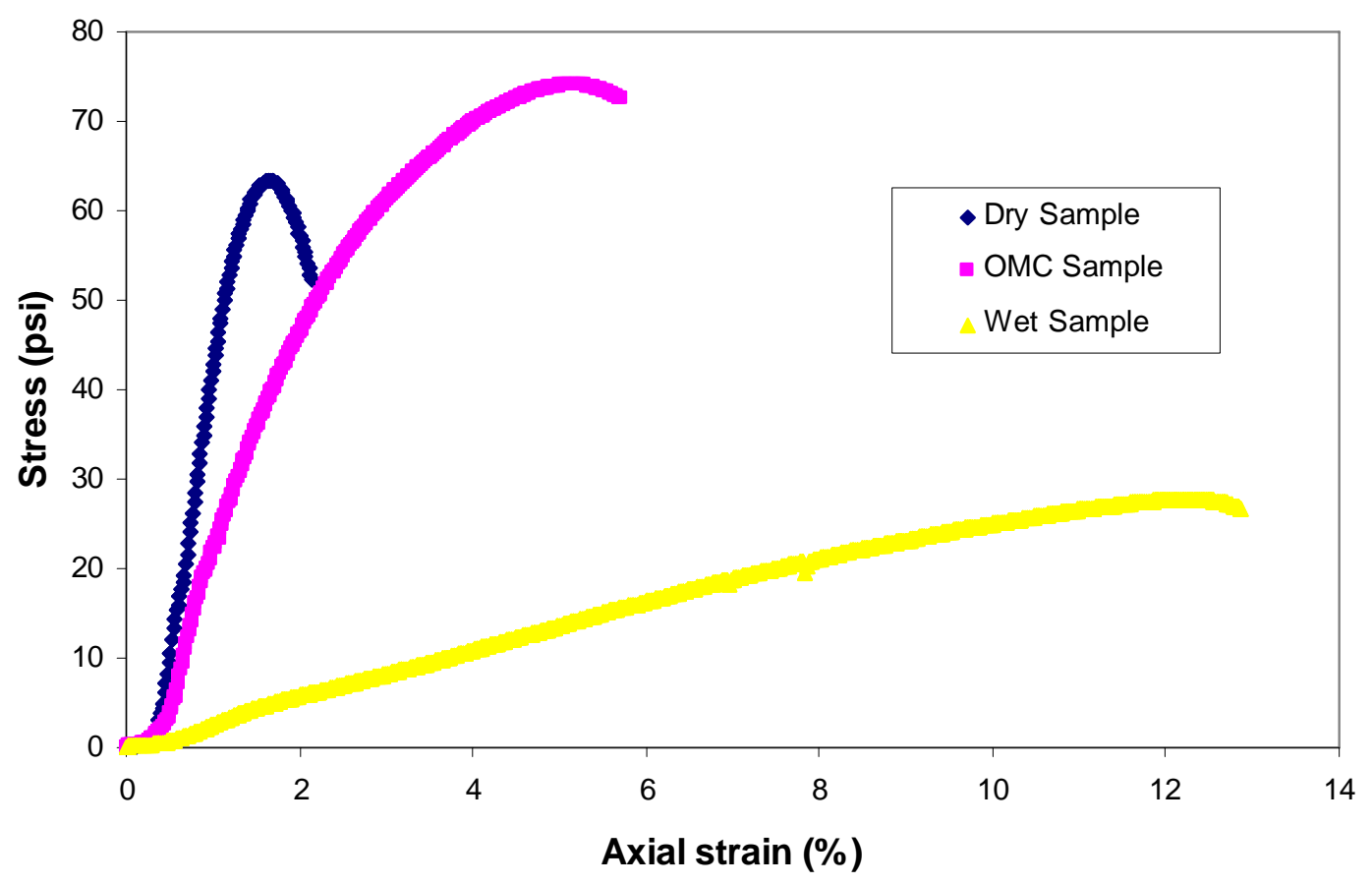

Figure 75. Unconfined compressive tests for Dry, OMC and Wet samples 


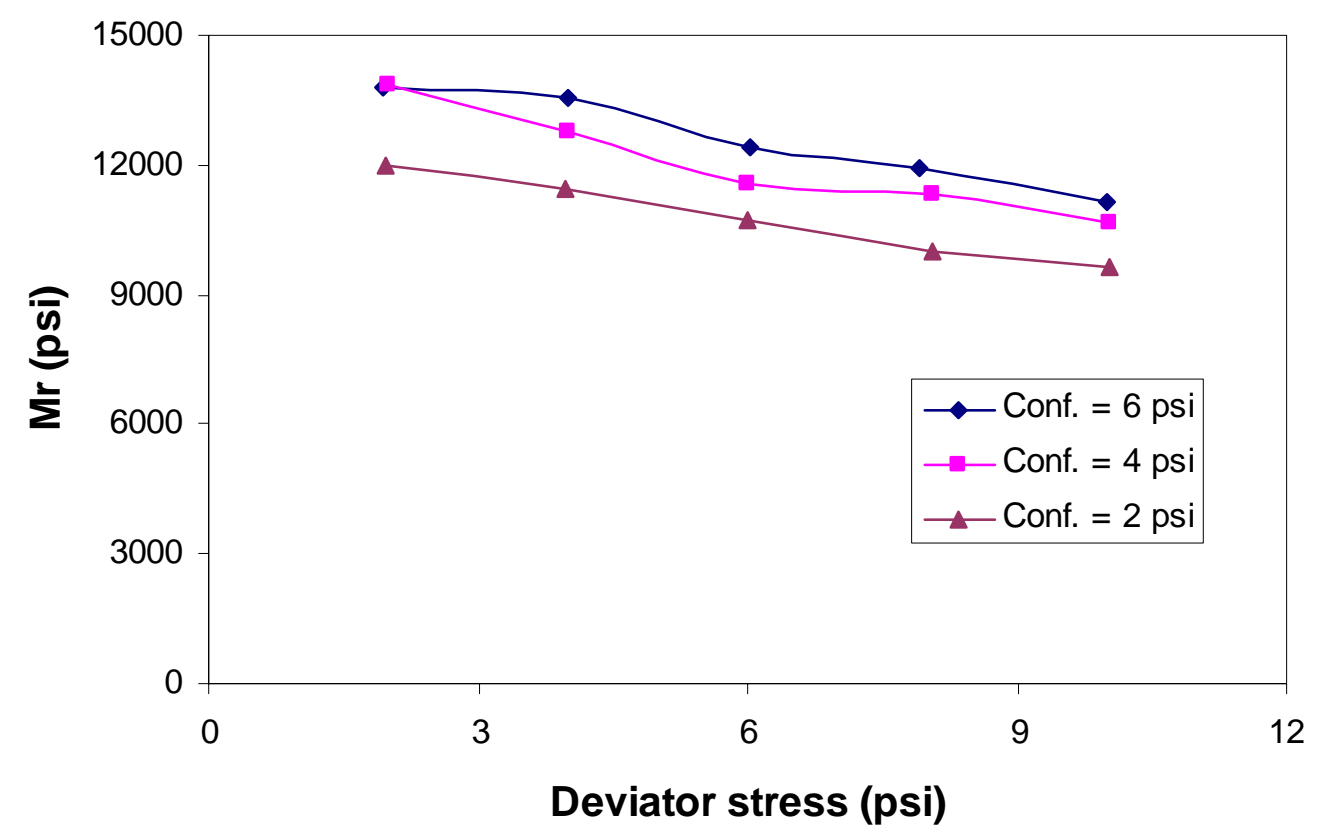

Figure 76. Resilient modulus test for OMC sample following AASHTO T-307

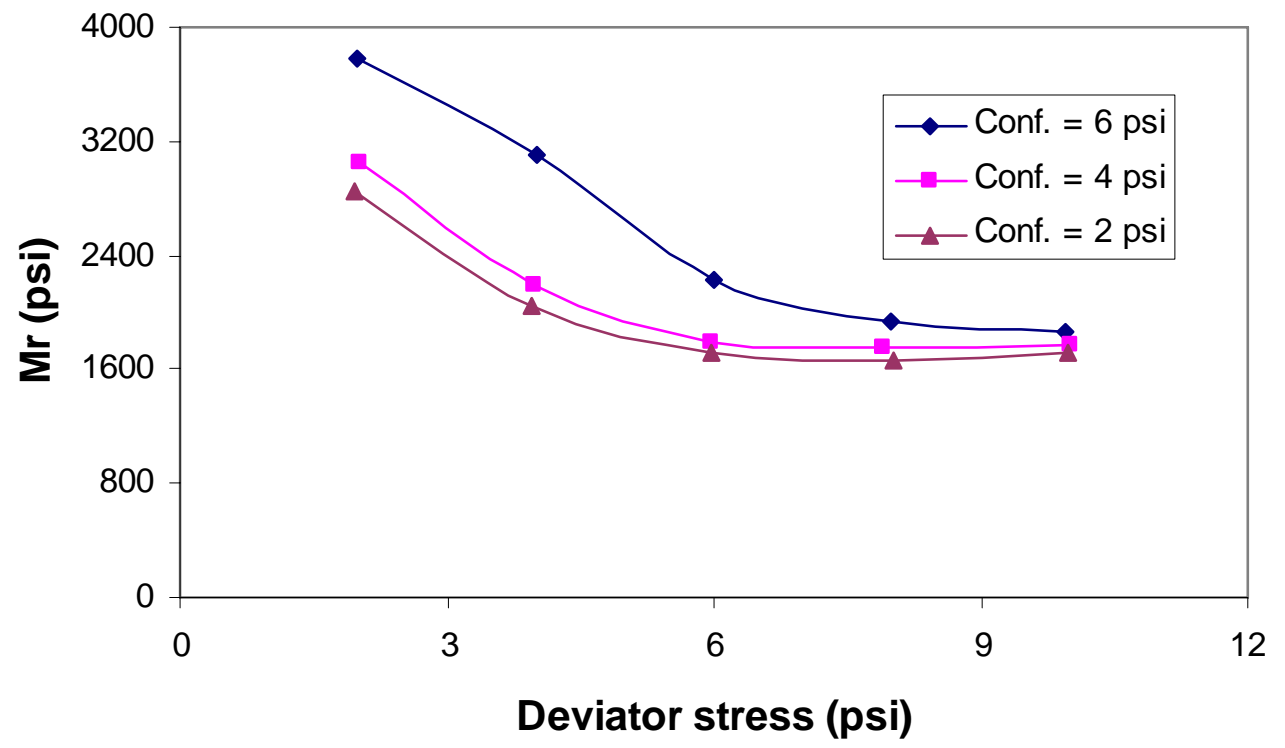

Figure 77. Resilient modulus test for wet sample following AASHTO T-307 
Table 9. Parameters for use in equation (8.2)

\begin{tabular}{|l|l|l|}
\hline Soil & OMC sample & WET sample \\
\hline OMC & 17.9 & 17.9 \\
\hline MC & 17.493 & 22.234 \\
\hline MCR & 0.977263 & 1.242123 \\
\hline MDD & 102.8 & 102.8 \\
\hline DD & 102.286 & 100.738 \\
\hline \%comp & 0.995 & 0.979942 \\
\hline SATU & 0.797 & 0.971 \\
\hline \%sand & 23.2 & 23.2 \\
\hline \%silt & 59.8 & 59.8 \\
\hline \%clay & 14.5 & 14.5 \\
\hline LL & 43 & 43 \\
\hline PI & 21 & 21 \\
\hline
\end{tabular}

The following procedure for Level 1 and Level 2 is recommended in the M-E Design Guide.

- Step 1: Assume initial compacted conditions are $\gamma_{\mathrm{d}}=\gamma_{\max }, \mathrm{w}=\mathrm{w}_{\mathrm{opt}}$, use $\gamma_{\mathrm{dmax}}$ and $\mathrm{w}_{\mathrm{opt}}$ for subbases and subgrades;

- Step 2: For each layer measure $\gamma_{\max }$ and $\mathrm{w}_{\mathrm{opt}}$;

- Step 3: For each layer measure $\mathrm{Mr}_{\mathrm{opt}}$ for a range of confining pressures and stress levels to obtain $\mathrm{k}_{1}, \mathrm{k}_{2}, \mathrm{k}_{3}$;

- Step 4: Use output from the EICM to estimate the moisture change from the optimum condition to the equilibrium condition, $\mathrm{S}_{\text {equil }}-\mathrm{S}_{\text {opt }}$;

- Step 5: Use equation (3.11) to estimate $\mathrm{Mr} / \mathrm{Mr}_{\text {opt }}$ for $\mathrm{Mr}$ for each layer, to account for moisture change; 
- Step 6: Account for change in moduli due to freezing, thawing, and recovery using the recommendations by NCHRP report (2004).

As discussed previously, the M-E Design Guide may lead to unconservative design for subgrade, the following conservative design procedure is proposed:

- Step 1: To be conservative assume $\gamma_{\mathrm{d}}=\gamma_{\mathrm{avg}}=\left(\gamma_{\mathrm{dmax}}+\gamma_{\mathrm{wet}}\right) / 2, \mathrm{w}=\mathrm{w}_{\mathrm{avg}}=$ $\left(\mathrm{w}_{\mathrm{opt}}+\mathrm{w}_{\mathrm{wet}}\right) / 2$, use $\gamma_{\mathrm{avg}}$ and $\mathrm{w}_{\mathrm{avg}}$ for subbases and subgrades. The maximum dry density and dry density corresponding to wet of optimum (95\% of $\left.\gamma_{\mathrm{dmax}}\right)$ and optimum moisture content and moisture content for wet of optimum can be obtained from compaction curve shown in Figure 74 . These are $\gamma_{\mathrm{dmax}}=$ 102.8 pcf, $\gamma_{\mathrm{wet}}=97.66 \mathrm{pcf}, \gamma_{\mathrm{avg}}=100.23 \mathrm{pcf}, \mathrm{w}_{\mathrm{opt}}=17.9 \%, \quad \mathrm{w}_{\mathrm{wet}}=24 \%$ and $\mathrm{w}_{\mathrm{avg}}=20.95 \%$;

- Step 2: For each layer determine $\gamma_{\text {avg }}$ and $\mathrm{w}_{\mathrm{avg}}$. Use the values obtained above;

- Step 3: For each layer measure $\mathrm{Mr}_{\mathrm{avg}}=\left(\mathrm{Mr}_{\mathrm{opt}}+\mathrm{Mr}_{\mathrm{wet}}\right) / 2$ for a range of confining pressures and stress levels to obtain $\mathrm{k}_{1}, \mathrm{k}_{2}, \mathrm{k}_{3}$ or use equation (8.2) based on the soil properties. $\mathrm{Mr}_{\mathrm{opt}}$ and $\mathrm{Mr}_{\mathrm{wet}}$ are obtained from Figures 76 and 77. $\mathrm{Mr}_{\mathrm{avg}}=6,207 \mathrm{psi}, \quad \mathrm{Mr}_{\mathrm{opt}}=9,855 \mathrm{psi}$, and $\mathrm{Mr}_{\mathrm{wet}}=2,559$ psi for a confining stress of 2 psi and a deviator stress of 6 psi are obtained using equation (8.2) based on the soil parameters shown in Table 9. When a resilient modulus test is not available, perform an unconfined compressive test as shown in Figure 75; 
- Step 4: Use output from the EICM to estimate the moisture change from the optimum condition to the equilibrium condition, $\mathrm{S}_{\text {equil }}-\mathrm{S}_{\mathrm{avg}}$, or use equation (3.10) to obtain $\mathrm{S}_{\text {equil }}$, or use SWCC diagram shown in NCHRP report (2004). $\mathrm{S}_{\mathrm{equil}}=0.97, \mathrm{~S}_{\mathrm{avg}}=0.884, \quad \mathrm{~S}_{\mathrm{wet}}=0.971, \mathrm{~S}_{\mathrm{opt}}=0.797 \mathrm{~S}_{\text {equil }}-\mathrm{S}_{\mathrm{avg}}=0.086$ are obtained;

- Step 5: Use equation (3.11) to estimate $\mathrm{Mr} / \mathrm{Mr}_{\text {avg }}$ for $\mathrm{Mr}$ for each layer, to account for moisture change. Figure 78 shows the variation in $\mathrm{Mr} / \mathrm{Mr}_{\mathrm{avg}}$ with respect to change degree of saturation;

- Step 6: Account for change in moduli due to freezing, thawing, and recovery using the recommendations following the M-E Design Guide. For the freezing moduli, use the values suggested by Lee et al. (1993) to be unconservative. For thawing $\mathrm{Mr}$, select the $\mathrm{Mr}$ for wet sample until the thawed $\mathrm{Mr}$ is accumulated.

Using the input parameters obtained with the proposed procedure, two analyses were performed: one with optimum values and the other with average values. A comparison of permanent deformations in the subgrade between the two analyses is shown in Figure 79. It is observed that when using the average values, the permanent strain in the subgrade is increased by approximately $23 \%$. Changes in resilient modulus over the design period are plotted in Figures 81 and 82. As expected, the smaller resilient modulus values are observed throughout the design life. As evidenced in Figure 80 by the change in resilient modulus with respect to the month, the M-E Design Guide assumes the thawed resilient modulus to be about 1,000,000 psi. 


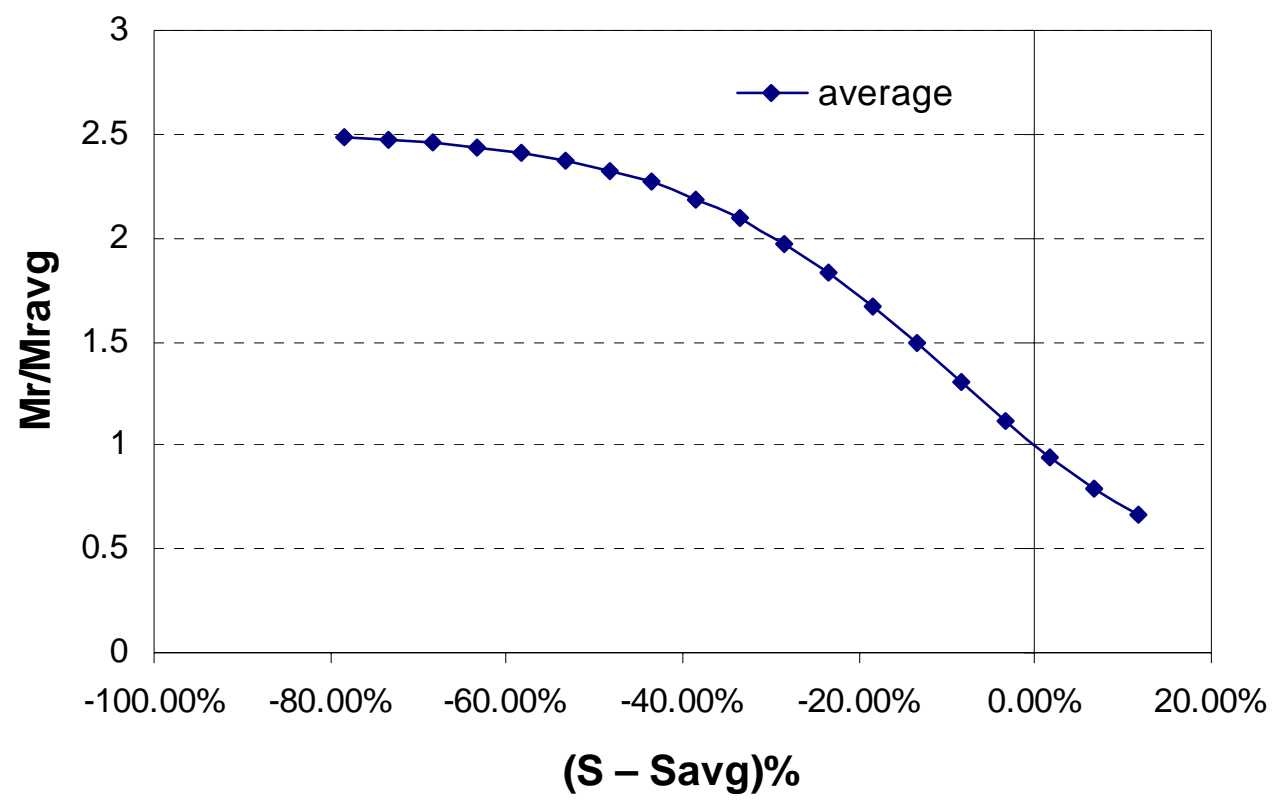

Figure 78. Modulus ratio due to change in moisture

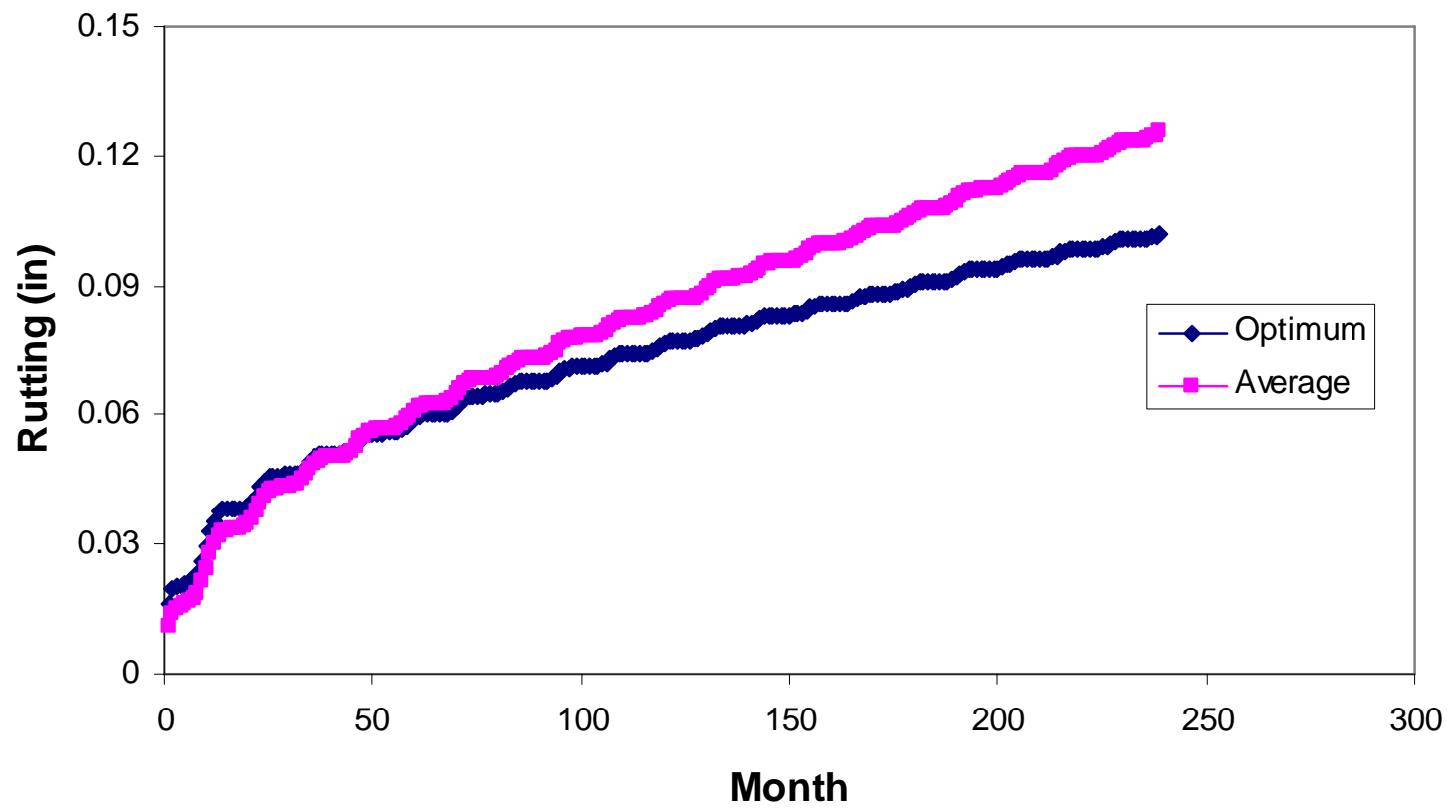

Figure 79. Comparison of permanent deformations (rutting) between optimum and average values 


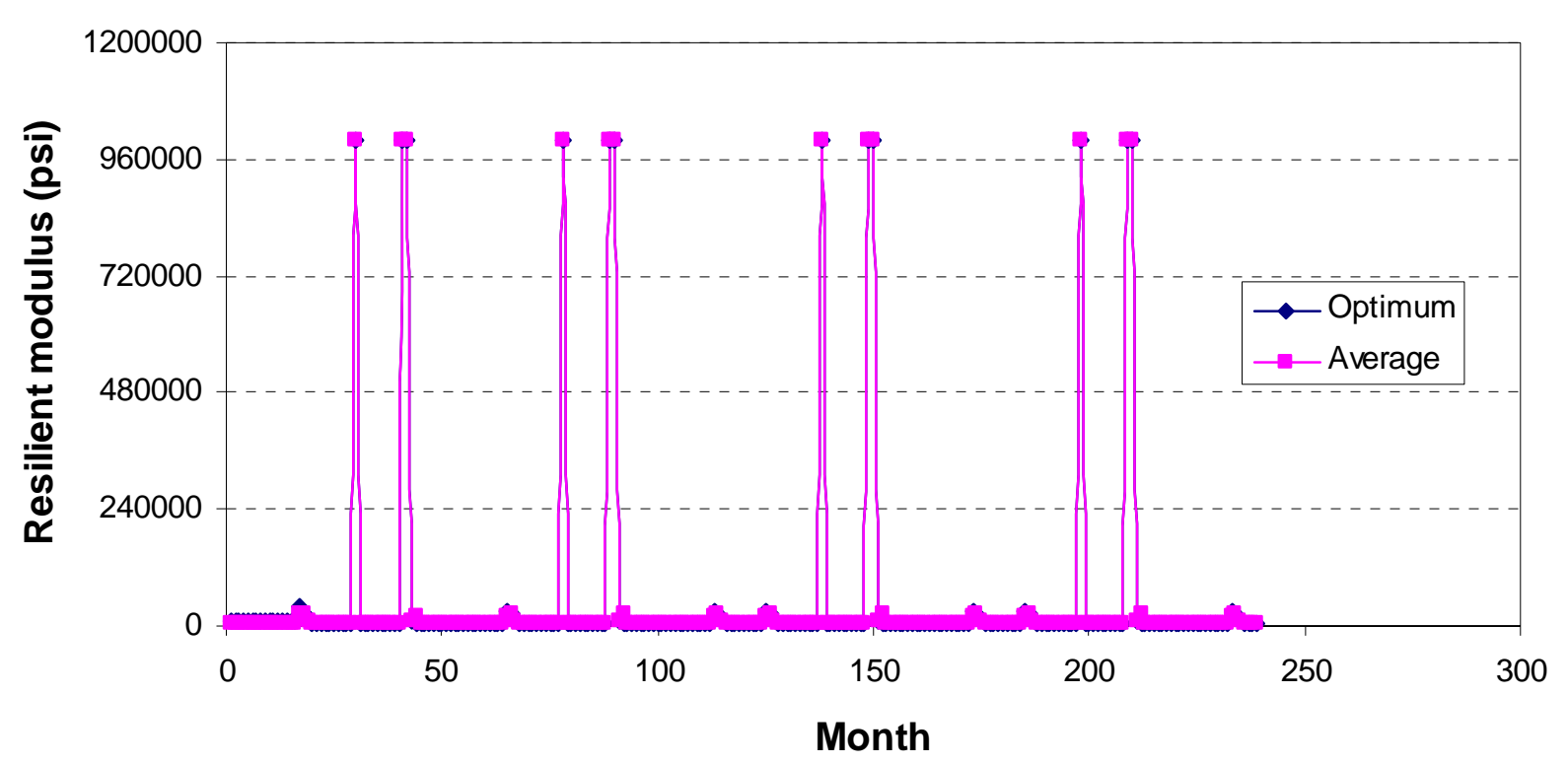

Figure 80. Modulus ratio due to change in moisture

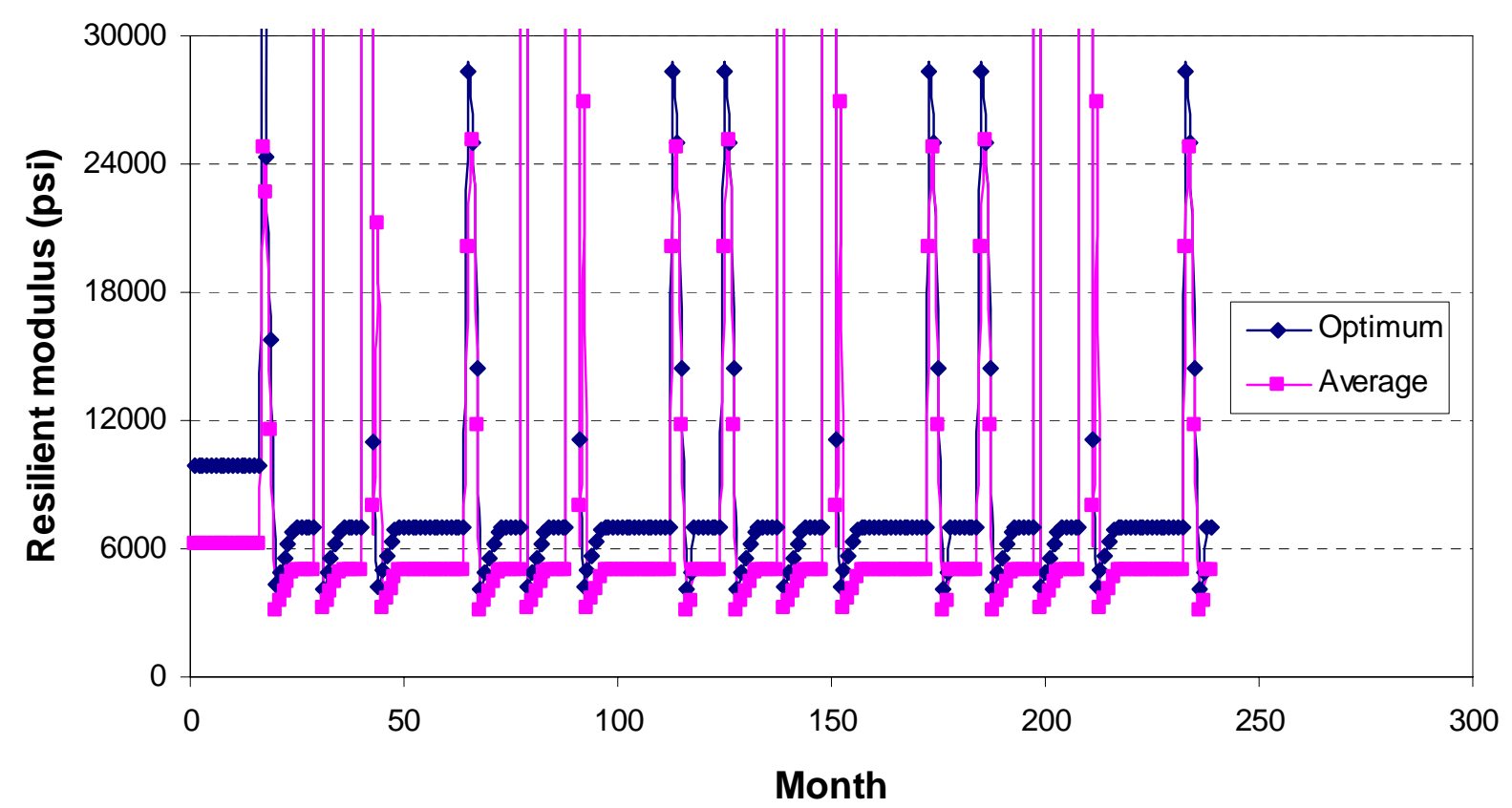

Figure 81. Modulus ratio due to change in moisture (expanded)

\subsubsection{Summary of Implementation Initiatives}


With the advent of the new M-E Design Guide, highway agencies are encouraged to implement an advanced design following its philosophies. As part of implementation of the M-E Design Guide, the present study reviewed the features embedded in this new design guide for unbound materials, especially subgrades.

The following can be summarized:

- The M-E Design Guide assumes that the subgrade is compacted to optimum moisture content, leading to unconservative design. In order to ensure a conservative design for subgrades, the use of the average values is recommended (to be more conservative, use of the Mr at wet of optimum may be possible);

- When laboratory testing for evaluating thawed $\mathrm{Mr}$ is not available, the use of Mr for wet of optimum would be reasonable;

- Caution needs to be taken to use the conservative frozen Mr value suggested in M-E Design Guide.

- In characterizing subgrade in Indiana, Mr testing program for both design inputs Level 2 and Level 1 is desirable.

\section{$\underline{\text { 8.3. Recommendations }}$}

1) In this study, the resilient and permanent behavior of cohesive subgrade was mainly investigated. Further study on resilient behavior of cohesionless subgrade 
is recommended. Further study on the long term resilient and permanent behavior is recommended.

2) The New M-E Design Guide accounts for the monthly variation of subgrades. Laboratory resilient modulus testing to assess the monthly variation and the freeze-thaw in the subgrade is recommended.

3) The New M-E Design guide employs the unsaturated soil characteristics. Laboratory evaluation on unsaturated soil properties such as soil water characteristic curve (SWCC) needs to be studied.

4) In this study, laboratory tests were done to evaluate the resilient behavior of subgrade soils. The calibration between lab $\mathrm{Mr}$ and In-situ Mr using Falling Weight Deflectometer (FWD) or Portable Weight Deflectometer (PFWD) or Dynamic Cone Penetrometer (DCP) needs to be done to realistically characterize the in-situ resilient modulus. 


\section{LIST OF REFERENCES}

"The AASHO Road Test". (1962). Report 7, American Association of State High Officials, Washington, D.C.

Bergado D. T., Anderson, L. R., Miura, N. and Balasubramaniam, A. S. (1996). "Soft Ground Improvement in Lowland and Other Environments", ASCE, New York.

Chen, W. F. and Saleeb, A. F. (1994). "Constitutive Equations for Engineering Materials", Vol. 2, Elsevier Science B.V, Amsterdam, The Netherlands.

Cook, R. D., Malkus, D. S. and Plesha, M. E. (1989). "Concepts and Applications of Finite Element Analysis, $3^{\text {rd }}$ edition, John Wiley \& Sons.

Daita, R. C., Drnevich, V., Kim, D. (2005). "Family of Compaction Curves for Chemically Modified Soils", M.S Thesis, Purdue University, West Lafayette, IN.

Desai, C. C. and Siriwardane, H. J. (1984). "Constitutive Laws for Engineering Materials with Emphasis on Geological Materials, Prentice-Hall, Englewood Cliffs, New Jersey.

Diyaljee, V. A. and Raymond, G. P. (1983). "Repetitive Load Deformation of Cohesionless Soil", Journal of Geotechnical and Engineering, ASCE, Vol. 108, No. 10, pp. 1215-1229.

Drumm, E. C., Boateng-Poku, Y. and Pierce, T. J. (1990). "Estimation of Subgrade Resilient Modulus from Standard Tests." Journal of Geotechnical Engineering, ASCE, Vol. 116, No. 5, pp. 774-789.

Drumm, E. C., Reeves, J. S., Madgett, M.R. and Trolinger, W. D. (1997). "Subgrade Resilient Modulus Correction for Saturation Effects." Journal of Geotechnical and Geoenvironmental Engineering, ASCE, Vol. 123, No. 7, pp. 663-670.

Elliott, R. P., and Thornton, S. I. (1988). "Resilient Modulus and AASHTO Pavement Design." Transportation Research Record, 1196, TRB, National Research Council, Washington, D.C., pp. 116-124. 
Elliott, R. P., Dennis, N. and Qiu, Y. (1999). "Permanent Deformation of Subgrade Soils, Phase II: Repeated Load Testing of Four Soils.” Report No. MBTC FR-1089, Final Report, National Technical Information Service, Springfiled, VA, pp.1-85.

Gaskin, P. N., Raymond, G. P. and Addo-Abedi, F. Y. (1979). "Repeated Compressive Loading of a Sand". Canadian Geotechnical Journal, National Research Council of Canada, Vol. 16, pp. 798-802.

Ghazzaly, O. and Ha, H. (1975). "Pore Pressures and Strains After Repeated Loading of Saturated Clay: Discussion." Canadian Geotechnical Journal. National Research Council of Canada, Vol. 12, pp. 265-267.

Hall, D. K. and Thompson, M. R. (1994). "Soil-Property-Based Subgrade Resilient Modulus Estimation for Flexible Pavement Design.” Transportation Research Record, 1449, TRB, National Research Council, Washington, D.C., pp. 30-38.

Hardin, B. O. and Black, W. L (1968). "Vibration Modulus of Normally Consolidted Clay", Journal of Soil Mechanics and Foundation Engineering Division, ASCE, 94(SM2), pp. 353-369.

Hardin, B. O. and Drnevich, V. P. (1972). "Shear Modulus and Damping in soils; Design Equations and Curves", Journal of Soil Mechanics and Foundations Divisions, ASCE, 98(7), pp. 667-692.

Hausmann, M. R. (1990). "Engineering Principles of Ground Modification”, McGrawHill Publishing Company.

Hicks, R. G., and Monismith, C. L. (1971). "Factors Influencing the Resilient Response of Granular Materials". Highway Research Record 345, Highway Research Board, Washington, D.C., pp. 15-31.

Huang, Y. H. (1993). "Pavement Analysis and Design", Prentice Hall, Englewood Cliffs, N.J.

Hyde, A. F. L. (1974). "Repeated load triaxial testing of soils".. Ph.D. Thesis, University of Notingham, U.K..

Indiana State. (2005). "Indiana Specification".

Kim, D. (2002). "Effects of Supersingle Tire Loadings on Subgrades', Ph. D thesis, Purdue University, West Lafayette, IN.

Kim, D. and Siddiki, N. Z. (2004). "Lime Kiln Dust-Lime - A Comparative Study in Indiana, Transportation Research Board, Washington D. C. 
Ladd, C. C., Foote, R., Ishihara, K., Schlosser, F. and Poulos, H. G. (1977). "Stress Deformation and Strength Characteristics", Proc., of $9^{\text {th }}$ International Conference on Soil Mechanics and Foundation Engineering, Tokyo, Vol. 2, pp. 421-494.

Lee, W. (1993). "Evaluation of In-Service Subgrade Resilient Modulus with Consideration of Seasonal Effects", Ph.D. Thesis, Purdue University, West Lafayette, IN.

Lee, W. J., Bohra, N. C., Altschaeffl, A. G. and White, T. D. (1997). "Resilient Modulus of Cohesive Soils", Journal of Geotechnical and Geoenvironmental Engineering, ASCE, Vol. 123, No. 2, pp. 131-136.

Lee, W., Bohra, N. C. and Altschaeffl, A.G. (1995). "Resilient Characteristics of Dune Sand”, Journal of Transportation Engineering, ASCE, Vol. 121, No. 6, pp. 502-506.

Lekarp, F., Isacsson, U. and Dawson, A. (2000). "State of The Art. I: Resilient Response of Unbound Aggregates”, Journal of Transportation Engineering, Vol. 126, pp.66-75.

Lekarp, F. and Dawson, A. (1998). "Modeling Permanent Deformation Behavior of Unbound Granular Materials", Construction and Building Materials, Elsevier Science Ltd, Vol. 12, No. 1, pp. 9-18.

Lekarp, F., Isacsson, U. and Dawson, A. (2000). "State of The Art. II: Permanent Strain of Unbound Aggregates", Journal of Transportation Engineering, Vol. 126, pp.76-83.

Lentz, R.W. and Baladi, G.Y. (1981). "Constitutive Equation for Permanent Strain of Sand Subjected to Cyclic Loading." Pumphrey, N.D. Jr., and Lentz, R.W.. "Deformation Analyses of Florida Highway Subgrade Sand Subjectd to Repeated Load Triaxial Tests", Transportation Research Record, 810, TRB, National Research Council, Washington, D.C., 1986, pp. 50-54.

Mohammad, L. N., Titi, H. H. and Herath, A. (1999). "Evaluation of Resilient Modulus of Subgrade Soil by Cone Penetration Test", Transportation Research Record, 1652, TRB, National Research Council, Washington, D.C., pp. 236-245.

Mohammad, L. N., Puppala, A. J. and Alavilli, P. (1995). "Resilient Properties of Laboratory Compacted Subgrade Soils", Transportation Research Record, 1196, TRB, National Research Council, Washington, D.C., pp. 87-102.

Monismith, C. L., Ogawa, N. and Freeme, C.R. (1975). "Permanent Deformation Characteristics of Subgrade Soils Due to Repeated Loading", Transportation Research Record, 537, TRB, National Research Council, Washington, D.C., pp. 1-17. 
Muhanna, A. S., Rahman, M. S., and Lambe, P. C. (1998). "Model for Resilient Modulus and Permanent Strain of Subgrade Soils", Transportation Research Record, 1619, TRB, National Research Council, Washington, D.C., pp. 85-93.

Pezo, R. F., Kim, D., Stokoe, K. H. II. and Hudson, W. R. (1991). “A Reliable Resilient Modulus Testing System", Transportation Research Record, 1307, TRB, National Research Council, Washington, D.C., 1990, pp. 90-98.

Pezo, R. and Hudson, W. R. (1994). "Prediction Models of Resilient Modulus for Nongranular Materials”, Geotechnical Testing Journal, Vol. 17, No. 3, pp. 349-355.

Poulsen, J. and Stubstad, R. N. (1978). "Laboratory Testing of Cohesive Subgrades: Results and Implications Relative to Structural Pavement Design and Distress Models", Transportation Research Record, 671, TRB, National Research Council, Washington, D.C., pp. 84-91.

Pumphrey, N. D. Jr. and Lentz, R. W. (1986). "Deformation Analyses of Florida Highway Subgrade Sand Subjectd to Repeated Load Triaxial Tests", Transportation Research Record, 1089, TRB, National Research Council, Washington, D.C., pp. 49-56.

Puppala, A. J., Mohammad, L. N. and Allen, A. (1996). "Non-Linear Models for Resilient Modulus Characterization of Granular Soils", Proceedings of Engr. Mechanics, ASCE, New York, N.Y., USA, Vol. 1, pp. 559-562.

Raad, L. and Zeid, B.A. (1990). "Repeated Load Model for Subgrade Soils: Model Development", Transportation Research Record, 1278, TRB, National Research Council, Washington, D.C., pp. 72-82.

Raymond, G. P., Gaskin, P. N. and Addo-Abedi, F. Y. (1979). "Repeated Compressive Loading of Leda Clay", Canadian Geotechnical Journal. National Research Council of Canada, Vol. 16, pp. 1-10.

Salgado, R. (1995). “Analysis of Penetration Resistance in Sand”, Ph.D. Thesis, Univ. of California, Berkeley, California.

Salgado, R., Bandini, P. and Karim, A. (1999). "Stiffness and Strength of Silty Sand", Journal of Geotechnical and Geoenvironmental Engineering, ASCE, 126(5), pp. 451-462.

Seed, H. B. and Chan, C.K. (1959). "Structure and Strength Characteristics of Compacted Clays", Journal of Soil Mechanics and Foundation Engineering Division, ASCE, Vol. 85, No. 5, pp. 87-128.

Seed, H. B. and Chan, C.K. (1957). "Thixotropic Characteristics of Compacted Clays", Journal of Soil Mechanics and Foundation Engineering Division, ASCE, Vol. 83, No. 6, pp. 31-47. 
Seed, H. B., and Chan, C. K. (1958). "Effect of Stress History and Frequency of Stress Application on Deformation of Clay Subgrades Under Repeated Loading", Proc., Highway Research Record, Vol. 37, Highway Research Board, Washington, D.C., pp. $555-575$.

Thompson, M. R. and Robnett, Q.L. (1979). "Resilient Properties of Subgrade Soils." Journal of Transportation Engineering, ASCE, Vol. 105, No. 1, pp. 71-89.

Wilson, B. E., Sargand, S. M., Hazen, G. A., and Green, R. (1990). "Multiaxial Testing of Subgrade", Transportation Research Record, 1278, TRB, National Research Council, Washington, D.C., pp. 91-95.

Wilson, N. E., and Greenwood, J. R. (1974). "Pore Pressures and Strains After Repeated Loading of Saturated Clay." Canadian Geotechnical Journal, National Research Council of Canada, Vol. 11, pp. 269-277. 


\section{APPENDIX}

\section{USER MATERIAL PROGRAM CODE IN ABAQUS}

SUBROUTINE UMAT(STRESS, STATEV, DDSDDE, SSE, SPD, SCD,

1 RPL, DDSDDT, DRPLDE, DRPLDT, STRAN, DSTRAN,

2 TIME, DTIME, TEMP, DTEMP, PREDEF, DPRED , CMNAME, NDI , NSHR, NTENS,

3 NSTATV, PROPS, NPROPS, COORDS, DROT, PNEWDT, CELENT,

C

4 DFGRD@, DFGRD1, NOEL, NPT, KSLAY, KSPT, KSTEP, KINC )

C

INCLUDE 'ABA_PARAM.INC'

\section{CHARACTER $* 80$ CMNAME}

DIMENSION STRESS(NTENS), STATEV(NSTATV),

1 DDSDDE (NTENS, NTENS) , DDSDDT (NTENS), DRPLDE(NTENS),

2 STRAN(NTENS), DSTRAN (NTENS), $\operatorname{TIME}(2), \operatorname{PREDEF}(1), \operatorname{DPRED}(1)$,

3 PROPS(NPROPS), $\operatorname{COORDS}(3), \operatorname{DROT}(3,3)$,

C

$4 \operatorname{DFGRD} \odot(3,3), \operatorname{DFGRD} 1(3,3)$

DIMENSION $\operatorname{TERM} 1(1,6), \operatorname{DOT}(1,6), \operatorname{CDQDS}(6,1), \operatorname{STEPSM}(6,6)$

real*8 E, Nu, rk1, rk2, rk3

real*8 s11, s22, s33, s12, s13, s23

real*8 pa, sd, toct, finu, MR, gp

real*8 d(6,6), daj(6,6), a(6), ps(6), w1(6), w2(6)

real*8 z, dfds11, dfds22, dfds33, dfds12, dfds13, dfds23

real*8 s_eff

real*8 dpe, s(6)

real*8 flag_loading

real*8 epi

logical debug

c --- beginning of executable codes -.-

debug $=$. false .

c initialize flow rule vector a

do $i=1,6$

$a(i)=0$.

end do

C

$\mathrm{C}$

C

C INPUT PARAMETERS FOR USER MATERIAL

C 
C
C
C
C
C
C
C
C
C

PROPS(1) - NU, POISSON'S RATIO

PROPS(2) - k1

PROPS(3) - k2

PROPS (4) - k3

C

C

$\mathrm{Nu}=\operatorname{PROPS}(1)$

$r k 1=\operatorname{PROPS}(2)$

$r k 2=\operatorname{PROPS}(3)$

$r k 3=\operatorname{PROPS}(4)$

epi $=1$.

if( nprops.ge.5) epi $=\operatorname{props}(5)$

C

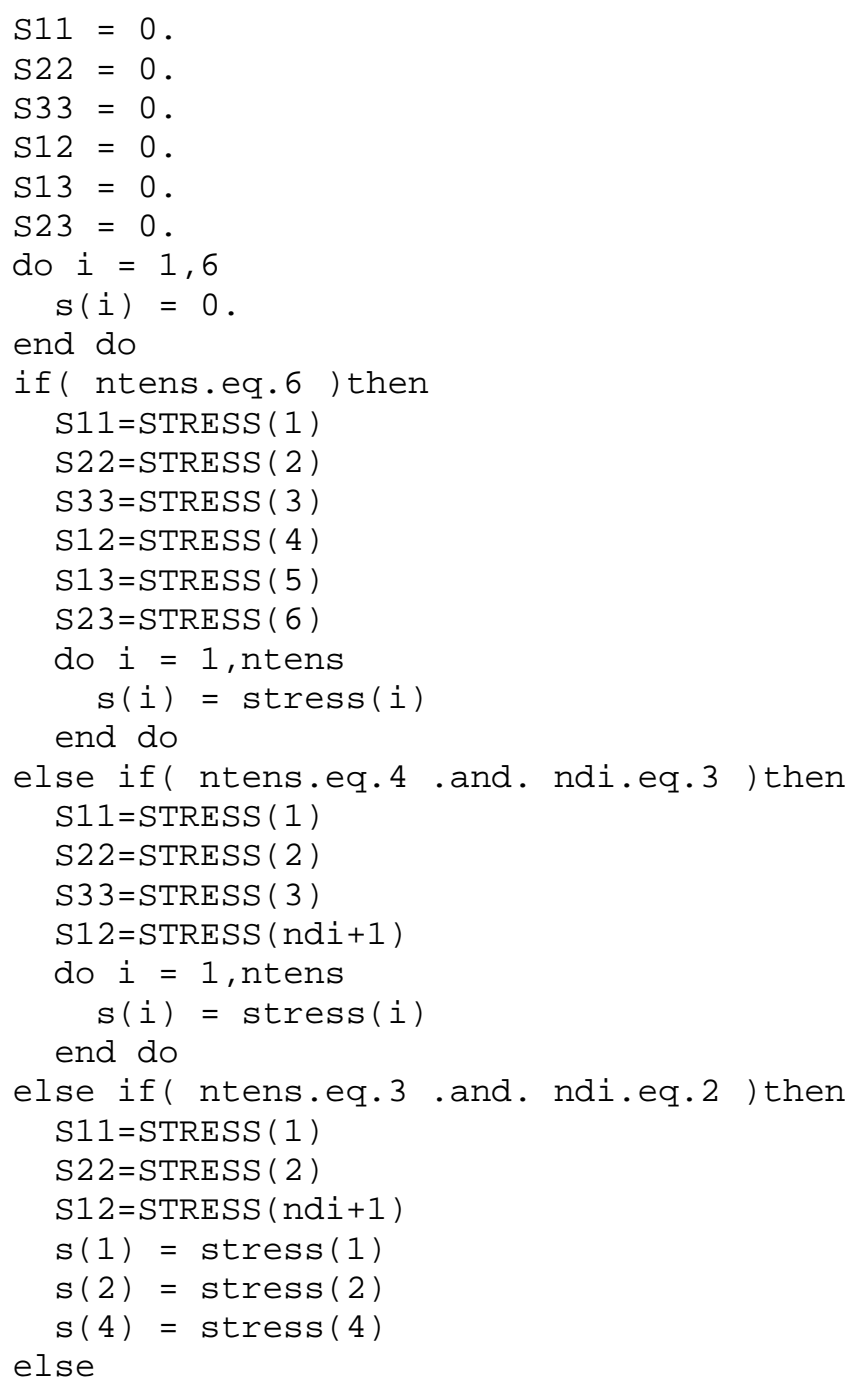


write $\left(6,{ }^{*}\right)$ 'ERR: element type NOT considered' call xit()

end if

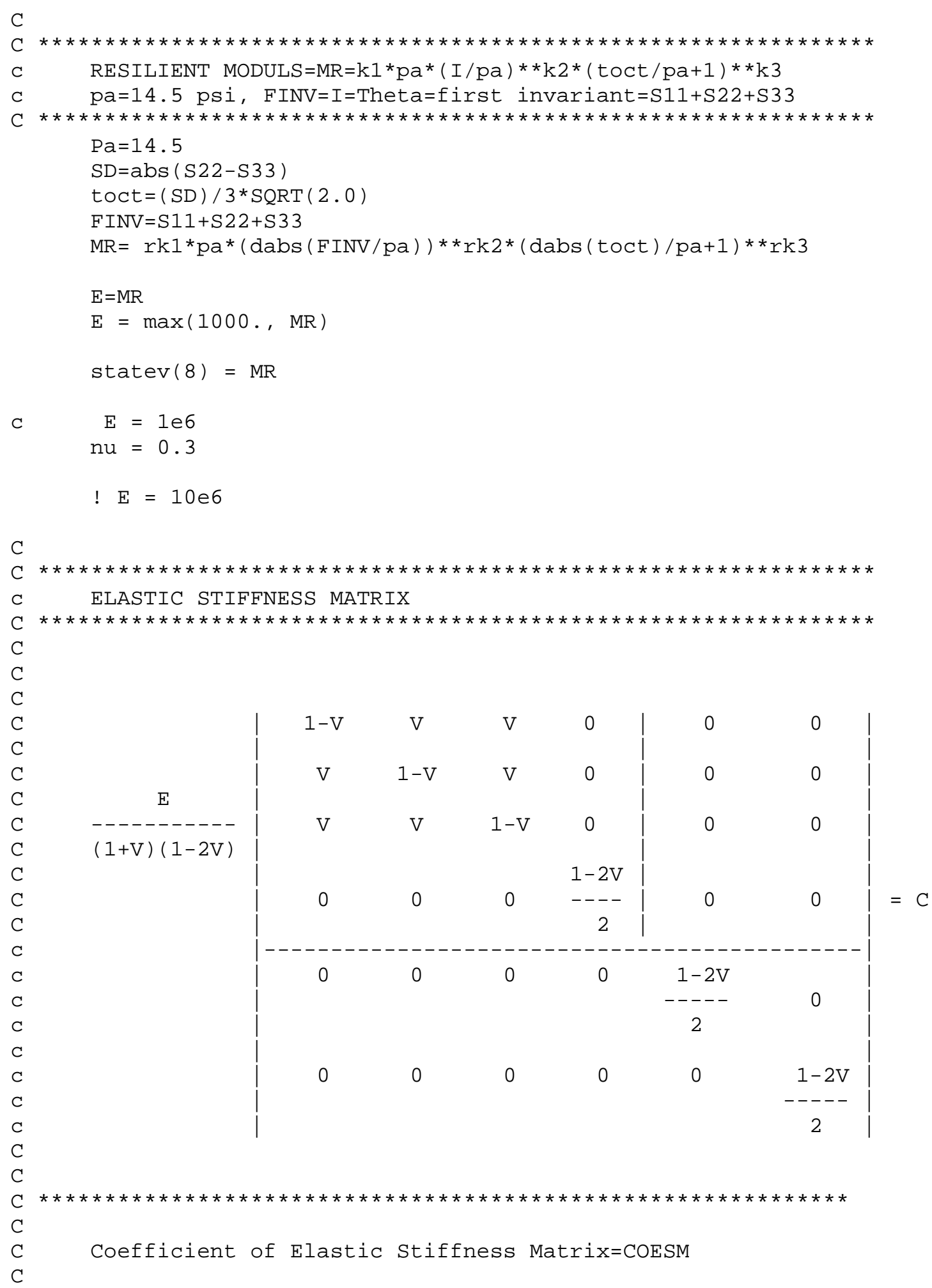


$\operatorname{COESM}=E /((1+N U) *(1-2 * N U))$

c

initialze array

do $i=1,6$

do $j=1,6$

$d(i, j)=0.0$

if ( $i . l e . n t e n s$ and. j.le.ntens )

$>\operatorname{DDSDDE}(i, j)=0$.

end do

end do

C DO $20 \mathrm{~K} 1=1$, NTENS

C DO $10 \mathrm{~K} 2=1$, NTENS

C $\quad \operatorname{DDSDDE}(\mathrm{K} 2, \mathrm{~K} 1)=\mathrm{COESM}^{*} \odot .0$

C 10 CONTINUE

c 20 CONTINUE

c calculate elastic stiffness matrix

D0 $40 \mathrm{~K} 1=1$, NDI

DO $30 \mathrm{~K} 2=1$, NDI

$\operatorname{DDSDDE}(\mathrm{K} 2, \mathrm{~K} 1)=\mathrm{COESM} * \mathrm{NU}$

30 CONTINUE

$\operatorname{DDSDDE}(K 1, K 1)=\operatorname{COESM}^{*}\left(1-2^{*} \mathrm{NU}\right)+\mathrm{COESM}^{*} \mathrm{NU}$
$\mathrm{d}(\mathrm{K} 1, \mathrm{~K} 1)=\operatorname{COESM}^{*}\left(1-2^{*} \mathrm{NU}\right)+\mathrm{COESM}^{*} \mathrm{NU}$

$4 \odot \quad$ CONTINUE

DO $5 \odot \mathrm{K} 1=\mathrm{NDI}+1$, NTENS

50 CONTINUE

$\operatorname{DDSDDE}(\mathrm{K} 1, \mathrm{~K} 1)=\operatorname{COESM}^{*}(1-2 * \mathrm{NU}) / 2$

do $i=4,6$

$d(i, i)=\operatorname{COESM}^{*}\left(1-2^{*} N U\right) / 2$

end do

c end calculating

c effective Mises

s_eff $=0.5^{*}((\mathrm{~S} 11-\mathrm{S} 22) * * 2+(\mathrm{S} 22-\mathrm{S} 33) * * 2+(\mathrm{S} 33-\mathrm{S} 11) * * 2$

$\left.>\quad+6 *\left(\mathrm{~S} 12 * * 2+\mathrm{S} 23^{* *} 2+\mathrm{S} 13^{* *} 2\right)\right)$

s_eff $=$ dsqrt $($ s_eff $)$

c if( s_eff.ge.1e-8)then

if ( s_eff.ge.1e-3) then

$z=1.0 /$ s_eff

else

$z=0$.

end if

C calculate effective stress derivative

DFDS11 $=Z^{*}(2 * \mathrm{~S} 11-\mathrm{S} 22-\mathrm{S} 33) / 2$.

DFDS22 $=z^{*}\left(-\mathrm{S} 11+2{ }^{*} \mathrm{~S} 22-\mathrm{S} 33\right) / 2$.

DFDS33 $=z^{*}(-\mathrm{S} 11-\mathrm{S} 22+2 * \mathrm{~S} 33) / 2$.

DFDS12 $=z^{*}(6 * S 12) / 2$. 


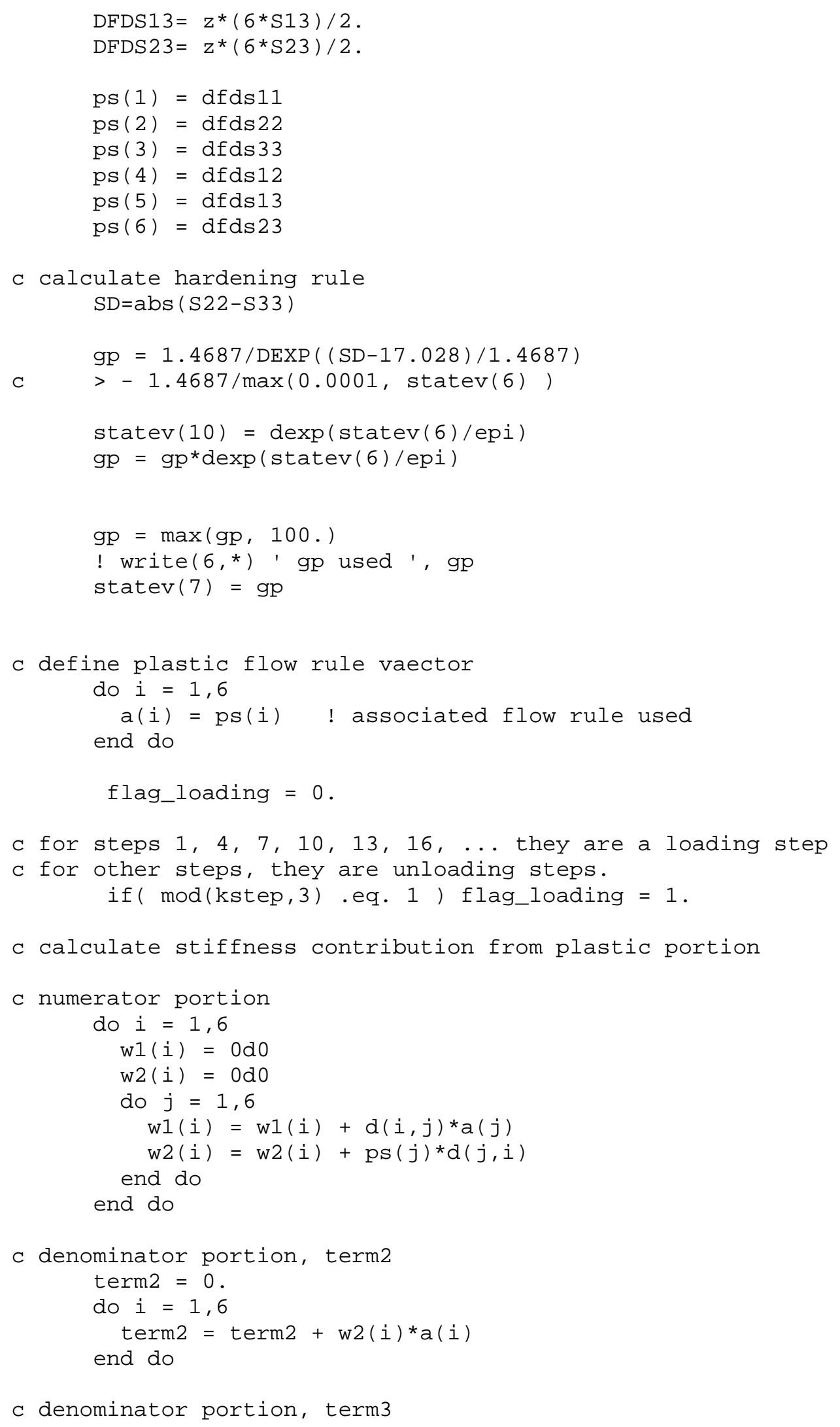




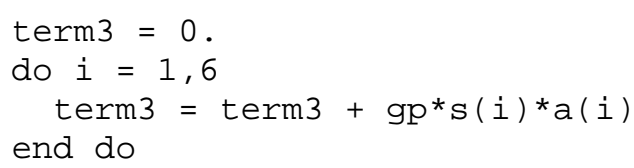

c calculate plastic stiffness daj

do $i=1,6$

do $j=1,6$

$\operatorname{daj}(i, j)=\operatorname{Od} \odot$

if ( abs(term2+term3).gt.1e-6)

$>\operatorname{daj}(i, j)=w 1(i){ }^{*} w 2(j) /($ term2+term3 $)$

end do

end do

c incremental equivalent plastic strain -- dpe

dpe $=\odot$.

if ( abs(term2+term3).gt.1e-6) then

do $i=1$, ntens

$\mathrm{dpe}=\mathrm{dpe}+\mathrm{w} 2(i){ }^{*} \mathrm{dstran}(i) /($ term2+term3 $)$

end do

end if

c $\quad \operatorname{statev}(6)=\operatorname{statev}(6)+$ dpe*s_eff

c during unloading, this dpe is $\odot$

if ( flag_loading.eq.e ) then

dpe $=0$.

end if

c total equivalent plastic strain -- statev(5), SDV5

$\mathrm{dpe}=\max (\odot \mathrm{d} \odot, \mathrm{dpe})$

statev $(5)=\operatorname{statev}(5)+d p e$

$\operatorname{statev}(6)=\operatorname{statev}(6)+$ dpe ${ }^{\star}$ s_eff

c vertical plastic strain - - statev(2), SDV2

statev $(1)=\operatorname{statev}(1)+a(1) * d p e$ ! SDV1

statev $(2)=$ statev $(2)+a(2) * d p e !$ SDV2

statev $(3)=\operatorname{statev}(3)+a(3) * d p e$ ! SDV3

statev $(4)=\operatorname{statev}(4)+a(4) * d p e !$ SDV 4

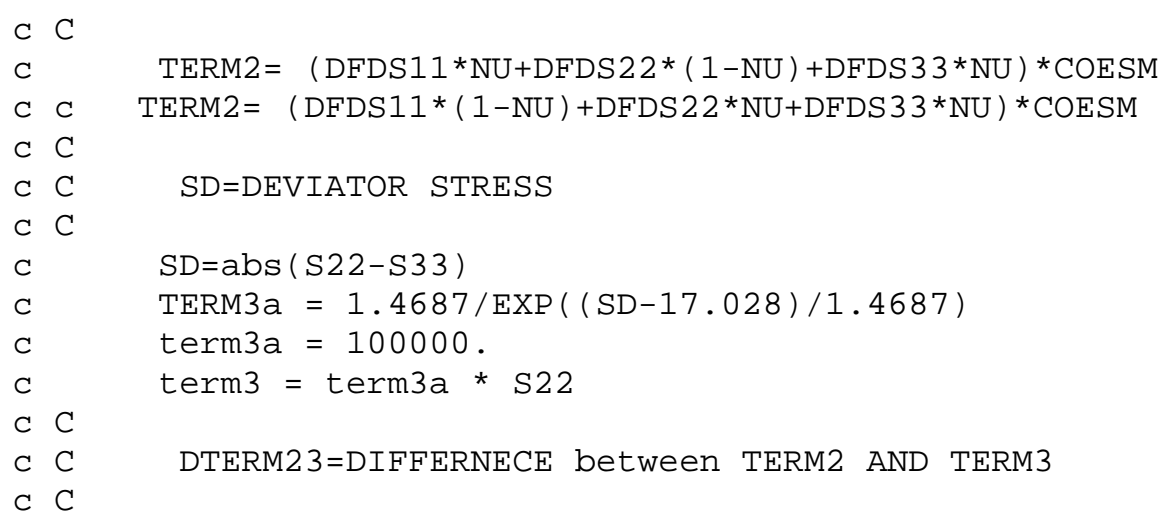




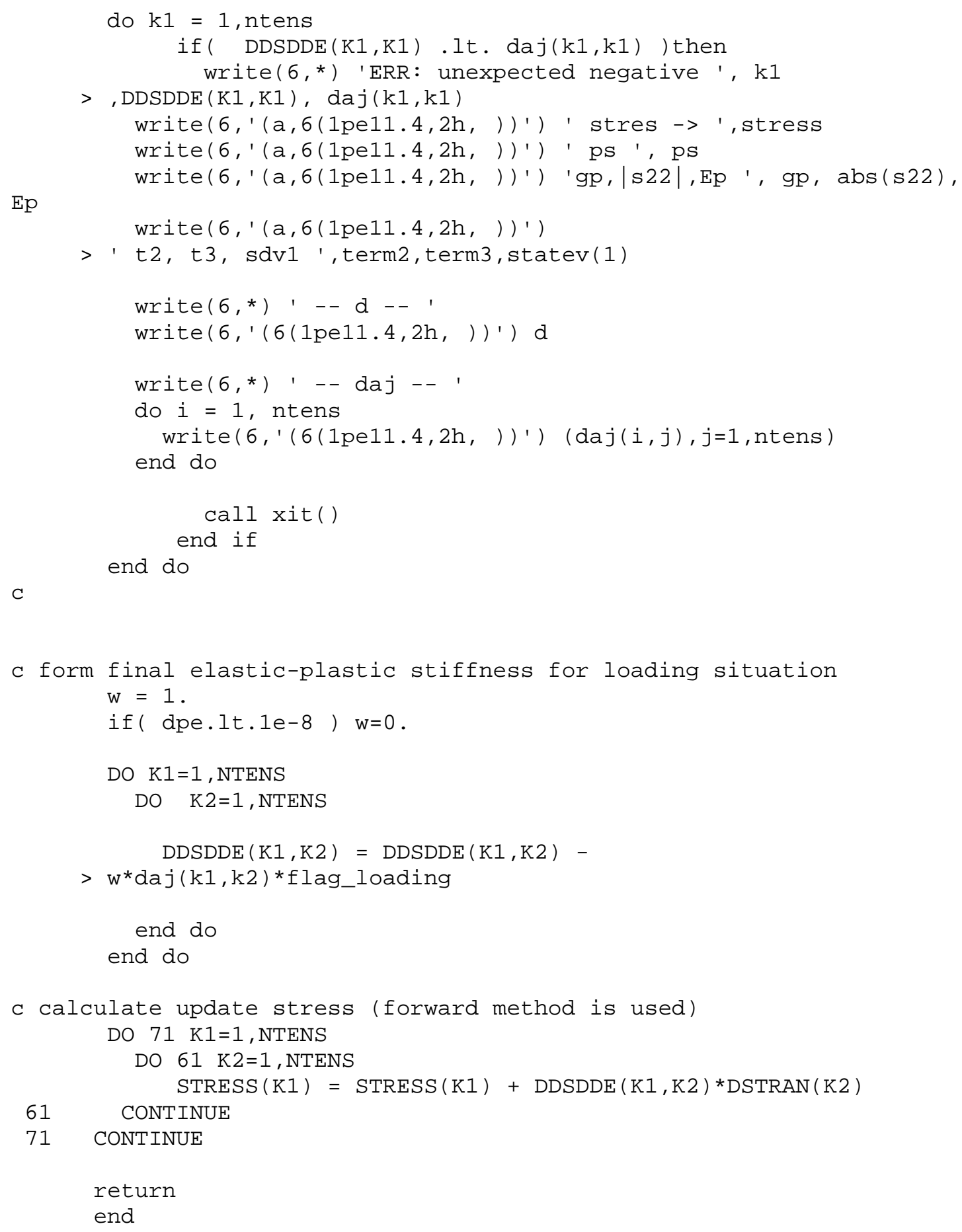




\section{Main Difference between AASHTO T274-82, T294-94 (SHRP Protocol P46), and} T307-99

There have been two JTRP research projects prior to the present study in INDOT. One was done according to the T274-82 and the other was performed following the T294-94. The current standard procedure for resilient modulus testing is explained in the T307-99. As seen in Tables A-1 to A-6, the main differences between those procedures are the combinations of confining and deviator stresses in the procedure of the $\mathrm{M}_{\mathrm{R}}$ testing. It is noted that the T274-82 and T294-94 for granular subgrade are composed of very high deviator stresses. This higher deviator stresses were modified not to overstress the samples in the T307-99. It is also noted that the T307-99 calls for one procedure for both cohesive and granular subgrades. Major differences are compared as shown in Table A-1. 
Table A-1. Comparison of AASHTO Mr testing methods

\begin{tabular}{|l|l|l|l|}
\hline & T274-82 & T294-94 & T307-99 \\
\hline Application & $\begin{array}{l}\text { Undisturbed } \\
\text { /disturbed subgrade } \\
\text { soils }\end{array}$ & $\begin{array}{l}\text { Undisturbed } \\
\text { /disturbed subgrade } \\
\text { soils and untreated } \\
\text { base/ subbase } \\
\text { material }\end{array}$ & $\begin{array}{l}\text { Undisturbed } \\
\text { /disturbed subgrade } \\
\text { soils and untreated } \\
\text { base/ subbase } \\
\text { material }\end{array}$ \\
\hline $\begin{array}{l}\text { Material } \\
\text { classification }\end{array}$ & Cohesive/ Granular & $\begin{array}{l}\text { Type 1 } \\
\text { (cohesionless), Type } \\
\text { 2 (cohesive) }\end{array}$ & $\begin{array}{l}\text { Type 1 } \\
\text { (cohesionless), Type } \\
\text { 2 (cohesive) }\end{array}$ \\
\hline Load wave & Haversine & Haversine & Haversine \\
(see Tables 1-6) & $\begin{array}{l}\text { Two methods for } \\
\text { cohesive and } \\
\text { granular subgrades }\end{array}$ & $\begin{array}{l}\text { Two methods for } \\
\text { Type 1 and Type 2 }\end{array}$ & $\begin{array}{l}\text { The same procedure } \\
\text { for Type 1 and Type } \\
2\end{array}$ \\
\hline Conditioning stage & $\begin{array}{l}\text { Various } \\
\text { combination of } \\
\text { stresses }\end{array}$ & One combination & $\begin{array}{l}\text { One combination } \\
\text { Note: If vertical } \\
\text { permanent strain } \\
\text { exceeds 5\%, } \\
\text { conditioning process } \\
\text { shall be terminated }\end{array}$ \\
\hline Drainage condition & $\begin{array}{l}\text { Krained/ undrained } \\
\text { Kneading }\end{array}$ & Drained & Drained \\
\hline Compaction & Granular: vibratory & $\begin{array}{l}\text { Type 1: vibratory } \\
\text { compaction } \\
\text { Type 2: static or } \\
\text { kneading } \\
\text { compaction }\end{array}$ & $\begin{array}{l}\text { Type 1: vibratory } \\
\text { compaction } \\
\text { Type 2: static or } \\
\text { kneading } \\
\text { compaction }\end{array}$ \\
\hline
\end{tabular}


Table A-2. AASHTO T307-99 for Type 1 and Type 2

\begin{tabular}{|c|c|c|c|}
\hline Sequence & Conf. stress & Dev. stress & $\begin{array}{c}\text { No. of Load } \\
\text { Application }\end{array}$ \\
\hline No. & psi & psi & \\
\hline Conditioning & 6 & 4 & $500-1000$ \\
\hline 1 & 6 & 2 & 100 \\
\hline 2 & 6 & 4 & 100 \\
\hline 3 & 6 & 6 & 100 \\
\hline 4 & 6 & 8 & 100 \\
\hline 5 & 6 & 10 & 100 \\
\hline 6 & 4 & 2 & 100 \\
\hline 7 & 4 & 4 & 100 \\
\hline 8 & 4 & 6 & 100 \\
\hline 9 & 4 & 8 & 100 \\
\hline 10 & 4 & 10 & 100 \\
\hline 11 & 2 & 2 & 100 \\
\hline 12 & 2 & 4 & 100 \\
\hline 13 & 2 & 6 & 100 \\
\hline 14 & 2 & 8 & 100 \\
\hline 15 & 2 & 10 & 100 \\
\hline
\end{tabular}

Table A-3. AASHTO T294-94 for Type 1

\begin{tabular}{|c|c|c|c|}
\hline Sequence & Conf. stress & Dev. stress & $\begin{array}{c}\text { No. of Load } \\
\text { Application }\end{array}$ \\
\hline No. & $\mathrm{psi}$ & $\mathrm{psi}$ & \\
\hline Conditioning & 15 & 15 & 1000 \\
\hline 1 & 3 & 3 & 100 \\
\hline 2 & 3 & 6 & 100 \\
\hline 3 & 3 & 9 & 100 \\
\hline 4 & 5 & 5 & 100 \\
\hline 5 & 5 & 10 & 100 \\
\hline 6 & 5 & 15 & 100 \\
\hline 7 & 10 & 10 & 100 \\
\hline 8 & 10 & 20 & 100 \\
\hline 9 & 10 & 30 & 100 \\
\hline 10 & 15 & 10 & 100 \\
\hline
\end{tabular}




\begin{tabular}{|l|l|l|l|}
\hline 11 & 15 & 15 & 100 \\
\hline 12 & 15 & 30 & 100 \\
\hline 13 & 20 & 15 & 100 \\
\hline 14 & 20 & 20 & 100 \\
\hline 15 & 20 & 40 & 100 \\
\hline
\end{tabular}

Table A-4. AASHTO T294-94 for Type 2

\begin{tabular}{|c|c|c|c|}
\hline Sequence & Conf. stress & Dev. stress & $\begin{array}{c}\text { No. of Load } \\
\text { Application }\end{array}$ \\
\hline No. & psi & psi & \\
\hline Conditioning & 6 & 4 & 1000 \\
\hline 1 & 6 & 2 & 100 \\
\hline 2 & 6 & 4 & 100 \\
\hline 3 & 6 & 6 & 100 \\
\hline 4 & 6 & 8 & 100 \\
\hline 5 & 6 & 10 & 100 \\
\hline 6 & 3 & 2 & 100 \\
\hline 7 & 3 & 4 & 100 \\
\hline 8 & 3 & 6 & 100 \\
\hline 9 & 3 & 8 & 100 \\
\hline 10 & 3 & 10 & 100 \\
\hline 11 & 0 & 2 & 100 \\
\hline 12 & 0 & 4 & 100 \\
\hline 13 & 0 & 6 & 100 \\
\hline 14 & 0 & 8 & 100 \\
\hline 15 & 0 & 10 & \\
\hline
\end{tabular}


Table A-5. AASHTO T274-82 for granular subgrade

\begin{tabular}{|c|c|c|c|}
\hline Sequence & Conf. stress & Dev. stress & $\begin{array}{l}\text { No. of Load } \\
\text { Application }\end{array}$ \\
\hline No. & psi & psi & \\
\hline \multirow{6}{*}{ conditioning } & 5 & 5 & 200 \\
\hline & 5 & 10 & 200 \\
\hline & 10 & 10 & 200 \\
\hline & 10 & 15 & 200 \\
\hline & 15 & 15 & 200 \\
\hline & 15 & 20 & 200 \\
\hline 1 & 20 & 1 & 200 \\
\hline 2 & 20 & 2 & 200 \\
\hline 3 & 20 & 5 & 200 \\
\hline 4 & 20 & 10 & 200 \\
\hline 5 & 20 & 15 & 200 \\
\hline 6 & 20 & 20 & 200 \\
\hline 7 & 15 & 1 & 200 \\
\hline 8 & 15 & 2 & 200 \\
\hline 9 & 15 & 5 & 200 \\
\hline 10 & 15 & 10 & 200 \\
\hline 11 & 15 & 15 & 200 \\
\hline 12 & 15 & 20 & 200 \\
\hline 13 & 10 & 1 & 200 \\
\hline 14 & 10 & 2 & 200 \\
\hline 15 & 10 & 5 & 200 \\
\hline 16 & 10 & 10 & 200 \\
\hline 17 & 10 & 15 & 200 \\
\hline 18 & 5 & 1 & 200 \\
\hline 19 & 5 & 2 & 200 \\
\hline 20 & 5 & 5 & 200 \\
\hline 21 & 5 & 10 & 200 \\
\hline 22 & 5 & 15 & 200 \\
\hline 23 & 1 & 1 & 200 \\
\hline 24 & 1 & 2 & 200 \\
\hline 25 & 1 & 5 & 200 \\
\hline 26 & 1 & 7.5 & 200 \\
\hline
\end{tabular}


Table A-6. AASHTO T274-82 for cohesive subgrade

\begin{tabular}{|c|c|c|c|}
\hline Sequence & Conf. stress & Dev. stress & $\begin{array}{c}\text { No. of Load } \\
\text { Application }\end{array}$ \\
\hline No. & psi & psi & \\
\hline & 6 & 1 & 200 \\
conditioning & 6 & 2 & 200 \\
& 6 & 4 & 200 \\
& 6 & 8 & 200 \\
\hline 1 & 6 & 10 & 200 \\
\hline 2 & 6 & 1 & 200 \\
\hline 3 & 3 & 1 & 200 \\
\hline 4 & 0 & 1 & 200 \\
\hline 5 & 6 & 2 & 200 \\
\hline 6 & 3 & 2 & 200 \\
\hline 7 & 0 & 2 & 200 \\
\hline 8 & 0 & 4 & 200 \\
\hline 9 & 0 & 8 & 200 \\
\hline
\end{tabular}


Table A-7. Sites of Subgrade Soils for Resilient Modulus Tests

\begin{tabular}{|c|c|c|c|c|c|c|}
\hline Soil & Soil Collection & City & County & AASHTO & USCS & Soil Description \\
\hline I65-146 & I65 Exit 146 & & Boone & A-4 & CL-ML & Dark gray silty clay \\
\hline I65-158 & I65 Exit 158 & Jefferson & Boone & A-4 & CL-ML & Dark gray silty clay \\
\hline I65-172 & I65 Exit 172 & Lafayette & Tippecanoe & A-6 & CL & Dark gray silty clay \\
\hline Dsoil & & West Lafayette & Tippecanoe & A-4 & CL-ML & Dark gray silty clay \\
\hline \#1 soil & 8392L SP.GR & & & A-7-6 & $\mathrm{CH}$ & Dark gray silty clay \\
\hline \#2soil & 8392L SP.GR & & & A-6 & CL & Dark gray silt with trace fine sand \\
\hline \#3soil & 8392L SP.GR & & & A-6 & $\mathrm{CL}$ & Dark gray silt with some fine sand \\
\hline \#4soil & 8392L SP.GR T-99 & & & A-7-6 & CL & Dark gray silty clay \\
\hline SR19 & $587+50 ; 5 \mathrm{~m} \mathrm{Lt}, 8392 \mathrm{~L}$ SP.GR & & & A-6 & $\mathrm{CL}$ & Dark gray \\
\hline US41 & $192+65 ; 80$ ' Rt,SP.GR & & Gibson & A-4 & $\mathrm{CL}$ & Dark gray \\
\hline Bloomington & Bloomington Subdistrict & Bloomington & Monroe & A-7-6 & $\mathrm{CL}$ & red orange clay \\
\hline Orchard & & West Lafayette & Tippecanoe & A-6 & CL & Dark gray clay \\
\hline Test road & & West Lafayette & Tippecanoe & A-4 & $\mathrm{CL}$ & Dark gray clay \\
\hline SR 165 & 2.2E of Poseyville & & Posey & A-4 & $\mathrm{CL}$ & bright gray with many roots \\
\hline US 50 & & & Davies & A-3 & SP & Dark sand \\
\hline $\begin{array}{l}\text { Indiana } \\
\text { Dunes }\end{array}$ & SR 49 (N Dune sand) & & $\begin{array}{l}\text { Porter Co. } \\
\text { State Park }\end{array}$ & A-3 & SP & Bright sand \\
\hline N Dune & SR 49 (N Dune sand) & & $\begin{array}{l}\text { Porter Co. } \\
\text { State Park }\end{array}$ & A-3 & SP & Bright sand \\
\hline Wildcat & & & & A-1-b & SP & Dark sand and gravel \\
\hline SR 26 & & & Tippecanoe & $\mathrm{A}-1-\mathrm{b}$ & GP & Dark sand and gravel \\
\hline
\end{tabular}


Table A-8. Range of $\mathrm{k}_{1}, \mathrm{k}_{2}$ and $\mathrm{k}_{3}$ for fine-grained soils (using Equation 8.3)

\begin{tabular}{|c|c|c|c|c|c|c|c|}
\hline \multirow{2}{*}{$\begin{array}{l}\text { AASHTO } \\
\text { classification }\end{array}$} & \multicolumn{2}{|c|}{$\mathrm{k}_{1}$} & \multicolumn{2}{|c|}{$\mathrm{k}_{2}$} & \multicolumn{2}{|c|}{$\mathrm{k}_{3}$} & \multirow{4}{*}{$\begin{array}{l}\text { OMC and Wet } \\
\text { correspond to the } \\
\text { moisture content } \\
\text { at OMC }\left(\gamma_{\mathrm{dmax}}\right) \\
\text { and at wet of } \\
\text { optimum } 95 \%\end{array}$} \\
\hline & $\mathrm{OMC}$ & Wet & $\mathrm{OMC}$ & Wet & $\mathrm{OMC}$ & Wet & \\
\hline \multirow[t]{2}{*}{ A-4 } & 1114 & 160 & 0.221 & $\begin{array}{c}-0.270 \\
\text { to }\end{array}$ & -1.905 & -2.807 & \\
\hline & $\begin{array}{c}\text { to } \\
1802\end{array}$ & $\begin{array}{c}\text { to } \\
352\end{array}$ & $\begin{array}{c}\text { to } \\
0.429\end{array}$ & $\begin{array}{c}\text { to } \\
0.572\end{array}$ & -2.806 & 1.045 & \\
\hline \multirow[t]{2}{*}{ A-6 } & 1301 & 159 & 0.221 & -0.319 & -2.310 & -6.528 & \multirow{4}{*}{$\begin{array}{l}\left.\times \gamma_{\text {dmax }}\right) \text { in the } \\
\text { compaction } \\
\text { curve, } \\
\text { respectively }\end{array}$} \\
\hline & $\begin{array}{c}\text { to } \\
2302\end{array}$ & $\begin{array}{c}\text { to } \\
913\end{array}$ & $\begin{array}{c}\text { to } \\
0443\end{array}$ & $\begin{array}{c}\text { to } \\
1.397\end{array}$ & $\begin{array}{c}\text { to } \\
-1.533\end{array}$ & $\begin{array}{c}\text { to } \\
1.105\end{array}$ & \\
\hline \multirow[t]{2}{*}{ A-7-6 } & 1127 & 179 & 0.080 & -0.608 & -1.778 & -3.795 & \\
\hline & $\begin{array}{c}\text { to } \\
1215\end{array}$ & $\begin{array}{c}\text { to } \\
1587\end{array}$ & $\begin{array}{c}\text { to } \\
0.241\end{array}$ & $\begin{array}{c}\text { to } \\
0.364\end{array}$ & $\begin{array}{l}\text { to }- \\
1.070\end{array}$ & $\begin{array}{c}\text { to } \\
-1.490\end{array}$ & \\
\hline
\end{tabular}

Note: the range of $k_{1}, k_{2}$ and $k_{3}$ was obtained for the fine-grained soils used in this study except for the I65-146 soil (refer to Table 2 or Table A-7).

Table A-9. Range of Resilient Modulus for fine-grained soils (for a confining stress of $2 \mathrm{psi}$ and a deviator stress of $6 \mathrm{psi}$ )

\begin{tabular}{|c|c|c|l|}
\hline \multirow{2}{*}{$\begin{array}{c}\text { AASHTO } \\
\text { classification }\end{array}$} & \multicolumn{2}{|c|}{$\begin{array}{c}\text { Resilient modulus (psi) } \\
\text { (average) }\end{array}$} & $\begin{array}{l}\text { OMC and Wet } \\
\text { correspond to the } \\
\text { moisture content } \\
\text { at OMC }\left(\gamma_{\text {dmax }}\right) \\
\text { and at wet of } \\
\text { optimum }(95 \% \\
\times \gamma_{\text {dmax }} \text { in the } \\
\text { compaction } \\
\text { curve, } \\
\text { respectively }\end{array}$ \\
\hline A-4 & $\begin{array}{c}\text { OMC } \\
\text { A-6 }\end{array}$ & $\begin{array}{c}10,040 \text { to } 11,980 \\
(11,880)\end{array}$ & $\begin{array}{c}2,160 \text { to } 4,740 \\
(3,100)\end{array}$ \\
\hline A-7-6 & $\begin{array}{c}10,880,600) \\
(12,320)\end{array}$ & $\begin{array}{c}1,710 \text { to } 3,640 \\
(3,170)\end{array}$ & $\begin{array}{c}1,920 \text { to } 12,060 \\
(6,060)\end{array}$ \\
\hline
\end{tabular}

Note: the range of resilient modulus was obtained for the fine-grained soils used in this study except for the I65-146 soil (refer to Table 2 or Table A-7). 